Tesis para optar el grado de

Doctor de la Facultad de Ciencias Agrarias y Forestales

Universidad Nacional de La Plata

\title{
RELACIONES FUNCIONALES ENTRE EFICIENCIA Y SEGURIDAD DEL SISTEMA DE TRANSPORTE DE AGUA EN CONÍFERAS: SU INFLUENCIA SOBRE LA RELACIÓN CRECIMIENTO-DENSIDAD DE MADERA- RESISTENCIA AL DÉFICIT HÍDRICO EN Pinus taeda $\mathrm{L}$.
}

\author{
Nardia M. L. Bulfe \\ Ingeniera Forestal
}

Directora: Dra. Maria Elena Fernández

Co Director: Dr. Tomás Schlichter

Lugar de trabajo:

Instituto Nacional de Tecnología Agropecuaria

(Estación Experimental Agropecuaria Montecarlo - Misiones)

La Plata, Diciembre de 2015 
Nada está construido en la piedra.

Todo está construido en la arena.

Pero debemos construirlo como si la arena fuese piedra.

Jorge Luis Borges 


\section{Agradecimientos}

Quiero agradecer de manera especial a la Dra. María Elena Fernández, quien como directora de esta tesis me ha guiado de manera incondicional durante todo mi aprendizaje en esta etapa de mi vida científica. A ella infinitas gracias por su paciencia y sabiduría, porque siempre me hizo sentir que la distancia geográfica nunca existió.

Al Dr. Tomás Schlichter por haber aceptado ser el co director y por sus valiosos aportes realizados desde los inicios de esta tesis.

Al Ing. Martin Pinazo por haberme guiado y acompañado como director de beca en esta etapa de mis inicios en el INTA. Por su colaboración y predisposición para que todo funcione. Por sus valiosos aportes realizados en el transcurrir de esta tesis.

Al Instituto Nacional de Tecnología Agropecuaria (INTA) por haberme dado la posibilidad de desarrollar mi doctorado, en especial a la EEA Montecarlo por las gestiones realizadas en el transcurso del mismo.

Al Ing. Aldo Keller por su colaboración y acompañamiento en gran parte del trabajo desarrollado para esta tesis.

Al grupo de mejoramiento forestal, en especial al Ing. Ector Belaber y la Dra. María Elena Gauchat por haberme facilitado el material base de este estudio, las diferentes progenies de Pinus taeda, y toda la información necesaria desde el Programa de Mejoramiento Genético.

A la Ing. Alicia Bhoren por los conocimientos transmitidos para la obtención y procesamiento de las muestras histológicas. Y a Iris Figueredo, porque siempre se brindó para realizar las placenteras tareas de histología vegetal.

A Delia Sosa y Otto Knebel por su colaboración y buena predisposición en las tareas de campo.

A Corina Graciano y Laura Faustino, porque me ayudaron a estudiar y comprender a esta especie, el Pinus taeda. Porque con ellas compartí largas jornadas de trabajo, tanto de campo como de laboratorio, en las cuales aprendí infinitas cosas, pero sobre todo porque siempre me han brindado su amistad. 
A Rubén Costas y Marcelo Arturi quienes me supieron guiar con los análisis estadísticos. A Adriana Quiñones Martorello, quien bajo los generosos aportes de Gloria Monterrubbianesi, ha colaborado gentilmente con parte del análisis estadístico realizado con el programa estadístico $R$.

A todos mis compañeros de la Estación Experimental Agropecuaria Montecarlo, porque cada día me regalan su amistad, y de una u otra manera me acompañaron de formas diferentes en este transcurrir de mi doctorado. En fin, por la calidez humana que encuentro día a día en este mi lugar de trabajo.

De manera muy especial quiero agradecer a mi familia, a mi compañero de vida, Martín, por acompañarme siempre de la mejor manera, estando al lado mío, construyendo nuestro hogar. A mi hija Mía, a quien le he quitado tiempo que era suyo para cumplir este objetivo, porque tan chiquita como es me completa el alma y me reconforta en los momentos difíciles, porque con ella aprendo a vivir día a día.

A mis hermanos Ariel y Aldo, porque son mis aliados en esta vida, son uno de los regalos más hermosos que me han dados mis padres para transitar mis días. Porque con ellos comparto tristezas pero también celebro triunfos.

Agradezco a mis padres Irma y Dimas porque me han formado como persona, con el mejor ejemplo de trabajo y honestidad, porque todo lo que soy se los debo a ellos. A mi madre por ser mi compañera incondicional de toda la vida, y a mi padre que a pesar de haber partido a mitad de este camino, hoy lo siento más presente que nunca, y tengo la certeza absoluta de que desde donde esté es feliz de compartir esto conmigo. A Dios, por darme la fortaleza de llegar hasta este punto, el cual seguramente no es de llegada sino de partida...

A todos muchas gracias!! 
Esta tesis está dedicada de manera especial a la memoria de mi padre 


\section{Resumen}

El agua es uno de los factores abióticos más determinantes del rendimiento en un sistema productivo vegetal. La misma influye de manera directa en la productividad de los ecosistemas, dado que presenta un rol crucial en casi todos los procesos fisiológicos de las plantas, y en particular, en la fijación de carbono que requiere en principio la apertura estomática para que el $\mathrm{CO}_{2}$ ingrese a las hojas. En el marco del cambio climático se predice que las precipitaciones se verán modificadas en cuanto a su distribución, provocando de esta manera pulsos de sequía, los cuales afectarán la disponibilidad de agua en muchas regiones del mundo, y en el NEA de la Argentina, en particular. Otra situación que afecta a la productividad de los sistemas productivos en esta región es el avance de éstos hacia sitios con menores aptitudes, dados los suelos someros o pedregosos que los caracterizan, debido a la competencia con otros usos de la tierra. En este contexto, el conocimiento de la respuesta productiva de especies claves de la economía regional a la sequía se torna relevante. Pinus taeda L. es la especie forestal por excelencia en la región de estudio, Noroeste de Misiones, provincia que a su vez forma parte del principal polo forestal de la República Argentina. Cuenta en la actualidad con un Programa de Mejoramiento Genético (PMG), iniciado en la década del '90 del siglo pasado, con avances importantes en cuanto a crecimiento y otros caracteres fenotípicos relacionados con la calidad de la madera. Sin embargo, se desconocen las implicancias que ha tenido la selección en base a productividad y calidad (ej. densidad) sobre la resistencia al estrés en los genotipos disponibles en esta región subtropical, donde la especie es sometida a condiciones ambientales muy distintas a las de su zona de origen en el SE de los EEUU.

Desde el punto de vista funcional, en general se plantea que existe un compromiso entre crecimiento y resistencia al estrés. Este compromiso estaría dado por el hecho de que el crecimiento se relaciona positivamente con la eficiencia de la conducción de agua del sistema hidráulico que conforma una planta, mientras que esta eficiencia se relaciona negativamente con la "seguridad" en el mismo. Por seguridad del sistema hidráulico se entiende a la vulnerabilidad del xilema a cavitar ante altas tensiones, lo que se traduce en pérdidas más o menos permanentes de conductividad hidráulica, es decir, de eficiencia de conducción. Esto es así porque los caracteres anatómicos que 
permiten una mayor conductividad (ej. elementos de conducción de mayor diámetro, más puntuaciones y de mayor permeabilidad entre elementos, mayor agrupamiento de elementos, etc.), así como favorecen el movimiento de agua dentro de la planta, también favorecerían la propagación de eventuales embolismos, tornándolo más susceptible a la disfunción. Existe abundante evidencia a favor de la existencia de este compromiso general que resulta en que las especies más productivas del mundo son también las más susceptibles a la falta de agua. Sin embargo, también existen ejemplos de especies con mecanismos de resistencia a la sequía alternativos a la baja vulnerabilidad a la cavitación, basados en un comportamiento evitador de la sequía, que permitiría maximizar la productividad en períodos de alta disponibilidad hídrica (por una alta eficiencia de conducción) y el mantenimiento de la integridad hidráulica en períodos de déficit. Asimismo, si se concentra el análisis a nivel intraespecífico, es decir, considerando un rango acotado de productividades y resistencias al estrés, podrían existir combinaciones de atributos que permiten optimizar ambos procesos a la vez, dentro de ciertos límites. Asimismo, la densidad de la madera es un carácter relacionado con la vulnerabilidad a la cavitación tanto en especies angiospermas como coníferas. Esta relación ocurre debido a que aquellas especies que, por ser menos vulnerables, están sometidas a mayores tensiones en el xilema, requieren un mayor refuerzo de los conductos para evitar la implosión de los mismos por diferencias de presión entre elementos cavitados y funcionales. En el marco conceptual anteriormente expuesto, se planteó como objetivo general comprender la relación funcional entre tasas de crecimiento, densidad de madera y resistencia a la sequía en distintas progenies de $P$. taeda, y el grado de influencia de la relación eficiencia de conducción - seguridad del sistema hidráulico sobre estos procesos, en estadíos iniciales del desarrollo de esta especie forestal.

Se plantearon los siguientes objetivos particulares, que fueron abordados mediante ensayos realizados en invernáculo (condiciones semi-controladas) y a campo: 1) evaluar los compromisos entre crecimiento y resistencia al déficit hídrico en edades tempranas de genotipos de Pinus taeda de tasa diferencial de crecimiento, y los procesos morfo-fisiológicos responsables de los patrones observados; 2) determinar las relaciones existentes entre anatomía, densidad y funcionalidad (conductividad 
hidráulica y vulnerabilidad a la cavitación) de la madera en progenies de $P$. taeda con distintas tasas de crecimiento, y la influencia del déficit hídrico sobre estas relaciones; 3) evaluar el efecto del momento de ocurrencia del déficit hídrico sobre el crecimiento de los plantines de P. taeda; 4) evaluar bajo condiciones de campo el efecto interactivo de las condiciones ambientales que se dan naturalmente en la región de estudio sobre distintas variables ecofisiológicas responsables del crecimiento en plantines de $P$. taeda; 5) analizar los patrones de regulación estomática del potencial hídrico foliar en P. taeda bajo distintas condiciones de déficit hídrico en el suelo y/o en la atmósfera, tomando a éste como un caracter clave en la adaptación a déficit hídrico, debido a su relación directa con la arquitectura hidráulica de la planta y su influencia sobre el intercambio gaseoso y el crecimiento.

Para abordar los resultados se trabajó con cuatro progenies de polinización abierta que diferían en crecimiento medio y en densidad de madera, según mediciones realizadas en los árboles madre a los 5 años de edad: dos progenies de alto crecimiento (AC) y dos progenies de (relativamente) bajo crecimiento (BC), combinando además alta y baja densidad de madera. Las tasas de crecimiento diferenciales solamente se manifestaron bajo condiciones óptimas de disponibilidad hídrica. Las progenies AC con mayores incrementos absolutos aéreos (diámetro de tallo y altura total) presentaron patrones de asignación de biomasa diferentes a las progenies BC, con menor proporción relativa de raíces, pero a su vez distintos entre sí. La progenie AC1 presentó mayor asignación a tallo, y la AC2, mayor asignación a hojas. La estrategia de la AC1 presumiblemente aumentó la eficiencia de conducción de agua por unidad de área foliar, lo que se vio reflejado también en menores pérdidas de conductividad hidráulica que en las otras progenies. Esta progenie fue la que presentó también la mayor eficiencia de crecimiento (EC, crecimiento de fuste:biomasa foliar) y en el uso del nitrógeno. La alta asignación a tejido foliar en la progenie AC2 pudo ser responsable de su alto incremento absoluto debido a la gran superficie para el intercambio gaseoso. Pero, se tradujo en baja EC y del uso del N. Estas progenies de alto crecimiento en términos absolutos tuvieron, sin embargo, menor crecimiento en forma relativa a su tamaño inicial en comparación con las BC. Estas últimas presentaron mayor asignación a raíces, mayor capacidad fotosintética (por unidad de área foliar) y mayor 
conductancia estomática $\left(g_{\mathrm{s}}\right)$ máxima. Asimismo, presentaron una menor sensibilidad estomática al déficit de presión de vapor (DPV) de la atmósfera relativa a la máxima $g_{\mathrm{s}}$ que las $A C$, aunque en general, las cuatro progenies mostraron un relativamente bajo control del potencial hídrico mínimo, perdiendo altos porcentajes de conductividad hidráulica $\left(k_{\mathrm{s}}\right)$ en ramas aún en condiciones de alta disponibilidad de agua en el suelo. Asimismo, esta baja capacidad de regulación estomática del potencial hídrico mínimo resultó en patrones variables, presentando situaciones de isohidrismo y más comúnmente de anisohidrismo, pero con un mantenimiento del gradiente de potencial entre el suelo y las hojas (isohidrodinamismo). Sin embargo, a diferencia de las condiciones ambientales típicas en las que se desarrolla el anisohidrismo en otras especies leñosas, en Pinus taeda los potenciales hídricos más negativos (menores a -4 $\mathrm{MPa}$ ) se desarrollaron con alto contenido de agua en el suelo pero alto DPV, situación ambiental en la que no hubo prácticamente cierre estomático hasta DPV tan altos como $6 \mathrm{kPa}$. Cuando existió cierto déficit hídrico en el suelo, se evidenció un control más fino del potencial mínimo, lo que sugiere la intervención de señales hormonales producidas en la raíz como primer mecanismo disparador del control estomático. Asimismo, sugiere una alta vulnerabilidad de estas progenies a olas de calor en momentos con alta disponibilidad hídrica en el suelo.

En contra de la hipótesis general, el crecimiento diferencial entre progenies no estuvo relacionado con la eficiencia hidráulica, si se estima ésta a través de la $k_{\mathrm{s}}$ de ramas. Asimismo, todas las progenies mostraron una vulnerabilidad a la cavitación (VC) relativamente alta, y se observó una tendencia a una mayor VC en las progenies AC, aunque no relacionadas con mayores $k_{s}$ máximas. Esto hace que no sea posible plantear un compromiso entre crecimiento y susceptibilidad al déficit hídrico desde la base de suponer relaciones entre $k_{\mathrm{s}}$ y VC en Pinus taeda. Por el contrario, los patrones de crecimiento máximo se relacionaron más con distintas asignaciones del $C$ dentro de la planta, y con una distinta sensibilidad estomática al DPV. En este sentido, las familias AC presentaron mayor asignación del $C$ a distintos órganos aéreos, denotando la existencia de diferentes estrategias entre sí, y una levemente mayor sensibilidad estomática al DPV que las BC. Estas últimas presentaron una alta capacidad intrínseca de intercambio gaseoso, pero su tamaño inicial más pequeño (medido a nivel áereo), 
posiblemente como producto de su mayor asignación relativa a raíces desde muy temprano en el desarrollo, las pone en desventaja frente a las AC en la fijación total de C.

Considerando el efecto del déficit hídrico -moderado y severo-sobre el crecimiento en las distintas progenies, todas presentaron una caída exponencial en el mismo, igualándose en el crecimiento final. Por lo tanto, si bien las familias AC tuvieron una mayor caída relativa en el crecimiento al comparar los tratamientos con déficit hídrico y el control, alcanzaron crecimientos similares a las familias $B C$ en condiciones de déficit hídrico. Esto evidencia que éstas últimas no manifiestan ninguna ventaja comparativa en estas condiciones. Asimismo, se observó un efecto marcado del momento de ocurrencia del déficit hídrico dentro del período total de crecimiento, siendo mayor cuando el déficit ocurre al inicio del período, en primavera.

Respecto a la anatomía funcional de la madera no se han observado respuestas, a nivel de célula, entre las familias analizadas tanto en condiciones hídricas óptimas como bajo situación de estrés. Sin embargo, se manifestaron diferencias significativas entre las familias y entre tratamientos de déficit hídrico en cuanto a la proporción de leño temprano y tardío, reflejando la variabilidad y plasticidad de este carácter. En este sentido, las familias BC fueron las que presentaron una mayor proporción de leño temprano respecto al grupo de las familias $A C$, característica que se tradujo en una tendencia a una mayor $k_{\mathrm{s}}$ máxima. A su vez, estas familias $\mathrm{BC}$ fueron las que se manifestaron como de mayor resistencia a la cavitación, lo que podría estar asociado al tamaño diferencial observado con respecto a las $A C$ en el torus de las puntuaciones de las traqueidas. Estos resultados se contraponen al compromiso entre eficiencia de conducción y vulnerabilidad a la cavitación propuesto para otras especies.

En condiciones de campo se manifestaron patrones similares de crecimiento aéreo entre familias $A C$ y $B C$ a los observados en condiciones de invernáculo. Sin embargo, se encontraron resultados opuestos a los de los ensayos en condiciones semi-controladas en cuanto al control estomático del potencial hídrico mínimo al comparar familias. En este sentido, en contraste con los resultados de invernáculo, a campo se evidenció un menor control estomático del potencial en la familia AC, lo que resultó en una mayor 
caída relativa en la $k_{\mathrm{s}}$ de ramas que en la familia $\mathrm{BC}$. Se requieren más estudios para explicar estas tendencias distintas entre condiciones de crecimiento.

Se concluye que desde el punto de vista de los caracteres a seleccionar en un programa de mejoramiento genético, buscando genotipos que optimicen el crecimiento aéreo y la resistencia al déficit hídrico, este estudio sugiere que, para condiciones de alta demanda evaporativa, es deseable una alta asignación inicial de biomasa a estructuras áereas, una alta sensibilidad estomática al DPV y una baja vulnerabilidad a la cavitación del leño. Asimismo una alta asignación de biomasa al leño en forma relativa al área foliar puede ser un carácter deseable optimizando la producción de madera y la eficiencia en el uso de los recursos del ambiente. Esta combinación de caracteres es posible de ser identificada entre las progenies de Pinus taeda disponibles en Argentina. 


\section{Abstract}

Water is one of the main factors determining yield in plant-based production systems. It has a direct influence on the productivity of ecosystems due to its crucial role in almost all physiological processes in plants, and in particular in carbon fixation which requires stomatal opening for $\mathrm{CO}_{2}$ input to the leaves. In the context of global climate change, it is predicted that precipitation will be modified in terms of distribution, causing pulses of drought, thus affecting the availability of water in many regions of the world, and in the N.E. of Argentina in particular. Another situation that affects the production systems in this region is the advancement of them to lower-productivity sites due to shallow or rocky soils, as a consequence of competition with other land uses. In this context, knowledge of the response to drought of key species for regional production systems becomes relevant. Pinus taeda L. is the main forestry species in the study region, West of Misiones province, which in turn is part of the main forest pole of Argentina. Currently there is a Breeding Program (PMG), which began in the 90s of last century, with significant progress in terms of growth and other phenotypic traits related to the wood quality. However, the implications that the selection based on productivity and quality (eg. density) have had on stress resistance of the available genotypes are unknown.

From a functional point of view, it is generally argued that there is a tradeoff between growth and stress resistance. This commitment would be given by the fact that growth is positively related to water conduction efficiency of the hydraulic system of a plant, whereas this efficiency is negatively related to its "safety". For safety of the hydraulic system is understood the xylem vulnerability to cavitation at high tension, which results in more or less permanent loss of hydraulic conductivity. This is because the anatomical features that allow greater conductivity (eg. larger diameter of xylem elements, more pits between them and greater permeability of their membranes, etc.) and favor the movement of water within the plant, they also favor the propagation of possible embolisms, making the system more susceptible to dysfunction. There is abundant evidence for the existence of this general tradeoff which results in the most productive species in the world are also the most susceptible to water shortage. However, there are also examples of species with resistance to drought mechanisms 
alternative to low vulnerability to cavitation, based on a drought avoidance behavior that would maximize productivity during periods of high water availability (for high conduction efficiency) and the maintenance of the hydraulic integrity during deficit periods by tight stomatal control of water potential. In addition, if the analysis is focused at the intraspecific level, i.e. considering a limited productivity and drought resistance ranges, there may be combinations of attributes that optimize both processes simultaneously, within certain limits. Also, the wood density is related to the vulnerability to cavitation in both angiosperm and conifer species. This relationship occurs because those species which, being less vulnerable, are subject to greater tension in the xylem, require further strengthening of the xylem elements to prevent their implosion by the pressure differences between cavitated and functional elements. In the above framework, the general objective of this study was to understand the functional relationship between growth rate, wood density and drought resistance in different progenies of loblolly pine, and the degree of influence of the conduction efficiency and xylem safety on these processes, in early stages of development of this forest species.

The following particular objectives were proposed and addressed by greenhouse and field trials: 1) to evaluate the tradeoffs between growth and resistance to water stress at early stages of Pinus taeda genotypes differing in mean growth rate, and the morpho-physiological traits responsible for the observed patterns; 2) to determine the relationship between anatomy, density and functionality (hydraulic conductivity and vulnerability to cavitation) of wood in progenies with different growth rates and the influence of water stress on these relationships; 3 ) to evaluate the effect of time of occurrence of water deficit on the growth of loblolly pine seedlings; 4) to evaluate under field conditions the interactive effect of environmental conditions that occur naturally in the study region on different ecophysiological variables responsible for growth in seedlings of $P$. taeda; 5$)$ to analyze patterns of stomatal regulation of leaf water potential in P. taeda under different conditions of water deficit in the soil and / or in the atmosphere, taking it as a key trait in the adaptation to water stress because of its direct relationship with the hydraulic architecture of the plant and its influence on gas exchange and growth. 
To address the objectives, we worked with four open-pollinated progenies differing in mean growth and wood density, as measured in the mother trees at 5 years of age: two progenies with high growth $(A C)$ and two progenies with (relatively) low growth (BC), also combining high and low wood density. Differential growth rates were observed only under optimum conditions of water availability. The AC progenies with higher absolute aerial increases (stem diameter and plant height) had different allocation patterns compared to BC progenies, presenting lower relative proportion of roots than $B C$, but different also between each other. The AC1 progeny had higher allocation to stem, and AC2 had increased allocation to leaves. AC1 strategy presumably increased water conduction efficiency per unit of leaf area, which was reflected also in lower losses of hydraulic conductivity than in the other progenies. This progeny presented also the highest growth efficiency (CE, growth stem: leaf biomass) and nitrogen use efficiency. High allocation to leaf tissue in AC2 progeny might be responsible for its high absolute growth due to the large surface area for gas exchange. But, it resulted in lower EC and $\mathrm{N}$ use efficiency. These progenies had high absolute growth but they presented however lower growth in relation to their initial size compared to BC progenies. The latter had higher allocation to roots, higher photosynthetic capacity (per unit leaf area) and higher maximum stomatal conductance $\left(g_{s}\right)$. They also had lower stomatal sensitivity to vapor pressure deficit (VPD) relative to their maximum $g_{\mathrm{s}}$ than AC. However, in general the four studied progenies showed a relatively low control of the minimum water potential, losing a high percentage of xylem hydraulic conductivity $\left(k_{\mathrm{s}}\right)$ of branches even under high soil water availability conditions. Also, this relatively low capacity of stomatal regulation of minimum water potential resulted in varying patterns, presenting isohydric and more frequently, anisohydric behaviours, but in this last case, usually maintaining a steady water potential gradient between the soil and the leaves (isohydrodynamics). However, unlike the typical environmental conditions in which anisohydric behaviour develops in other woody species, in Pinus taeda the lower water potentials (less than $4 \mathrm{MPa}$ ) were developed with high soil water content but high DPV, environmental situation in which there was virtually no stomatal closure until DPV as high as $6 \mathrm{kPa}$. When there was some water deficit in the soil, finer control of minimum water potential was evident, suggesting the involvement of hormonal signals produced in the 
roots as first trigger mechanism of stomatal control. The observed patterns also suggest a high vulnerability of these progenies to heatwaves in moments with high soil water availability.

Contrary to the general assumption, differential growth between progenies was not associated with hydraulic efficiency, if this is estimated through the branches $k_{\mathrm{s}}$. Also, all progenies showed a relatively high vulnerability to cavitation (VC), and there was a trend to greater $\mathrm{VC}$ in the AC progenies, although not associated with higher maximum $k_{\mathrm{s}}$. This makes not possible to propose a compromise between growth and susceptibility to water stress from the basis of assumed relationships between $k_{\mathrm{s}}$ and VC in Pinus taeda. By contrast, maximum growth patterns were more related to different biomass allocation within the plant, and to quite different sensitivity to stomatal DPV between progenies. In this sense, AC families had higher allocation to different aerial organs, denoting the existence of different strategies, and a slightly greater stomatal sensitivity to DPV than BC progenies. The latter showed high intrinsic capacity of gas exchange, but its smaller initial size (measured in aerial organs), possibly as a result of their increased allocation to roots very early in the development, left them at disadvantage against $A C$ in the total $C$ gain.

Considering the effect of water stress -moderate and high- on stem growth of different progenies, all showed an exponential decline, reaching all of them similar final growth. Therefore, although AC families had a higher relative decline in growth comparing treatments with water deficit and the control situation, they reached similar growth than BC families under water deficit. This suggests that BC progenies do not present any comparative advantage in these conditions. Also, a marked effect of time of drought occurrence has been observed, being higher when the deficit occurs at the beginning of the growth period, in early spring.

Regarding the functional anatomy of wood, no responses have been observed at cell level, comparing progenies or water conditions. However, significant differences between families and between water stress treatments were determined in the proportion of early - and latewood, reflecting the genetic variability and plasticity of this trait. In this regard, BC families were those that had the highest proportion of earlywood, which resulted in a trend toward higher maximum $k_{\mathrm{s}}$. In turn, these $\mathrm{BC}$ 
families presented greater resistance to cavitation, which could be associated with the observed different torus size in their tracheids compared to AC. These results are opposed to the tradeoff between conduction efficiency and vulnerability to cavitation proposed for other species.

Under field conditions similar patterns of shoot growth between $A C$ and $B C$ families were observed compared to those under greenhouse conditions. However, as opposed to the semi-controlled trials, under field conditions AC progeny presented lower stomatal control of water potential than BC progeny, resulting in a higher decline in relative $k_{\mathrm{s}}$ than in the $\mathrm{BC}$ family. Further studies are needed to explain these different trends between growth conditions.

We conclude that, from the point of view of the characters to select in a breeding program seeking to optimize aerial growth and resistance to water stress, this study suggests that for conditions of high evaporative demand, it is desirable high initial biomass allocation to aerial structures, high stomatal sensitivity to VPD and low xylem vulnerability to cavitation. Also high biomass allocation to stem instead of leaves may be a desirable trait optimizing wood production and efficiency of use of environmental resources. This combination of traits can be identified in progenies of Pinus taeda available in Argentina. 


\section{Trabajos derivados de esta tesis:}

Presentaciones en congresos y jornadas científicas

- Bulfe N, Fernández ME y Gyenge JE. (2010). Control estomático en plantines de Pinus taeda L. sometidos a estres hídrico en Misiones, Argentina. XXVIII Reunión Argentina de Fisiología Vegetal. La Plata, 26 al 29 de Septiembre de 2010.

- Bulfe N y Fernández ME. (2012). Bases fisiológicas del crecimiento diferencial de distintas familias de Pinus taeda L. bajo condiciones de campo y sus implicancias sobre la resistencia al estrés hídrico. XXIX Reunión Argentina de Fisiología Vegetal. Mar del Plata, 17 al 20 de Septiembre de 2012.

Publicaciones en revistas cientificas con referato

- Bulfe N \& Fernandez ME. 2016. Morpho-physiological response to drought of Pinus taeda L. genotypes of contrasting in mean growth rate. New Forests. Aceptado para su publicación. DOI: 10.1007/s11056-016-9524-x

- Bulfe N y Fernandez ME. (2014). Efecto del momento de ocurrencia del estrés hídrico sobre el crecimiento de plantines de Pinus taeda L. Revista de la Facultad de Agronomía, La Plata. Vol. 113 (1): 81-93

- Bulfe, N, Faustino L, Pinazo M, Graciano C y Fernández ME. Bases fisiológicas del crecimiento diferencial de distintas familias de Pinus taeda L. bajo condiciones de campo, en Misiones Argentina. Revista Bosque. En revisión 


\section{Índice general}

\section{Página}

CAPÍTULO 1

INTRODUCCIÓN GENERAL

MARCO CONCEPTUAL

El agua y las plantas

Compromisos entre eficiencia de conducción y resistencia al déficit hídrico

Fundamentos de la elección del tema y especie modelo

Objetivos e hipótesis de trabajo
$-1-$

- 2 -

-2 -

$-2-$

$-4-$

-10 -

-13 $-17-$

CAPÍTULO 2

\section{COMPROMISOS ENTRE CRECIMIENTO EN VOLUMEN DE TALLO Y RESISTENCIA A LA SEQUÍA EN DIFERENTES} FAMILIAS DE PINUS TAEDA L.

RESUMEN

INTRODUCCIÓN

-19 -

MATERIAL Y MÉTODOS

$-23-$

Área de estudio y diseño del experimento

- 23 -

Variables medidas

$-26-$

Análisis estadístico

- 32 -

RESULTADOS

Caracterización de los tratamientos

Incremento en volumen del tallo y partición de biomasa

$-35-$

Relaciones hídricas y parámetros hidráulicos

$-41-$

Intercambio gaseoso

$-44-$

Fisiología de hojas-Contenido de clorofilas, Nitrógeno foliar

$-47-$

Eficiencia en el uso de los recursos

$-49-$

Correlación entre crecimiento y variables morfo-fisiológicas

$-52-$

DISCUSIÓN

$-53-$

$-53-$

Procesos ecofisiológicos que explican el crecimiento diferencial entre familias

Respuestas de los grupos de familias $A C$ y $B C$ al déficit hídrico: ¿existe un compromiso entre crecimiento y resistencia a déficit hídrico?

- 56 - 
ANATOMÍ́ FUNCIONAL DE LA MADERA DE PROGENIES CON DISTINTAS TASAS DE CRECIMIENTO EN PINUS

TAEDA L.

$-62-$

RESUMEN

$-62-$

INTRODUCCIÓN

$-64-$

MATERIAL Y MÉTODOS

$-68-$

Material utilizado y diseño del experimento

$-68-$

Variables medidas

$-68-$

Análisis estadísticos

$-73-$

RESULTADOS

$-73-$

Evaluación del material genético a través de la progenie

$-73-$

Anatomía de la madera en progenies con tasas de crecimiento diferenciales

- 74 -

Funcionalidad de la madera

$-76-$

Curvas de vulnerabilidad a la cavitación

- 77 -

Efecto del déficit hídrico sobre la anatomía funcional de la madera

- 79 -

DISCUSION

$-82-$

Comportamiento del material genético

$-82-$

Anatomía de la madera en progenies con tasas de crecimiento diferenciales

$-83-$

Relación entre anatomía y funcionalidad de la madera

$-85-$

Efecto del déficit hídrico sobre la anatomía de la madera

$-87-$

CONCLUSIONES

$-89-$

CAPÍTULO 4

$-91-$

EFECTO del MOMENTO de OCURRENCIA DEL DÉFICIT HídRICO SOBRE EL CRECIMIENTO DE PLANTINES DE PINUS

TAEDA L.

-92 -

RESUMEN

-92 -

INTRODUCCIÓN

$-93-$

MATERIAL Y MÉTODOS

$-96-$

Área de estudio y diseño del ensayo

-96 -

Crecimiento y biomasa aérea

Mediciones anatómicas en hojas y leño 
Variables fisiológicas

Análisis estadístico

RESULTADOS

-104 -

Crecimiento en altura y diámetro basal

-104 -

Distribución de la biomasa aérea en los distintos compartimentos

-108 -

Anatomía de hojas y leño

- 109 -

Relaciones hídricas y el intercambio gaseoso en las plantas

- 110 -

DISCUSIÓN

- 115 -

Crecimiento en altura y diámetro basal

-115 -

Distribución de la biomasa aérea en los diferentes compartimentos

-116 -

Anatomía foliar y de leño

-117 -

Relaciones hídricas e intercambio gaseoso

-117 -

CONCLUSIONES

CAPÍTULO 5

$-121-$

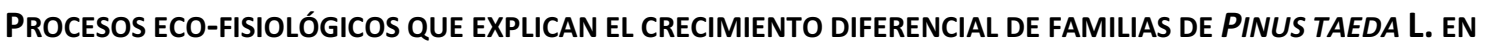
CONDICIONES DE CAMPO

RESUMEN

$-122-$

INTRODUCCIÓN

-124 -

MATERIAL Y MÉTODOS

-127 -

Área de estudio y material utilizado

-127 -

Diseño del experimento a campo

- 129 -

Variables medidas

Análisis estadísitico

RESULTADOS

Crecimiento en altura total y dac

Producción y distribución de la biomasa aérea

Conductancia estomática, potencial hídrico y fotosíntesis neta a saturación lumínica

- 137 -

Parámetros hidráulicos

-139 -

DISCUSIÓN

-140 -

Crecimiento en altura total y dac y producción de biomasa

-140 -

Distribución de la biomasa y su relación con el crecimiento

-142 -

Conductancia estomática, fotosíntesis y potencial hídrico

- 144 -

Parámetros hidráulicos

- 145 - 
RegulaCión estomÁtica del POTENCIAL hídRICO EN PINUS TAEDA L. BAJO DIFERENTES CONDICIONES AMBIENTALES.

RESUMEN

INTRODUCCIÓN

MATERIAL Y MÉTODOS

Área de estudio y material utilizado

Descripción de los ensayos

Variables medidas

$-156-$

Análisis estadístico

- 156 -

RESULTADOS

- 157 -

Ensayo en Macetas 1 (EnM1)

- 157 -

Ensayo en Macetas 2 (EnM2)

- $159-$

Ensayo a Campo (EnC)

- 162 -

DISCUSIÓN

$-165-$

CONCLUSIONES

- 169 -

\section{CAPÍTULO 7} -171 -

CONTRASTE DE HIPÓTESIS, CONCLUISONES GENERALES Y LÍNEAS DE INVESTIGACIÓN FUTURAS

CONTRASTE DE HIPÓTESIS

CONCLUSIONES GENERALES

-177 -

LÍNEAS DE INVESTIGACIÓN FUTURAS

-179 -

BIBLIOGRAFÍA

-180 - 
CAPÍTULO 1

INTRODUCCIÓN GENERAL 


\section{INTRODUCCIÓN GENERAL}

\section{MARCO CONCEPTUAL}

\section{El agua y las plantas}

La composición de la vegetación sobre la superficie terrestre es controlada principalmente por el agua, particularmente, por su cantidad y distribución, resultando la importancia ecológica del agua de su importancia fisiológica (Kramer y Boyer 1995). Cuando una planta está sometida a niveles de disponibilidad hídrica significativamente diferentes a los óptimos para su desarrollo, se dice que se encuentra bajo estrés hídrico (Valladares et al. 2004). En estas condiciones la planta se ve afectada en cuanto a crecimiento, productividad, supervivencia y reproducción (Herralde Traveria 2000). El estrés, en general, puede darse también por condiciones fuera del rango óptimo de otros recursos o condiciones ambientales como los nutrientes, la radiación, la temperatura, entre otras.

Las plantas requieren grandes cantidades de agua para las diferentes funciones dentro de la misma, aunque solamente el $1 \%$ del agua absorbida es retenida en forma de biomasa, siendo el remanente perdido por transpiración como balance de energía de las hojas (Lambers et al. 1998). Si bien el crecimiento está en función de numerosas variables fisiológicas integradas (e.g. Martín et al. 2005), las condiciones ambientales controlan la tasa del movimiento del agua en las plantas, siendo fundamentales la radiación solar neta y el déficit de presión de vapor del aire, ambas en el corto plazo, así como también la precipitación en el largo plazo, todas ellas afectando así a las variables fisiológicas.

Ante condiciones adversas las plantas manifiestan respuestas que tienden a evitar o mecanismos que les permitan tolerar los ambientes de mayor estrés en general (Valladares 2004). En cuanto al estrés hídrico en particular, en líneas generales se pueden producir dos tipos de respuestas antagónicas, que son aquellas con tendencia a evitar o prevenir (mecanismos evitadores) o los que permiten soportar o resistir (mecanismos tolerantes) el estrés. Éstas son denominadas como "estrategias", las 
cuales son características de cada especie (Lambers et al. 1998; Valladares 2004). Las primeras, evitadoras, son especies consideradas como sensibles las cuales pueden maximizar la absorción de agua mediante un sistema radical extensivo (derrochadoras), o bien minimizar las pérdidas a través de un cierre estomático temprao y/o riguroso (ahorradoras). Si bien ambos mecanismos pretenden mantener a la planta en estado de turgencia, el primero de ellos es menos probable de ser mantenido en el tiempo en el caso de que las condiciones ambientales extremas se acentúen o extiendan en el mediano plazo.

Las especies evitadoras tienden a evitar la deshidratación con un sistema de conducción de agua eficiente, que minimiza tensiones en el xilema, lo que suele tener como contracara, una alta vulnerabilidad a la cavitación o ruptura de la columna de agua (Meinzer y McCulloh 2013). En estas especies, la regulación estomática del potencial hídrico es esencial para preservar la continuidad hidráulica del continuo suelo-hoja (Sperry et al. 2002), el cual es fundamental para sostener la tasa fotosintética y con ello el crecimiento. En cuanto a esta regulación estomática, se destaca en la literatura una clasificación dicotómica que representan los extremos de un continuo de la regulación de la tensión hidráulica en el xilema. Por un lado, se presentan las especies isohídricas, las cuales tienden a mantener relativamente constante el valor mínimo del potencial hídrico xilemático, más allá de las condiciones ambientales presentes, siendo esto atribuido a un fuerte control estomático de la tasa de transpiración. En el otro extremo se presentan las anisohídricas, fluctuando el potencial hídrico mínimo diario en función de las condiciones ambientales existentes. El anisohidrismo es el resultado de una menor sensibilidad estomática al potencial hídrico foliar y al déficit de presión de valor de la atmósfera (Tardieu y Simonneau 1998; Franks et al. 2007).

Por otro lado, la tasa de movimiento de agua se ve básicamente determinada por la estructura hidráulica de la planta (Tyree y Ewers 1991; Bond y Kavanagh 1999); este transporte hidráulico a largas distancias ocurre a través de los lúmenes de elementos no vivos del xilema, vasos en el caso de especies latifoliadas o traqueidas para las coníferas, y de puntuaciones laterales que interconectan a estos elementos conductivos (Zimmermann 1983). 


\section{Compromisos entre eficiencia de conducción y resistencia al déficit hídrico}

El flujo de agua a través del continuo suelo-planta-atmósfera es tratado en la literatura como un proceso catenario análogo al de un circuito eléctrico compuesto por una serie de resistencias (Tyree y Ewers 1991). De esta manera puede ser definida la conductividad hidráulica específica $\left(k_{\mathrm{s}}\right)$ como el flujo de agua $\left(\mathrm{Kg} \mathrm{s}^{-1}\right)$ dado por un gradiente de presión (MPa), en un área de sección transversal determinada $\left(\mathrm{cm}^{2}\right)$. Ésta tiene una relación directa con el diámetro y el número de conductos, traqueidas o vasos, por unidad de sección transversal (Tyree 1999). De acuerdo a la fórmula de Hagen-Poiseuille la conductividad hidráulica de un sólo conducto se incrementa en una proporción de su radio a la cuarta potencia (Hacke y Sperry 2001). Esta variable está estrechamente relacionada con el crecimiento de los individuos, tanto en especies latifoliadas (e.g. Wang et al. 2003; Brodribb et al. 2005; Kondoh et al. 2006; Hajek et al. 2014) como en coníferas (e.g. Domec y Gartner 2003; Wang et al. 2003; GonzalezBenecke y Martin 2010), donde una mayor conductividad hidráulica se ve reflejada en un mayor crecimiento del individuo (Hajek et al. 2014). Esto es así porque mayores conductancias significan una mayor eficiencia o capacidad de la planta de proveer agua a las hojas para mantener los estomas abiertos por más tiempo o en mayor magnitud, y de esta manera, poder fijar más carbono (Hubbard et al. 2001; Santiago et al. 2004). Ahora bien, la conductividad hidráulica de una planta se ve afectada por el posible peligro de la cavitación. Se conoce como el fenómeno de cavitación a la formación de vapor de agua dentro del conducto, la cual es dada por presiones muy negativas (Hacke y Sperry 2001). De esta manera la cavitación en las plantas puede ser la resultante de condiciones ambientales extremas (a nivel de suelo o atmósfera), donde la demanda es superior al aporte dado desde las raíces hacia las hojas. Cada especie, y cada órgano dentro de una planta, tienen una curva característica de vulnerabilidad a la cavitación (Tyree 1999). Es así que la estructura de los conductos encargados del transporte de agua en el xilema es de vital importancia, donde combinaciones determinadas de espesor de pared, diámetro de lumen, densidad y diámetro de puntuaciones y características estructurales de las membranas de las mismas, serían las variables que otorgarían la seguridad en el transporte de agua (Zimmermann 1983; Hacke y Sperry 2001; Pittermann et al. 2006a; Pittermann et al. 2006b; Bouche et al. 
2014). A esto hay que sumarle otros caracteres morfo-fisiológicos de las plantas que resultan en la regulación de las pérdidas de agua, entre los que se pueden citar la regulación estomática del potencial hídrico foliar (Ewers et al. 2000; Gonzalez- Franks et al. 2007; Gonzalez-Benecke y Martin 2010) o las diferentes relaciones alométricas dadas entre los distintos órganos de la planta que componen su biomasa total (Bongarten y Teskey 1987; Faustino et al. 2013).

En términos generales, se plantea en la literatura que existe un compromiso entre la eficiencia de conducción hidráulica y la seguridad del sistema conductivo (Domec et al. 2006). Esto implicaría que no es posible optimizar al mismo tiempo la capacidad de crecimiento con la resistencia al déficit hídrico, si asumimos que existe una relación directa entre crecimiento-conductividad hidráulica y entre seguridad del sistema conductivo-resistencia al déficit hídrico. Se ha encontrado evidencia a favor de esta hipótesis comparando distintas partes de un individuo que varían en conductividad hidráulica, y en diferentes grupos de especies latifoliadas (e.g. Kondoh et al. 2006) y coníferas (e.g. Domec et al. 2006). Sin embargo, este concepto ha sido replanteado por Sperry et al. (2008) para especies de coníferas y latifoliadas, y más tarde por Hajet et al. (2014) para diferentes clones de Populus tremula y $P$. tremuloides, quienes han determinado una débil relación entre crecimiento y seguridad del sistema conductivo.

Asimismo, en contraste con este paradigma general, algunos estudios han propuesto que es posible encontrar, al menos en algunas especies o genotipos dentro de una especie, combinaciones de atributos que permiten maximizar la conductividad hidráulica y la seguridad del sistema conductivo al mismo tiempo. Tal sería el resultado de modificaciones en los diámetros de traqueidas, en el espesor de la pared celular, en el tamaño de sus puntuaciones o diferencias en las proporciones de leños tempranos y tardíos formados en el anillo de crecimiento. Estas evidencias fueron detectadas en especies de ecosistemas templado-frío tales como Pinus contorta (Wang et al. 2003) y Sequoia sempervirens (Burgess et al. 2006). Para S. sempervirens, se midió la conductividad hidráulica $\left(k_{s}\right)$ y la vulnerabilidad a la cavitación en ramas a 30 y $50 \mathrm{~m}$ de altura, las que son sometidas normalmente a distintas tensiones en el xilema. Se encontró que las ramas superiores de los árboles poseían menor vulnerabilidad a la cavitación, pero a la vez eran más conductivas que las de la parte más inferior del 
árbol. A nivel anatómico, los autores encontraron que la mayor seguridad del sistema conductivo puede ser explicada por menores tamaños de puntuaciones en las paredes de las traqueidas de las ramas superiores. Sin embargo, la mayor $k_{\mathrm{s}}$ podría ser explicada por una mayor proporción de leño temprano en el anillo de crecimiento de las mismas ramas, el cual posee diámetros de lúmenes mayores que el leño tardío (Burgess et al. 2006). Estos resultados son contradictorios con los hallados para Pseudotsuga menziesii (Domec et al. 2006), en el cual el $80 \%$ de la $k_{\mathrm{s}}$ de distintas porciones de la planta se pudo explicar por el tamaño medio de las puntuaciones, indicando que éstas no sólo influyen en forma directa sobre la vulnerabilidad a la cavitación sino también en la eficiencia del sistema conductivo. Por otro lado, el estudio mencionado en $P$. contorta analizó la tasa de crecimiento, densidad de la madera y resistencia al déficit hídrico de distintas progenies de esta especie. Asimismo, analizó la $k_{\mathrm{s}}$ y la vulnerabilidad a la cavitación. Se encontró que las progenies con mayor $k_{\mathrm{s}}$ fueron aquellas con mayores tasas de crecimiento. Sin embargo, esto no se vio reflejado en una mayor vulnerabilidad a la cavitación. En tres de las cuatro progenies evaluadas, la vulnerabilidad a la cavitación se mantuvo constante en un amplio rango de $k_{\mathrm{s}}$, mientras que el grupo de plantas de mayor $k_{\mathrm{s}}$ (y a su vez mayor crecimiento) fue el de menor vulnerabilidad a la cavitación (Wang et al. 2003). Asimismo, no encontraron una correlación entre densidad de la madera y el crecimiento (combinaciones de progenies con altos y bajos valores de ambas variables). Tres de las progenies que poseían distintas densidades de madera tuvieron igual vulnerabilidad a la cavitación, mientras que la de mayor crecimiento y resistencia a la cavitación resultó ser una progenie de alta densidad. Sin embargo los autores no exploraron las características anatómicas de la madera que pudieran explicar estos patrones, siendo ésta una variable actualmente poco estudiada en relación a la conductividad hidráulica y al crecimiento (Hajek et al. 2014).

Existen además situaciones intermedias, como las descriptas para Pinus ponderosa, en las que la resistencia al déficit hídrico no tiene relación directa con la vulnerabilidad a la cavitación del leño. En esta especie, si bien las procedencias (Zhang et al. 1997) y edades (Domec y Gartner 2003) con mayores $k_{\mathrm{s}}$ fueron las más vulnerables a la cavitación apoyando la hipótesis del compromiso entre eficiencia de conducción y 
seguridad del sistema hidráulico, altas tasas de crecimiento favorecidas por altas $k_{\mathrm{s}}$, durante los momentos con alta disponibilidad hídrica, unidas a altas sensibilidades estomáticas cuando el agua fue limitante, determinaron que los mayores crecimientos tanto bajo condiciones óptimas como bajo condiciones de estrés, se observaran en los individuos más vulnerables. Esto indicaría que, a pesar del compromiso propuesto, también es posible un buen desempeño bajo condiciones de estrés en individuos de alta tasa de crecimiento potencial mediante una estrategia altamente derrochadora de agua cuando ésta está disponible, y altamente conservativa, cuando la misma se encuentra en déficit. Los resultados contradictorios encontrados para las diferentes especies, demuestran la complejidad de las relaciones y los varios interrogantes por resolver respecto a las relaciones entre la anatomía, la capacidad de conducción hidráulica, el crecimiento y la resistencia a la sequía en especies leñosas en general, y en algunas de valor productivo, en particular.

La selección artificial en los programas de mejoramiento genético de especies forestales se basan principalmente en dos caracteres principales, el crecimiento y la densidad de la madera (anatomía de la madera), siendo ambas determinadas tanto por la genética de la especie, como por el ambiente en el cual se desarrollan. Tomando en consideración a la densidad de la madera de los individuos, principal determinante de su calidad, existen antecedentes que ponen de manifiesto que la presión en el xilema que causa el $50 \%$ de pérdida de conductividad hidráulica por cavitación $\left(P_{50}\right)$ está correlacionada con esta variable estructural (Hacke y Sperry 2001; Hacke et al. 2001; Pittermann et al. 2006b; Sperry et al. 2006; Dalla-Salda et al. 2014). Esto sería así porque las mayores tensiones que debe soportar un xilema poco vulnerable, requiere de paredes celulares más gruesas, para un diámetro de lumen dado, de manera de evitar la implosión del conducto que ocurriría debido a las diferencias de presión existentes a ambos lados de la pared, entre un elemento de conducción a alta tensión y uno cavitado (Hacke y Sperry 2001; Sperry et al. 2006). Si bien éste es un patrón general analizando diversas especies en un amplio rango de densidades de madera y $P_{50}$, cuando se analiza un rango acotado de densidades, como el que puede ocurrir dentro de una misma especie, no necesariamente existe una correlación entre densidad de madera y resistencia a la cavitación. Así, Bouffier et al. (2003) encontraron 
que individuos de distintas procedencias de $P$. ponderosa difirieron en su densidad de madera sin diferir en su vulnerabilidad a la cavitación y tasa de crecimiento.

Asimismo, algunos estudios comparando gran cantidad de especies han descripto un compromiso entre densidad de madera y conductividad hidráulica y/o fijación de $C$ (Santiago et al. 2004; Bucci et al. 2004; Meinzer et al. 2008), así como entre densidad de madera y tasa de crecimiento (e.g. Dutilleul et al. 1998; Bouffier et al. 2009). Sin embargo, otros estudios demuestran que no necesariamente existe un compromiso entre densidad de madera y tasa de crecimiento (e.g. Cregg et al. 1988; Livingston et al. 2004). En el caso del trabajo de Cregg et al. (1988), se observó un retraso de entre 10 a 15 días en la transición de leño temprano a tardío en un rodal de Pinus taeda de 10 años al cual se le aplicó un tratamiento de raleo. Este efecto es un reflejo del menor déficit hídrico de los árboles dentro de un rodal raleado en comparación con otro con mayor densidad de individuos en donde la disponibilidad de agua por árbol individual es menor. Los mismos autores mencionan que esta transición tardía entre leños se ve compensada por una mayor tasa de crecimiento del leño tardío, resultando entonces en que no haya cambios en la densidad de la madera del anillo completo. Wang et al. (2003) han determinado, en plantines de 2 años de edad de Pinus contorta con diferentes combinaciones de tasas de crecimiento y densidades de madera, que las plantas que logran mayor crecimiento lo hacen a través de incrementar su tasa de crecimiento diario (para individuos de baja densidad) o mediante la prolongación del período de crecimiento (para individuos de alta densidad). A su vez, encontraron que la selección de una subpoblación de rápido crecimiento no necesariamente afecta la resistencia al estrés. Bajo estas condiciones morfológicas a nivel de leño, es factible entonces aumentar la conductividad hidráulica-crecimiento junto con la resistencia al estrés sin ir en desmedro de la densidad de la madera, conjugando así alto crecimiento, alta densidad y alta resistencia al déficit hídrico. Por lo tanto, dependiendo de la especie considerada, es posible la selección de ejemplares con ambas características deseables, altos crecimientos y altas densidades de madera, dentro de los programas de mejoramiento genético de especies forestales.

Las características del leño formado en diferentes ambientes climáticos es el fundamento de los análisis dendrocronológicos para predecir climas pasados en base a 
la anatomía de los anillos de crecimiento de los árboles. Por ello, y para aumentar la complejidad del tema planteado, además del factor genético, la ocurrencia de déficit hídrico es un factor clave en la modificación de la estructura del leño. En términos generales, el déficit hídrico conlleva una pérdida de turgencia celular que impide la expansión de las células, y por lo tanto, se producen traqueidas (o vasos en el caso de especies latifoliadas) con lúmenes más pequeños (e.g. Abe y Nakai 1999). El engrosamiento de las paredes depende de la cantidad de fotosintetatos disponibles, por lo que el déficit hídrico puede llevar al desarrollo de elementos del xilema con paredes más finas, si se redujo marcadamente la fijación de $C$ (Antonova y Stasova 1997). Otro factor a tener en cuenta respecto al déficit hídrico es el momento dentro del período del año en el cual se produce un evento de sequía, ya que ello puede conducir a distintos patrones anatómicos, como por ejemplo, la generación de falsos anillos (e.g. Campelo et al. 2006), así como tener efectos diferenciales en la fijación de $C$ y con ello, el crecimiento. En este sentido, estudios de intercambio gaseoso, a nivel de bosque, llevados a cabo en $P$. ponderosa (Goldstein et al. 2000) mostraron que un evento de sequía severo en primavera redujo la fijación de $C$ de toda la temporada de crecimiento (efecto de mediano plazo), patrón que no se verifica si el déficit hídrico ocurre en la etapa final del período de crecimiento, correspondiente al verano. Fernández et al. (2014) han observado patrones similares en plantines de la misma especie, los cuales han evolucionado en ambientes con sequía estival.

Por lo expuesto, varios son los factores que intervienen en el crecimiento de las plantas y en la anatomía de la madera, siendo complejo el análisis de manera integrada de las interrelaciones entre ellos. Por ello, para poder abordar el objetivo general planteado en esta tesis se han determinado diferentes objetivos particulares, en los que se pretende el análisis de manera más puntual sobre relaciones morfofisiológicas desde diferentes ensayos y combinación de factores. A partir del análisis integrado posterior, se plantean al final conclusiones generales abordando los diferentes aspectos que afectan el crecimiento y la resistencia al déficit hídrico en la etapa inicial del desarrollo de distintos genotipos de Pinus taeda. 


\section{Fundamentos de la elección del tema y especie modelo}

A nivel mundial, las plantaciones con especies forestales exóticas han adquirido relevancia, principalmente en los países de climas cálidos donde las tasas de crecimiento son superiores a las alcanzadas en los lugares de origen de las especies de interés. En nuestro país predominan plantaciones de especies exóticas de coníferas del género Pinus, y latifoliadas de los géneros Eucalyptus y Populus. Para las distintas especies de estos géneros, el avance de la ciencia ha sido creciente en las últimas dos décadas, principalmente abarcando las áreas de mejoramiento genético y de manejo a nivel de rodal, apuntando a la producción de materia prima de calidad, a la optimización de los rendimientos y al abastecimiento de las demandas generadas tanto en el mercado interno como externo.

Desde el punto de vista de la actividad forestal en el país, Argentina cuenta con una superficie de bosques cultivados de aproximadamente un millón de hectáreas, siendo el principal polo forestal el comprendido por las provincias de Misiones, Corrientes y Entre Ríos, donde se concentra el 63\% de la superficie forestada del país (MAGyP 2013). Un $45 \%$ de esta superficie forestada pertenece a la provincia de Misiones (aproximadamente 300 mil hectáreas) de las cuales cerca del $80 \%$ pertenecen al género Pinus, predominando particularmente la especie Pinus taeda (SIFIP 2010).

Pinus taeda L. es la especie forestal nativa comercialmente más importante del sudoeste de los Estados Unidos, ocupando 11,7 millones de hectáreas en ese país (Baker y Langdon; reporte USFS; Figura 1.1). Esta especie ha sido introducida en varios continentes, con distinto grado de éxito en su cultivo (Cubagge et al. 2007). Originariamente es una especie proveniente de un clima templado húmedo, con veranos cálidos e inviernos suaves. Está ampliamente distribuida en su región de origen abarcando un amplio rango de condiciones de humedad ambiental, ocupando áreas costeras más húmedas e ingresando hacia el interior del continente donde predominan zonas más áridas (Bongarten y Teskey 1986). Este amplio rango de distribución natural determina una amplia adaptabilidad a diferentes condiciones ambientales. El área de distribución natural de la especie presenta un promedio de temperatura anual que abarca desde 13 a $24 \stackrel{\circ}{\circ}$, con un promedio de $27 \stackrel{\circ}{\circ}$ en verano, 


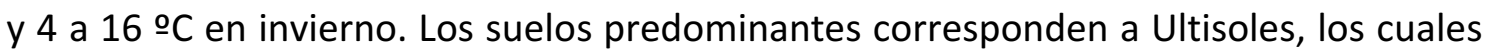
son suelos evolucionados, profundos y bien drenados. La especie puede encontrarse tanto en forma pura como asociada a otras especies de árboles o vegetaciones menores.

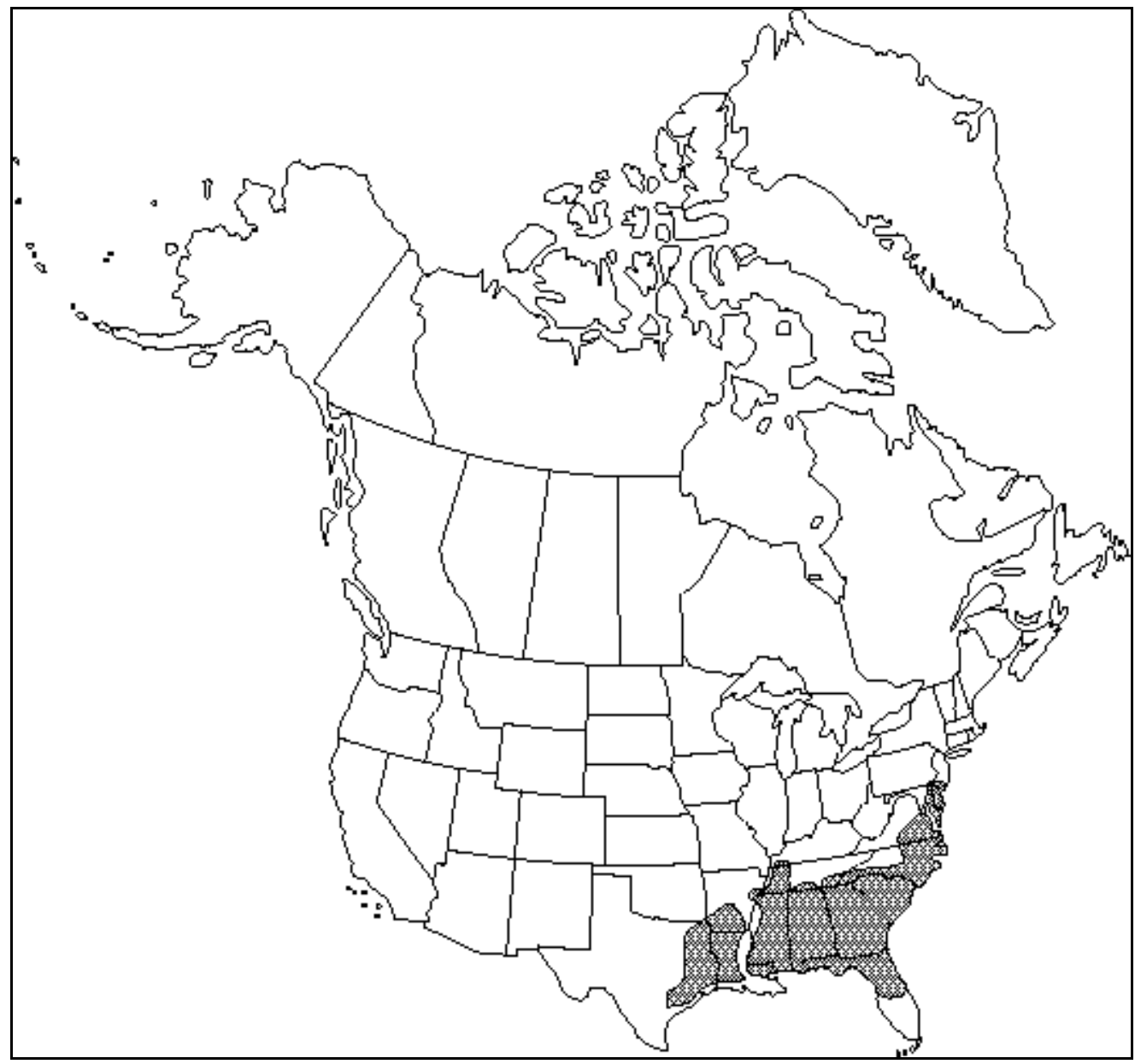

Figura 1.1 Distribución natural de Pinus taeda L. en los Estados Unidos de Norteamérica (eFloras 2014).

Según Ligier (2000), la provincia de Misiones cuenta con un conjunto de suelos rojos profundos de aproximadamente $33 \%$ de la superficie, donde comúnmente las plantaciones con especies forestales se desarrollan de manera efectiva. Sin embargo, existe un $35 \%$ de la superficie de la provincia donde predominan los suelos comúnmente denominados como "pedregosos", sobre los cuales la expansión de plantaciones con especies forestales está ocurriendo actualmente. Éstos son 
considerados como sitios marginales debido a que los suelos son de escasa profundidad o con algún grado de pendiente, por lo cual la disponibilidad hídrica se ve restringida. Sumado a ello, los pronósticos de cambio climático para muchas zonas del mundo indican una tendencia al aumento de la temperatura del aire y de las precipitaciones, aunque con modificaciones en los patrones de esta última resultantes en la ocurrencia de fenómenos extremos de precipitación y sequía (Bate et al. 2008). Para Argentina la tendencia es similar, con un calentamiento más rápido para el norte del país, donde se estima que para la región de Misiones, además de un incremento en la precipitación anual, ésta se tornará más variable con estaciones secas más frecuentes (Hulme y Sheard 1999). En este contexto general se pone de manifiesto la necesidad del desarrollo de conocimiento acerca de la adaptabilidad de las distintas especies cultivadas a condiciones con déficits hídricos de diferentes magnitudes.

Por ello, el tema que se pretende abordar en esta tesis se torna relevante, no sólo desde la generación de conocimiento básico acerca de los compromisos entre dos elementos claves para la ecología y las ciencias agropecuarias-forestales como son la resistencia al estrés y la productividad, sino también como generador de información base sobre algunos parámetros ecofisiológicos para el manejo y mejoramiento de una de las principales especies implantadas en la Argentina y otros países del mundo.

Si bien el material genético implantado en Argentina ha sido traído originalmente de EEUU, el desconocimiento de las procedencias exactas en algunos casos, así como las modificaciones ocurridas durante los procesos de mejora genética posteriores, hacen que los vastos antecedentes ecofisiológicos existentes para la especie (Martín et al. 2005) no sean eficaces de manera específica para el material implantado actualmente, principalmente en nuestra región de estudio donde las condiciones ambientales son diferentes a las de origen. Si bien, los rasgos generales de la especie son los mismos, existe una importante variabilidad en el comportamiento ecofisiológico de las distintas procedencias (Baker y Langdon; reporte USFS), por lo que se justifican estudios particulares para los genotipos locales utilizados.

En la provincia de Misiones se vienen desarrollando desde la década del '60 del siglo pasado los programas de mejoramiento genético de Pinus taeda L. con la instalación de ensayos de orígenes y procedencias. Desde inicios de los '90, el INTA, en conjunto 
con otras entidades, han desarrollado Programas de Mejoramiento Genético (PMG) creando los primeros huertos semilleros de alta calidad (Rodríguez 2003; Gauchat y Rodríguez 2005). En la actualidad estos PMG apuntan, además de al crecimiento en volumen, a otros caracteres de alta relevancia como la calidad de la madera (densidad). Hasta el presente, sin embargo, se desconoce la respuesta potencial de los distintos genotipos a condiciones de estrés. En este contexto, la ecofisiología cumpliría un rol fundamental en integrar procesos y mecanismos que hacen al crecimiento, rendimiento y calidad de la madera ante distintas condiciones ambientales y de manejo de las plantaciones, aportando información diferencial para distintas entidades genéticas en el corto plazo y también a largo plazo dados los cambios ambientales (Martín et al. 2005).

Aunque en los últimos tiempos el avance en el conocimiento referente a la calidad de la madera ha sido de importancia (Winck et al. 2015), se ha detectado un vacío en cuanto a la información referente a la interrelación entre calidad de madera ambiente en especies de coníferas con potencialidad de crecer en ambientes subtropicales como la región de estudio. Trabajos de esta índole fueron encontrados para algunas especies de coníferas de clima templado-frío como $P$. contorta (Wang et al. 2003), P. ponderosa (Domec y Gartner 2003) y Pseudotsuga menziesii (Dalla-Salda et al. 2014), mientras que para Pinus taeda en la región de estudio se cuenta con escasos antecedentes, siendo de relevancia el trabajo de Faustino et al. (2013), donde los autores encontraron variabilidad de respuestas entre materiales genéticos respecto a la distribución de la biomasa y a la arquitectura hidráulica de la planta.

\section{Objetivos e hipótesis de trabajo}

\section{Objetivo General}

El objetivo general de esta tesis es comprender la relación funcional entre tasa de crecimiento, densidad de madera y resistencia a la sequía de Pinus taeda, y el grado de influencia de la relación eficiencia de conducción - seguridad del sistema hidráulico en el estadío inicial de la especie (Figura 1.2). 


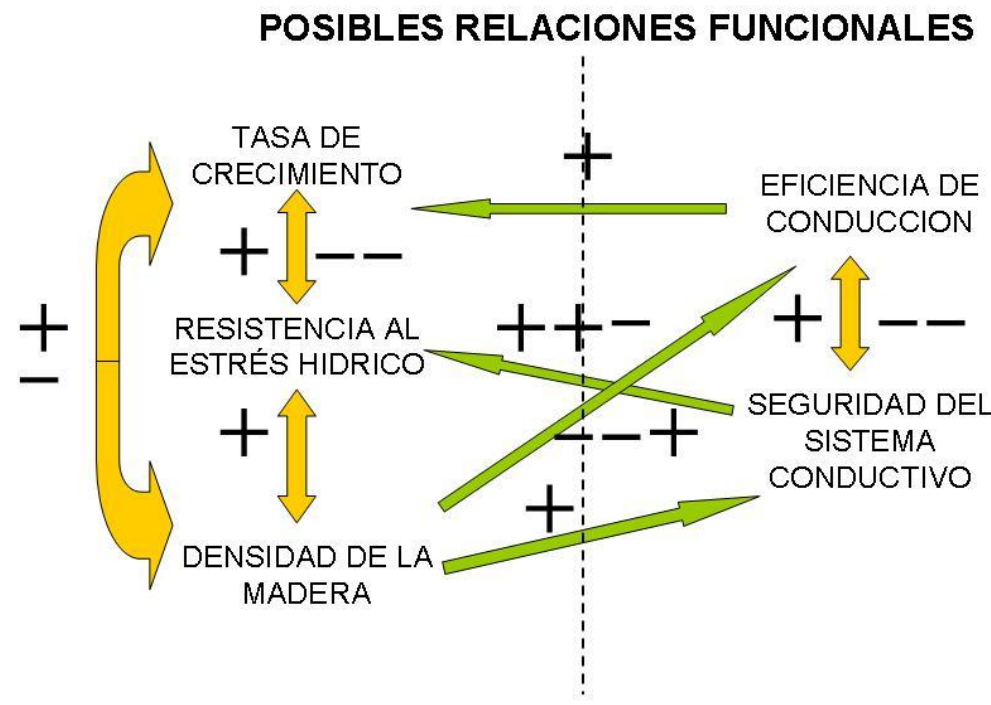

+ - : indica relaciones positivas (directa) o negativas (inversas), respectivamente, de acuerdo a la bibliografía (datos de múltiples especies). Doble signo indica que dicho tipo de relación es más frecuente.

Figura 1.2 Posibles relaciones funcionales entre tasa de crecimiento-resistencia al déficit hídrico y densidad de madera en especies leñosas, y su influencia mutua con la relación eficiencia de conducción-seguridad del sistema conductivo. Los signos indican el tipo (positiva o negativa) y frecuencia de relación de acuerdo a varios estudios en múltiples especies reportados en la bibliografía.

\section{Objetivos Específicos}

- Evaluar los compromisos entre crecimiento y resistencia al déficit hídrico en edades tempranas de genotipos de Pinus taeda de tasa diferencial de crecimiento, y los procesos morfo-fisiológicos responsables de los patrones observados.

- Determinar las relaciones existentes entre la anatomía, la densidad y la funcionalidad (conductividad hidráulica y vulnerabilidad a la cavitación) de la madera en progenies de Pinus taeda con distintas tasas de crecimiento, así como la influencia del déficit hídrico sobre estas relaciones.

- Evaluar el efecto del momento de ocurrencia del déficit hídrico sobre el crecimiento de plantines de Pinus taeda L.

- Evaluar bajo condiciones de campo el efecto interactivo de las condiciones ambientales que se dan naturalmente en la región de estudio sobre distintas 
variables ecofisiológicas responsables del crecimiento en plantines de Pinus taeda.

- Analizar los patrones de regulación estomática del potencial hídrico foliar en Pinus taeda bajo distintas condiciones de déficit hídrico en el suelo y/o en la atmósfera, tomando a éste como un caracter clave en la adaptación a déficit hídrico, debido a su relación directa con la arquitectura hidráulica de la planta y su influencia sobre el intercambio gaseoso y el crecimiento.

Hipótesis de trabajo

- Existe un compromiso entre crecimiento y resistencia al déficit hídrico en plantines de Pinus taeda debido a que las estructuras de la planta que permiten un mayor crecimiento (e.g. mayor desarrollo de área foliar y mayor $k_{\mathrm{s}}$ ) son penalizantes frente a condiciones de déficit hídrico (por una mayor superficie transpiratoria y mayor vulnerabilidad a la cavitación, respectivamente).

- Como hipótesis alternativa se propone que es posible encontrar combinaciones de atributos en algunos genotipos de Pinus taeda que permiten la selección conjunta de alta productividad y alta resistencia al déficit hídrico.

- La disminución del crecimiento acumulado al final de la estación de crecimiento es mayor cuando el déficit hídrico ocurre al inicio de la primavera en plantines de Pinus taeda, debido a que en este período se observan las mayores tasas de crecimiento. La tasa de crecimiento posterior, aun cuando las condiciones sean favorables para el crecimiento de la planta, no alcanzan a compensar la disminución del crecimiento durante la etapa inicial.

- En condiciones de campo, las diferentes tasas de crecimiento de los genotipos están relacionadas con un comportamiento estomático y una asignación de biomasa entre compartimentos aéreos (hojas vs. tejido leñoso) diferenciales. En este sentido, el genotipo de rápido crecimiento presenta una mayor sensibilidad estomática, permitiéndole una menor caída relativa de su conductividad hidráulica, además de una menor asignación de biomasa a hojas 
y una mayor a fuste favoreciendo la eficiencia de conducción de agua hacia las hojas. 


\section{CAPÍTULO 2}

\section{COMPROMISOS ENTRE CRECIMIENTO EN VOLUMEN DE TALLO Y RESISTENCIA A LA SEQUÍA EN DIFERENTES FAMILIAS DE Pinus taeda $\mathrm{L}$.}




\section{COMPROMISOS ENTRE CRECIMIENTO EN VOLUMEN DE TALLO Y RESISTENCIA A LA SEQUÍA EN DIFERENTES FAMILIAS DE Pinus taeda L.}

\section{RESUMEN}

Las tasas de crecimiento divergentes que pueden encontrarse entre genotipos son debidas a las diferentes características morfo-fisiológicas de los mismos, las que a su vez pueden dar lugar a diferentes estrategias para hacer frente al déficit hídrico. El objetivo de este capítulo fue evaluar los posibles compromisos entre crecimiento y resistencia al déficit hídrico, y los procesos ecofisiológicos involucrados, en familias de Pinus taeda L. Se estudiaron plantines de dos familias de alto (AC1 y AC2) y dos de bajo crecimiento ( $\mathrm{BC} 1$ y $\mathrm{BC2}$ ), bajo dos intensidades de déficit hídrico (moderado y severo) y un control (sin limitaciones de agua en suelo). Se midió incremento en altura y diámetro basal del tallo, asignación de biomasa entre distintos compartimentos, conductividad hidráulica específica de la madera $\left(k_{\mathrm{s}}\right)$, comportamiento estomático $\left(g_{\mathrm{s}}\right)$, máximas tasas de fotosíntesis $\left(A_{\text {sat }}\right)$, contenido foliar de nitrógeno y clorofilas. En condiciones de alta disponibilidad de agua en suelo (control) se encontraron diferencias significativas en incremento entre familias, siguiendo los criterios de alto y bajo crecimiento observados en los árboles madres. Frente al déficit hídrico todas las familias tuvieron incrementos similares, con caídas exponenciales con respecto a los valores observados en el control. Las familias AC presentaron mayor incremento absoluto, pero menor incremento relativo (al tamaño inicial) que las BC. La conductividad hidráulica de las ramas disminuyó a altos valores de déficit de saturación de aire (DPV), incluso en el control. Las familias BC presentaron mayor capacidad fotosintética por unidad de área foliar, menor sensibilidad estomática al DPV y menor asignación de biomasa a la porción aérea de la planta, lo que podría explicar, al menos en parte, su menor crecimiento aéreo en las condiciones de alto DPV de la región de estudio. Entre las familias AC, se observaron diferentes combinaciones de atributos morfo-fisiológicos. La familia AC2 asignó relativamente más biomasa a hojas que las otras, incrementando su capacidad de fijación de carbono a nivel de planta entera. Por otro lado, la familia AC1 presentó una asignación de 
biomasa diferencial hacia tallo, y menores pérdidas de $k_{\mathrm{s}}$ durante el día. Esta menor inversión en hojas se tradujo en una mayor eficiencia en el uso de los recursos y de crecimiento. Nuestros resultados no soportan la hipótesis de un posible compromiso entre crecimiento y resistencia a la sequía en plantines de $P$. taeda, sino que existen combinaciones de atributos, como los de las familias AC, que conducen a un alto crecimiento cuando la disponibilidad de agua en el suelo es alta, y menor crecimiento pero similar a la presentada por familias BC - en condiciones de déficit hídrico. Las diferencias en la sensibilidad estomática al DPV, la vulnerabilidad a la cavitación y los patrones de asignación de biomasa pueden ser rasgos claves que explican las respuestas de crecimiento ante diferentes condiciones hídricas en la especie estudiada.

La mayor parte de los resultados de este capítulo han sido expuestos en un manuscrito el cual ha sido aceptado para su publicación:

Bulfe N \& Fernández ME. 2016. Morpho-physiological response to drought of Pinus taeda L. genotypes of contrasting mean growth rate. New Forests. DOI: $10.1007 / \mathrm{s} 11056-016-9524-x$ 


\section{INTRODUCCIÓN}

Informes del IPCC (2007) indican que la frecuencia e intensidad de algunos fenómenos meteorológicos han cambiado en los últimos cincuenta años. Por otro lado, mencionan que en regiones subtropicales se producirá una modificación en la distribución de las precipitaciones, afectando notablemente la disponibilidad de agua, y comprometiendo la productividad de algunos cultivos. En este contexto, en el capítulo 4 se presenta en la Figura 4.1 datos correspondientes a la precipitación ocurrida durante un período de cuatro años recientes para la zona de estudio, donde se desarrollaron los diferentes ensayos en el marco de esta tesis.

En Argentina, Sudamérica, la región del Noreste, principal productora forestal, experimentará un aumento severo de déficit hídrico. Los sectores ubicados en el centro y este de la región tenderían a presentar déficit hídrico durante los meses de primavera y verano (Hulme y Sheard 1999). Los mismos autores mencionan que para esta región, en líneas generales la precipitación anual se incrementará, pero además se tornará más variable, provocando estaciones secas más frecuentes. Estos antecedentes sumados a que los sistemas forestales se expanden a sitios más marginales por su competencia con otros usos de la tierra como ser la agricultura, la conservación de bosques nativos, entre otros, hacen pensar que la resiliencia y la productividad de los cultivos se verán comprometidos a futuro.

Pinus taeda L. es una especie forestal de gran importancia en su país de origen, EEUU (Baker y Langdon; reporte USFS), y es la principal especie exótica implantada en Argentina (MAGyP 2013). El mejoramiento genético implementado durante décadas ha permitido un incremento substancial en la productividad de varias especies forestales, y en particular de $P$. taeda, que ha sido seleccionada tanto en programas de mejoramiento llevados a cabo en Norteamérica (Cooperative Tree Improvement Program (CTIP - NC State University); Forest Biology Research Cooperative (FBRC University of Florida) y Arkansas Forestry Commission (AFC) entre otros) como en Argentina, utilizando genotipos mejores adaptados a las condiciones locales. En este país, los programas de mejoramiento genéticos han logrado incrementos significativos en productividad, pero desconociendo las bases fisiológicas que explican las mayores 
tasas de crecimiento, además de su adaptabilidad a diferentes condiciones de estrés (e.g. sequía por déficit hídrico en el suelo y/o alta demanda evaporativa del aire).

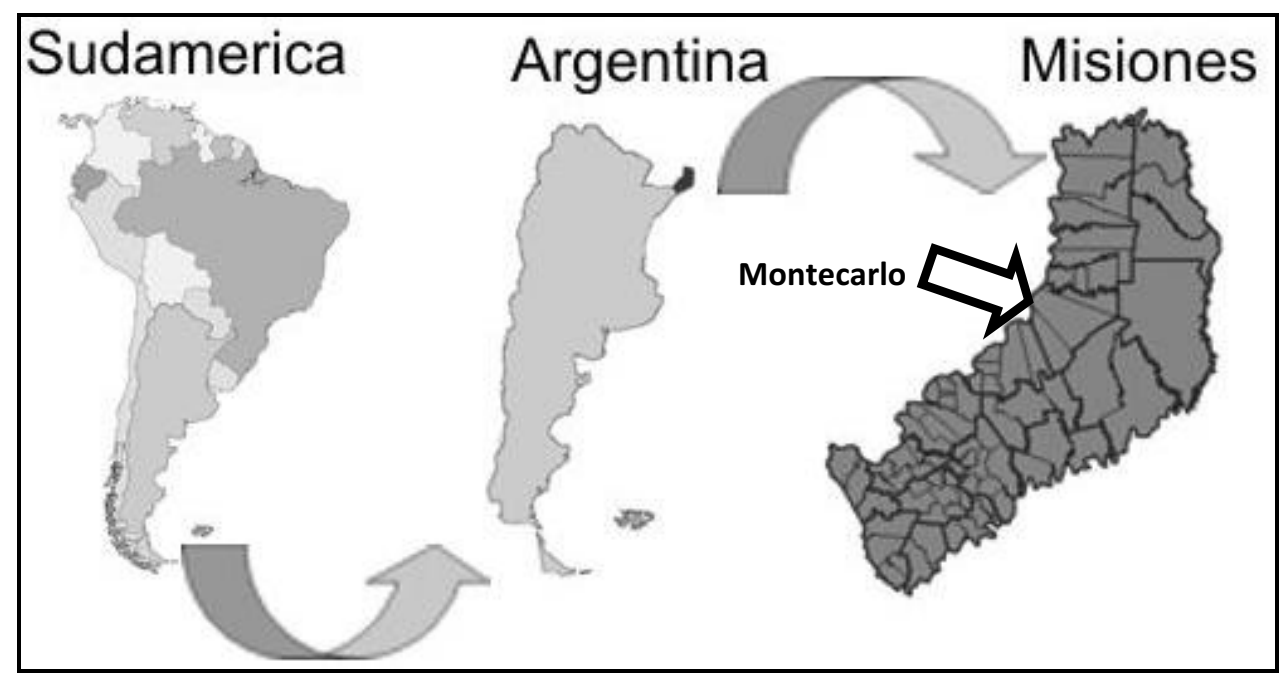

Figura 2.1 Ubicación geográfica de la provincia de Misiones, en el territorio Argentino. Los ensayos fueron desarrollados en la región noroeste de la provincia, en el departamento de Montecarlo (flecha indicativa sobre el mapa de la provincia).

Teniendo en consideración los cambios proyectados en el clima, se torna fundamental conocer los posibles compromisos entre productividad y resistencia al estrés, en los que las características hidráulicas de la especie y otros mecanismos morfo-fisiológicos juegan un rol clave.

Entre los componentes hidráulicos de la planta, la conductividad hidráulica específica $\left(k_{\mathrm{s}}\right)$ de distintos órganos, como las ramas, se destaca por estar directamente relacionada con el crecimiento de los individuos, tanto en especies latifoliadas (e.g. Kondoh et al. 2006; Brodribb et al. 2005; Hajek et al. 2014) como en coníferas (e.g. Domec y Gartner 2003; Wang et al. 2003). Esta se ve afectada por la ruptura de la columna de agua dentro de los elementos de conducción, fenómeno conocido como cavitación (Hacke y Sperry 2001). La cavitación se produce cuando se superan umbrales de tensión ante determinadas condiciones ambientales de déficit hídrico a nivel de suelo y/o la atmósfera, provocando una disminución del crecimiento y en el peor de los casos, la muerte del individuo (e.g. Sperry y Pockman 1993; Rice et al. 2004; Breda et al. 2011). 
En términos generales, se plantea que existe un compromiso entre la conductividad hidráulica y la seguridad del sistema conductivo (Kondoh et al. 2006; Domec et al. 2006), siendo esto replanteado por Sperry et al. (2008), coincidiendo en parte con resultados de Hajek et al. (2014) para especies del género Populus, donde no han encontrado un fuerte compromiso entre crecimiento y seguridad del sistema conductivo, dado que este último varió independiente de la tasa de crecimiento. De la misma manera, en algunas especies coníferas -o genotipos dentro de una especie- de ecosistemas templado-fríos se ha observado que existen combinaciones de atributos que permiten maximizar la conductividad hidráulica y la seguridad del sistema conductivo al mismo tiempo (Burgess et al. 2006; Wang et al. 2003), siendo las coníferas capaces de alcanzar mayores resistencias a la cavitación sin sacrificar de manera considerable la eficiencia hidráulica, en comparación con las angiospermas (Bouche et al. 2014). Por otro lado, en algunas especies, tales como el pino ponderosa ( $P$. ponderosa), la resistencia al déficit hídrico no tiene relación directa con la vulnerabilidad a la cavitación (Zhang et al. 1997; Domec y Gartner 2003). En esta especie se encontró que es posible un buen desempeño bajo condiciones de estrés en individuos de alta tasa de crecimiento potencial mediante una estrategia altamente derrochadora de agua cuando ésta está disponible, y altamente conservativa, cuando ésta se encuentra en déficit. Los resultados contradictorios mencionados dependiendo de las especies, demuestran que existen muchos interrogantes por resolver acerca de la relación entre capacidad de conducción hidráulica, crecimiento y resistencia a la sequía en especies leñosas en general, y en algunas de mayor interés comercial, en particular. Este capítulo tiene como objetivo evaluar los compromisos entre crecimiento y resistencia al déficit hídrico en edades tempranas de genotipos de Pinus taeda de tasas de crecimiento diferencial, y los procesos morfo-fisiológicos responsables de los patrones observados. Se planteó como hipótesis que existe un compromiso entre crecimiento y resistencia al déficit hídrico debido a que las estructuras de la planta que permiten un mayor crecimiento (e.g. mayor desarrollo de área foliar y mayor $k_{\mathrm{s}}$ ) son penalizantes frente a condiciones de déficit hídrico (por una mayor superficie transpiratoria y mayor vulnerabilidad a la cavitación, respectivamente). Como hipótesis alternativa se propone que es posible encontrar 
combinaciones de atributos en algunos genotipos de $P$. taeda que permiten la selección conjunta de alta productividad y alta resistencia al déficit hídrico.

\section{MATERIAL Y MÉTODOS}

\section{Área de estudio y diseño del experimento}

El área de estudio está localizada en el departamento de Montecarlo en la provincia de

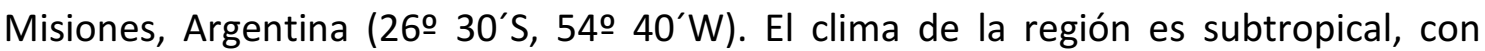
precipitaciones anuales promedio de $2000 \mathrm{~mm}$ y una temperatura media anual de 20은 C (Ligier 2000). El ensayo fue desarrollado bajo condiciones semi-controladas en invernáculo, el cual fue construido con perfiles de hierro de arco redondeado, presentando como cubierta superior polietileno transparente LTD (larga duración térmica) de 150 micrones de espesor, con paredes laterales cubiertas con malla media sombra $50 \%$ color negro.

En abril de 2010 se seleccionaron árboles madres de Pinus taeda L., de un huerto semillero clonal de 15 años de edad perteneciente al Programa de Mejoramiento Genético (PMG) del Instituto Nacional de Tecnología Agropecuaria (INTA) de Argentina (Figura 2.2). Esta selección fue realizada a través de la progenie de los clones del HSC.

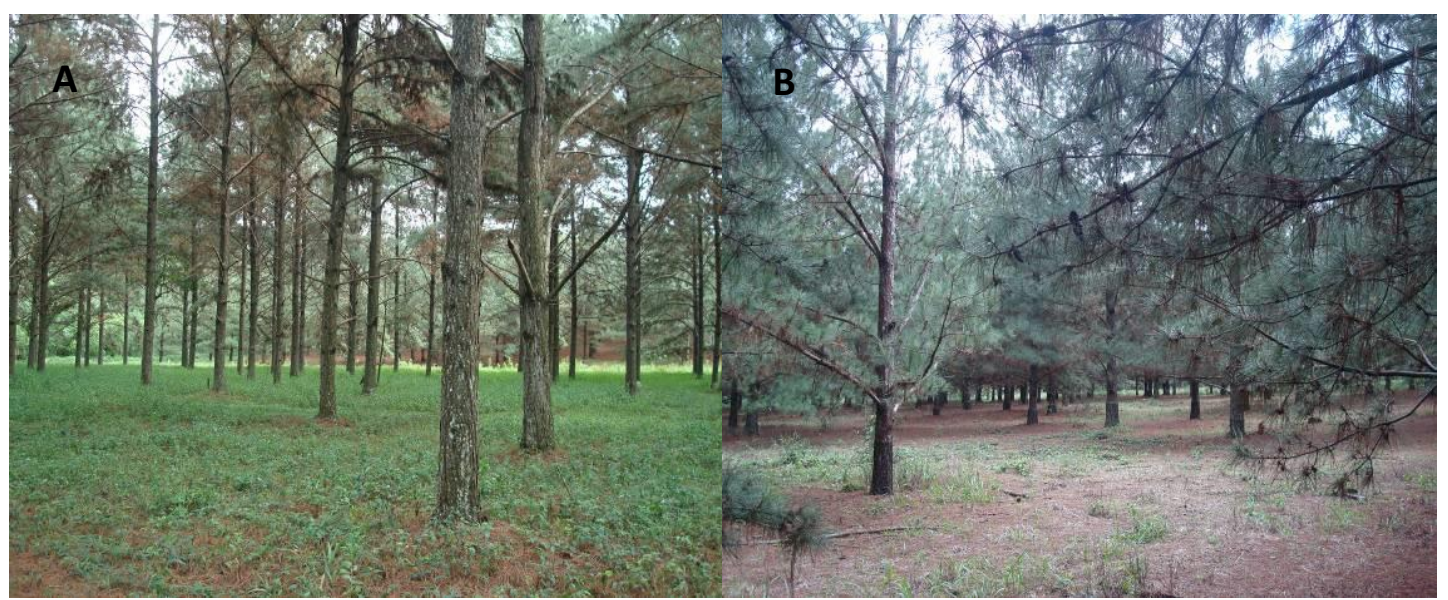

Figura 2.2 Vista del Huerto Semillero Clonal (HSC) del INTA en el Campo Anexo Manuel Belgrano, en San Antonio, Misiones. A) HSC de las familias de bajo crecimiento (BC1 y BC2), plantación realizada en el año 1999. B) HSC de las familias de alto crecimiento (AC1 y AC2), plantación realizada en el año 1993 para la familia AC2 y 1995 para la familia AC1. 
Las progenies de las plantas del HSC forman parte de una red de siete ensayos implantados en el año 2002 en las provincias de Misiones y Corrientes. Mediante el crecimiento en volumen y la rectitud del fuste al quinto año de edad se elaboró un ranking genético en las progenies de las 224 plantas madres pertenecientes al PMG.

A partir de este ranking fueron seleccionadas las cuatro familias a ser utilizadas en la presente tesis (I35, M11, T17 y T10, nomenclatura utilizada por el PMG). De estas cuatro familias dos presentan altas tasas de crecimiento en volumen y rectitud de fuste (Grupo de familias AC: AC1 y AC2) y dos, relativamente bajas tasas de crecimiento y rectitud de fuste (Grupo de familias BC: BC1 y BC2) (Figura 2.3).

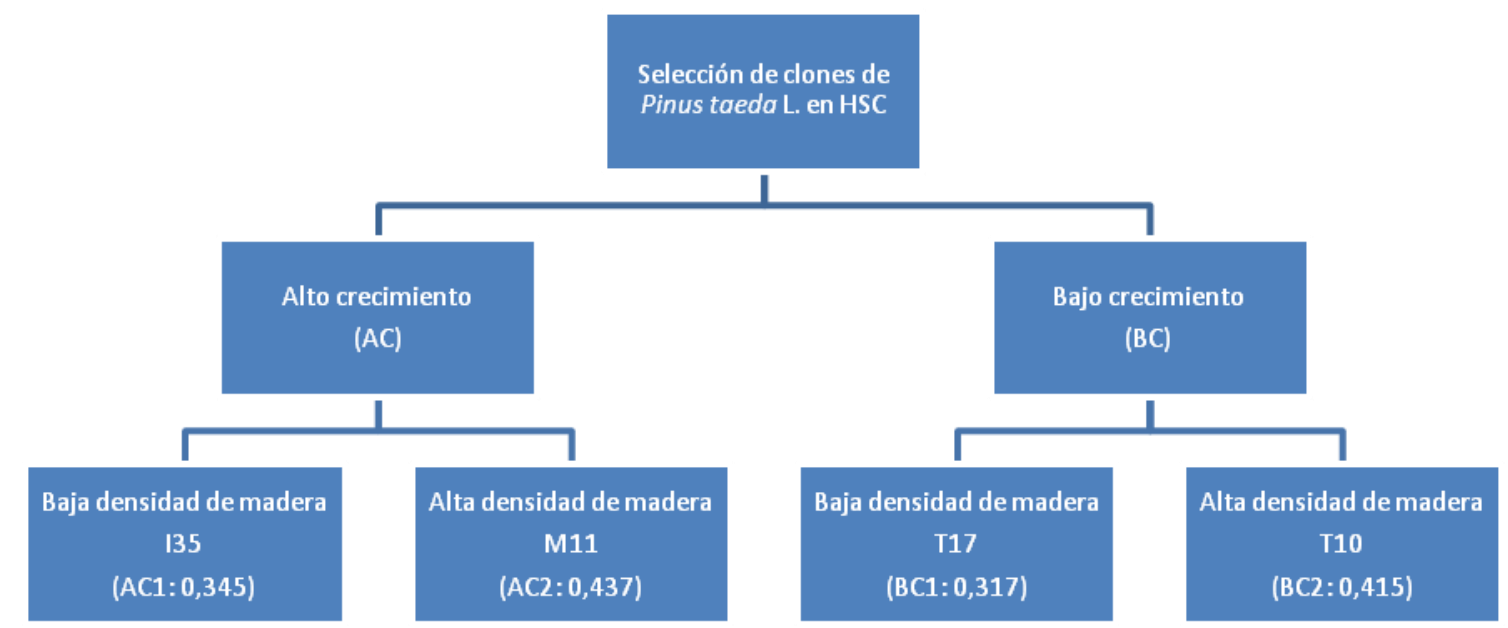

Figura 2.3 Configuración esquemática de la selección de familias de Pinus taeda L. para el desarrollo del experimento bajo invernáculo. Densidad de madera expresada en $\mathrm{gr} \mathrm{cm}^{-3}$.

Para la obtención de plantines se realizó en las semillas un tratamiento pre-

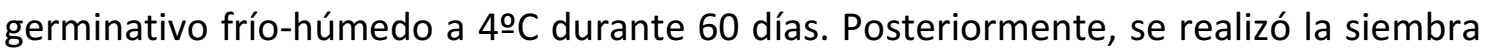
en agosto del mismo año. En enero de 2011 se realizó el trasplante de 36 plantines de cada familia a macetas de 20 litros las cuales fueron ubicadas al azar en el invernáculo. El sustrato utilizado en las macetas fue $1 / 3$ de corteza de pino, $1 / 3$ de arena y $1 / 3$ de suelo rojo (Ultisol, suelo en el cual es normalmente cultivada la especie en Misiones). Esta combinación fue utilizada para que las plantas se desarrollen con buen drenaje y 
fertilidad, además de que la textura gruesa facilita la recuperación de las raíces para su posterior análisis de biomasa subterránea.
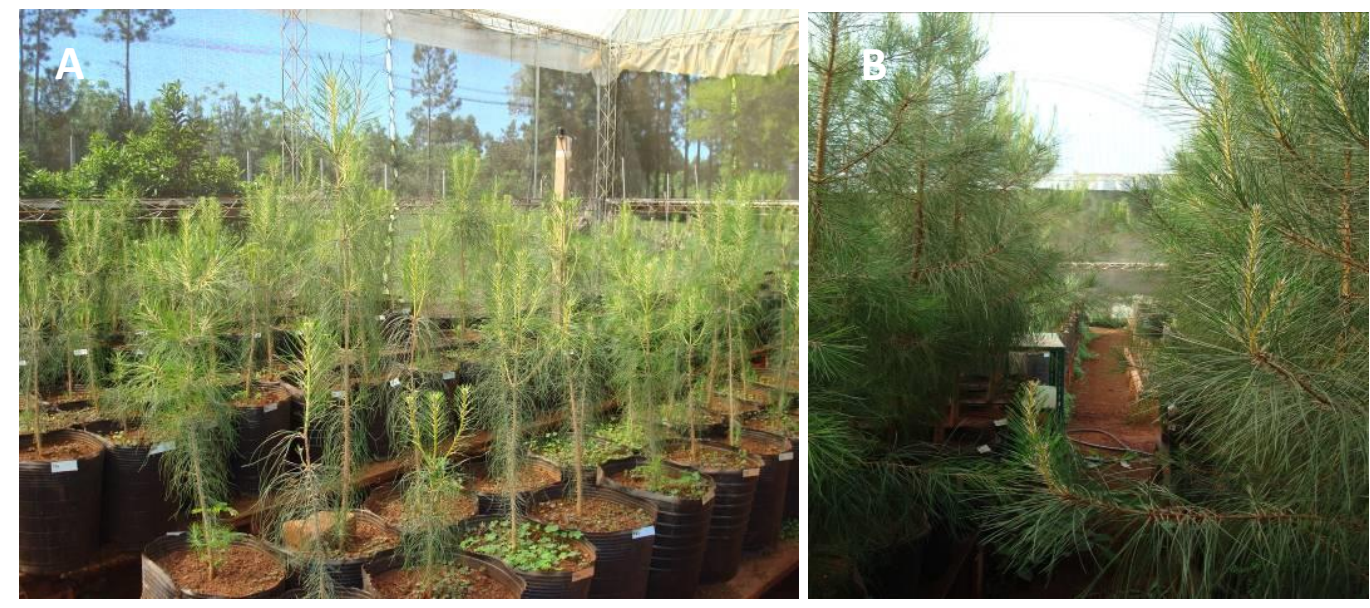

Figura 2.4 Vista general del ensayo, plantines de Pinus taeda en macetas bajo invernáculo. A) Plantines al inicio del ensayo (Septiembre de 2011), previo a la aplicación de los tratamientos. B) Plantines al final del período de crecimiento (Marzo de 2012).

Las plantas fueron distribuidas al azar en tres tratamientos, resultando en 12 plantas por familia dentro de cada uno de ellos, los cuales son descriptos a continuación:

- Control (C): las plantas fueron regadas a saturación, con 2000 cc de agua por planta, con una frecuencia de riego de dos veces por semana.

- Déficit hídrico moderado (DM): las plantas fueron regadas con una frecuencia de riego igual al control pero con menor cantidad de agua para cada riego, 500 cc por planta.

- Déficit hídrico severo (DS): este tratamiento tuvo una frecuencia de riego menor a los anteriores, siendo de una vez por semana, con igual cantidad de agua por riego que DM (500 cc por planta).

Los tratamientos de riego fueron determinados en base a considerar que las plantas estuvieran siempre por encima de un valor umbral de agua en suelo que permite el mantenimiento del potencial hídrico en pre-alba mayor a -0,5 $\mathrm{MPa}$ en el caso del tratamiento control, y por debajo de este potencial, en menor o mayor medida, en los otros dos tratamientos. Este valor umbral, que resultó en $18 \%$ Vol., fue determinado 
en un ensayo preliminar, que relacionó el potencial en pre-alba con el contenido de agua en suelo. Considerando que las macetas tenían un volumen de $20 \mathrm{I}$, se requieren 3,6 I de agua para alcanzar ese valor umbral partiendo de un sustrato seco completamente. Asimismo, se estimó de manera preliminar que plantas de similar tamaño y familias que las medidas en este ensayo transpiran en promedio $400 \mathrm{~cm}^{3}$ de agua por día. Por lo tanto, comenzamos el experimento regando en exceso todas las plantas, y luego aplicamos $2000 \mathrm{~cm}^{3}$ cada 3 días en las control, para reemplazar (o aún exceder) el agua consumida en el período entre riegos (aprox. $1200 \mathrm{~cm}^{3}$ ), mientras que en los otros tratamientos el agua adicionada no reemplazaba al agua consumida de manera de conducir al deficit hídrico moderado y severo.

Todos los tratamientos fueron aplicados durante el período comprendido entre el 12 de Septiembre de 2011 (Figura 2.4 panel A) y el 11 de Enero de 2012 (Figura 2.4 panel B). A los fines de dar a conocer las características ambientales dentro del invernáculo donde se desarrolló el ensayo del presente capítulo, se presentan en la Tabla 2.1 los datos meteorológicos correspondientes al período de medición setiembre 2011 a enero 2012.

Tabla 2.1 Datos meteorológico correspondientes al período comprendido entre Septiembre de 2011 y Enero de 2012 en el invernáculo donde se desarrollaó el ensayo en plantines de Pinus taeda L. para los resultados del presente capítulo.

\begin{tabular}{lcccc}
\hline Mes & $\begin{array}{c}\text { RFA } \\
\left(\mu \mathrm{mol} \mathrm{m}^{-2} \mathbf{s}^{-\mathbf{1}}\right)\end{array}$ & $\begin{array}{c}\text { Temperatura } \\
(\mathbf{O} \mathrm{C})\end{array}$ & $\begin{array}{c}\text { Humedad } \\
\text { Relativa (\%) }\end{array}$ & DPV (kPa) \\
\hline Septiembre & 313,7 & $21,5 \pm 7,0$ & $72,0 \pm 18,0$ & $1,0 \pm 1,0$ \\
Octubre & 342,4 & $22,8 \pm 6,8$ & $73,8 \pm 18,2$ & $1,0 \pm 1,1$ \\
Noviembre & 442,3 & $24,6 \pm 7,6$ & $73,1 \pm 18,6$ & $1,2 \pm 1,4$ \\
Diciembre & 658,6 & $27,0 \pm 8,5$ & $64,4 \pm 20,5$ & $1,8 \pm 1,8$ \\
Enero & 350,4 & $28,2 \pm 7,6$ & $61,3 \pm 19,6$ & $2,0 \pm 1,8$ \\
\hline Media & $\mathbf{4 3 7 , 6}$ & $\mathbf{2 4 , 8} \pm \mathbf{2 , 8}$ & $\mathbf{6 8 , 9} \pm \mathbf{5 , 7}$ & $\mathbf{1 , 4} \pm \mathbf{0 , 5}$ \\
general & & & &
\end{tabular}

\section{Variables medidas}

Se registraron aproximadamente cada 15 días durante todo el período del ensayo la altura total $\left(h_{\mathrm{t}}, \mathrm{m}\right)$ y el diámetro del tallo (dac, mm). Para la medición del dac, en la primera medición, se realizó una marca sobre el tallo a $10 \mathrm{~cm}$ de la superficie del 
sustrato, la cual fue tomada como referencia para las mediciones posteriores a los fines de minimizar el error. Ambas variables fueron registradas en la totalidad de plantas de las diferentes familias dentro de cada tratamiento. Con las variables registradas se estimó el volumen del tallo de cada individuo, considerando a cada uno como de forma cilíndrica.

$\operatorname{Vol}\left(\mathrm{cm}^{3}\right)=\pi \times r^{2} \times h$

Ecuación (1)

Donde:

Vol= volumen del tallo $\left(\mathrm{cm}^{3}\right)$

$r=$ radio del tallo sobre el dac $(\mathrm{cm})$

$h=$ altura total de la planta $(\mathrm{cm})$

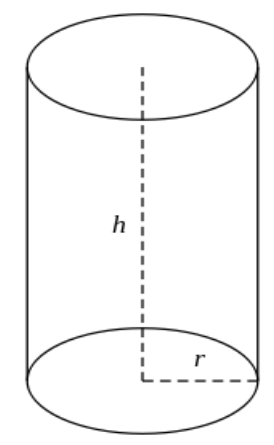

En enero del 2012, al final del experimento, seis plantas enteras de cada familia fueron cosechadas para la estimación de la biomasa aérea y subterránea. La biomasa aérea fue separada en los compartimentos hojas, ramas y tallos. Las raíces de cada planta cosechada fueron cuidadosamente lavadas para la estimación de la biomasa subterránea. La totalidad del material fresco de cada compartimento, tanto aéreo como subterráneo, fue luego secado en estufa a temperatura constante de $65 \pm 5 \stackrel{\circ}{ }$, y posteriormente pesado hasta la obtención de su peso seco constante, expresándose los resultados en peso seco.

El crecimiento fue estimado a partir del incremento en el diámetro del tallo, la altura total y el volumen del tallo, en forma absoluta y relativa de acuerdo a las siguientes ecuaciones:

Incremento Absoluto (IA)

$I A=T_{\text {final }}-T_{\text {inicial }}$

Ecuación (2) 
Incremento relativo (IR)

$$
I R=\frac{T_{\text {final }}-T_{\text {inicial }}}{T_{\text {inicial }}} \times 100
$$

Donde:

$T_{\text {inicial: }}$ variable al inicio del ensayo

$T_{\text {final }}$ : variable al final del ensayo

El potencial hídrico foliar $\left(\Psi_{\mathrm{f}}, \mathrm{MPa}\right)$ fue registrado en dos plantas por familia en cada tratamiento, antes del amanecer en pre-alba, a media mañana (aproximadamente 9 a.m.), y temprano por la tarde (aproximadamente 2 p.m.), horario en el que habitualmente se registran las temperaturas máximas diarias. Esta variable fue medida con una cámara de presión (BIO-CONTROL, Argentina, modelo que permite un valor máximo de presión de $6 \mathrm{MPa})$. La estimación de la conductancia estomática $\left(g_{\mathrm{s}}\right.$, mol $\mathrm{m}^{-2} \mathrm{~s}^{-1}$ ) se realizó en forma inmediata a las determinaciones de $\Psi_{\mathrm{f}}$ de media mañana y por la tarde, con un porómetro Decagon Devices modelo SC-1.

La tasa fotosintética máxima $\left(A_{\text {sat }}, \mu \mathrm{mol} \mathrm{m}^{-2} \mathrm{~s}^{-1}\right)$, siendo la fotosíntesis neta a saturación lumínica (1200 $\left.\mu \mathrm{mol} \mathrm{m} \mathrm{m}^{-2} \mathrm{~s}^{-1}\right)$, fue medida en dos días consecutivos, 26 y 27 de octubre del 2011, en cuatro plantas por familia en los diferentes tratamientos. La misma se determinó sobre tres fascículos completamente expandidos los cuales completaban el área de la cámara del analizador de gases infrarrojo (PPSystems TPS-2; concentración de $\mathrm{CO}_{2}: 400$ ppm; temperatura media del aire durante la medición: 25 oC). Estas mediciones fueron realizadas dentro del período de máxima tasa de crecimiento (Capítulo 4).

A los fines de determinar en el corto plazo la respuesta de la $g_{\mathrm{s}}$ al déficit de presión de vapor de la atmósfera (DPV, KPa), se realizaron curvas diarias de $g_{\mathrm{s}}$ en días de alto DPV (13 y 14 de diciembre del 2011). Para ello, se midió esta variable cada 30 minutos entre las 10 a.m. y las 2 p.m. en ambas fechas en un total de cuatro plantas por familia, solamente en la situación control. Para cada medición se tomaron tres fascículos completamente expandidos de la parte media de la copa de cada planta. De esta forma la cámara siempre permaneció completa en su área para cada medición. EI DPV fue estimado a partir de la humedad relativa y la temperatura del aire, datos 
registrados automáticamente cada 2 minutos con un termohigrómetro Hobo (Pro v2 Onset) colocado dentro del invernáculo. La sensibilidad estomática al DPV fue analizada según Oren et al. (1999), relacionando la $g_{\mathrm{s}}$ y el InDPV, y estimando la pendiente (sensibilidad) y el intercepto ( $g_{\mathrm{s}}$ de referencia, que es la $g_{\mathrm{s}}$ a DPV $\left.=1 \mathrm{KPa}\right)$ de esta relación lineal.

En las mismas fechas en las que se determinó la respuesta de la $g_{\mathrm{s}}$ al DPV, se realizaron mediciones de conductividad hidráulica específica $\left(k_{\mathrm{s}}, \mathrm{Kg} \mathrm{s}^{-1} \mathrm{~m}^{-1} \mathrm{MPa}^{-1}\right)$ en ramas, siendo el valor mínimo diario debido a que las ramas fueron colectadas en un horario donde la demanda evaporativa fue alta ( 2 p.m. aproximadamente). Esta estimación de $k_{\mathrm{s}}$ fue realizada sin previa eliminación de posibles embolismos, diferenciándose así de la $k_{s}$ máxima.

A los fines de reforzar los datos de conductividad hidráulica anteriormente detallados, los cuales arrojaron valores muy bajos y con una alta variabilidad (ver resultados), se realizaron mediciones complementarias de $k_{\mathrm{s}}$ en un ensayo adicional. Para ello se tomaron cuatro plantas de cada familia en situaciones control y bajo un nivel de déficit hídrico. Las muestras fueron tomadas temprano en la mañana e hidratadas hasta un potencial hídrico foliar cercano a cero, para lo cual las mismas permanecieron en ambiente oscuro por un mínimo de 24 horas. En ellas se determinó el valor máximo de $k_{\mathrm{s}}$ y de $k_{\mathrm{l}}\left(\mathrm{m} \mathrm{s}^{-1} \mathrm{MPa}^{-1}\right)$ es decir, la $k_{\mathrm{h}}\left(\mathrm{Kg} \mathrm{m} \mathrm{s}^{-1} \mathrm{MPa}^{-1}\right)$ dividida por la biomasa foliar $(\mathrm{kg})$ alimentada por la sección de rama medida. Se utilizó la biomasa en lugar del área foliar debido a que todas las familias presentaron similar área foliar específica $(p>0,05$; datos no mostrados). Debido a que las ramas pertenecen a un material vegetal muy joven, se ha considerado toda la sección transversal sin corteza como área conductiva.

Las estimaciones de $k_{\mathrm{s}}$ fueron realizadas utilizando un conductímetro multicanal construido en PVC, con ocho canales. Este consiste en un recipiente con agua (en este caso, se trabajó con agua destilada) colocado a 1 metro de altura para generar un gradiente de presión, y acoples de silicona para unir las ramas (e.g. Fernández et al. 2010). El agua que perfundió en cada rama fue colectada en un recipiente que fue pesado en una balanza digital con una precisión de 0,001 g. Las variables fueron evaluadas en cuatro plantas por familia en cada tratamiento en cada fecha de medición. Además de la determinación de la biomasa en los diferentes 
compartimentos, los cuales fueron explicados anteriormente, otras variables que requieren muestreo destructivo fueron determinadas al final del experimento en enero del 2012:

- Área foliar específica (AFE, $\mathrm{m}^{2} \mathrm{Kg}^{-1}$ ): fue estimada en tres plantas por familia dentro de cada tratamiento. Para ello en cada planta se cosechó el total de las hojas y se separaron en tres clases de tamaño en función del largo de los fascículos; dentro de cada clase se tomó una muestra de 20 fascículos que fueron estimados como se indica abajo (ecuación 4) y luego relacionados a su peso seco. Para estimar el área foliar de fascículos individuales se utilizó una ecuación que representa al mismo como 6 superficies rectangulares de lado $r$ y longitud I más un cilindro externo, resultando en la siguiente fórmula general (e.g. Gyenge et al. 2009):

$$
A F_{i}\left(\mathrm{~cm}^{2}\right)=2 \Pi+6 \times\left(\frac{r_{1}+r_{2}+r_{3}}{3}\right) \times l
$$

donde:

$r$ : radio de cada acícula $(\mathrm{cm})$.

I= largo total del fascículo $(\mathrm{cm})$.

Una vez realizadas las mediciones fueron llevados a estufa a 65 으 hasta alcanzar peso seco constante. Los fascículos restantes también fueron llevados a peso seco constante con lo cual se estimó el área foliar total y el AFE $\left(\mathrm{m}^{2} \mathrm{~kg}^{-1}\right)$ para cada planta.

- Concentración de clorofila en hojas $\left(\mathrm{cl}, \mathrm{mg} \mathrm{g}^{-1}\right)$ : fue estimada con un espectrofotómetro (SHIMADZU UV - 160 A), en el laboratorio de INFIVE de la Universidad Nacional de La Plata (Argentina). Se colocaron porciones de acículas de 2 cm de longitud en Dimetilformamida, las cuales permanecieron un mínimo de 48 horas en oscuridad previamente al análisis. Esta variable fue estimada en nueve plantas por familia en cada tratamiento. se realizaron estimaciones de concentración para cada tipo de clorofila, la total $\left(\mathrm{cl}_{\mathrm{t}}\right)$, clorofila a $\left(\mathrm{cl}_{\mathrm{a}}\right)$ y clorofila $\mathrm{b}\left(\mathrm{c} \mathrm{l}_{\mathrm{b}}\right)$ mediante las ecuaciones 5, 6 y 7 como se indica en Inskeep y Bloom (1985).

$$
\begin{aligned}
& c l_{t}\left(m g \cdot g^{-1}\right)=17.9 \times A_{647}+8.08 \times A_{664.5} \\
& c l_{a}\left(m g \cdot g^{-1}\right)=12.7 \times A_{664.5}-2.79 \times A_{647}
\end{aligned}
$$

Ecuación (5)

Ecuación (6) 
$c l_{b}\left(m g \cdot g^{-1}\right)=20.7 \times A_{647}-4.62 \times A_{664.5}$

donde $A_{664,5}$ es la absorbancia a $664,5 \mathrm{~nm}$, máxima absorbancia para la clorofila a, y $A_{647}$ es la absorbancia a $647 \mathrm{~nm}$, máxima absorbancia para la clorofila b.

- Contenido foliar de nitrógeno: se determinó en el Laboratorio de Suelos del INTA, en la ciudad de San Carlos de Bariloche (Argentina), en cuatro plantas por familia en cada tratamiento usando el método de nitrógeno total según Kjeldah (IRAM 295721). De esta manera se determinó el contenido de nitrógeno foliar $\left(N_{\mathrm{f}}, \%\right)$ expresado como porcentaje, describiendo los g de $N$ en $100 \mathrm{~g}$ de hoja seca. A partir de este dato se estimó el contenido de nitrógeno en la copa $\left(N_{c}, g\right)$, mediante la biomasa foliar total de la planta.

- Eficiencia de crecimiento $\left(E C, \mathrm{~cm}^{3} \mathrm{~g}^{-1}\right)$ : fue estimada como el cociente entre el incremento absoluto en volumen del tallo y la biomasa foliar total de cada planta.

- Productividad del nitrógeno $\left(\mathrm{PN}, \mathrm{cm}^{3} \mathrm{~g}^{-1}\right)$ : fue estimada como el cociente entre el incremento absoluto en volumen del tallo y el contenido de nitrógeno foliar en la biomasa total de hojas de la planta. Las hojas son los órganos que concentran la mayor parte del nitrógeno de la planta (e.g. contenido de $N$ en Pinus ponderosa es cercano al $1 \%$ de la biomasa seca del tejido, mientras este representa cerca del 0,07\% de la biomasa del leño (e.g. Gyenge y Fernández 2014)); por lo tanto, se utilizó solamente el contenido de $N$ foliar en la estimación de la PN, resultando en algunos casos la sobreestimación de la PN real, la cual debería considerar además el contenido de $N$ de otros órganos de la planta. Asimismo, la PN fue utilizada como una aproximación a la eficiencia del uso del $N$ asumiendo que la permanencia promedio del $N$ en la planta fue similar en todas las situaciones.

- Eficiencia intrínseca en el uso del agua $\left(E \cup A_{i}\right)$ : la proporción de ${ }^{13} \mathrm{C}$ a ${ }^{12} \mathrm{C}$ en tejido leñoso (tallo + ramas, $\delta 13 \mathrm{C}$, \%) fue utilizada como un proxy de la EUA $\mathrm{A}_{\mathrm{i}}$. Las muestras de cuatro plantas por familia en cada tratamiento fueron analizadas en un espectrómetro de masa de relación isotópica (Finnigan MAT Delta S, USA) siguiendo la metodología de Hoefs y Schidlowski (1967) y Panarello (1987) en el Instituto de Geocronología y Geología Isotópica INGEIS (CONICET-Universidad de Buenos Aires, Argentina). 


\section{Análisis estadístico}

Se aplicó análisis factorial de la varianza (ANOVA, $\alpha=0,05)$ para evaluar el efecto de las siguientes fuentes de variación: Tasa de crecimiento (TC, con dos niveles, altos crecimientos $(A C)$ y bajos crecimientos $(B C))$, déficit hídrico $(\mathrm{DH}$, con tres niveles, control (C), déficit moderado (DM) y déficit severo (DS)), la interacción $\mathrm{TC} \times \mathrm{DH}, \mathrm{y}$ familia anidada en TC. Para el análisis de ANOVA se utilizó el software estadístico R ( Core Team 2014).

Asimismo, algunas variables (ver resultados) fueron analizadas mediante modelos de regresión, relacionándolas con el gradiente de estrés al que fueron sometidas las plantas, tomando como variable independiente la integral del potencial hídrico (MPa día) en cada familia y tratamiento. Si bien dentro de cada tratamiento todas las plantas fueron sometidas al mismo nivel de riego, esta variable permite incorporar la variación en disponibilidad hídrica que pudo ocurrir entre individuos debido a posibles diferencias en el tamaño de las plantas y/o a las diferentes tasas de uso del agua que pudieran ocurrir entre las diferentes familias estudiadas. De esta manera para cada familia, dentro de cada tratamiento, se calculó la integral del potencial hídrico como:

$\int \psi=\sum\left|\psi_{i}\right| \times n$

Ecuación (8)

donde $\int \Psi$ es la Integral del potencial hídrico; $\left|\psi_{i}\right|$ es el potencial hídrico pre-alba (en valor absoluto) promedio de la familia para el intervalo de tiempo $i$ y $n$ corresponde al número de días que conforman el intervalo de tiempo $i$ (tiempo comprendido entre dos mediciones sucesivas).

Diferentes funciones matemáticas pueden describir la relación entre el incremento en volumen y la integral del potencial hídrico, pero se eligió la función $\ln y=a+\frac{b}{x}$ dada su simplicidad y alto ajuste a los datos (altos coeficientes de determinación $R^{2}$ ). Los análisis de regresión fueron realizados con el software Table Curve 2D (Jandel Scientific, AISN Software). Los modelos fueron comparados entre familias y tratamientos mediante el test $F$ (Zar 1999). 


$$
F_{\text {obs }}=\frac{(\operatorname{SSE}(R)-\operatorname{SSE}(F)) / 2}{\left(\operatorname{SSE}(F) /\left(n_{1}+n_{2}-4\right)\right)}
$$

Donde $\operatorname{SSE}(R)$ es la suma del cuadrado del error del conjunto de datos; SSE(F) es la suma de cuadrado del error del modelo 1 + suma de cuadrado del error del modelo 2 y $\mathrm{n}_{1}$ y $\mathrm{n}_{2}$ son el número de réplicas en cada tratamiento.

Para el análisis de las relaciones alométricas se realizó un análisis de regresión lineal, como es propuesto en Bongarten y Teskey (1987). Mediante un test de $F$ se evaluaron los términos del modelo determinados para cada familia o tratamiento dentro de cada relación alométrica, estableciendo de esta manera la igualdad de pendiente e interceptos $\left(\mathrm{H}_{0}\right)$ o la diferencia para cada uno de ellos $\left(\mathrm{H}_{1}\right)$, comparando las rectas de regresión. Para este análisis se procedió a linealizar los datos mediante el In de la biomasa de cada compartimento. A los fines de establecer diferencias entre los tratamientos y familias para cada término del modelo, se realizó como paso siguiente el análisis de regresión lineal mediante variables auxiliares Dummy, tomando como variable de referencia al control cuando se analizó a los tratamientos y a la familia AC1 (I35) para el análisis de las familias. En cada caso se realizó la matriz de comparación para obtener las diferencias entre los tratamientos o familias que no fueron usadas como de referencia.

A fin de determinar cuáles son las principales variables morfo-fisiológicas responsables de la variación en el crecimiento observado entre familias, se aplicó análisis de correlación entre el incremento absoluto y relativo en volumen del fuste con variables tales como $k_{\mathrm{s}}, k_{\mathrm{l}}, A_{\mathrm{sat}}, N_{\mathrm{f}}$, concentración clorofilas y biomasa total y en los diferentes compartimentos, tomando los valores de todos los individuos medidos (independientemente de la familia) y los valores medios para cada familia para el tratamiento control.

\section{RESULTADOS}

\section{Caracterización de los tratamientos}

Ambas variables, altura total $\left(h_{\mathrm{t}}, \mathrm{m}\right)$ y diámetro basal del tallo (dac, $\left.\mathrm{mm}\right)$, al comienzo del ensayo, presentaron diferencias significativas entre grupos de plantas 
diferenciadas por tasas de crecimiento $A C$ y $B C(18,2 \mathrm{~cm}$ de diferencia promedio en altura total, y 1,1 $\mathrm{mm}$ de diferencia en dac), reflejando que las diferencias en tasa de crecimiento determinadas a los 5 años de edad en las madres son establecidas ya en los primeros estadios del desarrollo del plantín (Tabla 2.2).

Tabla 2.2 Altura total $\left(h_{\mathrm{t}}, \mathrm{m}\right)$ y diámetro a la altura del cuello (dac, $\mathrm{mm}$ ) promedios \pm desvío estándar al inicio del ensayo. AC1 y AC2: familias de alto crecimiento, BC1 y BC2: familias de bajo crecimiento. Letras en negrita indican diferencias significativas $(\alpha=0,05)$. TC= efecto de Tasa de Crecimiento, DH= efecto del tratamiento de déficit hídrico, en este caso no refiriéndose al efecto estrés en sí, ya que es una medición al inicio, sino que evalúa si hay diferencias en tamaño entre plantas distribuidas (al azar) entre los tratamientos. F: efecto de la familia anidada dentro de TC.

\begin{tabular}{lcc}
\hline Familia & $\boldsymbol{h}_{\mathrm{t}}(\mathbf{m})$ & dac $(\mathbf{m m})$ \\
\hline AC1 & $0,74 \pm 0,15$ & $7,5 \pm 1,4$ \\
AC2 & $0,65 \pm 0,15$ & $7,2 \pm 1,7$ \\
BC1 & $0,52 \pm 0,10$ & $6,1 \pm 1,2$ \\
BC2 & $0,50 \pm 0,83$ & $6,4 \pm 1,2$ \\
\hline $\boldsymbol{P}_{\text {TC }}$ & $<\mathbf{0 , 0 0 0 1}$ & $<\mathbf{0 , 0 0 0 1}$ \\
$\boldsymbol{P}_{\text {DH }}$ & 0,290 & 0,414 \\
$\boldsymbol{P}_{F \text { (anidada en TC) }}$ & $\mathbf{0 , 0 1 9}$ & 0,496 \\
\hline
\end{tabular}

Además, dentro del grupo AC, las plantas de la familia AC1 tuvieron en promedio 8,7 cm más de altura total que las plantas de la familia AC2 $(p<0,05)$. La distribución al azar de las plantas al inicio del ensayo resultó en que no haya diferencias en tamaño inicial de plantas destinadas a cada tratamiento de déficit hídrico $\left(P_{D H}>0,05\right.$ en Tabla 2.1).

La caracterización de los tratamientos se realizó en base a la integral del potencial hídrico ( $\int \Psi, \mathrm{MPa}$ día), el cual refleja el estado hídrico de las plantas durante el período de estudio. Dado que éste se estima a partir de valores de potencial hídrico pre-alba absolutos, una $\Psi \int$ mayor significa que la planta presentaba valores más bajos de potenciales hídricos en pre-alba durante el período de estudio, lo cual se relaciona directamente con un mayor déficit hídrico de la planta. 
Bajo la condición Control, los valores promedios de $\int \Psi$ fueron muy similares entre las familias, con valores promedio de 52,4; 55,5; 51,7 y 49,8 MPa día para las familias AC1, $A C 2, B C 1$ y $B C 2$, respectivamente, y con un valor promedio general para todas las familias de 52,3 MPa día. Bajo condiciones de déficit hídrico, las familias del grupo AC tendieron a presentar $\int \Psi$ más alta, es decir un mayor estrés acumulado respecto al grupo de las familias BC. En el tratamiento DM, las plantas presentaron un valor promedio de 108,3; 119,5; 84,1 y 100,5 MPa día para las familias AC1, AC2, BC1 y BC2, respectivamente. En el tratamiento DS la $\int \Psi$ fue de 187,$9 ; 175,8 ; 174,4$ y $158,9 \mathrm{MPa}$ día para iguales familias respectivamente. El promedio general de $\int \Psi$ para todas las familias juntas fue de 103,1 MPa día para DM y 174,2 MPa día para DS, reflejando el mayor déficit hídrico del suelo en ambos tratamientos de estrés respecto al observado para el control, notándose además las diferencias entre los niveles de déficit "moderado" y "severo".

\section{Incremento en volumen del tallo y partición de biomasa}

El patrón del incremento en volumen del tallo, tanto absoluto como relativo, fue similar entre grupos de tasas de crecimiento (TC) en respuesta al déficit hídrico, con una caída pronunciada (comportamiento exponencial negativo) con el incremento en la $\int \Psi$ (Figura 2.5). Los modelos ajustados a las relaciones crecimiento vs. $\int \Psi$ son presentados en la Figura 2.5 para cada familia, los cuales mostraron valores de $R^{2}$ superiores a 0,9 en todos los casos. Los modelos de las plantas AC difirieron significativamente de aquellas plantas dentro del grupo de familias $B C$ (test $F, \alpha=0,05$ ), presentando una mayor caída relativa en las familias $A C$ que en las $B C$ cuando el crecimiento absoluto es considerado.

Ambos factores, $\mathrm{TC}$ y $\mathrm{DH}$, tuvieron un efecto significativo sobre el incremento absoluto y relativo en volumen del tallo durante el período de estudio, con una interacción significativa entre factores y sin diferencias entre familias de cada grupo de TC. Respecto al incremento absoluto, las plantas de las familias AC tuvieron mayores incrementos promedios en volumen que las plantas del grupo BC, y en ambos casos, las plantas del control tuvieron mayores incrementos que en ambos tratamientos de déficit, sin diferencias entre estos dos últimos (Figura 2.5 panel A). En promedio, la 
caída del crecimiento absoluto para las plantas bajo el tratamiento DM fue de $72 \%$ respecto al control, mientras que en las plantas bajo el tratamiento de déficit más severo (DS), el crecimiento decreció $85 \%$ respecto a las plantas control.

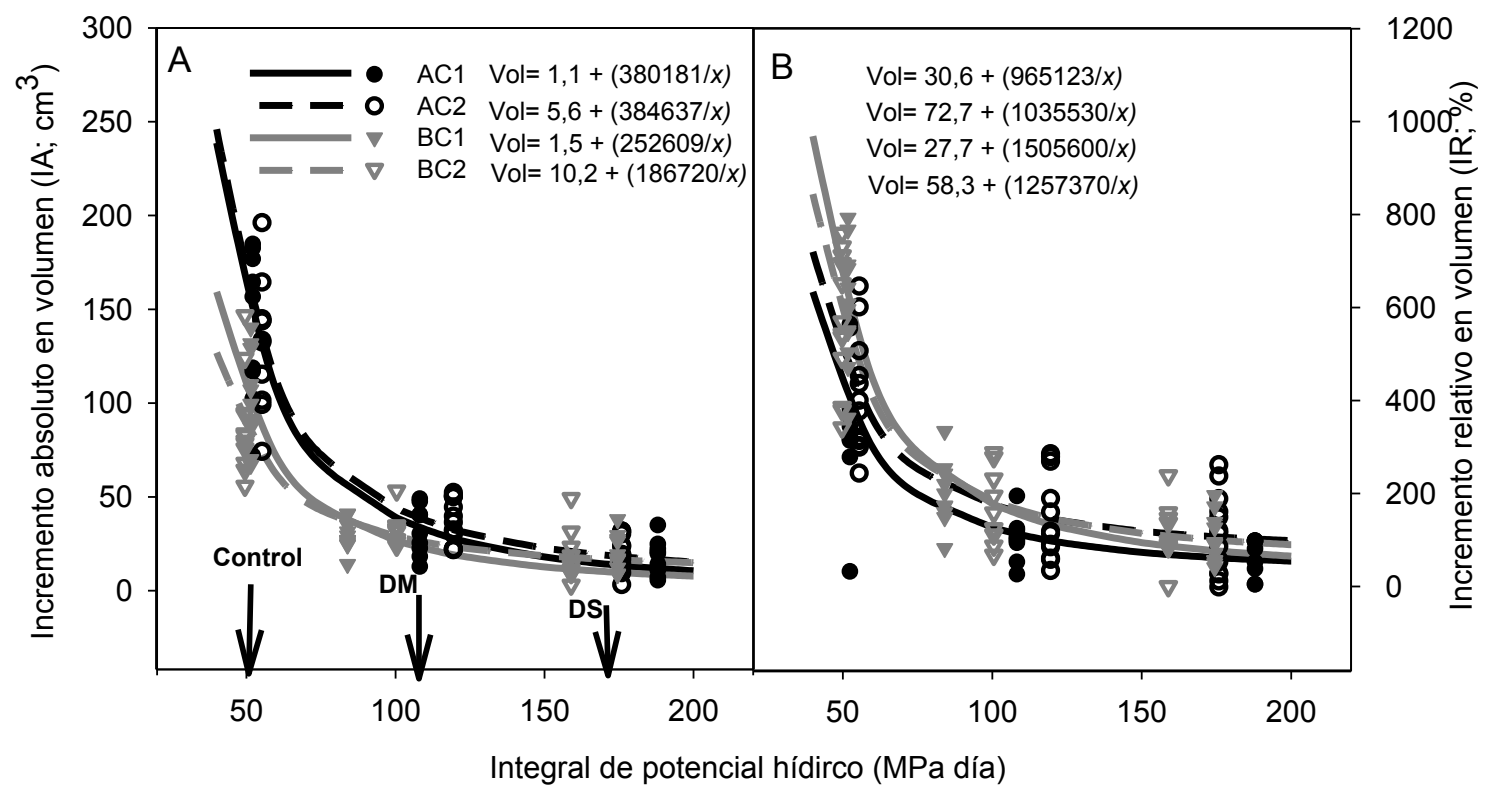

Figura 2.5 Incremento en volumen del tallo $\left(\mathrm{cm}^{3}\right)$ medido en todo el período de ensayo (Septiembre de 2011-Enero de 2012) en familias de Pinus taeda de alto crecimiento (AC) y de bajo crecimiento (BC) bajo diferentes condiciones de disponibilidad hídrica, en función de la integral del potencial hídrico (MPa día). A) Incremento absoluto en volumen del tallo (IA, $\left.\mathrm{cm}^{3}\right)$. B) Incremento relativo en volumen del tallo (IR, \%). Las líneas representan los modelos ajustados $\left(R^{2}>0,90\right.$ en todos los casos).

Considerando el incremento relativo en volumen del tallo, las plantas de las familias BC presentaron mayores incrementos relativos que las familias AC (Figura 2.5 panel B). La magnitud de la disminución en el incremento relativo en volumen debido al efecto del déficit hídrico fue menor que en los casos de valores absolutos, presentando una disminución de $63 \%$ en el tratamiento DM y del $80 \%$ en el DS, ambos comparados al control.

La biomasa total de las plantas (aérea + subterránea) medida al final del ensayo se vio afectada por ambos factores, TC y $\mathrm{DH}$, disminuyendo la biomasa total conforme aumenta la intensidad del déficit hídrico. Las familias AC tuvieron mayor biomasa que las familias $\mathrm{BC}(p<0,05)$. 
La biomasa aérea al final del experimento fue también afectada por los factores TC y

$\mathrm{DH}$, en igual sentido que la biomasa total. Por el contrario, la biomasa subterránea (raíces) fue solamente afectada por el factor $\mathrm{DH}$, cuyos promedios $\pm \mathrm{DE}$ para todas las familias fueron de $23,7 \pm 7,6 \mathrm{~g}, 11,9 \pm 3,2 \mathrm{~g}$ y $8,0 \pm 2,2 \mathrm{~g}$ para el control, y los tratamientos DM y DS, respectivamente.
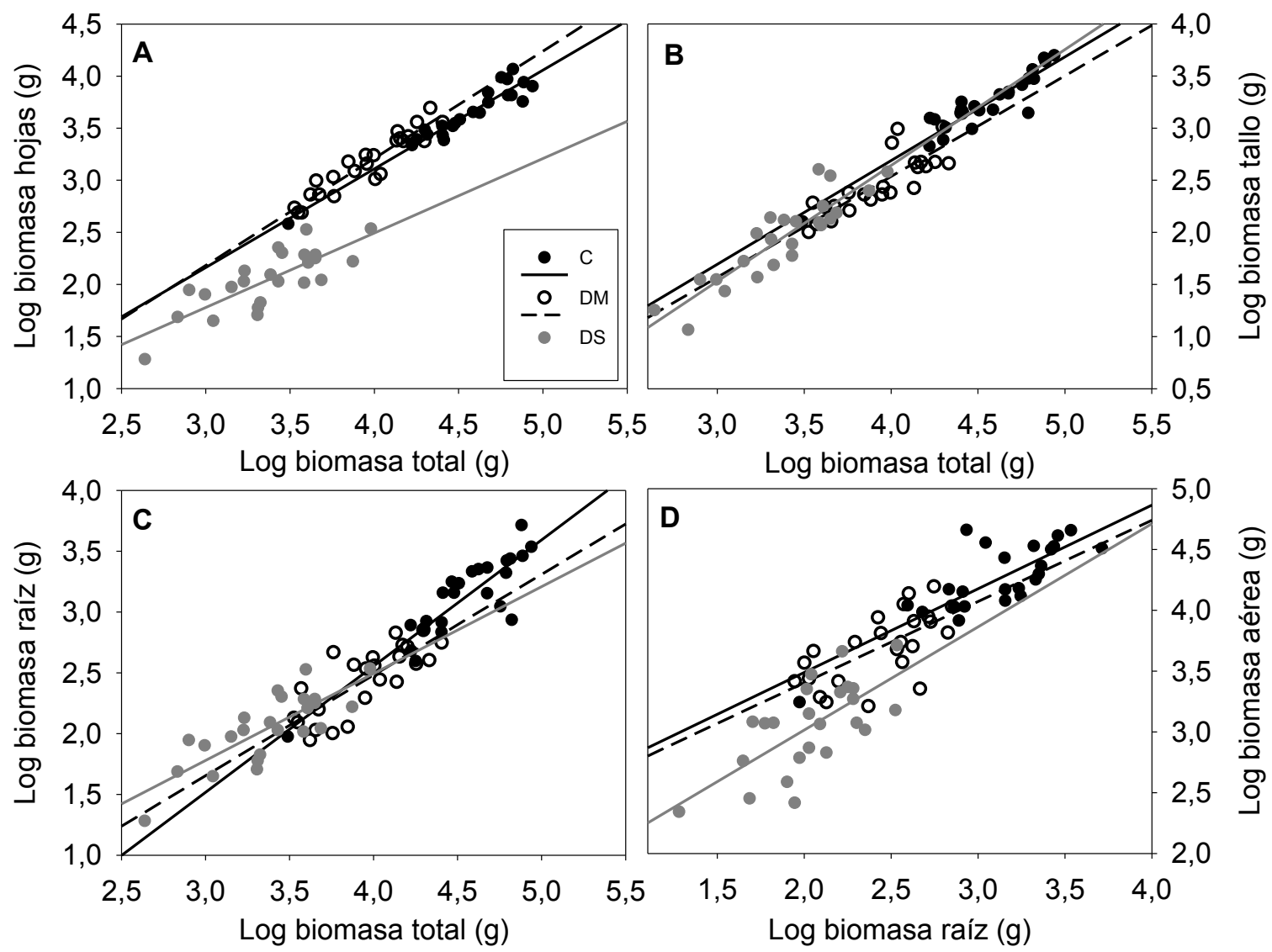

Figura 2.6 Regresiones lineales para las relaciones alométricas de plantines (conjunto de plantas de 4 familias) de Pinus taeda L. bajo diferentes condiciones de disponibilidad hídrica. A) Regresión lineal entre Log de biomasa de hojas (g) y Log de la biomasa total (g) de la planta dentro de cada tratamiento. B) Regresión lineal entre Log de biomasa del tallo (g) y Log de la biomasa total (g) de la planta dentro de cada tratamiento. C) Regresión lineal entre Log de biomasa de raíces (g) y Log de la biomasa total (g) de la planta dentro de cada tratamiento. D) Regresión lineal entre Log de biomasa aérea (hojas, ramas y tallo, g) y Log de la biomasa de raíces (g) de la planta dentro de cada tratamiento. C: control; DM: déficit moderado; DS: déficit severo.

En las relaciones alométricas analizadas, el efecto del factor $\mathrm{DH}$ fue observado en todos los casos (Tabla 2.3). Considerando los diferentes componentes dentro de la fracción aérea, las plantas tanto del control como del déficit moderado destinaron más 
biomasa a tallo y hojas respecto a la biomasa total y una menor proporción a biomasa de raíces comparado a las plantas sometidas a déficit severo. Para la relación biomasa aérea:biomasa subterránea se observó una menor asignación a biomasa aérea en plantas sometidas a déficit severo. Estas diferencias se manifiestan de acuerdo al análisis de los términos de las ecuaciones lineales ajustadas a cada una de las relaciones alométricas ectahlecidas en Ins diferentes tratamientos
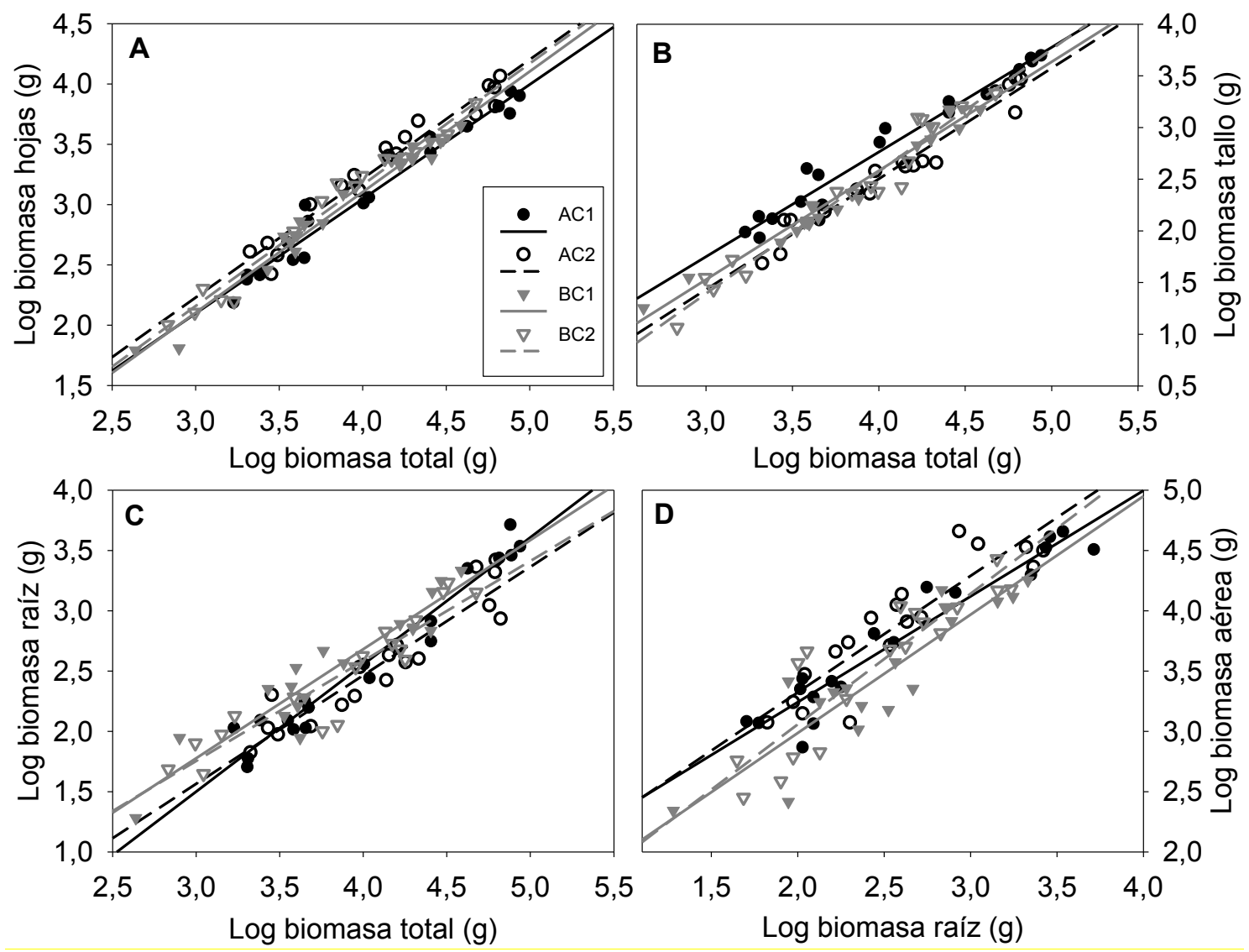

Figura 2.7 Regresiones lineales para las relaciones alométricas en familias (conjunto de plantas de los 3 tratamientos) de Pinus taeda L. con diferentes tasas de crecimiento. A) Regresión lineal entre Log de biomasa de hojas (g) y Log de la biomasa total (g) de la planta para cada familia. B) Regresión lineal entre Log de biomasa del tallo (g) y Log de la biomasa total (g) de la planta para cada familia. C) Regresión lineal entre Log de biomasa de raíces (g) y Log de la biomasa total (g) de la planta para cada familia. D) Regresión lineal entre Log de biomasa aérea (hojas, ramas y tallo) (g) y Log de la biomasa de raíces (g) de la planta dentro para cada familia. AC1 y AC2: familias de $P$. taeda con altas tasas de crecimiento; BC1 y BC2: familias de $P$. taeda con bajas tasas de crecimiento.

Respecto al efecto de TC ( $A C$ vs $B C$ ), no se observaron diferencias significativas en la asignación a los compartimentos aéreos de las plantas. Sin embargo, la asignación a biomasa subterránea fue mayor para el grupo de familias $\mathrm{BC}(p=0,0028)$. La regresión 
lineal entre log biomasa aérea y log biomasa subterránea presentó interceptos estadísticamente distintos para los grupos de familias, presentando las familias BC menor biomasa aérea respecto a la subterránea (Tabla 2.3).

En el análisis de las relaciones alométricas diferenciando a cada familia en particular (Figura 2.7), en general se han observado diferencias en el intercepto de las relaciones lineales, no así para las pendientes (Tabla 2.3). En este sentido, para el compartimento tallo respecto a la biomasa total se observó que la familia AC1 manifestó una mayor asignación a este compartimento diferenciándose estadísticamente de las demás familias ( $A C 2, B C 1$ y BC2; $p<0,0001)$. Por otro lado, la asignación a biomasa de hojas presentó un aumento significativo para la familia AC2 respecto a las demás familias (AC1, BC1 y $\mathrm{BC} 2 ; p<0,0001)$. 
Tabla 2.3 Resumen de las regresiones ajustadas a las relaciones alométricas para los factores Tasa de crecimiento (TC), tratamiento de déficit hídrico (DH) y familia (F). Las relaciones alométricas analizadas fueron: relación entre log biomasa de tallo (g) y log biomasa total (aérea + subterránea) (g); relación entre log biomasa de raíces $(\mathrm{g})$ y log biomasa total $(\mathrm{g})$; relación entre log biomasa de hojas (g) y log biomasa total (g) y relación entre log biomasa aérea $(\mathrm{g})$ y log biomasa de raíces (g). C: control; DM: déficit hídrico moderado; DS: déficit hídrico severo. AC1 y AC2: familias de alta tasa de crecimiento (AC), BC1 y BC2: familias de baja tasa de crecimiento (BC).

\begin{tabular}{|c|c|c|c|c|c|c|}
\hline \multirow{2}{*}{$\begin{array}{l}\text { Relaciones } \\
\text { alométricas }\end{array}$} & \multicolumn{2}{|c|}{ Factor Tasa de Crecimiento } & \multicolumn{2}{|c|}{ Factor Déficit Hídrico } & \multicolumn{2}{|c|}{ Factor Familia } \\
\hline & $\begin{array}{l}\text { Ajuste del } \\
\text { modelo }\end{array}$ & $\begin{array}{c}\text { Comparación } \\
\text { de los } \\
\text { coeficientes } \\
\text { del modelo }\end{array}$ & $\begin{array}{l}\text { Ajuste del } \\
\text { modelo }\end{array}$ & $\begin{array}{c}\text { Comparación } \\
\text { de los } \\
\text { coeficientes } \\
\text { del modelo }\end{array}$ & $\begin{array}{l}\text { Ajuste del } \\
\text { modelo }\end{array}$ & $\begin{array}{c}\text { Comparación } \\
\text { de los } \\
\text { coeficientes } \\
\text { del modelo }\end{array}$ \\
\hline \multirow{2}{*}{ 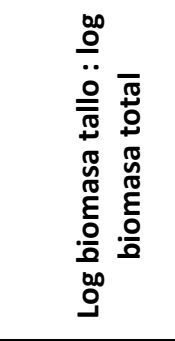 } & \multirow[b]{2}{*}{$\begin{array}{l}\mathrm{R}^{2}=93,6 \% \\
p<0,0001\end{array}$} & $\begin{array}{l}\text { Pendientes } \\
\text { iguales }\end{array}$ & \multirow[b]{2}{*}{$\begin{array}{l}\mathrm{R}^{2}=93,3 \% \\
p<0,0001\end{array}$} & $\begin{array}{l}\text { Pendientes } \\
\text { iguales }\end{array}$ & \multirow[b]{2}{*}{$\begin{array}{l}\mathrm{R}^{2}=95,7 \% \\
p<0,0001\end{array}$} & $\begin{array}{l}\text { Pendientes } \\
\text { iguales }\end{array}$ \\
\hline & & $\begin{array}{l}\text { Interceptos } \\
\text { iguales }\end{array}$ & & $\begin{array}{c}\text { Interceptos } \\
\text { diferentes: } \\
\text { DS < biomasa } \\
\text { Tallo que DM } \\
\text { y C }\end{array}$ & & $\begin{array}{c}\text { Interceptos } \\
\text { diferentes: } \\
\text { AC1 > biomasa } \\
\text { Tallo que AC2, } \\
\text { BC1 Y BC2 }\end{array}$ \\
\hline \multirow{2}{*}{ 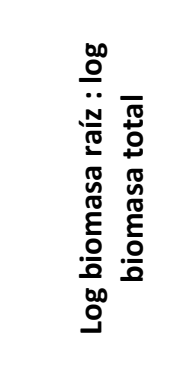 } & \multirow[b]{2}{*}{$\begin{array}{l}\mathrm{R}^{2}=89,1 \% \\
p<0,0001\end{array}$} & $\begin{array}{l}\text { Pendientes } \\
\text { iguales }\end{array}$ & \multirow[b]{2}{*}{$\begin{array}{l}\mathrm{R}^{2}=88,7 \% \\
p<0,0001\end{array}$} & $\begin{array}{l}\text { Pendientes } \\
\text { iguales }\end{array}$ & \multirow[b]{2}{*}{$\begin{array}{l}\mathrm{R}^{2}=89,8 \% \\
p<0,0001\end{array}$} & $\begin{array}{c}\text { Pendientes } \\
\text { iguales }\end{array}$ \\
\hline & & $\begin{array}{c}\text { Interceptos } \\
\text { diferentes: } \\
\text { BC > biomasa } \\
\text { Raíces que } \\
\text { AC }\end{array}$ & & $\begin{array}{c}\text { Interceptos } \\
\text { diferentes: } \\
\text { DS < biomasa } \\
\text { Raíz que DM } \\
\text { y C }\end{array}$ & & $\begin{array}{l}\text { Interceptos } \\
\text { diferentes: } \\
\text { BC1 Y BC2 > } \\
\text { biomasa Raíz } \\
\text { que AC1 Y AC2 }\end{array}$ \\
\hline \multirow{2}{*}{ 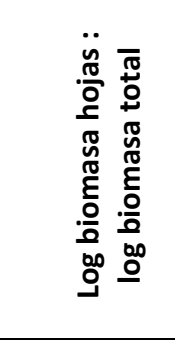 } & \multirow[b]{2}{*}{$\begin{array}{l}\mathrm{R}^{2}=95,6 \% \\
p<0,0001\end{array}$} & $\begin{array}{c}\text { Pendientes } \\
\text { iguales }\end{array}$ & \multirow[b]{2}{*}{$\begin{array}{l}\mathrm{R}^{2}=95,8 \% \\
p<0,0001\end{array}$} & $\begin{array}{c}\text { Pendientes } \\
\text { iguales }\end{array}$ & \multirow[b]{2}{*}{$\begin{array}{l}\mathrm{R}^{2}=96,8 \% \\
p<0,0001\end{array}$} & $\begin{array}{c}\text { Pendientes } \\
\text { iguales }\end{array}$ \\
\hline & & $\begin{array}{l}\text { Interceptos } \\
\text { iguales }\end{array}$ & & $\begin{array}{c}\text { Interceptos } \\
\text { diferentes: } \\
\text { DS < biomasa } \\
\text { hojas que DM } \\
\text { y C }\end{array}$ & & $\begin{array}{c}\text { Interceptos } \\
\text { diferentes: } \\
\text { AC2 > biomasa } \\
\text { Hojas que AC1, } \\
\text { BC1 Y BC2 }\end{array}$ \\
\hline \multirow{2}{*}{ 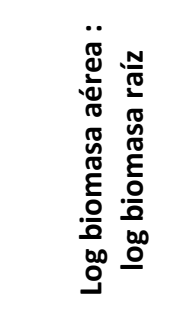 } & \multirow[b]{2}{*}{$\begin{array}{l}\mathrm{R}^{2}=82,3 \% \\
p<0,0001\end{array}$} & $\begin{array}{c}\text { Pendientes } \\
\text { iguales }\end{array}$ & \multirow[b]{2}{*}{$\begin{array}{l}\mathrm{R}^{2}=83,3 \% \\
p<0,0001\end{array}$} & $\begin{array}{c}\text { Pendientes } \\
\text { iguales }\end{array}$ & \multirow[b]{2}{*}{$\begin{array}{l}\mathrm{R}^{2}=83,2 \% \\
p<0,0001\end{array}$} & $\begin{array}{c}\text { Pendientes } \\
\text { iguales }\end{array}$ \\
\hline & & $\begin{array}{l}\text { Interceptos } \\
\text { diferentes: } \\
\text { BC < biomasa } \\
\text { Aérea que AC }\end{array}$ & & $\begin{array}{l}\text { Interceptos } \\
\text { diferentes: } \\
\text { DS < biomasa } \\
\text { Aérea que } \\
\text { DM y C }\end{array}$ & & $\begin{array}{c}\text { Interceptos } \\
\text { diferentes: } \\
\text { BC1 y } \mathrm{BC} 2< \\
\text { biomasa Aérea } \\
\text { que AC1 Y AC2 }\end{array}$ \\
\hline
\end{tabular}

Concordando con las diferencias encontradas para los grupos de TC, el análisis de las 4 familias mostró que ambas familias BC se diferenciaron por su mayor asignación a raíces que las $\mathrm{AC}$, sin diferencias dentro de ellas (Tabla 2.2). 


\section{Relaciones hídricas y parámetros hidráulicos}

El déficit hídrico afectó significativamente el potencial hídrico máximo (pre-alba) y mínimo (mediodía) diarios, sin diferencias significativas entre familias al considerar todo el período de ensayo. Los valores mínimos mostraron un promedio $\pm \mathrm{DE}$ de todas las fechas de medición de $-1,37 \pm-0,25 \mathrm{MPa},-1,94 \pm-0,58 \mathrm{MPa}$ y $-2,38 \pm-0,81 \mathrm{MPa}$ en el control, DM y DS, respectivamente. Los potenciales mínimos absolutos que se alcanzaron en los distintos tratamientos fueron de $-1,5 ;-2,5$ y $-3,0 \mathrm{MPa}$ en el control, DM y DS, respectivamente. A pesar de que las diferencias no fueron significativas al promediar todos los tratamientos, dentro de cada uno, la familia AC1 presentó potenciales hídricos más negativos tanto en pre-alba como al mediodía en la casi totalidad del período. 


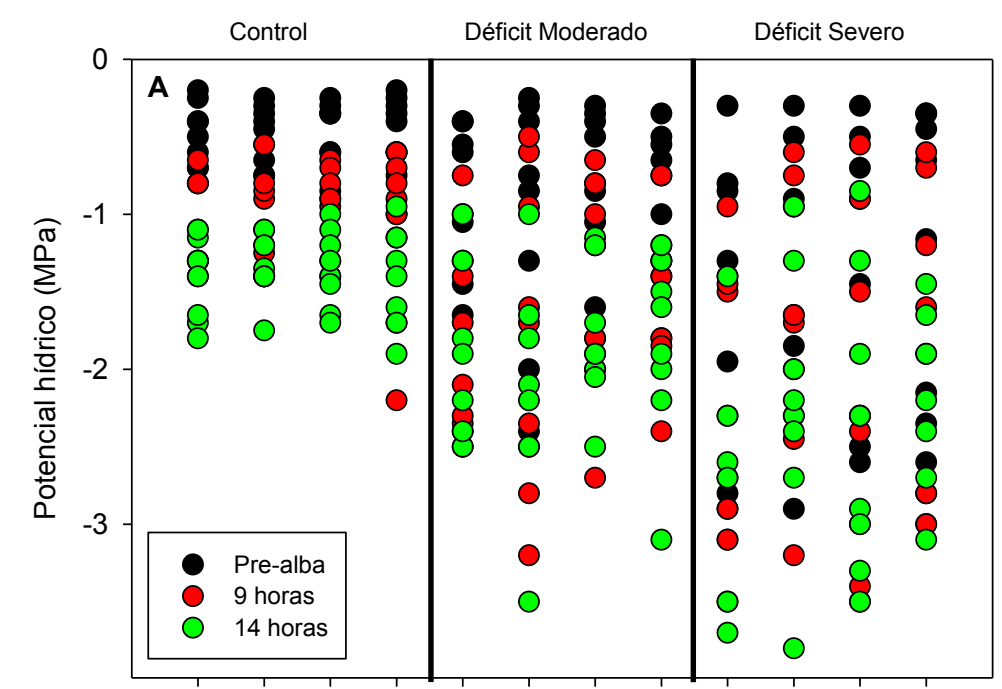

AC1 C AC2 C BC1 C BC2 C AC1 M AC2 M BC1 M BC2 M AC1 S AC2 S BC1 S BC2 S Familias

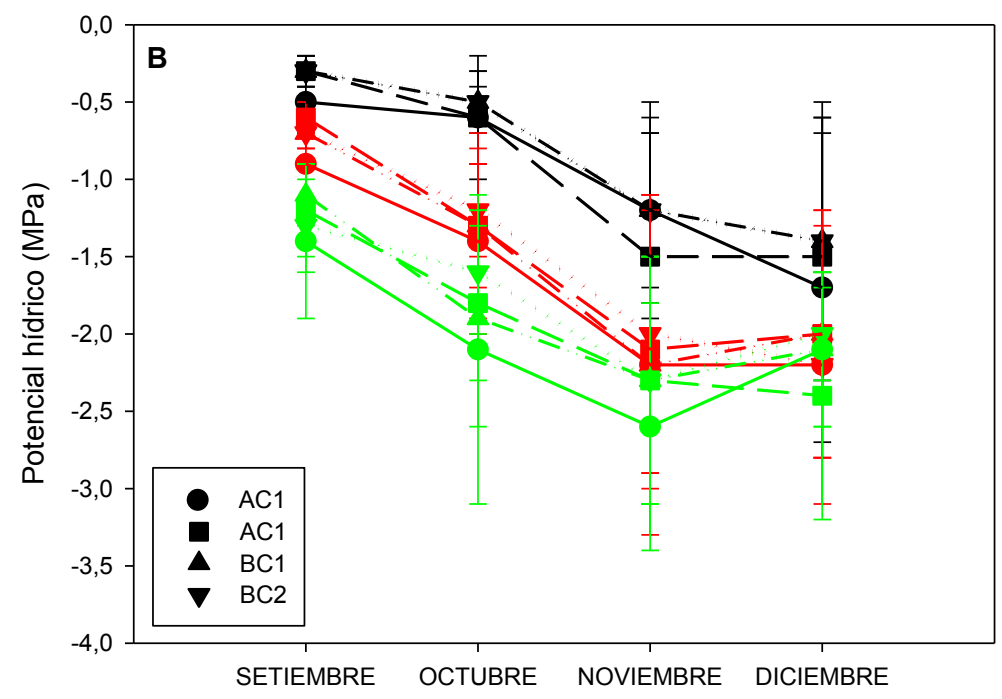

Figura 2.8 Potencial hídrico foliar (MPa) en plantines de Pinus taeda L. A) Valores absolutos de potencial hídrico foliar en las progenies dentro de cada tratamiento en los diferentes momentos de medición diaria. B) Valores promedios y desvíos estándares del potencial hídrico foliar en las progenies en los diferentes momentos de medición durante el período de estudio.

En la Figura 2.8 se pueden observar los valores absolutos de potencial hídrico foliar en los diferentes tratamientos evaluados. En ella se puede apreciar la variación de este parámetro tanto para las diferentes progenies como la evoluación del mismo durante el período de estudio. En líneas generales se observa que el potencial hídrico, en los diferentes momentos del día, se hace más negativos conforme aumenta la intensidad del déficit hídrico atmosférico, así como también decrece en el tiempo durante el período de crecimiento. Esta última afirmación se corresponde con un aumento en la media de las condiciones meteorológicas (temperatura y humedad relativa), 
determinando un incremento en la demanda atmosférica. Nótese que se produce una disminución en el tiempo del potencial en pre-alba aún en el tratamiento control, lo que sugiere que la alta temperatura nocturna en los meses de noviembre y diciembre impidió el total equilibrio en el potencial hídrico de los plantines durante la noche.

La conductividad hidráulica específica de las ramas $\left(k_{s}\right)$ medida in situ fue similar entre los tratamientos de DH ( $p=0,467$ en Noviembre; $p=0,403$ en Diciembre), recordando que para esta variable sólo se comparó el control y el nivel de déficit más severo (DS), así como también fueron similares las familias anidadas en TC ( $p=0,531$ en Noviembre; $p=0,159$ en Diciembre). Los valores promedios por tratamiento en noviembre fueron de $0,20 \pm 0,19$ y $0,27 \pm 0,28 \mathrm{~kg} \mathrm{~s}^{-1} \mathrm{~m}^{-1} \mathrm{MPa}^{-1}$ para el control y el DS respectivamente, en tanto que en diciembre los valores promedios fueron de $0,32 \pm 0,36$ y $0,24 \pm 0,14 \mathrm{~kg} \mathrm{~s}^{-1}$ $\mathrm{m}^{-1} \mathrm{MPa}^{-1}$ para iguales tratamientos, respectivamente. Esta variable fue medida al mediodía donde la demanda evaporativa del ambiente fue alta, siendo el DPV para noviembre de $3,5 \mathrm{kPa}$ y de 5,5 $\mathrm{kPa}$ para diciembre (en ambos casos los valores corresponden al promedio entre las 12 y 14 horas en los días que fueron tomadas las muestras para la estimación de $k_{\mathrm{s}}$ ). Sumado a lo anterior se destaca el déficit hídrico en el suelo para el caso del DS. De este modo, la $k_{\mathrm{s}}$ de la planta fue la mínima esperable, observándose valores cercanos a cero en algunos individuos tanto en el tratamiento de déficit severo como en el control. Los valores promedios para cada familia se presentan en la Tabla 2.4 .

La $k_{\mathrm{s}}$ máxima en ramas presentó valores similares entre TC, DH y $\mathrm{F}$ anidada en TC (Tabla 2.4). Sin embargo, el DH afectó significativamente la $k_{l}$, la cual fue mayor en el tratamiento de déficit severo respecto al control (Tabla 2.4), lo que puede ser explicado por el menor área foliar de las ramas en el tratamiento con déficit hídrico. En particular, la familia BC2 mostró una $k$ ı significativamente mayor en DS comparado al control.

Al comparar los valores mínimos de $k_{\mathrm{s}}$ observados al mediodía con las máximas de cada familia dentro de cada tratamiento (Tabla 2.4), se observó que todas las familias pierden conductividad hidráulica en los picos de estrés diarios, dadas las altas demandas evaporativas, sin diferencias entre el control y el tratamiento de déficit hídrico. Sin embargo, la familia AC1 mostró en promedio pérdidas de $k_{\mathrm{s}}$ menores al 
$40 \%$ en comparación al resto de las familias, las cuales perdieron más del $50 \%$ de $k_{\mathrm{s}}$ en todos los casos (Tabla 2.4).

Tabla 2.4 Promedio ( \pm desvío estándar) de la conductividad hidráulica foliar específica máxima de ramas ( $k_{\perp}$ max); conductividad hidráulica específica máxima de ramas ( $k_{\mathrm{s}}$ max); conductividad hidráulica específica mínima medida en noviembre $\left(k_{s}, \min\right.$ noviembre), conductividad hidráulica específica mínima medida en diciembre $\left(k_{\mathrm{s}}, \min\right.$ diciembre), y $\boldsymbol{k}_{\mathrm{s}}$ mínima relativa a la máxima (promedio de $k_{\mathrm{s}}$ en noviembre y diciembre dividido por la $\boldsymbol{k}_{\mathrm{s}}$ máxima promedio de la familia). Valores de $k_{\mathrm{s}}$ expresados en $\mathrm{Kg} \mathrm{s}^{-1} \mathrm{~m}^{-1} \mathrm{MPa}^{-1}$ y $k_{\mathrm{l}}$ en $\mathrm{m}^{-1} \mathrm{~s}^{-1} \mathrm{MPa}^{-1}$. Los valores de probabilidad del ANOVA se proporcionan para los efectos de TC: tasa de crecimiento (AC: familias de alto crecimiento; BC: familias de bajo crecimiento); DH: factor de déficit hídrico (condición control; DS: nivel de déficit hídrico severo); F: factor familia anidado dentro de TC.

\begin{tabular}{|c|c|c|c|c|c|c|}
\hline Tratamiento & Familia & $k_{1} \max$ & $k_{\mathrm{s}} \max$ & $k_{\mathrm{s}} \min$ nov & $k_{\mathrm{s}} \min \mathrm{dic}$ & $k_{\mathrm{s}} \min / k_{\mathrm{s}} \max$ \\
\hline \multirow{4}{*}{ Control } & $\mathrm{AC1}$ & $0,09 \pm 0,02$ & $0,53 \pm 0,12$ & $0,34 \pm 0,22$ & $0,60 \pm 0,64$ & 0,89 \\
\hline & AC2 & $0,06 \pm 0,01$ & $0,44 \pm 0,11$ & $0,10 \pm 0,12$ & $0,19 \pm 0,13$ & 0,33 \\
\hline & $\mathrm{BC} 1$ & $0,07 \pm 0,04$ & $0,69 \pm 0,28$ & $0,24 \pm 0,19$ & $0,18 \pm 0,17$ & 0,30 \\
\hline & $\mathrm{BC} 2$ & $0,06 \pm 0,02$ & $0,61 \pm 0,17$ & $0,13 \pm 0,21$ & $0,32 \pm 0,21$ & 0,37 \\
\hline \multirow{4}{*}{ DS } & $\mathrm{AC1}$ & $0,11 \pm 0,04$ & $0,57 \pm 0,08$ & $0,38 \pm 0,22$ & $0,33 \pm 0,10$ & 0,62 \\
\hline & AC2 & $0,10 \pm 0,06$ & $0,60 \pm 0,14$ & $0,34 \pm 0,21$ & $0,22 \pm 0,13$ & 0,47 \\
\hline & $\mathrm{BC} 1$ & $0,07 \pm 0,02$ & $0,48 \pm 0,05$ & $0,14 \pm 0,20$ & $0,21 \pm 0,18$ & 0,36 \\
\hline & $\mathrm{BC} 2$ & $0,12 \pm 0,02$ & $0,64 \pm 0,16$ & $0,20 \pm 0,18$ & $0,20 \pm 0,16$ & 0,31 \\
\hline$\overline{P_{T C}}$ & & 0,512 & 0,171 & 0,195 & 0,275 & \\
\hline $\boldsymbol{P}_{D H}$ & & 0,010 & 0,858 & 0,467 & 0,403 & \\
\hline $\boldsymbol{P}_{F \text { (anidado en TC) }}$ & & 0,280 & 0,856 & 0,531 & 0,159 & \\
\hline $\boldsymbol{P}_{T C \times D H}$ & & 0,983 & 0,133 & 0,356 & 0,715 & \\
\hline
\end{tabular}

\section{Intercambio gaseoso}

La $g_{s}$ promedio no varió entre TC y familias, pero sí se vio afectada por los tratamientos de déficit hídrico. Durante el período evaluado, ésta comenzó a diferenciarse estadísticamente entre el control y los tratamientos de déficit hídrico en octubre y lo hizo hasta el final del experimento ( $\alpha=0,05$ en cada fecha), disminuyendo la $g_{\mathrm{s}}$ promedio en cada tratamiento a lo largo del período, incluyendo al control (Figura 2.9). 


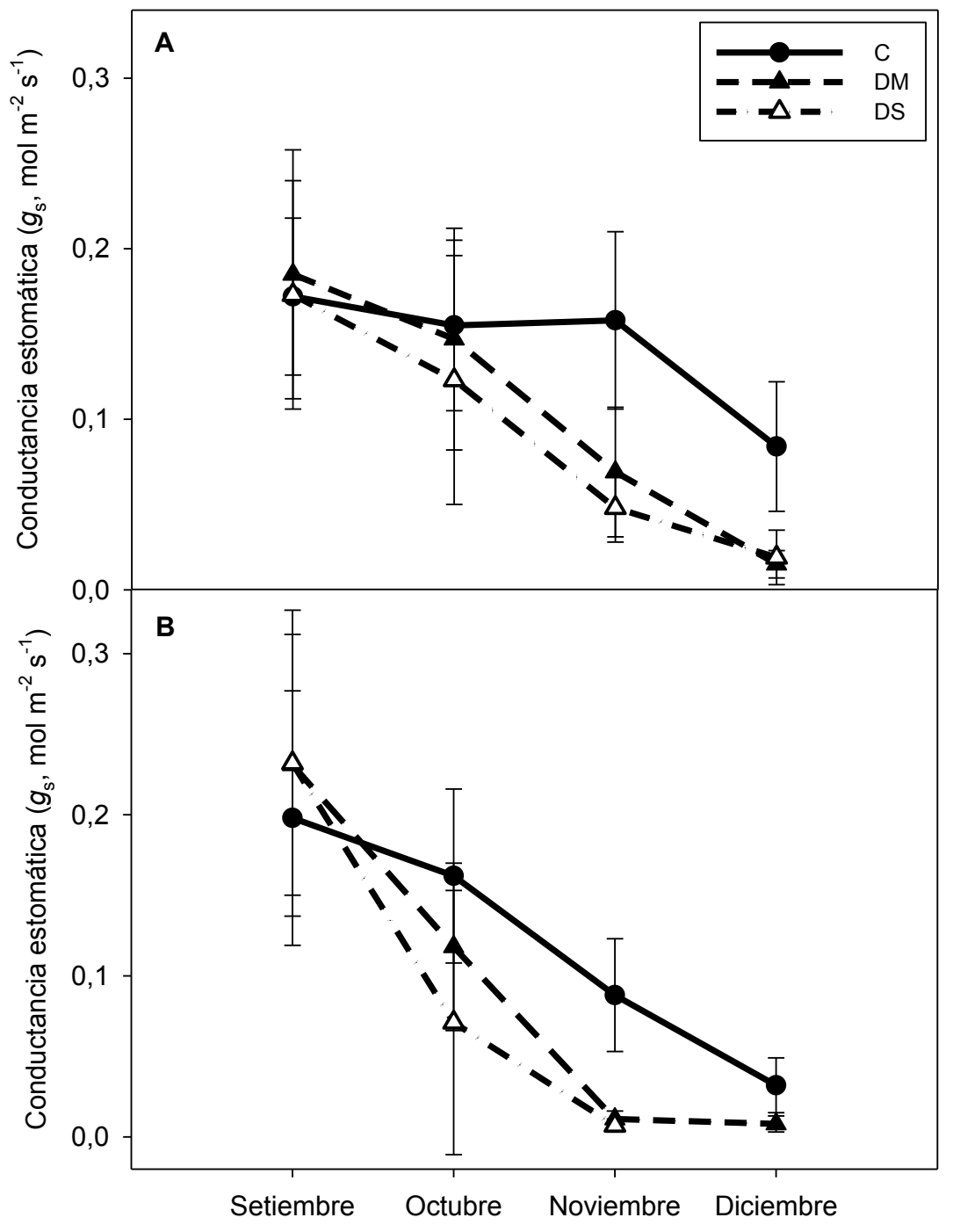

Figura 2.9 Conductancia estomática $\left(g_{\mathrm{s}}, \mathrm{mol} \mathrm{m}^{-2} \mathrm{~s}^{-1}\right)$ promedio \pm DE para los diferentes tratamientos. A) conductancia estomática medida a las 9 de la mañana. B) conductancia estomática medida a las 14 horas.

No se observaron diferencias significativas en la $g_{s}$ promedio entre los dos niveles de déficit hídrico (DM y DS). En diciembre se observaron los valores mínimos de $g_{\mathrm{s}}$ en todos los tratamientos, relacionados a altos valores de DPV registrados en esa fecha. El DPV promedio registrado a las 9 horas fue igual o menor a 0,3 kPa de septiembre a diciembre, mientras que a las 14 horas, horario en el cual se alcanza la temperatura máxima del día, se registró un máximo de hasta 5,9 kPa en diciembre. 


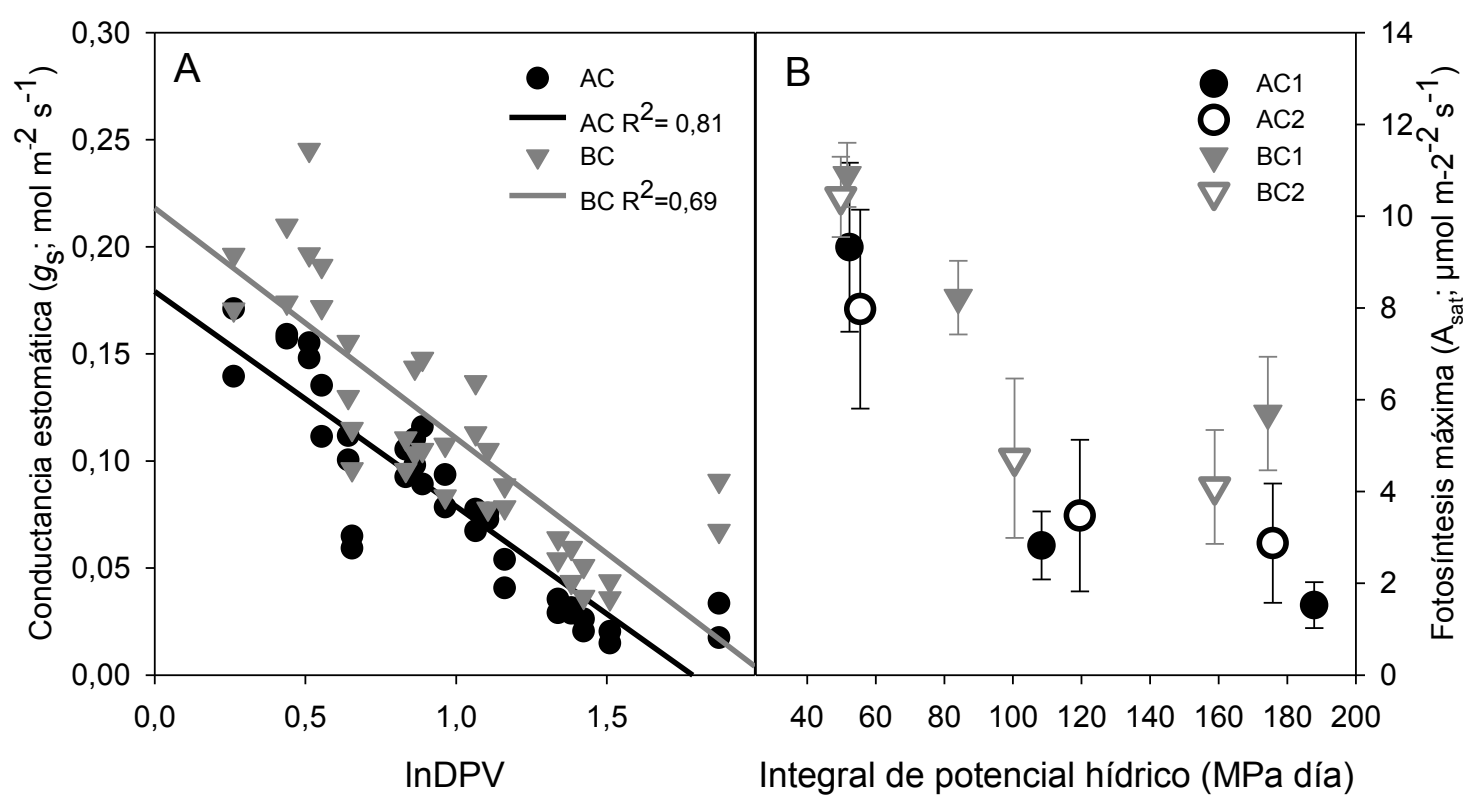

Figura 2.10 Sensibilidad estomática al déficit de presión de vapor (DPV) y fotosíntesis máxima medida en las familias de alto (AC) y bajo crecimiento (BC) en plantines de Pinus taeda. A) Conductancia estomática $\left(g_{\mathrm{s}}, \mathrm{mol} \mathrm{m}^{2} \mathrm{~s}^{-1}\right)$ en función del logaritmo natural del DPV en el tratamiento control. B)

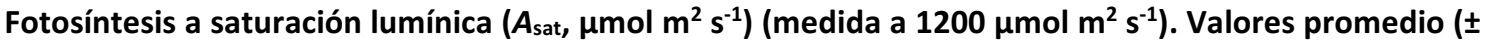
desvío estándar) presentados por familia y tratamiento en función de la integral de potencial hídrico (MPa día).

Las familias BC se caracterizaron por presentar mayores $g_{s}$-para iguales valores de DPV- que las familias AC, manteniéndose una $g_{\mathrm{s}}$ relativamente alta a niveles de DPV de hasta $6 \mathrm{kPa}$ (Figura 2.10 panel A), destacándose asimismo que las mismas no presentaron cierre estomático total en ningún momento. La sensibilidad estomática al DPV, cuantificada en la pendiente de las rectas que relacionan $g_{\mathrm{s}}$ con el $\ln (\mathrm{DPV})$, fue similar entre los grupos de familias AC y BC (Figura 2.10 panel A), pero el modelo completo fue diferente entre $A C$ y $B C$ debido a diferencias en la ordenada al origen (análisis de covariancia, $p<0,0001$ ). Por esta razón, el cociente entre la sensibilidad estomática y la $g_{\mathrm{s}}$ de referencia (i.e. aquella que se presenta a DPV $=1 \mathrm{kPa}$, ordenada al origen de la recta) fue de 0,56 para ambas familias del grupo AC, mientras que las familias $\mathrm{BC} 1$ y $\mathrm{BC} 2$ presentaron un cociente menor $(0,53$ y 0,45 para $B C 1$ y $B C 2$, respectivamente).

La fotosíntesis máxima $\left(A_{\text {sat }}\right)$ de las plantas medida durante un período de alta actividad de crecimiento fue afectado por TC y los tratamientos de $\mathrm{DH}$, con un efecto significativo del factor familia anidado en TC (Figura 2.10 panel B). En ambas familia AC 
y en la familia $\mathrm{BC2}$, la $A_{\text {sat }}$ en las plantas control fue mayor que en ambos tratamientos de $\mathrm{DH}$, no diferenciándose entre ellos, sin embargo en la familia $\mathrm{BC} 1$ se detectaron diferencias significativas entre los tratamientos aplicados (control y ambos niveles de estrés) (Tabla 2.5). Las familias BC tuvieron mayor $A_{\text {sat }}$ que las familias del grupo AC, así como se observaron diferencias significativas en $A_{\text {sat }}$ entre las familias BC1 y BC2. Los valores promedios (para todos los tratamientos) fueron $4,6 \pm 3,7$ y $4,8 \pm 2,8 \mu \mathrm{mol} \mathrm{m}{ }^{2} \mathrm{~s}^{-}$ ${ }^{1}$ para las familias $A C 1$ y $A C 2$, y $8,3 \pm 2,4$ y $6,4 \pm 3,2 \mu$ mol $\mathrm{m}^{2} \mathrm{~s}^{-1}$ para las familias $B C 1$ y BC2.

\section{Fisiología de hojas-Contenido de clorofilas, Nitrógeno foliar}

La clorofila total $\left(\mathrm{c} \mathrm{l}_{\mathrm{t}}\right.$ ) en las hojas no fue afectada por la TC ni por los tratamientos de $\mathrm{DH}(p=0,458$ y 0,803 , respectivamente).

Sin embargo, las proporciones de clorofila a $\left(\mathrm{cl}_{\mathrm{a}}\right)$ y clorofila $\mathrm{b}\left(\mathrm{cl} \mathrm{b}_{\mathrm{b}}\right)$ fueron afectadas por los tratamientos de DH (Tabla 2.5). En general, las plantas del control $(2,05 \pm 0,96 \mathrm{mg}$ $\left.\mathrm{g}^{-1}\right)$ y las del tratamiento $\mathrm{DM}\left(2,23 \pm 1,1 \mathrm{mg} \mathrm{g}^{-1}\right)$ tuvieron mayores concentraciones de $\mathrm{Cl}_{\mathrm{a}}$ que las plantas del tratamiento DS $\left(1,15 \pm 0,7 \mathrm{mg} \mathrm{g}^{-1}\right)$. A nivel de familia, en plantas de las familias $A C 1$ y $B C 1$ se observaron diferencias significativas en $\mathrm{cl}_{a}$ entre el control y DS, y entre ambos tratamientos de déficit hídrico. Adicionalmente, se encontraron diferencias significativas en $\mathrm{Cl}_{a}$ entre los tratamientos DM y DS en la familia BC2 (Tabla 2.5).

El comportamiento de la concentración de la $\mathrm{cl}_{\mathrm{b}}$ fue opuesto al de la $\mathrm{cl}_{\mathrm{a}}$. Las plantas sujetas a DS tuvieron mayor concentración de $\mathrm{cl}_{\mathrm{b}}\left(2,35 \pm 1,23 \mathrm{mg} \mathrm{g}^{-1}\right)$ que las control $\left(1,45 \pm 1,15 \mathrm{mg} \mathrm{g}^{-1}\right)$ y que el tratamiento $\operatorname{DM}\left(1,5 \pm 0,64 \mathrm{mg} \mathrm{g}^{-1}\right)$. Sin embargo, a nivel de familia, solamente la familia AC2 mostró diferencias significativas en este parámetro entre tratamientos de estrés (DM y DS). Esta familia incrementó la concentración de $\mathrm{Cl}_{\mathrm{b}}$ en DS comparado al control. 
Tabla 2.5 Promedio \pm desvío estándar de variables fisiológicas a nivel de hoja por familia y tratamiento. Asat: fotosíntesis neta a saturación lumínica $\left(\mu \mathrm{mol} \mathrm{m}^{2} \mathrm{~s}^{-1}\right)$; concentración de clorofila total $\left(\mathrm{Cl}_{\mathrm{t}}, \mathrm{mg} \mathrm{g}^{-1}\right)$; concentración de clorofila a $\left(\mathrm{Cl}_{\mathrm{a}}, \mathrm{mg} \mathrm{g}^{-1}\right)$; concentración de clorofila b $\left(\mathrm{Cl}_{\mathrm{b}}, \mathrm{mg} \mathrm{g}^{-1}\right)$; DM: nivel de déficit hídrico moderado; DS: nivel de déficit hídrico severo. Los valores de probabilidad del ANOVA se proporcionan para los efectos de TC: tasa de crecimiento (AC: familias de alto crecimiento; BC: familias de bajo crecimiento); DH: factor de déficit hídrico (control, DM y DS); F: factor familia anidada dentro de TC.

\begin{tabular}{|c|c|c|c|c|c|}
\hline Tratamiento & Familia & $A_{\text {sat }}$ & $\mathrm{Cl}_{\mathrm{t}}$ & $\mathrm{Cl}_{\mathrm{a}}$ & $\mathrm{Cl}_{\mathrm{b}}$ \\
\hline \multirow{4}{*}{ Control } & AC1 & $9,3 \pm 1,8$ & $4,1 \pm 2,6$ & $2,3 \pm 1,5$ & $1,8 \pm 1,9$ \\
\hline & $\mathrm{AC2}$ & $8,0 \pm 2,2$ & $2,6 \pm 0,8$ & $1,5 \pm 0,4$ & $1,1 \pm 0,8$ \\
\hline & $\mathrm{BC} 1$ & $10,9 \pm 0,7$ & $4,4 \pm 1,4$ & $2,2 \pm 0,5$ & $1,5 \pm 0,8$ \\
\hline & $\mathrm{BC} 2$ & $10,4 \pm 0,9$ & $3,6 \pm 1,3$ & $2,2 \pm 1,0$ & $1,4 \pm 0,9$ \\
\hline \multirow{4}{*}{ DM } & AC1 & $2,8 \pm 0,7$ & $3,6 \pm 1,0$ & $2,1 \pm 1,0$ & $1,4 \pm 0,5$ \\
\hline & AC2 & $3,5 \pm 1,6$ & $3,7 \pm 0,4$ & $1,9 \pm 0,8 d$ & $1,6 \pm 0,7$ \\
\hline & $\mathrm{BC} 1$ & $8,2 \pm 0,8$ & $4,3 \pm 1,6$ & $2,3 \pm 0,9$ & $1,6 \pm 0,6$ \\
\hline & $\mathrm{BC} 2$ & $4,7 \pm 1,7$ & $3,6 \pm 1,7$ & $2,6 \pm 1,7$ & $1,3 \pm 0,8$ \\
\hline \multirow{4}{*}{ DS } & AC1 & $1,5 \pm 0,5$ & $3,2 \pm 2,7$ & $1,0 \pm 1,0$ & $2,2 \pm 1,7$ \\
\hline & $\mathrm{AC2}$ & $2,3 \pm 1,3$ & $4,4 \pm 1,8$ & $1,3 \pm 0,6$ & $3,1 \pm 1,3$ \\
\hline & $\mathrm{BC} 1$ & $5,7 \pm 1,2$ & $3,2 \pm 0,5$ & $1,0 \pm 0,4$ & $2,0 \pm 0,5$ \\
\hline & $\mathrm{BC} 2$ & $4,1 \pm 1,2$ & $3,7 \pm 1,1$ & $1,3 \pm 0,8$ & $2,1 \pm 1,0$ \\
\hline$P_{T C}$ & & $<0,0001$ & 0,458 & 0,184 & 0,388 \\
\hline$P_{D H}$ & & $<0,0001$ & 0,803 & $<0,0001$ & $<0,0001$ \\
\hline$P_{F \text { (anidado en TC) }}$ & & $<0,01$ & 0,721 & 0,476 & 0,905 \\
\hline$P_{T C \times D H}$ & & 0,388 & 0,446 & 0,722 & 0,502 \\
\hline
\end{tabular}

La concentración de nitrógeno foliar $\left(N_{\mathrm{f}}\right)$, expresada en porcentaje de $N$ en $100 \mathrm{~g}$ de peso seco foliar, fue afectada por los factores TC y DH. El déficit hídrico aumentó significativamente la concentración de $N_{\mathrm{f}}$ manifestando valores promedios de 1,43 \pm 0,15 y $1,41 \pm 0,20 \%$ para DM y DS, respectivamente en comparación con las plantas creciendo en el control el cual presentó un promedio $1,18 \pm 0,13 \%$ de $N$. Las familias $\mathrm{BC}$, destacándose dentro de ellas la familia BC1, presentaron mayores concentraciones de $N_{\mathrm{f}}$ que las familias AC.

Integrando la concentración de $N_{\mathrm{f}}$ y la biomasa foliar total de la planta, se observó que hubo una compensación entre variables, resultando en valores similares de nitrógeno en la copa $\left(N_{c}\right)$ en todas las familias. El tratamiento tuvo efecto significativo sobre el $N_{c}$, presentando valores promedios de $0,45 \pm 0,11 ; 0,35 \pm 0,08$ y $0,18 \pm 0,05 \mathrm{~g}$ por planta para el Control y los tratamientos DM y DS, respectivamente. 


\section{Eficiencia en el uso de los recursos}

La eficiencia de crecimiento (EC) fue afectada por los factores TC, DH y F (anidada en TC) (Tabla 2.6). La EC de las plantas mostró una caída exponencial en las plantas estresadas comparadas a las control, sin diferencias significativas entre ambos niveles de estrés (DM y DS), con valores promedio (para todas las familias) de $2,79 \pm 0,61 \mathrm{~cm}^{3}$ $\mathrm{g}^{-1} ; 1,28 \pm 0,38$ y $1,27 \pm 0,50 \mathrm{~cm}^{3} \mathrm{gr}^{-1}$ para el control, DM y DS, respectivamente.

A nivel de familia, considerando todos los tratamientos juntos, la familia AC2 presentó los menores valores de EC, diferenciándose significativamente de la familia AC1; sin embargo, la EC de la familia AC1 fue marcadamente mayor que la de las demás familias estudiadas (Figura 2.11 panel A). La EC no se diferenció entre las familias del grupo BC, las cuales presentaron valores intermedios a los de las familias del grupo AC.

Tabla 2.6 Promedio \pm desvío estándar de variables tomadas como proxy de la eficiencia en el uso de los recursos por familia y tratamiento. EC: eficiencia del crecimiento (crecimiento en volumen del tallo por unidad de biomasa foliar $\left(\mathrm{cm}^{3} \mathrm{~g}^{-1}\right)$ ); PN: productividad del nitrógeno (crecimiento absoluto en volumen del tallo por gramo de nitrógeno de la copa $\left.\left(\mathrm{cm}^{3} \mathrm{~g}^{-1}\right)\right) ; \delta 13 \mathrm{C}$ : relación ${ }^{13} \mathrm{C}$ a ${ }^{12} \mathrm{C}$ en tejido leñoso (\%o). DM: déficit hídrico moderado; DS: déficit hídrico severo. Los valores de probabilidad del ANOVA se proporcionan para los efectos de TC: tasa de crecimiento (AC: familias de alto crecimiento; BC: familias de bajo crecimiento); DH: factor de déficit hídrico (Control, DM y DS); F: factor familia anidado dentro de TC.

\begin{tabular}{|c|c|c|c|c|}
\hline Tratamiento & Familia & $\overline{E C}$ & PN & $\delta^{13} \mathrm{C}$ \\
\hline \multirow{4}{*}{ Control } & AC1 & $3,62 \pm 0,32$ & $330,8 \pm 33,3$ & $-27,8 \pm 0,4$ \\
\hline & $A C 2$ & $2,32 \pm 0,56$ & $182,8 \pm 59,9$ & $-27,7 \pm 0,8$ \\
\hline & $\mathrm{BC} 1$ & $2,62 \pm 0,37$ & $206,0 \pm 32,8$ & $-28,5 \pm 0,2$ \\
\hline & $\mathrm{BC2}$ & $2,63 \pm 0,10$ & $216,9 \pm 19,6$ & $-28,3 \pm 0,4$ \\
\hline \multirow{4}{*}{ DM } & $\mathrm{AC1}$ & $1,52 \pm 0,51$ & $95,1 \pm 30,3$ & $-26,2 \pm 0,2$ \\
\hline & $A C 2$ & $0,93 \pm 0,23$ & $78,2 \pm 22,8$ & $-26,5 \pm 0,5$ \\
\hline & $\mathrm{BC} 1$ & $1,52 \pm 0,12$ & $97,6 \pm 9,2$ & $-26,5 \pm 0,5$ \\
\hline & $\mathrm{BC} 2$ & $1,2 \pm 0,23$ & $82,0 \pm 2,3$ & $-26,3 \pm 0,5$ \\
\hline \multirow{4}{*}{ DS } & $\mathrm{AC1}$ & $1,57 \pm 0,74$ & $140,3 \pm 40,2$ & $-27,1 \pm 0,7$ \\
\hline & $\mathrm{AC2}$ & $0,93 \pm 0,21$ & $75,1 \pm 21,3$ & $-26,5 \pm 0,6$ \\
\hline & $\mathrm{BC} 1$ & $1,27 \pm 0,26$ & $86,1 \pm 16,2$ & $-27,0 \pm 0,8$ \\
\hline & $\mathrm{BC} 2$ & $1,34 \pm 0,46$ & $111,6 \pm 39,8$ & $-27,1 \pm 0,5$ \\
\hline$\overline{P_{T C}}$ & & 0,481 & 0,081 & 0,039 \\
\hline$P_{D H}$ & & $<0,0001$ & $<0,0001$ & $<0,0001$ \\
\hline$P_{F(\text { anidado en TC) }}$ & & $<0,0001$ & $<0,0001$ & 0,776 \\
\hline$P_{T C \times D H}$ & & 0,071 & 0,069 & 0,339 \\
\hline
\end{tabular}


La productividad del nitrógeno (PN), fue afectada por el factor $\mathrm{DH}$ y el factor familia anidado en TC, con un comportamiento similar a la EC (caída exponencial en condiciones de déficit hídrico) (Tabla 2.6 y Figura 2.11 panel B). Sin embargo, no se observaron diferencias en PN entre niveles de déficit hídrico moderado y severo. La familia AC1 presentó mayor PN que la familia AC2, independientemente del tratamiento aplicado (Figura 2.11 panel B). No se encontraron diferencias significativas entre las familias del grupo BC.

Contrariamente a la caída en la eficiencia de crecimiento y la productividad del $N$ observadas frente al déficit hídrico, ambos tratamientos de déficit hídrico presentaron una menor discriminación en contra del isótopo ${ }^{13} \mathrm{C}$ comparado al control (Tabla 2.6 y Figura 2.11 panel C), sugiriendo una mayor $E \cup A_{i}$ en plantas sometidas a restricción hídrica. Asimismo, se observaron diferencias significativas entre los tratamientos DM y DS, presentando el DM la mayor concentración de ${ }^{13} \mathrm{C}$ (mayor EUA $A_{i}$ ). No se observaron efectos significativos de los factores TC y $\mathrm{F}$ en la concentración de ${ }^{13} \mathrm{C}$. 


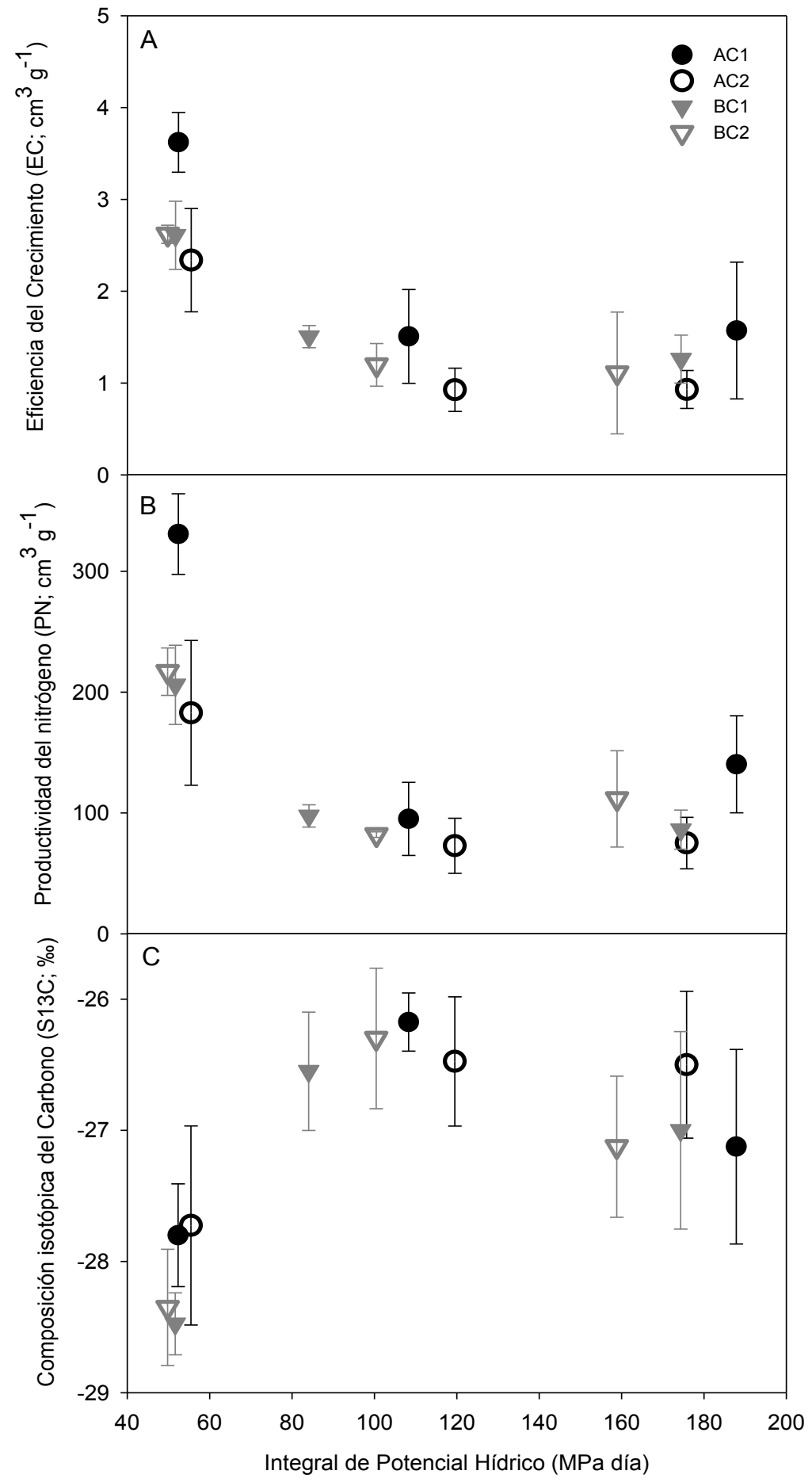

Figura 2.11 Variables utilizadas como una aproximación de la eficiencia en el uso de los recursos de familias de Pinus taeda de alto (AC) y bajo crecimiento $(B C)$ en función de la integral de potencial hídrico (MPa día), valores promedios \pm desvío estándar. A) Eficiencia del crecimiento (EC, $\mathrm{cm}^{3} \mathrm{~g}^{-1}$ ): crecimiento en volumen del tallo por unidad de biomasa foliar. B) Productividad del nitrógeno (PN, $\mathrm{cm}^{3} \mathrm{~g}^{-1}$ ): crecimiento absoluto en volumen de tallo por gramo de nitrógeno foliar. C) Composición isotópica del carbono en tejido leñoso (tallo + ramas) $\left(\delta^{13} \mathrm{C}, \%\right.$ ). 


\section{Correlación entre crecimiento y variables morfo-fisiológicas}

Se observaron altas correlaciones positivas $(r>0,75)$ entre el incremento absoluto en volumen del tallo y la biomasa final de los distintos compartimientos de la planta (biomasa de tallo, foliar, aérea (hojas + ramas + fuste) y raíces) (Tabla 2.7). Sin embargo, contrariamente a lo inicialmente esperado, se observaron correlaciones negativas entre el incremento absoluto en volumen del tallo y las variables fisiológicas a nivel de leño $\left(k_{1}, r=-0,38\right)$ o de hojas $\left(A_{\text {sat: }} r=-0,57\right)$, sin que se observe una correlación significativa con la $k_{\mathrm{s}}$ de ramas $(p=0,3)$ y el contenido de clorofilas $\left(\mathrm{cl}_{\mathrm{t}}\right.$ : $p=$ $0,2)$. Esto significa que las plantas de mayor crecimiento absoluto en volumen fueron las de menor capacidad de conducción de agua por unidad de área foliar y de fijación de carbono, ambos expresados por unidad de área foliar.

Tabla 2.7 Coeficientes de correlación de Pearson entre el incremento en volumen del tallo absoluto ( $\left.I V_{\text {abs}}\right)$ o el incremento en volumen del tallo relativo ( $\left(V_{\text {rel }}\right)$ durante el ensayo (septiembre de 2011 enero de 2012) y diferentes caracteres fisiológicos y morfológicos. Conductividad hidráulica específica de ramas $\left(k_{\mathrm{s}}, \mathrm{Kg} \mathrm{s}^{-1} \mathrm{~m}^{-1} \mathrm{MPa}^{-1}\right)$; conductividad hidráulica foliar específica ( $\mathrm{kh} /$ biomasa foliar) $\left(\mathrm{k}_{\mathrm{l}}, \mathrm{m}^{-1} \mathrm{~s}^{-1}\right.$ $\left.\mathrm{MPa}^{-1}\right)$; fotosíntesis neta máxima a saturación lumínica $\left(A_{\mathrm{sat}}, \mu \mathrm{mol} \mathrm{m}^{2} \mathrm{~s}^{-1}\right)$; contenido de nitrógeno en la copa ( $\mathrm{Nc}, \mathrm{g})$; concentración de clorofila total ( $\left.\mathrm{cl}_{\mathrm{t}}, \mathrm{mg} \mathrm{g}^{-1}\right)$; concentración de clorofila a (cla, $\mathrm{mg} \mathrm{g}^{-1}$ ); concentración de clorofila $b\left(c_{b}, \mathrm{mg} \mathrm{g}^{-1}\right)$. En negrita se destacan estadísticos significativos $(\alpha=0,05)$.

\begin{tabular}{lcccc} 
& \multicolumn{2}{c}{$\mathbf{I V}_{\text {abs }}$} & \multicolumn{2}{c}{ IV $_{\text {rel }}$} \\
\hline Parámetros & $\mathbf{r}$ & $\boldsymbol{p}$ & $\mathbf{r}$ & $\boldsymbol{p}$ \\
\hline$k_{\mathrm{s}}$ & 0,19 & 0,300 & 0,330 & 0,070 \\
$k_{\mathrm{l}}$ & $-0,38$ & $\mathbf{0 , 0 3 0}$ & $-0,310$ & 0,080 \\
$A_{\text {sat }}$ & $-0,57$ & $\mathbf{0 , 0 2 0}$ & 0,26 & 0,330 \\
$N_{\mathbf{c}}$ & 0,69 & $<\mathbf{0 , 0 1}$ & $-0,450$ & 0,080 \\
$\mathrm{cl}_{\mathrm{t}}$ & $-0,24$ & 0,168 & 0,220 & 0,196 \\
$\mathrm{cl}_{\mathrm{a}}$ & $-0,13$ & 0,463 & 0,020 & 0,920 \\
$\mathrm{cl}_{\mathrm{b}}$ & $-0,26$ & 0,128 & 0,200 & 0,252 \\
Biomasa total & 0,91 & $<\mathbf{0 , 0 0 0 1}$ & $-0,530$ & $\mathbf{0 , 0 1 0}$ \\
Biomasa aérea & 0,87 & $<\mathbf{0 , 0 0 0 1}$ & $-0,490$ & $\mathbf{0 , 0 2 0}$ \\
Biomasa subterránea & 0,80 & $<\mathbf{0 , 0 0 0 1}$ & $-0,510$ & $\mathbf{0 , 0 1 0}$ \\
Biomasa tallo & 0,96 & $<\mathbf{0 , 0 0 0 1}$ & $-0,480$ & $\mathbf{0 , 0 1 0}$ \\
Biomasa ramas & 0,69 & $<\mathbf{0 , 0 0 0 1}$ & $-0,470$ & $\mathbf{0 , 0 2 0}$ \\
Biomasa hojas & 0,75 & $<\mathbf{0 , 0 0 0 1}$ & $-0,430$ & $\mathbf{0 , 0 3 0}$ \\
\hline
\end{tabular}

No se encontraron correlaciones significativas entre el incremento relativo en volumen del tallo y los parámetros funcionales analizados $\left(\mathrm{Cl}_{\mathrm{t}}, A_{\text {sat }}, \mathrm{k}_{\mathrm{l}}\right)$, pero una correlación positiva marginalmente significativa $(p=0,07)$ fue determinada entre el incremento 
relativo en volumen del tallo y la $k_{s}$ en ramas. Además, contrario a lo observado en los valores absolutos del incremento en volumen del tallo, los valores relativos mostraron correlaciones negativas con las variables de biomasa y su partición dentro de la planta ( $r$ entre $-0,43$ y $-0,53$ ), en las que las plantas más grandes tuvieron los menores incrementos en volumen en relación con el tamaño de los órganos involucrados (Tabla 2.7).

\section{DISCUSIÓN}

\section{Procesos ecofisiológicos que explican el crecimiento diferencial entre familias}

Este estudio contempla dos familias consideradas como de altas tasas de crecimiento (AC) y dos familias de bajas tasas de crecimiento (BC). Estas tendencias fueron confirmadas en el tamaño inicial de las plantines a los 8 meses de edad, previamente a la aplicación del déficit hídrico, y al final del ensayo dentro del tratamiento control, en el que las familias AC tuvieron mayor biomasa y volumen de tallo respecto a las familias BC. Es importante considerar, sin embargo, que a pesar de que las familias AC presentaron mayor crecimiento absoluto durante el período de estudio, las familias BC presentaron significativamente mayores crecimientos relativos a su tamaño inicial.

El análisis de correlación entre crecimiento del tallo (absoluto o relativo) y las variables morfo-fisiológicas estudiadas indicaron que las características morfológicas tales como la biomasa total y la biomasa en los diferentes compartimentos aéreos fueron aquellas que mejores correlacionaron con el incremento en volumen del tallo durante el período de estudio. Dado que las plantas grandes al final del experimento fueron también aquellas con mayor tamaño inicial, parece que el mayor tamaño inicial de las plantas AC (mayor superficie de intercambio gaseoso) fue el principal factor explicando mayores crecimientos absolutos en aquellas plantas comparadas a las familias BC. Algunos estudios mencionan que el crecimiento absoluto es más efectivo que el crecimiento relativo para explicar las diferencias en crecimiento observados en diferentes genotipos de Pinus taeda (Aspinwall 2013) y en otros géneros de Pinaceae (Van den Driessche 1992), coincidiendo ello con nuestros resultados. Es importante determinar, sin embargo, cuáles procesos son responsables para las diferencias iniciales en el tamaño de las plantas, procesos que operan en estadios iniciales del 
desarrollo del plantín. Estos procesos aparentemente cambian en posteriores estadios, tal como los evaluados aquí, ya que la tasa de crecimiento relativo fue mayor en las familias BC que en las familias AC.

Por otro lado, las familias AC fueron diferentes de las familias BC en su capacidad fotosintética $\left(A_{\mathrm{sat}}, N_{\mathrm{f}}\right), g_{\mathrm{s}}$ máxima y sensibilidad estomática al DPV (relacionada a la $g_{\mathrm{s}}$ máxima). En estos caracteres, ambas familias AC presentaron similares patrones entre ellas, caracterizadas por una baja $A_{\text {sat, }}$ bajo $N_{\mathrm{f}}$, menor $g_{\mathrm{s}}$ máxima y mayor sensibilidad estomática al DPV, que las familias BC. Todas estas características podrían ser útiles para explicar, al menos en parte, los menores crecimientos relativos observados en las familias AC comparados a las BC, dado que pueden llevar a una menor fijación de $C$ por unidad de biomasa foliar o área.

Además de las diferencias expuestas, ambas familias BC presentaron mayor asignación de biomasa a raíces que las AC. Esta última característica podría ser determinante para explicar el menor crecimiento que se observa en la porción aérea de las familias BC, posiblemente desde muy temprano en el desarrollo de las mismas, a pesar de poseer caracteres que sugieren una alta capacidad de fijación de C (al menos ante condiciones de bajo DPV).

No todas las características coincidieron entre ambas familias AC. Ellas difirieron en la distribución de la biomasa aérea (hojas vs fuste) y en los niveles de pérdidas de $k_{\mathrm{s}}$ invivo. Las tendencias opuestas entre ellas en estos caracteres hacen que sea imposible relacionar una única combinación de caracteres a los patrones de alto crecimiento. Así, en lo que respecta a la distribución de la biomasa, la familia AC2 presentó mayor asignación al compartimento foliar comparada a todas las familias estudiadas, coincidiendo con antecedentes que reportan una correlación positiva entre la biomasa foliar y la productividad de toda la planta en Pinus taeda (Teskey et al. 1987). Por otro lado, la estrategia de la otra familia con alto crecimiento absoluto (AC1) estuvo caracterizada por una mayor asignación de biomasa al tallo, en detrimento de la biomasa foliar (Figura 2.7 panel B). Mientras la $k_{\text {। }}$ individual en ramas no se diferenció de las determinadas en las otras familias, a nivel de planta entera, este tipo de partición de biomasa aérea podría incrementar la conductancia hidráulica foliar total y la capacitancia, lo cual hace referencia al almacenamiento de agua, contribuyendo a 
un transporte de agua eficiente, siendo también consistente con altas tasas de crecimiento (Tyree y Ewers 1991).

Como consecuencia de las diferencias en la partición de la biomasa entre ambas familias AC, la familia AC1 estuvo caracterizada por alta EC y PN, mientras que la familia AC2 fue la de menor eficiencia en estos términos. Esto se debió a la alta asignación a hojas en esta última familia, dado que la biomasa foliar (o $N_{c}$ ) es el denominador en ambas ecuaciones de eficiencias. Las familias BC presentaron valores de eficiencias cercanos a aquellos de la familia AC2. Nuestros resultados coinciden con aquellos reportados por Aspinwall et al. (2013), quienes no encontraron relación entre la productividad y la eficiencia del crecimiento para Pinus taeda, donde los genotipos más productivos no fueron necesariamente los más eficientes. Otro precedente para $P$. taeda (Birk y Vitousek 1986) mostró que plantas individuales con mayores eficiencias en el uso del nitrógeno (EUN) no necesariamente tuvieron mayor biomasa total. Estos resultados contrastan, sin embargo, con algunos de los encontrados en este capítulo, como es el caso de la familia AC1, que tuvo la mayor PN y también mayor biomasa final y crecimiento del tallo.

Finalmente, contrario a muchos estudios que reportan una estrecha relación entre crecimiento y conductividad hidráulica máxima de diferentes órganos de la planta (e.g. Domec y Gartner 2003; Wang et al. 2003; Brodribb et al. 2005; Kondoh et al. 2006), en este estudio, no se ha encontrado ninguna correlación entre capacidad hidráulica máxima $\left(k_{\mathrm{s}}\right.$ y $k_{\mathrm{l}}$ ) de ramas y crecimiento. Sin embargo, bajo condiciones control, una de las familias de alto crecimiento (AC1) fue excepcional por sus menores niveles de pérdidas de $k_{s}$ comparado a las otras familias estudiadas, sugiriendo una menor vulnerabilidad a la cavitación y/o una mayor conductancia hidráulica o capacitancia reduciendo la tensión del xilema, lo que podría contribuir a mayores crecimientos bajo las condiciones de alta demanda evaporativa de la región de estudio. Cabe destacar que la familia AC1 es una familia de baja densidad de madera, lo que podría redundar en alta capacitancia, de acuerdo a la relación entre capacitancia y densidad reportada para otras especies leñosas (Scholz et al. 2007; Carrasco et al. 2014). Sin embargo, al no presentar la otra familia, denominada como AC2, igual estrategia para explicar los mayores crecimientos, esto sugiere que no existe una única estrategia. 
Respuestas de los grupos de familias $A C$ y $B C$ al déficit hídrico: ¿existe un compromiso entre crecimiento y resistencia a déficit hídrico?

Respecto a los tratamientos de déficit hídrico, solamente bajo la situación control (i.e. sin déficit hídrico en el suelo), las familias AC presentaron mayores crecimientos absolutos en tallo pero menores crecimientos relativos respecto a las familias BC. Bajo déficit hídrico en suelo (moderado y severo) no se observaron diferencias en crecimiento entre las familias AC y BC (Figura 2.5). Bongarten y Teskey (1987) también observaron similar comportamiento de diferencias significativas en crecimiento bajo alta disponibilidad hídrica, desapareciendo estas diferencias bajo condiciones de sequía cuando compararon procedencias de Pinus taeda de regiones más húmedas (costeras) con las de zonas más secas (continentales) en EEUU. Parece, por lo tanto, que la capacidad de diferenciarse en crecimiento entre genotipos de esta especie puede ser expresada sólo bajo condiciones hídricas óptimas del suelo pero no bajo condiciones de alguna restricción hídrica.

En cuanto a la distribución de la biomasa, algunos estudios reportan que, en respuesta a un evento de déficit hídrico, Pinus taeda incrementa la asignación de la biomasa al tallo (Gebremedhin 2003) a expensas de un decrecimiento en la biomasa de raíces, sin modificaciones en la biomasa foliar (Green et al. 1994). También Bongarten y Teskey (1987) han determinado que la distribución de la biomasa responde tanto a las condiciones hídricas en las cuales las plantas se desarrollan como a la procedencia de la misma. En el primer caso, las plantas que se desarrollan bajo condiciones de estrés presentan una mayor asignación a raíces y menor a la biomasa de tallo. Para el segundo caso, aquellas plantas que proceden de ambientes más húmedos asignan más biomasa a hojas y menos a tallos cuando se desarrollan bajo condiciones hídricas óptimas. En los resultados presentados en este capítulo no se ha encontrado una única distribución en respuesta al estrés en las familias estudiadas. Sin embargo, la asignación a raíces en respuesta al déficit hídrico decreció, al igual que en los antecedentes existentes para la especie. De este modo, y como dato relevante, se ha observado que ambas familias BC presentaron una mayor asignación de biomasa a su sistema radical ante estrés, estrategia que coincide con la teoría óptima de la distribución de la biomasa (Bloom et al. 1985), y en parte con lo determinado por 
Bongarten y Teskey (1987). Sin embargo, esta mayor asignación a raíces también se verifica en condiciones control en estas familias comparativamente con las AC, patrón que se acentúa ante déficit hídrico.

El potencial hídrico máximo se diferenció entre tratamientos de estrés, reflejando un comportamiento anisohídrico (Tardieu y Simonneau 1998), sin presentar una clara diferencia entre las familias de Pinus taeda estudiadas. Sin embargo, la especie ha sido previamente descripta como isohídrica (Hacke et al. 2000; Ewers et al. 2000) o isohidrodinámica (Gonzalez-Benecke y Martin 2010). De acuerdo con los resultados presentados en el presente capítulo, el comportamiento observado fue debido al pobre control estomático de la transpiración por las plantas, donde las mismas mantienen sus estomas parcialmente abiertos incluso a DPV tan altos como $5 \mathrm{kPa}$ (Figura 2.10 panel A). Aunque hubo una respuesta lineal de la $g_{\mathrm{s}}$ a incrementos del In(DPV), coincidiendo con lo reportado por Faustino et al. (2013) para la misma especie bajo condiciones de campo, analizando la $g_{\mathrm{s}}$ de referencia (i.e. $g_{\mathrm{s}}$ a $1 \mathrm{kPa}$ ) y la sensibilidad estomática al DPV (pendiente del modelo lineal) de los diferentes grupos de tasas de crecimiento (TC), se observó que ambas tienen una relación menor que 0,6 que es el valor predicho por modelos hidráulicos si la planta cierra sus estomas de manera de evitar pérdidas de $k_{\mathrm{s}}$ por cavitación (Oren et al. 1999). El comportamiento de la familia BC2 fue el más notable, mostrando una relación menor que las otras familias (0,45 vs. mayor a 0,5 en las otras familias), lo que indica un menor control estomático del potencial hídrico que podría redundar en pérdidas de conductividad hidráulica en mayor magnitud y/o de manera anticipada en el tiempo ante condiciones de déficit hídrico respecto a las demás familias.

Algunos genotipos de Pinus taeda han sido previamente descriptos también como insensibles al DPV, presentando mayores conductancias estomáticas que otros y además incrementando la susceptibilidad a la cavitación (Tang et al. 2003; Aspinwall et al. 2011a). En este sentido, a pesar de que no se encontró una correlación entre $k_{\mathrm{s}}$ máxima y crecimiento promedio en las familias estudiadas, esto no quiere decir que los diferentes niveles de cavitación (debido a diferencias en la regulación estomática del potencial hídrico foliar) no tengan ningún significado sobre la fijación del carbono durante el período de déficit hídrico. De esta forma, la mayor sensibilidad estomática 
al DPV encontrada en algunos genotipos por Aspinwall et al. (2011a) estuvo relacionada a una maximización de la asimilación del carbono cuando las condiciones hídricas fueron favorables y a una minimización del estrés y de las pérdidas de agua bajo condiciones desfavorables. De manera similar, la familia AC1 fue excepcional por sus menores pérdidas de $k_{\mathrm{s}}$ y el mayor crecimiento bajo condiciones control (aunque éste no difirió estadísticamente del de la familia AC2). Es importante notar, sin embargo, que no se encontraron diferencias de crecimiento entre familias bajo condiciones de déficit hídrico. Esto sugiere que la ventaja potencial de la familia AC1 en términos de sus menores pérdidas de $k_{s}$ (ya sea a causa de su comportamiento estomático, mayor conductancia hidráulica total que genere menores tensiones, mayor capacitancia y/o menor vulnerabilidad a la cavitación) no son suficientes para permitir un mejor comportamiento del crecimiento de esta familia bajo condiciones de déficit hídrico comparado a las otras familias estudiadas.

Retomando la hipótesis principal de este capítulo, el supuesto compromiso entre crecimiento o fijación de $C$ y la resistencia al déficit hídrico en especies leñosas es sugerido sobre bases relacionadas a la capacidad hidráulica de las plantas (e.g. $k_{\mathrm{s}}$ y $k_{\mathrm{l}}$ de diferentes órganos) y a la vulnerabilidad a la cavitación. A partir de los resultados de este capítulo, no es posible asignar un rol central de la $k_{\mathrm{s}}$ máxima o de la $k_{\mathrm{l}}$ de ramas para explicar las diferencias de crecimiento entre los grupos de familias. Esto hace a la hipótesis carecer de sentido desde su base. Ahora bien, si tomamos en cuenta el crecimiento absoluto dentro de cada tratamiento, y no la disminución relativa entre crecimiento máximo y mínimo de cada familia (es decir, la caída relativa en el crecimiento), pareciera ser que no existen compromisos entre crecimiento y resistencia al déficit hídrico en Pinus taeda, sino que por el contrario, existen combinaciones de caracteres, tales como aquellos en las familias AC, que permiten maximizar el crecimiento en condiciones de alta disponibilidad hídrica, y mantener cierto nivel de crecimiento (similar al de otras familias) en condiciones de estrés. Esto puede deberse a que las tasas máximas de crecimiento de estas familias no son debidas a un incremento en la capacidad de fijación del $C$ a nivel de hoja o a un incremento en la capacidad de conducción de agua a nivel de ramas, sino que son debidas al tamaño inicial de la planta (mayor superficie de fijación de $C$ ) en 
combinación con estrategias que permiten mantener su capacidad fisiológica bajo condiciones de alta demanda evaporativa (por ej. por un mayor control del potencial hídrico ante alto DPV).

\section{CONCLUSIONES}

Las diferencias de crecimiento entre plantas de diferentes grupos de crecimiento (AC vs. BC) ocurrieron solamente bajo condiciones de alta disponibilidad de agua en el suelo (condición control), mientras que todas las familias tuvieron crecimientos similares bajo condiciones de restricción hídrica (DM y DS). Estos resultados sugieren que podría ser apropiado utilizar plantas con altas tasas de crecimiento (familias AC) debido a que ellas pueden crecer más cuando las condiciones son favorables, y a igual tasa que las otras familias bajo condiciones de sequía. Al parecer, estas familias de alto crecimiento tienen una alta tasa de crecimiento inicial (en estadio de plantín) que las llevan a un mayor tamaño de planta, y en algún punto en el tiempo de su desarrollo, su crecimiento relativo puede ser similar o más bajo que el de las familias BC. Sin embargo, sus mayores tamaños les permiten una mayor acumulación de biomasa en términos absolutos comparado a las familias BC. Bajo condiciones de campo, donde las familias fueron evaluadas en el Programa de Mejoramiento Genético (PMG) y clasificadas como familias $A C$ y $B C$, diferencias de tamaños entre familias $(A C>B C)$ fueron mantenidas por lo menos hasta los 5 años de edad. Las familias AC presentaron diferentes (pero no únicos) patrones de distribución de biomasa y un relativamente alto control estomático de pérdidas de $k_{\mathrm{s}}$ comparado a las familias $\mathrm{BC}$. Aunque no se encontró una ventaja diferencial de alguna de las estrategias presentadas por AC1 y AC2 para hacer frente a las condiciones de estrés, se espera que la estrategia de la familia AC1 (alta asignación a tallo y menor pérdida de $k_{\mathrm{s}}$ ) podría ser la más eficiente en condiciones de déficit hídrico y en la utilización de los recursos ambientales disponibles. Futuros estudios son necesarios para confirmar esta hipótesis, y de ser confirmado, sería interesante determinar cuáles combinaciones de atributos son más sustentables para diferentes sitios de plantación.

Finalmente, se ha encontrado un control estomático del potencial hídrico relativamente bajo resultando en moderadas a altas pérdidas de $k_{\mathrm{s}}$ en todas las 
familias estudiadas, aún bajo condiciones de alto contenido de agua en el suelo, pero combinado con un alto DPV. Del mismo modo, otras especies seleccionadas y cultivadas por sus altas tasas de crecimiento tienen una estrategia similar, operando al límite de su umbral funcional (e.g. Eucalyptus globulus, Pita et al. 2005). Esta estrategia les permite tener altos crecimientos bajo condiciones hídricas óptimas, teniendo crecimiento significativo dentro de ciertos rangos de estrés (como los evaluados en este capítulo), pero podrían ser letales bajo condiciones de estrés que excedan estos umbrales. Esto debería ser tomado en cuenta considerando el uso de las especies en sitios marginales y/o donde el impacto potencial del déficit hídrico pueda resultar ser más severo en el marco del cambio climático. 
CAPÍTULO 3

\section{ANATOMÍA FUNCIONAL DE LA MADERA DE PROGENIES CON DISTINTAS TASAS DE CRECIMIENTO EN Pinus taeda L.}




\section{ANATOMÍA FUNCIONAL DE LA MADERA DE PROGENIES CON DISTINTAS TASAS DE CRECIMIENTO EN Pinus taeda $\mathrm{L}$.}

\section{RESUMEN}

Mediante mejoramiento genético y posiblemente debido a las distintas condiciones ambientales, se ha observado que la especie Pinus taeda puede alcanzar tasas de crecimiento superiores a las de su región de origen cuando se la cultiva en el Noreste de Argentina. Sin embargo, se desconocen los compromisos que este tipo de selección, basada en la productividad, puede tener en la resistencia al déficit hídrico y en particular en aquellos caracteres de la madera relacionados con este proceso, como es la vulnerabilidad a la cavitación. El objetivo de este capítulo fue analizar las relaciones entre anatomía del leño, densidad de la madera y su funcionalidad en distintas familias de P. taeda L. con tasas de crecimiento contrastantes entre sí (AC= alto crecimiento; $\mathrm{BC}=$ bajo crecimiento), y la variación en los caracteres estructurales de la madera ante déficit hídrico. Durante un período de cuatro meses, bajo condiciones de invernáculo, se aplicaron dos tratamientos de déficit hídrico (Moderado y Severo) más un control (con riego frecuente). Al final del período se realizaron cortes anatómicos del leño, evaluando caracteres a nivel de traqueidas individuales, proporciones de leño temprano y tardío en el anillo de crecimiento, y la densidad de la madera. Asimismo, se realizaron curvas de vulnerabilidad a la cavitación en las diferentes familias y se estimó la $k_{\mathrm{s}}$ teórica en función del tamaño de las traqueidas. Si bien ambos grupos de familias difirieron en el crecimiento absoluto $(A C>B C)$ y relativo $(B C>A C)$ del tallo bajo condiciones hídricas óptimas, no presentaron diferencias significativas en las características anatómicas del leño. Bajo la misma condición, todas las familias presentaron alta vulnerabilidad a la cavitación, sin embargo una de ellas (BC1) fue estadísticamente más resistente a la cavitación con un $P_{50}$ de $-2,1 \mathrm{MPa}$ (el $P_{50}$ promedio de las 3 familias restantes fue de $-1,7 \mathrm{MPa}$ ). Bajo condiciones de estrés el crecimiento se vio afectado, sin modificarse las variables anatómicas del leño a nivel celular. Sin embargo, la proporción de leño tardío aumentó con la intensidad del estrés. Dados los caracteres analizados en estas familias, se puede establecer que no 
existe un compromiso entre crecimiento relativo y vulnerabilidad a la cavitación. La proporción de los distintos tipos de leño fue la característica más plástica para la especie, aunque no redundó en una variación significativa en la $k_{\mathrm{s}}$ teórica. 


\section{INTRODUCCIÓN}

La madera no es un material homogéneo debido a la heterogeneidad presente a nivel de sus propiedades anatómicas. Esta heterogeneidad puede ser observada a nivel macro y microscópico. Sin embargo, el leño de las coníferas se presenta de manera más simple comparada al leño de las latifoliadas en cuanto a los elementos que la constituyen (Hacke et al. 2004). En este contexto, el 90\% del volumen xilemático total de las coníferas está constituido por traqueidas (García Esteban et al. 2003). En su sección transversal se pueden diferenciar los anillos de crecimiento, donde se distinguen dos tipos de leño formados en estaciones del año diferentes, de acuerdo a las condiciones ambientales predominantes en cada una de ellas. En líneas generales se observa el leño de primavera, comúnmente denominado como leño temprano, y el leño de verano, al cual se lo denomina como leño tardío. Estos se diferencian básicamente por su color, principalmente por las características propias de las células que la componen, donde en líneas generales, las traqueidas formadas en primavera presentan mayores diámetros de lúmenes, confiriéndoles una alta eficiencia en la conducción de agua. Por otro lado, el leño de verano presenta traqueidas de diámetros más estrechos con menor capacidad de conducción de agua (Sperry y Tyree 1990; Sperry et al. 2006). Esta característica está a su vez asociada generalmente a una mayor resistencia a la cavitación (Sperry et al. 2006). Sin embargo, hay especies, como Pseudotsuga menziesii, en las que el leño tardío es más vulnerable a la cavitación que el leño temprano (Domec y Gartner 2002; Dalla Salda et al. 2014).

Si bien las células conductoras de agua son células muertas cuando están completamente desarrolladas, éstas previamente pueden modificarse en función del ambiente dentro del cual se desarrollan (Fonti y Jansen 2012). Sin embargo, las traqueidas no solamente cumplen la función del transporte de agua en la planta, sino también constituyen el mecanismo de soporte de ésta (Sperry et al. 2006). Para esta función son características de importancia la longitud de las mismas, así como el diámetro y el espesor de pared de las células, características que influyen también en el funcionamiento del sistema hidráulico. Por otro lado, las características anatómicas de las traqueidas otorgan ciertas propiedades al leño, dentro de las cuales se destaca 
la densidad de la madera, la cual está considerada como un importante indicador de la calidad de la misma, variable requerida en la industria de la madera.

Para cuantificar la resistencia al flujo de agua en traqueidas con distintos tamaños de lúmenes usualmente se realiza una simplificación asumiendo que actúan como capilares. Esta simplificación no toma en cuenta las resistencias que ocurren a nivel de las puntuaciones que las interconectan (ver más adelante), sino sólo la que ejerce la propia pared en conductos de mayor o menor diámetro. A pesar de las limitaciones de esta aproximación, es muy utilizada como primera aproximación a la conductividad hidráulica específica teórica $\left(k_{\mathrm{ST}}\right)$, que por lo expuesto, sobrestima a la $k_{\mathrm{s}}$ real. A través de los capilares, la tasa del flujo de agua $\left(J_{\mathrm{w}}\right)$ es proporcional al gradiente de presión aplicado $(\Delta \Psi)$, creado por la transpiración, y a la conductividad hidráulica $\left(k_{\mathrm{h}}\right)$ (Zimmermann 1983). De acuerdo a la Ley de Hagen-Poiseuille, el flujo capilar es estacionario sobre la pared del capilar, incrementando su velocidad hacia el centro del mismo, causando un flujo parabólico el cual es proporcional a la cuarta potencia del radio del capilar (Zimmermann 1983). De esta manera, un pequeño incremento en el diámetro de la traqueida causa un incremento considerable (exponencial a la cuarta potencia) en la conductividad hidráulica del conducto.

En la planta, el gradiente de presión $(\Delta \Psi)$ que genera el flujo de agua, está dado por la tensión superficial a nivel foliar. Esta tensión es transmitida a través de una columna continua de agua desde las hojas a las raíces y en todas las partes del apoplasto en cada órgano de la planta (Tyree 2003). Cuando las tensiones del xilema son suficientemente negativas, ya sea por una alta demanda atmosférica y/o por una baja disponibilidad de agua a nivel de las raíces, se rompe la continuidad de la columna de agua en el conducto, siendo este evento denominado como cavitación (Tyree 2003). En la medida que las tensiones se hacen más negativas, las burbujas pueden propagarse a través de los poros que interconectan los conductos lateralmente. Estas perforaciones laterales son llamadas puntuaciones, las cuales son formadas por una discontinuidad de la pared secundaria de los elementos conductivos. Éstas pueden ser simples, mediante una interrupción abrupta de la pared secundaria, o areoladas, dadas por la separación de parte de la pared secundaria formando la cámara de la puntuación (Figura 3.1). Las puntuaciones areoladas son características en el leño de 
las gimnospermas, y por ende, en Pinus taeda. En su morfología simplificada presentan el torus y el margo, siendo el primero el que sella la puntuación aislando un conducto cavitado de otro funcional, comúnmente conocido como efecto "válvula". En este sentido, tanto el diámetro del torus como el de la apertura de la puntuación, así como las características (ej. elasticidad) de la membrana que conforma el margo, son importantes en la prevención de la cavitación en gimnospermas (Sperry et al. 2006). De acuerdo con esto, varios autores han encontrado que la resistencia a la cavitación está influenciada por la estructura de las puntuaciones, y es por ello que son tomadas en cuenta cuando se analiza la resistencia a la sequía en distintas especies (Sperry et al. 2006; Pitterman et al. 2006a; Pittermann et al. 2006b; Bouche et al. 2014).

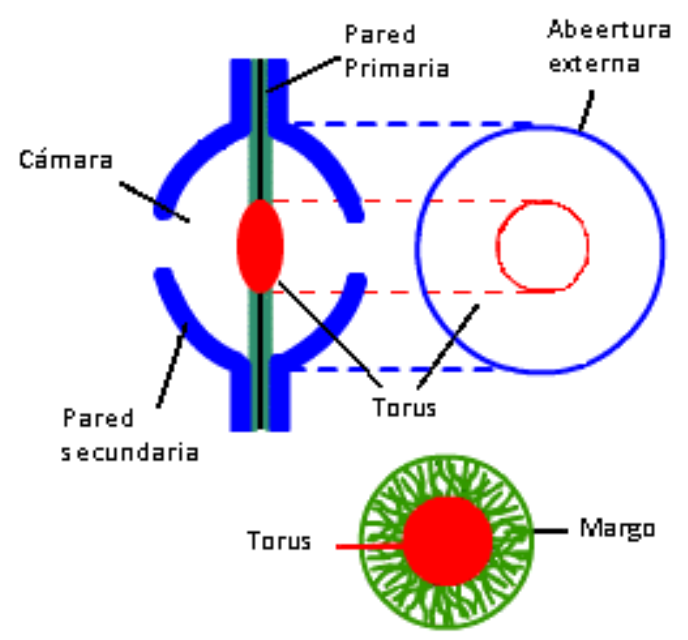

Figura 3.1 Esquema simplificado de una puntuación areolada característica en Pinus taeda L.

Por otra parte, hay un fuerte compromiso entre la seguridad hidráulica y mecánica de las traqueidas en un amplio número de especies (Bouche et al. 2014). Se ha reportado en diferentes trabajos una relación entre el diámetro del torus y el refuerzo de las traqueidas (relación entre el espesor de la pared y el diámetro de la traqueida), donde se establece que éstas son dos características importantes para estimar la resistencia a la cavitación en especies de coníferas (Hacke et al. 2001; Sperry et al. 2006; Bouche et al. 2014). Por otro lado, estos estudios mencionan que el refuerzo de la traqueida estuvo influenciado por un aumento en el espesor de la pared sin manifestar una disminución en el diámetro del lumen, resultando de esta manera en un menor 
impacto sobre la eficiencia hidráulica, tanto en especies de angiospermas como de gimnospermas.

En lo referente a la vulnerabilidad a la cavitación, ésta depende de la especie (e.g. Choat et al. 2012), y del órgano considerado. Esta variable puede ser conocida mediante la relación entre la pérdida porcentual de la conductividad hidráulica y el nivel de tensión del agua en el xilema (potencial hídrico), generándose así las curvas de vulnerabilidad a la cavitación (CVC) (e.g. Gyenge y Dalla Salda 2010). Esta puede ser trazada mediante diferentes técnicas, las cuales difieren en el modo en el cual se induce y/o se estima la cavitación. En cuanto al modo de inducir la cavitación, se encuentran por ejemplo, la deshidratación de ramas, la inyección de aire y la centrifugación. Mientras que en cuanto a la manera en que se mide la cavitación en sí, se destacan la medición del porcentaje de pérdida de conductividad hidráulica, las emisiones acústicas in vivo (Cochard et al. 2013), y más recientemente, la observación de los elementos de conducción con agua o aire a través de microtomografía (e.g. Dalla Salda et al. 2014).

El potencial hídrico al cual es reducida la conductividad hidráulica al 50\% $\left(P_{50}\right)$ es ampliamente utilizado como un indicador de la vulnerabilidad a la cavitación promedio (Meinzer et al. 2009; Choat et al. 2012; Vergeynst et al. 2014; Bouche et al. 2014). Sin embargo, las plantas operan con distintos márgenes de seguridad. Este margen de seguridad está dado por la diferencia entre el potencial hídrico mínimo $\left(\Psi_{\min }\right)$ que realmente alcanzan y el $P_{50}$. En términos generales, las angiospermas operan con márgenes de seguridad relativamente pequeños, mientras que las gimnospermas desarrollan márgenes de seguridad mayores (Meinzer y McCulloh 2013), sin embargo, no están exentas de fallas hidráulicas (Choat et al. 2012). A pesar de ello también existe una gama intermedia de innumerables ejemplos de angiospermas tolerantes (y que desarrollan grandes márgenes de seguridad), y de gimnospermas evitadoras (y que desarrollan márgenes de seguridad relativamente pequeños). Por otro lado, Hacke et al. (2001) mencionan una relación entre la densidad de la madera y el $P_{50}$, donde mayores densidades fueron asociadas con valores de $P_{50}$ más negativos tanto en angiospermas como en gimnospermas. 
En este contexto, se ha planteado como objetivo del presente capítulo determinar las relaciones existentes entre la anatomía del leño, la densidad de la madera y su funcionalidad en familias de Pinus taeda L. con tasas de crecimiento contrastantes entre sí. Asimismo, se planteó analizar la variación en los caracteres estructurales de la madera ante situaciones de déficit hídrico.

\section{MATERIAL Y MÉTODOS}

\section{Material utilizado y diseño del experimento}

De entre los materiales disponibles en el Programa de Mejoramiento Genético (PMG) del INTA fueron seleccionadas, dentro de los Huertos Semilleros Clonales (HSC) de polinización abierta, clones de dos familias con altas tasas de crecimiento (AC), y clones de dos familias con bajas tasas de crecimiento (BC). En cada grupo de tasa de crecimiento, se seleccionaron clones cuyas familias presentan densidades de madera contrastantes (mayor información del material genético en Materiales y Métodos del capítulo 2; Figura 2.3).

Las plantas provenientes de semilla cosechada de los clones de alto y bajo crecimiento fueron establecidas bajo invernáculo en contenedores de 20 litros con una mezcla de sustrato comprendiendo $1 / 3$ de arena, $1 / 3$ de suelo rojo y $1 / 3$ de material orgánico. Fueron distribuidas al azar en tres tratamientos, un control y dos intensidades de déficit hídrico, con 12 plantas por familia en cada uno. Los tratamientos fueron aplicados durante el período comprendido entre el 12 de Septiembre de 2011 y el 11 de Enero de 2012. Los detalles de este experimento han sido descriptos en forma detallada en el Capítulo 2.

\section{Variables medidas}

Al final del ensayo (enero de 2012), sobre la altura de referencia de medición del diámetro a la altura del cuello de la raíz (dac), la cual fue a $10 \mathrm{~cm}$ sobre la superficie del suelo de la maceta, fue realizado un corte transversal sobre el tallo, extrayendo una porción del mismo en tres plantas por familia y tratamiento. A partir de esta muestra, se obtuvieron cortes para el análisis histológico. Estos cortes fueron realizados en las 
secciones transversal y radial (Figura 3.2) en un micrótomo de deslizamiento (Leica SM 2400), con un espesor de corte de $40 \mu$. Estos cortes fueron posteriormente teñidos en safranina al $5 \%$ y montados en un medio de montaje rápido para microscopía (Entellan $\left.{ }^{\circledR}\right)$.

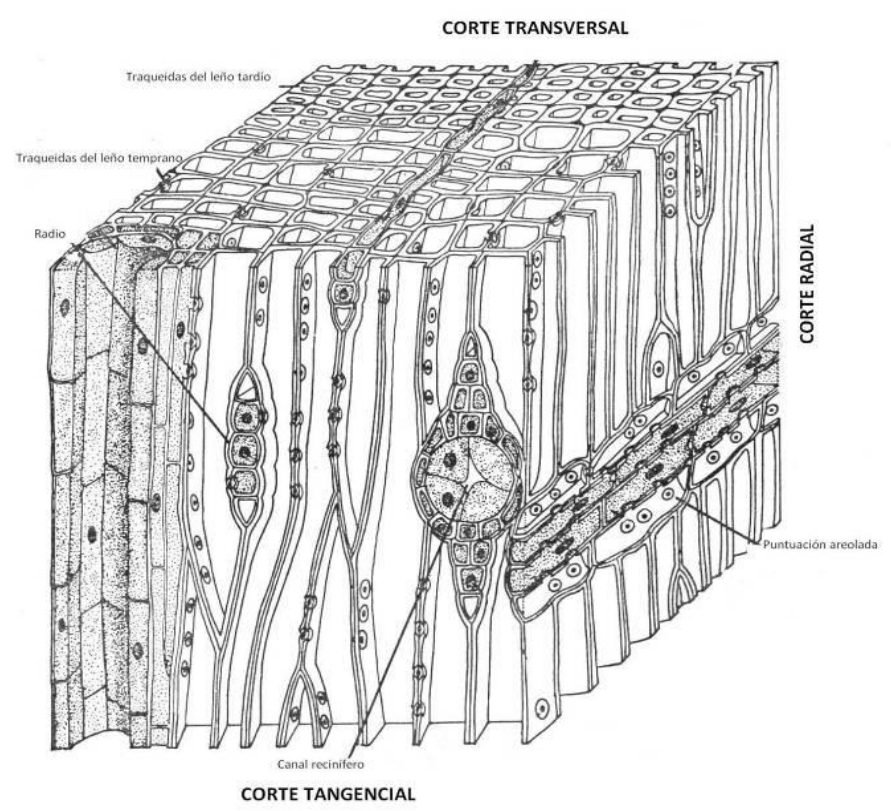

Figura 3.2 Esquema de secciones de corte y estructura microscópica del leño de una especie conífera.

Los cortes fueron fotografiados con una cámara MotiCAM 2000 montada sobre un microscopio trinocular (Carl Zeiss Modelo Pirámide Axiolab) utilizando los objetivos 4X para la medición de proporción de leño temprano y tardío (Figura 3.3 panel A) y de 10X para las mediciones de los parámetros de las traqueidas (Figura 3.3 panel B) y de las puntuaciones areoladas (Figura 3.3 panel C). En el corte transversal se realizaron las mediciones de las proporciones de leño temprano y tardío y los diámetros y espesores de pared de traqueidas, mientras que en el corte radial se realizaron las mediciones de los diámetros de las puntuaciones y del torus, así como también, la densidad de las puntuaciones. El pasaje de un tipo de leño a otro fue bastante abrupto en las muestras evaluadas, las células del leño tardío presentando paredes celulares más gruesas en relación al diámetro del lumen que las del leño temprano, lo que determinó dos patrones claros de coloración en el anillo. Por simplicidad, las células del leño de transición fueron consideradas dentro del leño temprano. Como criterio cuantitativo 
de separación se consideró como células del leño tardío a aquellas en las que el doble espesor de pared representaba $40 \%$ o más del diámetro del lúmen. No se pudo aplicar el criterio del índice de Mork (Denne, 1988), usualmente utilizado, para clasificar a las células del leño tardío, debido a que si bien se podían determinar dos grupos de células con características distintivas (ver Resultados), las del leño tardío no llegaban a cumplir el criterio de presentar doble grosor de pared igual o mayor que el diámetro del lúmen en todas las familias estudiadas. Todas las imágenes fueron analizadas con el software Movile.

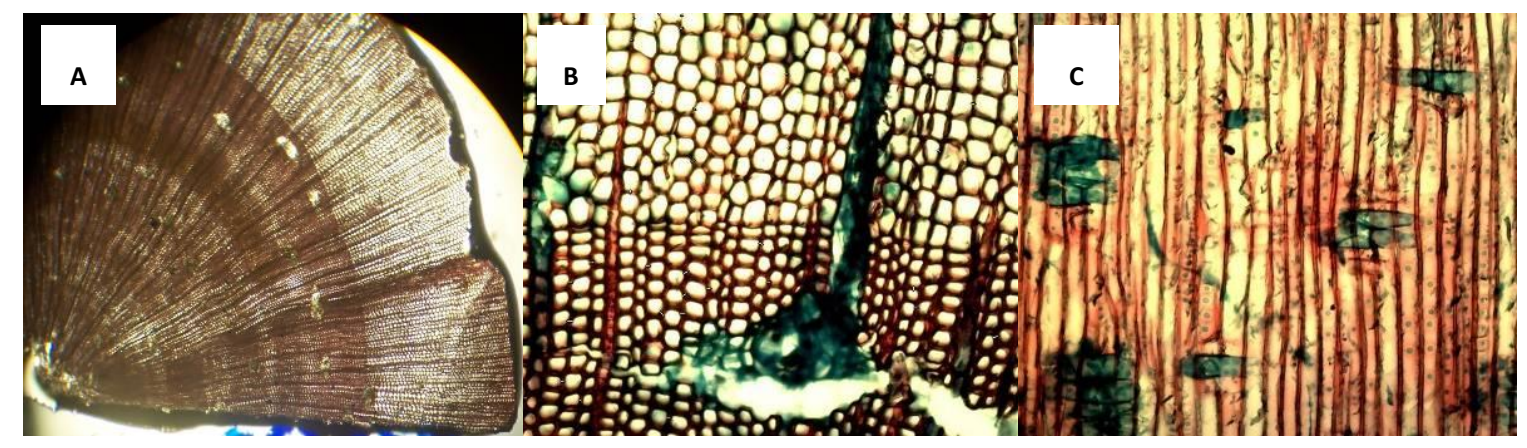

Figura 3.3 Fotografías de cortes histológicos del leño en plantines de Pinus taeda L. A) imagen tomada con un objetivo $4 \mathrm{X}$ para la estimación de la proporción de leño temprano y tardío. B) imagen tomada con un objetivo 10X para la medición de las variables anatómicas en los diferentes tipos de leño. C) imagen de corte radial tomada con un objetivo 10X para la medición de las dimensiones de las puntuaciones areoladas.

Se estimó el refuerzo de traqueidas como la relación entre el espesor de la doble pared (e) de dos traqueidas contiguas y el diámetro del lumen de la traqueida (d). Esta relación es esquematizada a continuación.

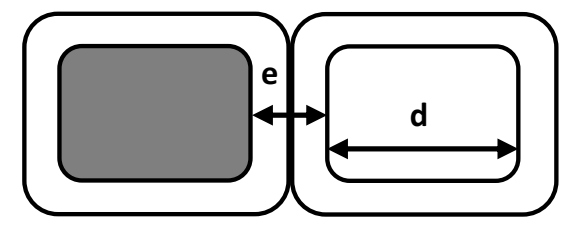

Esquema de un corte transversal de dos traqueidas contiguas de las cuales una está funcional (gris) y otra cavitada. Parámetros considerados para la estimación del refuerzo de traqueidas.

Se determinó la densidad localizada de la madera $\left(D_{\mathrm{Z}}\right)$ para cada familia dentro de cada tratamiento, siguiendo la metodología establecida por Zhu et al. (2008) (Ecuación 1). 
$D_{Z}\left(g . \mathrm{cm}^{-3}\right)=\left(\frac{4 \cdot E_{T}{ }^{2} \cdot d}{\alpha \cdot R \cdot T}\right) \cdot\left(\frac{\alpha \cdot R+T}{2 \cdot E_{T}}\right)$

Ecuación (1)

Donde $E_{\mathrm{T}}$ es el espesor tangencial de la pared, $R$ y $T$ son el diámetro radial y tangencial de la traqueida (asumidos aquí como iguales), $\alpha$ es la anisotropía del grosor de la pared en sentido radial y tangencial (asumidas aquí como células isotrópicas, $\alpha=1$ ) y $d$ es la densidad de la pared de la traqueida (asumida como $1500 \mathrm{Kg} \mathrm{m}^{-3}$ ). Zhu et al. (2008) considera a esta estimación como una densidad localizada de la traqueida. En este sentido, se ha determinado la densidad promedio a partir de las dimensiones de las traqueidas en cada tipo de leño (temprano y tardío), considerando las proporciones de cada uno de ellos para la estimación de la $D_{z}$ en el tallo para cada familia y tratamiento.

Por otro lado, se determinó la densidad básica de la madera $\left(D_{\mathrm{b}}\right)$ por el método de desplazamiento de agua en una porción del tallo próxima a la región de la medición del dac. Las muestras se prepararon individualmente y fueron colocadas en recipientes con agua destilada hasta su saturación. Posteriormente, cada muestra se introdujo en un vaso de precipitado lleno de agua colocado sobre una balanza analítica de 0,001 g de precisión, evitando siempre tocar las paredes o el fondo del recipiente para determinar el peso del agua desplazada, que corresponde al volumen en fresco de la muestra $\left(V_{\mathrm{f}}, \mathrm{cm}^{3}\right)$, considerando la densidad del agua como 1 . Posteriormente las muestras fueron llevadas a estufa a $60 \stackrel{\circ}{C}$ hasta su peso seco constante $\left(P_{\mathrm{s}}, \mathrm{g}\right)$ (Ecuación 2). Esta variable fue estimada en cuatro individuos por familia en cada tratamiento.

$$
D_{b}\left(g . c m^{-3}\right)=\left(\frac{P_{s}}{V_{f}}\right)
$$

Se trazaron curvas de vulnerabilidad a la cavitación en ramas de 4 individuos de Pinus taeda en la progenie de cada familia, solamente dentro del tratamiento control. Los diámetros de las ramas muestreadas estuvieron comprendidos entre 2,4 y 3,9 mm y sus longitudes entre 7,2 y $14,2 \mathrm{~cm}$. Las plantas fueron regadas a saturación, y temprano a la mañana siguiente, posterior a la medición del potencial hídrico foliar para corroborar la hidratación de la misma, se realizó el corte de la rama. Estas fueron sumergidas en agua y vueltas a cortar, seleccionando una porción media por encima 
de aproximadamente $10 \mathrm{~cm}$ de la base de la rama. El método de inducción a la cavitación utilizado fue el de inyección de aire (e.g. Gyenge y Dalla Salda 2010) mediante una cámara de presión o bomba de Scholander (Bio-Control) de hasta 6 MPa. La conductividad hidráulica máxima $\left(k_{\max }\right)$ fue considerada como la primera medición de $k_{\mathrm{h}}$ con la rama completamente hidratada, con valores de potencial hídrico foliar entre -0,1 y -0,3 MPa. Para cada punto de la curva, la presión fue aplicada por cinco minutos dentro de la cámara de cavitación, en un rango de 0,2 a $5 \mathrm{MPa}$ a intervalos de presión de 0,5 MPa aproximadamente, para luego ser liberada para la posterior medición de la conductividad hidráulica específica $\left(k_{\mathrm{s}}, \mathrm{kg} \mathrm{m}^{-1} \mathrm{~s}^{-1} \mathrm{MPa}^{-1}\right)$. Esta fue medida a través del método de perfusión, utilizando una pipeta graduada colocada $1 \mathrm{~m}$ por encima del segmento de la rama, y conectada a la misma por una manguera transparente de manera de poder observar la ausencia de burbujas de aire dentro del sistema de medición. Se tomó como dato válido una vez alcanzada la estabilización de la $k_{\mathrm{s}}$, lo cual en líneas generales se manifestó aproximadamente entre 10 y 15 minutos para cada punto de medición. Se estimó el porcentaje de pérdida de conductividad hidráulica (PCH) de acuerdo a la ecuación 3.

$$
\operatorname{PCH}(\%)=100 \cdot \frac{\left(k_{\max }-k\right)}{k_{\max }}
$$

Se determinó la conductividad hidráulica específica teórica $\left(k_{\mathrm{sT}}, \mathrm{Kg} \mathrm{m}^{-1} \mathrm{~s}^{-1} \mathrm{MPa}^{-1}\right)$ según la ley de Hagen-Poiseuille (Ecuación 4) (Zimmermann 1983) en las diferentes familias dentro de cada tratamiento.

$$
k_{s T}\left(K g \cdot m^{-1} \cdot s^{-1} \cdot M P a^{-1}\right)=\frac{\left(r^{4} \cdot \pi\right)}{8 \cdot \eta}
$$

Donde $r$ es el radio de la traqueida, y $\eta$ es la viscosidad del líquido $\left(1,002 \times 10^{-9} \mathrm{MPa} \mathrm{s}^{-}\right.$ $\left.{ }^{1}\right)$. Para el cálculo de esta variable fueron considerados los valores promedios de los diámetros de lúmenes de las traqueidas en cada tipo de leño, temprano y tardío, tomando además en consideración las proporciones de cada uno de ellos para el cálculo de la $k_{s t}$ del anillo completo. 


\section{Análisis estadísticos}

Los datos fueron analizados mediante análisis de varianza (ANOVA). Para las variables densidad localizada $\left(D_{\mathrm{z}}\right)$ y densidad básica $\left(D_{\mathrm{b}}\right)$ de la madera, proporciones de leño temprano y tardío, diámetros de traqueidas, espesor de pared, conductividad hidráulica máxima $\left(K_{\max }\right)$ y teórica $\left(K_{\mathrm{s}}\right)$ se utilizaron como factores principales tasa de crecimiento (TC) y familia (F). En los casos donde el ANOVA fue significativo $(p<0,05)$, la comparación de medias fue realizada mediante tests de Tukey $(\alpha=0,05)$.

El modelo ajustado a los datos de las curvas de pérdida porcentual de conductividad hidráulica corresponde a una ecuación sigmoidea exponencial (Pammenter y Vander Willligen 1998) (Ecuación 5).

$$
P C H \frac{100}{1+(a(\Psi-b))}
$$

Ecuación (5)

Donde $\Psi$ corresponde al potencial hídrico y $a$ y $b$ son constantes. La primera constante está relacionada a la pendiente de la curva, determinando el rango de potencial hídrico sobre el cual la conductividad hidráulica se pierde más abruptamente. La segunda constante determina la posición de la curva sobre la abscisa que corresponde al potencial hídrico al cual se produce el $50 \%$ de pérdida de conductividad hidráulica $\left(P_{50}\right)$ en el xilema, en este caso de la rama.

\section{RESULTADOS}

\section{Evaluación del material genético a través de la progenie}

Como se describió en el Capítulo 2, los grupos de familias clasificadas por tasas de crecimiento fueron estadísticamente diferentes entre sí al inicio del ensayo (Tabla 2.2 y Tabla 3.1). El grupo de familias seleccionadas por sus altas tasas de crecimiento (grupo de familias AC) presentaron mayores tamaños de plantas, en valores absolutos, respecto al grupo de las familias BC. Estas diferencias de tamaño de plantas entre grupos fueron observadas para ambas variables, altura total y dac, con excepción de las familias $A C 2$ y $B C 2$ que no presentaron diferencias significativas entre ellas para la variable dac. Dentro del grupo de familias AC se observaron diferencias estadísticas significativas entre ellas para la variable altura total, sin embargo, las familias del grupo 
$\mathrm{BC}$ fueron similares entre sí para esta variable. En lo que se refiere a la variable dac, no se encontraron diferencias significativas entre las familias dentro de cada grupo de tasa de crecimiento al inicio del ensayo (Tabla 3.1, y datos en capítulo 2).

Tabla 3.1 Características de la progenie del material genético seleccionado del Huerto Semillero Clonal (HSC) del Programa de Mejoramiento Genético (PMG) del INTA, Misiones. Altura total $\left(h_{t}, m\right), y$ diámetro a la altura del cuello (dac, $\mathrm{mm}$ ) al inicio del ensayo, densidad básica $\left(D_{\mathrm{b}}, \mathrm{g} \mathrm{cm}^{-3}\right)$ y densidad localizada de Zhu $\left(D_{z}, \mathrm{~g} \mathrm{~cm}^{-3}\right)$, promedios \pm desvío estándar en las familias AC1 y AC2: progenies con alta tasa de crecimiento, $\mathrm{BC1}$ y $\mathrm{BC2}$ : progenies con baja tasa de crecimiento. Letras en negrita indican diferencias significativas $(\alpha=0,05)$.

\begin{tabular}{lcccc}
\hline Familia & $\boldsymbol{h}_{\mathbf{t}}$ & dac & $\boldsymbol{D}_{\mathbf{b}}$ & $\boldsymbol{D}_{\mathbf{z}}$ \\
\hline AC1 & $0,74 \pm 0,15 \mathrm{a}$ & $7,5 \pm 1,4 \mathrm{a}$ & $0,289 \pm 0,03$ & $0,547 \pm 0,08$ \\
AC2 & $0,65 \pm 0,15 \mathrm{~b}$ & $7,2 \pm 1,7 \mathrm{ab}$ & $0,283 \pm 0,02$ & $0,508 \pm 0,09$ \\
$\mathbf{B C 1}$ & $0,52 \pm 0,10 \mathrm{c}$ & $6,1 \pm 1,2 \mathrm{c}$ & $0,300 \pm 0,05$ & $0,411 \pm 0,05$ \\
$\mathbf{B C 2}$ & $0,50 \pm 0,83 \mathrm{c}$ & $6,4 \pm 1,2 \mathrm{bc}$ & $0,298 \pm 0,01$ & $0,482 \pm 0,03$ \\
\hline $\boldsymbol{P}_{\text {TC }}$ & $<\mathbf{0 , 0 0 0 1}$ & $<\mathbf{0 , 0 0 0 1}$ & 0,396 & $\mathbf{0 , 0 3 1}$ \\
$\boldsymbol{P}_{\boldsymbol{F}}$ & $\mathbf{0 , 0 1 9}$ & 0,496 & 0,865 & 0,084 \\
\hline
\end{tabular}

Los valores promedios estimados de densidad de la madera variaron en función de la metodología utilizada para la determinación de dicha variable. La densidad básica estimada mediante el método por desplazamiento de agua $\left(D_{\mathrm{b}}\right)$ fue inferior a la densidad localizada $\left(D_{z}\right)$ estimada según la metodología de Zhu et al. (2008) en todas las familias (Tabla 3.1), cuyos valores generales promedios fueron de 0,292 \pm 0,03 g $\mathrm{cm}^{-3}$ para la $D_{\mathrm{b}}$ y $0,487 \pm 0,08 \mathrm{~g} \mathrm{~cm}^{-3}$ para la $D_{\mathrm{z}}$.

Los valores de densidad básica no fueron afectados por los factores analizados (TC y F), mientras que la densidad localizada $\left(D_{z}\right)$ fue afectada únicamente por el factor TC. En este sentido, las familias del grupo AC presentaron en promedio mayor $D_{Z}$ respecto a las familias del grupo BC.

\section{Anatomía de la madera en progenies con tasas de crecimiento diferenciales}

Los valores promedios de las variables anatómicas del leño en las diferentes familias estudiadas, bajo condiciones hídricas óptimas, pueden observarse en la Tabla 3.2. A los 18 meses de edad de las plantas se observa que los factores TC y F no influyeron en las 
características anatómicas del leño de Pinus taeda L. Los elementos correspondientes al leño temprano presentaron valores promedios con tendencia a diámetros de traqueidas superiores y espesor de pared inferior respecto al leño tardío. Sin embargo, no se observaron diferencias significativas entre familias $A C$ y $B C$ dentro de cada tipo de leño. Para cada grupo de familias, los valores promedios de diámetro de traqueida de leño temprano y tardío fueron de $20,9 \pm 3,9 \mu \mathrm{m}$ y $13,2 \pm 1,6 \mu \mathrm{m}$, respectivamente para las familias $A C$ y de $21,5 \pm 3,0 \mu \mathrm{m}$ y $15,1 \pm 2,3 \mu \mathrm{m}$, respectivamente para las familias BC; mientras que el espesor de pared del leño temprano y tardío fue de 2,3 \pm $0,5 \mu \mathrm{m}$ y $3,5 \pm 0,6 \mu \mathrm{m}$ para el grupo de familias $A C$, y de $2,0 \pm 0,5 \mu \mathrm{m}$ y $3,2 \pm 0,8 \mu \mathrm{m}$ para el grupo de familias BC. Entre grupos de tasas de crecimiento no se observaron diferencias estadísticas para ninguno de los parámetros antes mencionados (Tabla 3.2).

Tabla 3.2 Variables anatómicas, bajo condiciones hídricas óptimas, en familias de Pinus taeda seleccionadas del Huerto Semillero Clonal (HSC) del Programa de Mejoramiento Genético (PMG) del INTA, Misiones. Diámetro de traqueida en leño temprano ( $\left.\mathrm{DT}_{\mathrm{Tem}}, \mu \mathrm{m}\right)$; diámetro de traqueida en leño tardío $\left(D T_{T a r}, \mu \mathrm{m}\right)$; espesor de pared de traqueidas en leño temprano $\left(E P_{\mathrm{Tem}}, \mu \mathrm{m}\right)$; espesor de pared de traqueidas en leño tardío (EPTar, $\mu \mathrm{m})$; diámetro de puntuaciones $\left(D_{\mathrm{P}}, \mu \mathrm{m}\right)$; diámetro del torus de la puntuación $\left(D_{\mathrm{T}}, \mu \mathrm{m}\right)$. Promedios \pm desvío estándar en las familias AC1 y AC2: familias con alta tasa de crecimiento, BC1 y BC2: familias con baja tasa de crecimiento.

\begin{tabular}{|c|c|c|c|c|c|c|}
\hline Familia & $\mathrm{DT}_{\mathrm{Tem}}$ & $\mathrm{DT}_{\mathrm{Tar}}$ & $\mathrm{EP}_{\mathrm{Tem}}$ & $\mathrm{EP}_{\mathrm{Tar}}$ & $D_{\mathrm{P}}$ & $D_{\mathrm{T}}$ \\
\hline AC1 & $19,8 \pm 3,0$ & $13,0 \pm 1,7$ & $2,1 \pm 0,5$ & $3,7 \pm 0,4$ & $12,9 \pm 1,55$ & $5,87 \pm 0,77$ \\
\hline $\mathrm{AC2}$ & $22,2 \pm 5,0$ & $13,5 \pm 1,6$ & $2,4 \pm 0,5$ & $2,9 \pm 0,6$ & $13,3 \pm 1,55$ & $5,86 \pm 0,35$ \\
\hline BC1 & $21,2 \pm 2,1$ & $15,9 \pm 1,7$ & $1,7 \pm 0,3$ & $3,0 \pm 0,8$ & $13,8 \pm 0,35$ & $5,29 \pm 0,23$ \\
\hline $\mathrm{BC2}$ & $21,9 \pm 4,1$ & $13,5 \pm 3,1$ & $2,3 \pm 0,5$ & $3,7 \pm 0,6$ & $13,2 \pm 1,50$ & $5,26 \pm 0,39$ \\
\hline $\boldsymbol{P}_{T C}$ & 0,706 & 0,091 & 0,235 & 0,558 & 0,543 & 0,039 \\
\hline$P_{F}$ & 0,748 & 0,198 & 0,146 & 0,277 & 0,862 & 0,285 \\
\hline
\end{tabular}

El diámetro de la puntuación, no fue afectado por ninguno de los factores analizados (TC y F). Los valores promedios de los diámetros de las puntuaciones para cada grupo de familias fueron de $11,0 \pm 3,43$ y de $11,4 \pm 3,59 \mu$ m para $A C$ y $B C$, respectivamente bajo condiciones hídricas óptimas. Respecto al diámetro del torus, éste sí fue afectado por la tasa de crecimiento bajo condiciones hídricas óptimas, resultando el grupo de familias de alta tasa de crecimiento (AC) con mayores diámetros de torus respecto a 
las familias de bajo crecimiento (BC). Los valores promedios fueron de 5,87 $\pm 0,54 \mu \mathrm{m}$ para el grupo de familias AC y de 5,27 $\pm 0,29 \mu \mathrm{m}$ para el grupo de familias BC.

Respecto a la proporción de los diferentes tipos de leño que componen el anillo de crecimiento, ésta fue afectada de manera significativa por los factores tasa de crecimiento y familia (Figura 3.4). De manera contraria a lo esperado, las familias del grupo AC presentaron mayores proporciones de leño tardío, y por ende, menor proporción de leño temprano, respecto a las familias del grupo BC. Para ambos tipos de leño no se manifestaron diferencias entre las familias dentro de cada grupo de tasa de crecimiento.

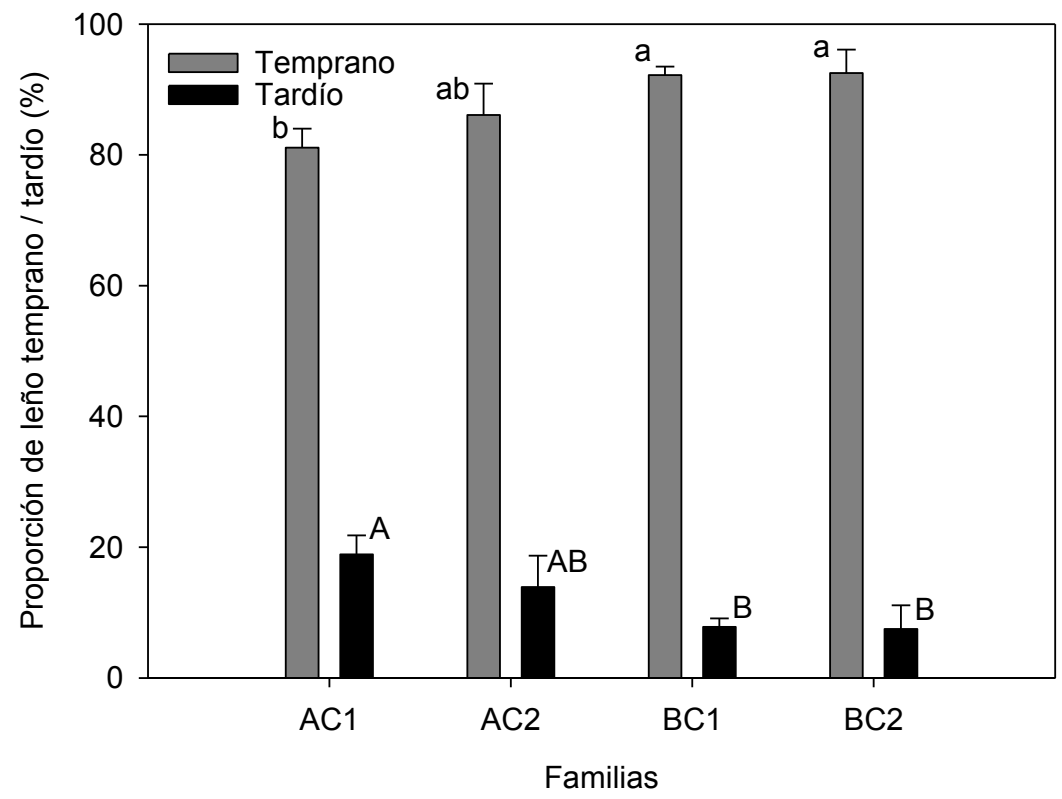

Figura 3.4 Proporción de leño temprano y tardío en plantines de Pinus taeda L. a los 18 meses de edad en las familias AC1 y AC2: progenies con alta tasa de crecimiento, BC1 y BC2: progenies con baja tasa de crecimiento. Letras minúsculas distintas indican diferencias significativas para el leño temprano y letras mayúsculas distintas indican diferencias significativas para el leño tardío.

\section{Funcionalidad de la madera}

Los valores promedios de $k_{\mathrm{s}}$ máxima ( $k_{\mathrm{smax}}$ ) no fueron afectados por ninguno de los factores analizados (TC y F). Sin embargo, se pudo observar una tendencia a que las familias $\mathrm{BC}$ presentaron una mayor $k_{\text {smax }}$ respecto a las $\mathrm{AC}$, cuyos valores promedios fueron $0,488 \pm 0,12$ y $0,652 \pm 0,22 \mathrm{~kg} \mathrm{~m}^{-1} \mathrm{~s}^{-1} \mathrm{MPa}^{-1}$ para $\mathrm{AC}$ y $\mathrm{BC}$, respectivamente. 
Estos valores encontrados coinciden con la mayor proporción de leño temprano en las familias BC (Figura 3.4), variable ésta que ha sido afectada por ambos factores analizados. Los valores promedios por familia para las plantas bajo condiciones control fueron $0,534 \pm 0,12 ; 0,442 \pm 0,11 ; 0,695 \pm 0,28$ y $0,610 \pm 0,17$ para las familias AC1, $A C 2, B C 1$ y $B C 2$, respectivamente.

\section{Curvas de vulnerabilidad a la cavitación}

Las curvas de vulnerabilidad a la cavitación para cada familia pueden observarse en la Figura 3.5, cuyos parámetros están descritos en la Tabla 3.3.

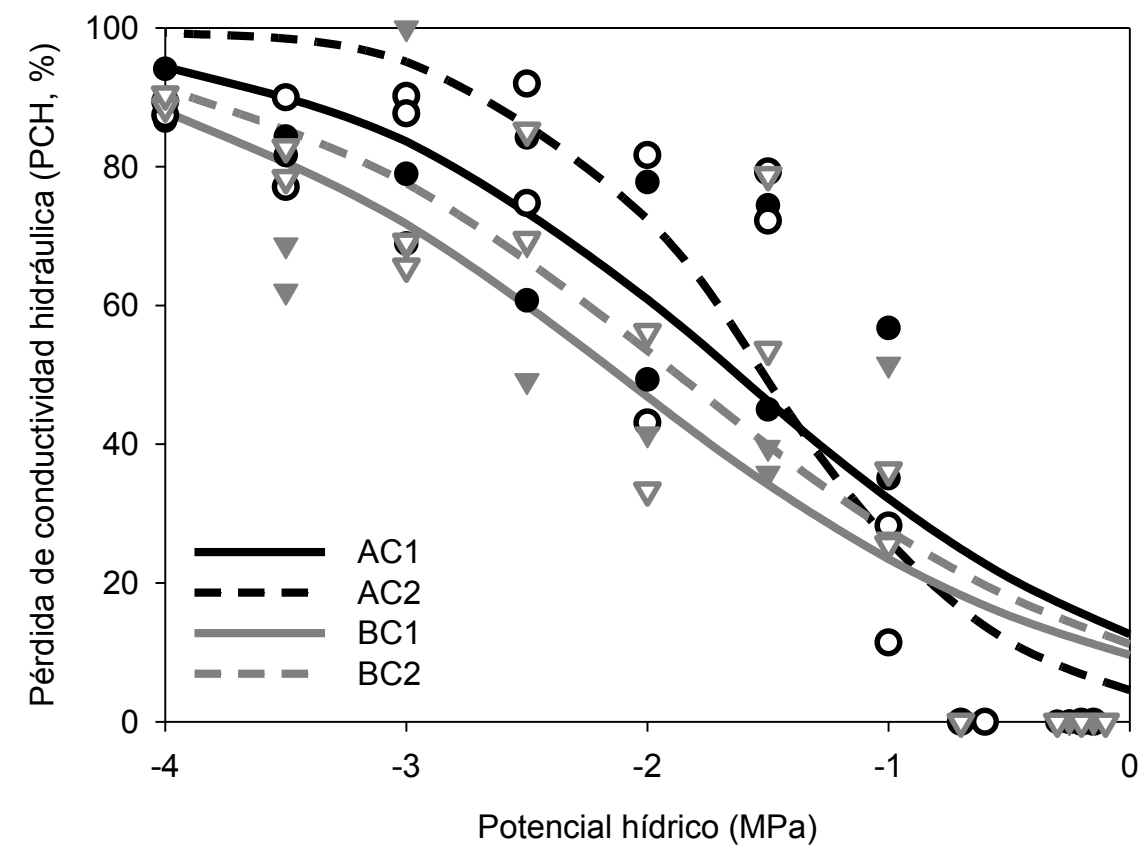

Figura 3.5 Curvas de vulnerabilidad a la cavitación en las diferentes familias de Pinus taeda L. Relación entre el porcentaje de pérdida de conductividad hidráulica y el incremento de la presión en el xilema. Familias AC1 (círculos cerrados) y AC2 (círculos abiertos) seleccionadas por su alta tasa de crecimiento. Familias BC1 (triángulos cerrados) y BC2 (triángulos abiertos) seleccionadas por su baja tasa de crecimiento.

En líneas generales, las familias catalogadas como de alto crecimiento (AC1 y AC2) muestran una tendencia a ser más vulnerables a la cavitación, mostrando menores valores absolutos de $P_{50}$, respecto a las familias catalogadas como de bajo crecimiento ( $\mathrm{BC1}$ y $\mathrm{BC2}$ ). De esta manera se manifiesta un compromiso general entre crecimientoresistencia a la cavitación. Sin embargo, estadísticamente se observó que solamente la 
familia BC1 fue diferente de ambas familias AC, siendo de esta manera la de mayor resistencia a la cavitación. De acuerdo con los parámetros evaluados en las curvas de vulnerabilidad a la cavitación, la familia AC2 se manifestó como la más vulnerable a la cavitación, diferenciándose de ambas familias de bajo crecimiento. En este sentido, la familia AC2 presentó una mayor pendiente $(-2,0)$, produciéndose un $50 \%$ de pérdida de conductividad hidráulica $\left(P_{50}\right)$ a un potencial hídrico de tan sólo 1,5 MPa (Tabla 3.3).

Tabla 3.3 Parámetros de seguridad hidráulica de cada familia bajo condiciones hídricas óptimas. Pendiente de la curva de vulnerabilidad a la cavitación; potencial hídrico al que se produce un $50 \%$ de pérdida de $\boldsymbol{k}_{\mathrm{s}}\left(P_{50}, \mathrm{MPa}\right) ; \mathbf{R}^{2}$ ajustado y resultado del test $F(\alpha=0,05)$ aplicado para comparar los modelos completos ajustados a cada familia, donde letras similares indican que no hay diferencias entre los modelos de las familias consideradas. Familias AC1 y AC2: seleccionadas por su alta tasa de crecimiento, familias BC1 y BC2: seleccionadas por su baja tasa de crecimiento.

\begin{tabular}{lcccc}
\hline Familia & Pendiente & $\boldsymbol{P}_{\mathbf{5 0}}$ & $\mathbf{R}^{\mathbf{2}}$ ajustado & Test $\mathbf{F}$ \\
\hline AC1 & $-1,2 \pm 0,22$ & $1,6 \pm 0,16$ & 0,84 & $\mathrm{ab}$ \\
AC2 & $-2,0 \pm 0,45$ & $1,5 \pm 0,13$ & 0,83 & $\mathrm{a}$ \\
BC1 & $-1,0 \pm 0,18$ & $2,1 \pm 0,17$ & 0,81 & $\mathrm{c}$ \\
BC2 & $-1,1 \pm 0,19$ & $1,9 \pm 0,17$ & 0,82 & $\mathrm{bc}$ \\
\hline
\end{tabular}

Respecto al refuerzo promedio determinado para las traqueidas al final del período evaluado (a los 18 meses de edad de las plantas), no se han encontrado efectos de los factores analizados (TC $p=0,567$ y F $p=0,131$; Figura 3.6), posiblemente debido a la alta variabilidad de los datos entre las familias. 


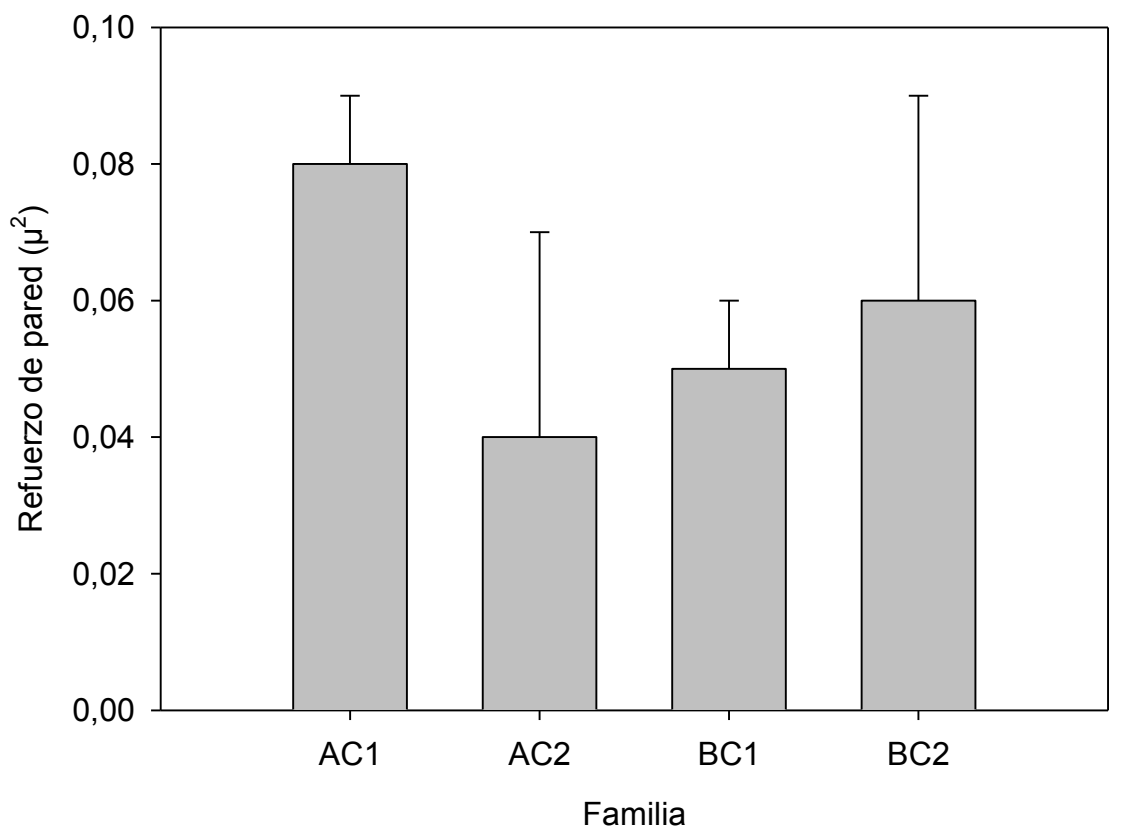

Figura 3.6 Refuerzo de pared $\left((\mathrm{e} / \mathrm{d})^{2}, \mu^{2}\right)$ promedio para plantines de Pinus taeda a los 18 meses de edad bajo condiciones control.

\section{Efecto del déficit hídrico sobre la anatomía funcional de la madera}

Los diámetros de traqueidas, tanto en leño temprano como tardío, no se modificaron cuando las plantas fueron sometidas a déficit hídrico, ya que no se observaron diferencias para este parámetro entre los tratamientos analizados (Tabla 3.4 con los resultados de los 2 tratamientos de déficit) incluyendo al control en el análisis (Tabla 3.2). Sin embargo, para la variable espesor de pared, se observó un efecto del factor familia, en el que la familia AC1 se diferenció estadísticamente de la familia BC1. Por otro lado, el factor tratamiento no tuvo efecto sobre esta variable, al igual que sobre el diámetro de la puntuación. No se observó interacción entre los factores analizados, reflejando que todos los tratamientos actuaron de igual manera en todas las familias.

El diámetro de las puntuaciones se vio afectado solamente por el factor familia. Los valores promedios por familia para todos los tratamientos fueron de $12,2 \pm 1,34 ; 12,0$ $\pm 1,34 ; 14,0 \pm 1,63$ y $12,5 \pm 1,03 \mu \mathrm{m}$ para $\mathrm{AC} 1, \mathrm{AC2}, \mathrm{BC} 1$ y $\mathrm{BC} 2$, respectivamente, diferenciándose estadísticamente solamente la familia BC1 de las demás estudiadas. Por otro lado, el diámetro del torus fue afectado por ambos factores analizados (DH y F) y a su vez, ha manifestado interacción entre los factores (Tabla 3.4). 
Tabla 3.4 Variables anatómicas de la madera en familias de Pinus taeda bajo distintos niveles de déficit hídrico (DM: déficit moderado; DS: déficit severo; y control). Los resultados del tratamiento control (sin restricción hídrica en suelo) se presentan en la Tabla 3.2. Los análisis estadísticos (efecto de tratamiento y familia), cuyo valor de $p$ se reporta en la presenta tabla incluyeron los datos del tratamiento control en el análisis. Diámetro de traqueida en leño temprano (DTTem, $\mu \mathrm{m}$ ); diámetro de traqueida en leño tardío ( $\left.D T_{T a r}, \mu \mathrm{m}\right)$; espesor de pared de traqueidas en leño temprano (EP $\left.\mathrm{Pem}_{\mathrm{Te}} \mu \mathrm{m}\right)$; espesor de pared de traqueidas en leño tardío $\left(E P_{T a r} \mu \mathrm{m}\right)$; diámetro de puntuaciones $\left(D_{\mathrm{P}}, \mu \mathrm{m}\right)$; diámetro del torus de la puntuación $\left(D_{\mathrm{T}}, \mu \mathrm{m}\right)$. Promedios \pm desvío estándar en las familias AC1 y AC2: familias con alta tasa de crecimiento, BC1 y BC2: familias con baja tasa de crecimiento.

\begin{tabular}{|c|c|c|c|c|c|c|c|}
\hline Tratamiento & Familia & $\mathbf{D T}_{\mathrm{Tem}}$ & DTtar & $\mathrm{EP}_{\text {Tem }}$ & EPTar & $D_{p}$ & $D_{\text {T }}$ \\
\hline \multirow{4}{*}{ DM } & AC1 & $23,4 \pm 8,8$ & $19,4 \pm 7,9$ & $2,7 \pm 1,3$ & $4,7 \pm 1,3$ & $12,2 \pm 1,50$ & $4,8 \pm 0,73$ \\
\hline & AC2 & $20,0 \pm 6,7$ & $12,6 \pm 4,1$ & $2,3 \pm 1,0$ & $2,6 \pm 0,8$ & $11,3 \pm 0,29$ & $4,6 \pm 0,17$ \\
\hline & BC1 & $20,1 \pm 6,7$ & $13,5 \pm 4,0$ & $2,1 \pm 0,8$ & $2,5 \pm 0,8$ & $13,6 \pm 2,4$ & $5,4 \pm 0,20$ \\
\hline & BC2 & $17,3 \pm 6,6$ & $14,2 \pm 9,8$ & $2,1 \pm 0,8$ & $3,2 \pm 1,6$ & $12,4 \pm 0,63$ & $5,2 \pm 0,69$ \\
\hline \multirow{4}{*}{ DS } & AC1 & $19,3 \pm 5,3$ & $12,3 \pm 4,4$ & $2,2 \pm 1,1$ & $2,9 \pm 1,0$ & $11,4 \pm 0,97$ & $5,42 \pm 0,59$ \\
\hline & $A C 2$ & $17,8 \pm 5,2$ & $13,0 \pm 5,1$ & $1,9 \pm 0,7$ & $3,3 \pm 1,2$ & $11,5 \pm 1,18$ & $4,46 \pm 0,33$ \\
\hline & BC1 & $17,6 \pm 5,7$ & $13,2 \pm 10,3$ & $1,7 \pm 0,7$ & $3,3 \pm 1,0$ & $14,6 \pm 0,84$ & $6,68 \pm 0,19$ \\
\hline & BC2 & $20,1 \pm 7,5$ & $14,4 \pm 5,2$ & $2,3 \pm 2,4$ & $4,2 \pm 2,0$ & $11,86 \pm 0,87$ & $4,66 \pm 0,65$ \\
\hline$P_{D H}$ & & 0,168 & 0,334 & 0,383 & 0,879 & 0,115 & 0,019 \\
\hline$P_{F}$ & & 0,852 & 0,636 & 0,044 & 0,106 & 0,005 & 0,004 \\
\hline$P_{D H \times F}$ & & 0,316 & 0,189 & 0,481 & 0,486 & 0,558 & $<0,001$ \\
\hline
\end{tabular}

En este sentido, el tratamiento de déficit moderado se diferenció estadísticamente del control, presentando un menor diámetro de torus respecto al control. Los valores promedios por tratamiento fueron de $5,6 \pm 0,51,5,0 \pm 0,59$ y 5,3 $\pm 0,94 \mu \mathrm{m}$ para el control y los tratamientos de déficit moderado y severo, respectivamente.

Por otro lado, ambas estimaciones de densidad de la madera $\left(D_{\mathrm{b}}\right.$ y $\left.D_{\mathrm{z}}\right)$ fueron afectadas por el factor tratamiento (Tabla 3.5). Las plantas sometidas a déficit severo presentaron una densidad básica de la madera inferior, diferenciándose estadísticamente del déficit moderado y del control. Sin embargo, la $D_{z}$ manifestó una densidad de madera superior cuando las plantas fueron sometidas a un déficit hídrico severo, diferenciándose estadísticamente del control. 
Tabla 3.5 Densidad de la madera de las familias bajo distintos niveles de déficit hídrico (DM: déficit moderado; DS: déficit severo; y control). Los resultados del tratamiento control (sin restricción hídrica en suelo) se presentan en la Tabla 3.1. Los análisis estadísticos (efecto del tratamiento (DH) y familia (F)), cuyo valor de $p$ se reporta en la presenta tabla incluyeron los datos del tratamiento control en el análisis. Densidad básica de la madera medida en tallo $\left(D_{\mathrm{b}}, \mathrm{g} \mathrm{cm}^{-3}\right)$; densidad estimada a partir de anatomía de la madera (Zhu et al. 2008) $\left(D_{z}, \mathrm{~g} \mathrm{~cm}^{-3}\right)$. Valores promedios \pm desvío estándar en las familias AC1 y AC2: familias con alta tasa de crecimiento, BC1 y BC2: familias con baja tasa de crecimiento.

\begin{tabular}{lccc}
\hline \multirow{2}{*}{ Tratamiento } & Familia & $\boldsymbol{D}_{\mathrm{b}}$ & $\boldsymbol{D}_{\mathrm{z}}$ \\
& & & \\
\hline \multirow{3}{*}{ DM } & AC1 & $0,304 \pm 0,04$ & $0,498 \pm 0,07$ \\
& AC2 & $0,271 \pm 0,05$ & $0,544 \pm 0,10$ \\
& BC1 & $0,291 \pm 0,02$ & $0,470 \pm 0,08$ \\
& BC2 & $0,309 \pm 0,05$ & $0,656 \pm 0,16$ \\
\hline \multirow{3}{*}{ DS } & AC1 & $0,228 \pm 0,07$ & $0,703 \pm 0,14$ \\
& AC2 & $0,203 \pm 0,07$ & $0,527 \pm 0,05$ \\
& BC1 & $0,223 \pm 0,06$ & $0,593 \pm 0,11$ \\
\hline $\boldsymbol{P}_{\text {EH }}$ & BC2 & $0,287 \pm 0,02$ & $0,599 \pm 0,13$ \\
$\boldsymbol{P}_{\boldsymbol{F}}$ & & $\mathbf{0 , 0 0 7}$ & $\mathbf{0 , 0 0 6}$ \\
$\boldsymbol{P}_{\text {DH } \boldsymbol{x} \text { F }}$ & & 0,373 & 0,098 \\
\hline
\end{tabular}

La $k_{\mathrm{sT}}$ no manifestó efecto del tratamiento. Sin embargo, se observó una tendencia a disminuir dicha variable en plantas bajo restricción hídrica. Los valores promedios por tratamientos fueron de $13,5 \pm 3,7 ; 10,9 \pm 5,3$ y $10,1 \pm 3,0 \mathrm{Kg} \mathrm{m}^{-1} \mathrm{~s}^{-1} \mathrm{MPa}^{-1}$ para el control y los tratamientos déficit hídrico moderado y severo, respectivamente.

Ante la imposición del déficit hídrico, las plantas de Pinus taeda modificaron las proporciones de los diferentes tipos de leño (Figura 3.4 y Figura 3.7). Los valores promedios de la proporción de leño tardío para el conjunto de las cuatro familias fueron de 12,$0 ; 33,4$ y $54,5 \%$, mientras que para el leño temprano fueron de 88,0 ; 66,6 y $45,5 \%$, para los tratamientos control, déficit moderado y déficit severo, respectivamente, siendo estadísticamente significativas las diferencias entre los tratamientos para cada tipo de leño. Este efecto del tratamiento se verificó en todas las familias analizadas, aunque los individuos de la familia AC1 aumentaron en mayor medida la proporción de leño tardío a mayor intensidad de déficit hídrico, mientras que en menor medida lo hizo la familia BC2 para igual intensidad de estrés (Figura 3.7). 


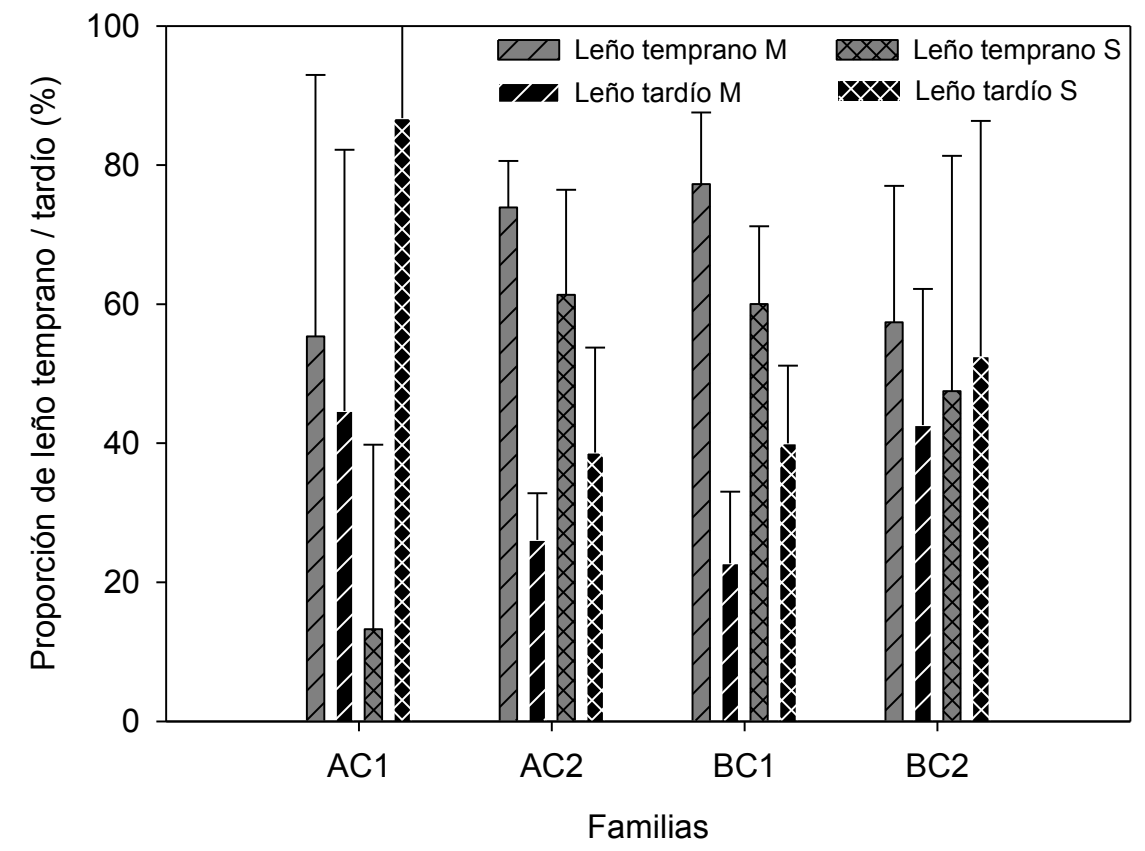

Figura 3.7 Proporción de leño temprano y tardío en plantines de Pinus taeda L. a los 18 meses de edad bajo déficit hídrico moderado (M) y severo (S). AC1 y AC2: progenies con alta tasa de crecimiento, BC1 y BC2: progenies con baja tasa de crecimiento. Los valores para la condición control se presentan en la Figura 3.4.

Tanto en el leño temprano como en el tardío no se observaron interacciones entre los factores tratamiento y familia, por lo cual se puede afirmar que todas las familias manifestaron igual variación en ambos tipos de leño frente a los distintos niveles de disponibilidad hídrica.

\section{DISCUSION}

\section{Comportamiento del material genético}

El tamaño inicial de las plantas difirió entre los grupos de familias $A C$ y $B C$ al inicio del ensayo, denotando diferencias en crecimiento anteriores a esta fecha. Estas diferencias en crecimiento absoluto se mantuvieron durante el transcurso del ensayo, sin embargo, en términos relativos al tamaño inicial de la planta, la progenie de ambas familias BC crecieron más que la progenie de las familias AC (Capítulo 2). Esta correspondencia entre la tasa de crecimiento de los árboles madres y su descendencia, no se vio verificada en la densidad de la madera. Más aún, se observó la importancia del método de determinación de esta variable, dado que los resultados difirieron entre 
ambos métodos aquí utilizados. Respecto a esta variable es necesario establecer la importancia de la heredabilidad (proporción que indica el grado en el cual los progenitores transmiten sus características a su descendencia). En este sentido, la densidad de la madera presenta pocos antecedentes a nivel regional, sin embargo, es una característica altamente heredable (Heredabilidad individual en sentido estricto alrededor de 0,5) y de baja interacción con el ambiente tanto en Eucalytus grandis (López 2005) como en Pinus elliottii var. elliottii (López y Staffieri 2003), mientras que para Pinus taeda la heredabilidad individual en sentido amplio varió entre 0,36 y 0,7 (López y Genes 2009). Conforme a la alta heredabilidad de este caracter, cabe la posibilidad de que la misma no sea manifestada a tan temprana edad, como es en este caso donde se analizaron plantas de un año y medio de edad, lo cual explicaría la falta de similitud entre progenitor y progenie para esta variable.

\section{Anatomía de la madera en progenies con tasas de crecimiento diferenciales}

Los patrones encontrados en los diferentes tipos de leño se corresponden con los valores promedios reportados en la literatura para las coníferas en general (García Esteban et al. 2003; Sperry et al. 2006; Pittermann et al. 2006b) así como también García Esteban et al. (2003) han determinado valores también similares en árboles de Pinus halepensis y Faustino et al. (2013) en individuos de Pinus taeda en particular. En este sentido, Sperry et al. (2006) encontraron diámetros de traqueidas de entre 10 a $42 \mu \mathrm{m}$ para un amplio grupo de especies de gimnospermas comprendiendo 18 especies dentro de las familias Pinaceae, Cupressaceae, Podocarpaceae y Araucariaceae. Por otro lado, Hacke y Jansen (2009) determinaron, para esta variable, valores de entre 11 y $17 \mu \mathrm{m}$ para especies de la familia Pinaceae, mientras que Pittermann et al. (2006b) determinaron valores de diámetros de traqueidas entre 15 a $35 \mu \mathrm{m}$ para varias especies del género Pinus. De manera más comparativa a los datos reportados en este capítulo, dadas las características del ensayo, se detallan los encontrados por Faustino et al. (2013), quienes determinaron valores entre 18 y $22 \mu \mathrm{m}$ para el diámetro de traqueidas en $P$. taeda de 2 años de edad en condiciones de campo para la misma región de estudio del presente trabajo. 
En cuanto a los valores de espesor de pared, Winck et al. (2015) han determinado valores promedios de 3,04 y 4,22 $\mu$ m para leño temprano y tardío respectivamente, datos pertenecientes a una plantación de Pinus taeda de 9 años de edad con diferentes intensidades de raleo. Estos autores han encontrado que el espesor de pared para esta especie presenta una variación significativa con la posición en el sentido radial, en el que cercanamente a la médula los valores promedios de espesor de pared fueron de 2,7 y $4,0 \mu \mathrm{m}$ para el leño temprano y tardío respectivamente, siendo estos valores similares a los reportados aquí.

Hacke y Jansen (2009) han reportado valores promedio de $11,6 \pm 1,0 \mu \mathrm{m}$ para el diámetro de las puntuaciones y de 5,7 $\pm 0,6 \mu \mathrm{m}$ para el diámetro del torus. Pittermann et al. (2006a) determinaron diámetros promedios de puntuaciones areoladas del leño entre 8 y $17 \mu \mathrm{m}$ para un amplio número de especies de coníferas, encontrándose al género Pinus entre valores de 10,5 y $17 \mu \mathrm{m}$ para esta variable. Los valores promedios de tamaños de puntuaciones determinados aquí están dentro de los valores citados anteriormente.

Las características anatómicas del leño de las plantas control pueden ser consideradas como la máxima expresión de cada una de las variables evaluadas. En este sentido se han encontrado diferencias significativas a favor de la progenie de las familias AC en la mayor proporción de leño tardío y el mayor diámetro del torus. Dadas estas características anatómicas encontradas entre las familias analizadas, es evidente que la densidad de la madera ha sido influenciada por las proporciones del leño tardío, más que por las características dimensionales a nivel de traqueida en cada tipo de leño, tanto temprano como tardío.

Asimismo, un resultado interesante de esta tesis es el hecho de haber encontrado diferencias en el diámetro del torus entre familias con distintas tasas de crecimiento, si bien éstas son contrarias a las indicadas por la bibliografía que postula que torus mayores se asocian a una mayor seguridad del sistema conductivo (Domec et al. 2006). En este estudio las familias más vulnerables a la cavitación, es decir las AC, fueron las que presentron mayores diámetros de torus. Se requieren estudios complementarios de las características del margo para comprender el rol funcional que esta estructura anatómica estaría teniendo en Pinus taeda. 


\section{Relación entre anatomía y funcionalidad de la madera}

Respecto a la vulnerabilidad a la cavitación, solamente se pudieron observar tendencias en los datos, sin embargo, dada la importancia de esta variable en la resistencia al estrés hídrico de los individuos en general, se resaltan las mayores vulnerabilidades en el grupo de familias $A C$, los cuales se mostraron con coherencia respecto a otras variables evaluadas, como ser los mayores diámetros de torus en las traqueidas de estas familias.

Por otro lado, Zimmermann (1983) menciona que según la ley de Hagen-Poiseuille los mayores diámetros de las traqueidas del leño temprano son los responsables de los mayores flujos de agua dentro de un anillo, coincidiendo con el comportamiento encontrado en las familias estudiadas. En este sentido, las familias con mayores $k_{\text {smax }}$ presentaron mayores proporciones de leño temprano en el tallo de la planta, mostrando además este tipo de leño mayores diámetros de lúmenes en comparación al leño tardío, con promedios generales para el diámetro de la traqueida de $21,2 \pm 3,4$ y $14,1 \pm 2,11 \mu \mathrm{m}$ para leño temprano y tardío, respectivamente. Estas características podrían resultar en individuos con mayor vulnerabilidad a la cavitación. Sin embargo, de forma contradictoria, Domec y Gartner (2002) han encontrado que la vulnerabilidad a la cavitación no necesariamente está ligada a la eficiencia en la conducción, dado que el leño temprano con mayor eficiencia en la conducción resultó en una menor vulnerabilidad a la cavitación a potenciales hídricos normales en condiciones de campo para Pseudostuga menziesii, mencionando que no existe un compromiso entre ambas variables para esa especie. No se han encontrado antecedentes que describan la vulnerabilidad diferencial del leño temprano y tardío para el caso de Pinus taeda en particular.

Respecto a valores de $P_{50}$ para otros géneros de la familia Pinaceae, éstos variaron entre 3 y $6 \mathrm{MPa}$ (Hacke y Jansen (2009). Sin embargo, los valores reportados para la especie en estudio también fueron superiores (en valor absoluto) a $3 \mathrm{MPa}$, correspondiendo a estudios realizados en la zona de origen de la especie Pinus taeda (Hacke et al. 2000; Ewers et al. 2000). Hacke et al. (2000) determinaron valores promedios de vulnerabilidad a la cavitación $\left(P_{50}\right)$ de Pinus taeda entre 3,25 y 3,8 $\mathrm{MPa}$ 
en función del tipo de suelo, coincidiendo con Ewers et al. (2000) quienes determinaron un valor promedio de $P_{50}$ de 3,5 MPa. Hacke et al. (2004) mencionan un valor de $P_{50}$ de 3,8 MPa para esta misma especie. Todos estos trabajos han sido desarrollados en individuos jóvenes de 15 años de edad. En un rango más amplio de especies de gimnospermas, Pittermann et al. (2006a) han encontrado valores de $P_{50}$ entre 1,9 MPa para la especie Agathis ovata de la familia Araucariaceae, hasta 7,8 MPa para Juniperus osteosperma de la familia Cupressaceae, sin embargo han determinado valores promedios de 3,3 y 5,5 MPa para especies del género Pinus. Para la zona de estudio, nordeste de Argentina, no se han encontrado datos de vulnerabilidad a la cavitación para la especie, por lo cual no es posible realizar una comparación más estricta de esta variable para la especie considerando los genotipos implantados en esta región.

Comparando los valores de vulnerabilidad a la cavitación reportados anteriormente con los determinados para las diferentes familias aquí estudiadas, se observa que todas las familias son muy vulnerables en la región de estudio, al menos en el estadío de vida analizado (menos de 2 años de vida). Estos resultados sugieren una gran variación en este carácter entre orígenes de Pinus taeda, y/o que podría presentar diferentes valores promedios de vulnerabilidad a la cavitación en relación a la edad y/o al ambiente en el cual se encuentre la especie, resultando ser ésta una especie de alta plasticidad fenotípica. En términos generales, y considerando las progenies evaluadas, éstas serían catalogadas como de resistencia a la cavitación moderada a baja. Comparando la curva de cavitación con los valores de potencial hídrico mínimos alcanzados por los plantines en condiciones de campo e invernáculo (ver Capítulos 2 y 6), se comprende por qué se observaron ramas con conductividad hidráulica específica nula en algunos casos, o con muy baja $k_{\mathrm{s}}$ comparativamente con la máxima medida. La baja capacidad de regulación estomática del potencial observada, especialmente en días con alta disponibilidad de agua en el suelo, hace que estas progenies operen con márgenes de seguridad muy pequeños o incluso negativos (es decir, el potencial mínimo es menor al $\left.P_{50}\right)$, característica que es compatible con el crecimiento y la supervivencia sólo en casos en los que la planta tiene mecanismos alternativos de 
compensación, como reparación de embolismos o efectos iónicos sobre la $k_{\mathrm{s}}$ (Meinzer y McCulloh 2013).

Considerando el refuerzo de pared de las traqueidas en relación con el diámetro de los lúmenes, variable relacionada con el o esfuerzo de flexión que puede soportar una pared que divide un conducto con agua de otro con aire o cavitado, cabe destacarse que la familia AC2 fue la que presentó una tendencia a un menor refuerzo de pared en comparación a las demás familias bajo condiciones hídricas óptimas, coincidiendo con el hecho de que es la familia más vulnerable a la cavitación. Los valores encontrados para esta variable se encuentran entre los valores determinados por Hack y Jansen (2009) quienes han reportado valores entre 0,05 y 0,09 para especies de los géneros Picea y Abies. Sin embargo, Hacke et al. (2001) han reportado un rango más amplio para un mayor número de especies, dentro de las familias Cupressaceae y Pinaceae, con valores de 0,07 a 0,18, abarcando en parte los valores determinados en el presente trabajo (Figura 3.6).

Por otro lado, considerando la relación entre las otras variables anatómicas de la madera y la VC, y tomando en cuenta la limitación de este análisis debido a que las mediciones de anatomía y las curvas de VC se realizaron en distintas muestras de madera, puede observarse que las familias BC, de tendencia a una menor VC, fueron las que presentaron mayor proporción de leño temprano, y menor diámetro de torus en las puntuaciones. La característica anatómica de mayor proporción de leño temprano resulta contraria a la esperada para individuos de alta resistencia a cavitar de acuerdo a la mayoría de los antecedentes bibliográficos, aunque estaría de acuerdo con los reportes ya citados en Pseudotsuga menziesii, especie en la que el leño temprano es menos vulnerable que el tardío (Domec y Gartner 2002), y en la que inclusive el leño de transición (no diferenciado en este trabajo) marcaría una diferencia crucial -por su menor vulnerabilidad- en cuanto a la VC entre progenies (Dalla Salda et al. 2014).

\section{Efecto del déficit hídrico sobre la anatomía de la madera}

Nuestros resultados evidenciaron un efecto del déficit hídrico sobre algunas de las variables anatómicas evaluadas en la madera de Pinus taeda. Se destacaron las 
modificaciones en el diámetro de torus, donde se evidenció que un déficit hídrico moderado produjo una disminución de esta variable respecto al control. Esta variable ha manifestado una interacción entre los factores familia y déficit hídrico, lo cual pone de manifiesto que no todas las familias responden de igual manera frente a un déficit hídrico, pudiendo ser más o menos plásticas en relación con esta variable anatómica que parecería clave para entender la vulnerabilidad a la cavitación en las familias estudiadas.

Otra variable de importancia, en cuanto a la hidráulica de la planta, que ha sido alterada por el déficit hídrico, fue la composición de los diferentes tipos de leño dentro del año de crecimiento. En este sentido se ha evidenciado un aumento en la proporción de leño tardío frente al déficit hídrico. La producción de células del xilema más pequeñas en respuesta al déficit de agua en la planta ha sido reportada en numerosas ocasiones (ej. Abe y Nakai 1999), aunque esto no necesariamente impacta en la proporción de leño temprano y tardío dentro del anillo de crecimiento. En este sentido, en árboles jóvenes de Pinus taeda se ha observado que el estrés hídrico en condiciones de campo, como producto de una temporada de crecimiento cálida y seca, induce la formación de leño tardío antes en el tiempo, en forma comparada a una temporada húmeda (Cregg et al., 1988). Sin embargo, la producción de células en el período seco es menor a las que se forman en un período húmedo, resultando en una proporción de leño tardío menor en el conjunto del anillo en la temporada seca (Cregg et al. 1988), lo que contrasta con los resultados hallados en esta tesis en la misma especie, pero en estadíos más tempranos del desarrollo. Por otro lado, comparando las diferentes familias analizadas, se ha enontrado una tendencia a un mayor aumento de esta proporción de leño tardío en los genotipos de la familia AC1 frente a un déficit hídrico. En el otro extremo se destacan los genotipos de la familia BC2 con una tendencia a un menor aumento de esta proporción de leño tardío frente a una situación de deficiencia hídrica, denotando nuevamente diferente grado de plasticidad fenotípica entre familias. 


\section{CONCLUSIONES}

Las familias AC, seleccionadas por la mayor tasa de crecimiento de los árboles progenitores, condición que se reflejó en el tamaño de las plantas al inicio del ensayo, no presentaron sin embargo, el mayor crecimiento relativo durante el período evaluado y bajo condiciones de alta disponibilidad de agua en el suelo. Por el contrario, ambas familias $B C$ fueron las que más crecieron en términos relativos a su tamaño inicial (resultados presentados en Capítulo 2). Estas diferencias en crecimiento no se reflejaron en términos generales en la anatomía del leño. Las variables morfológicas a nivel de traqueidas no presentaron diferencias entre las familias (excepto para el diámetro del torus). Sin embargo, la principal diferencia en cuanto al leño fue encontrada en las proporciones de los diferentes tipos de leño. Las familias del grupo BC presentaron mayor proporción de leño temprano bajo la condición control, así como también manifestaron una tendencia a tener una mayor $k_{\text {smax }}$ la cual si bien no fue estadísticamente significativa, sin embargo podría explicar, al menos en parte, las diferencias en crecimiento relativo encontradas entre familias.

En cuanto a la vulnerabilidad a la cavitación, las familias del grupo BC mostraron una tendencia a ser más resistentes, debido a que ambas familias presentaron menores pendientes y mayores potenciales hídricos promedios al cual manifestaron el $50 \%$ de pérdida de conductividad hidráulica, comparado a las familias del grupo AC. Sin embargo, únicamente la familia AC2 resultó ser estadísticamente la más vulnerable a la cavitación en comparación a las demás familias estudiadas. Cabe destacarse que esta familia se destacó por una mayor asignación a área foliar (resultado presentado en Capítulo 2), lo que constituye un caracter compatible con altas tasas potenciales de crecimiento, pero que en conjunto con su mayor vulnerabilidad a la cavitación podría resultar en una menor tolerancia ante condiciones de déficit hídrico más severas que los ensayadas en este estudio.

Hasta este punto del análisis se puede concluir entonces que no existe un compromiso entre crecimiento (relativo)-eficiencia de conducción $\left(k_{\text {smax }}\right)$ y vulnerabilidad a la cavitación, al menos para algunas familias de la especie Pinus taeda, cuando las condiciones hídricas son óptimas. 
Considerando la respuesta plástica de las características anatómicas del leño ante déficit hídrico, se observó que aquellas referidas a nivel de traqueidas individuales no se vieron afectadas por los tratamientos de estrés, presentando iguales parámetros tanto en condiciones control como bajo déficit hídrico. Sin embargo, las proporciones de los diferentes tipos de leño fueron afectados por ambos factores analizados, tratamiento y familia, sugiriendo que éste es el carácter más plástico ante condiciones ambientales cambiantes y a su vez es el más variable genéticamente. En este sentido, la aplicación del déficit hídrico provocó un aumento de la proporción de leño tardío en todas las familias, destacándose a su vez la familia AC1, la que presentó la mayor proporción de este tipo de leño. Estos cambios en la proporción de leño temprano y tardío ante déficit hídrico se reflejó en la estimación de la densidad de madera $\left(D_{z}\right)$, que aumentó especialmente ante la imposición del déficit severo. Esta tendencia no se vio reflejada, sin embargo, en la medición directa de la densidad con el método de desplazamiento de agua $\left(D_{\mathrm{b}}\right)$, posiblemente debido a la influencia en este último de otras partes del tallo no consideradas en la estimación de $D z$, como ser la corteza, el floema y la médula.

Por otro lado, las modificaciones encontradas a nivel de proporción de tipos de leño en los diferentes tratamientos no modificaron de manera significativa la $k_{\mathrm{s}}$ teórica $\left(k_{\mathrm{s}}\right)$. Sin embargo, se detectó una tendencia a disminuir la $k_{\mathrm{s}}$ cuando las plantas fueron sometidas a déficit hídrico, siendo esta disminución mayor con la intensidad del estrés. Se desconoce qué consecuencias pueden tener estos cambios sobre la vulnerabilidad a la cavitación del xilema, por lo que se requieren estudios futuros de esta variable en respuesta a condiciones de estrés. 
CAPÍTULO 4

\section{EFECTO DEL MOMENTO DE OCURRENCIA DEL DÉFICIT HÍDRICO SOBRE EL CRECIMIENTO DE PLANTINES DE PinUS taeda $\mathrm{L}$.}




\section{EFECTO DEL MOMENTO DE OCURRENCIA DEL DÉFICIT HÍDRICO SOBRE EL CRECIMIENTO DE PLANTINES DE Pinus taeda $\mathrm{L}$.}

\section{RESUMEN}

En el marco del cambio climático se predice una mayor frecuencia de eventos de sequía en la región de cultivo de Pinus taeda en Argentina, lo que se sobreimpone a la expansión de la misma a suelos con menor capacidad de retención hídrica. Existen antecedentes acerca de la respuesta de esta especie al déficit hídrico, aunque se desconoce el efecto del momento de ocurrencia del mismo, aspecto que fue evaluado en el presente capítulo. Además de la situación control, se impuso déficit hídrico a plantines por restricción del riego al inicio de la primavera, al final de la misma y en el verano. Se midió periódicamente el crecimiento en altura total $\left(h_{\mathrm{t}}\right)$ y el diámetro basal del tallo (dac), y al final del ensayo se analizó la producción y partición de biomasa aérea, y la anatomía de las hojas. Durante la primavera se determinaron el potencial hídrico foliar, la conductancia estomática $\left(g_{s}\right)$, la capacidad fotosintética, la conductividad hidráulica específica de ramas $\left(k_{\mathrm{s}}\right)$ y la capacidad de ajuste osmótico. El déficit de agua en el suelo durante la primavera afectó negativamente el crecimiento en altura y dac, con distinta capacidad de recuperación en función del momento de ocurrencia del déficit. El estrés en verano no afectó de manera significativa el crecimiento. La disminución del crecimiento en primavera se vio acompañada por cambios a nivel foliar ( $A_{\mathrm{sat}}, g_{\mathrm{s}}$, tamaño y densidad de estomas), pero sin cambios en la partición de biomasa entre estructuras aéreas, potencial osmótico y en la $k_{\mathrm{s}}$, que impliquen cambios en la arquitectura hidráulica de las plantas.

Los resultados de este capítulo han sido publicados en: Bulfe $\mathrm{N}$ y Fernández ME. 2014. Efecto del momento de ocurrencia del déficit hídrico sobre el crecimiento de plantines de Pinus taeda L. Revista de la Facultad de Agronomía. Vol. 113 (1): 81-93. 


\section{INTRODUCCIÓN}

La distribución natural de Pinus taeda L. abarca un amplio rango de condiciones de humedad, desde Carolina del Norte hasta Texas, en los Estados Unidos de Norteamérica, hacia el interior del continente donde el déficit hídrico aumenta. Debido a su uso extendido en plantaciones tanto en EEUU como en otros países, ha sido objeto de numerosos estudios sobre su ecología, silvicultura y ecofisiología. En este sentido, se cuenta con amplia información sobre la respuesta de esta especie al déficit hídrico (e.g. Bongarten y Teskey 1986; Teskey et al. 1987; Wakamiya-Noborio et al. 1999; Hacke et al. 2000; Aspinwall et al. 2011ab). Se ha descripto que la funcionalidad del sistema de conducción de agua está relacionada con la conductancia estomática $\left(g_{s}\right)$, y en particular con la sensibilidad estomática diferencial al déficit de presión de vapor de la atmósfera (DPV) de distintos genotipos (Aspinwall et al. 2011a). Asimismo, el sistema de conducción de agua está sujeto a modificaciones en función de la plasticidad fenotípica de la planta, que le permite una mayor capacidad de exploración del suelo modificando la asignación de biomasa a las raíces cuando los recursos hídricos son escasos (Barnes 2002). También se ha encontrado que la especie responde a la fertilización con nitrógeno $(N)$ y fósforo $(P)$, generando un gradiente de respuestas entre diferentes genotipos (Faustino et al. 2013).

De acuerdo a los antecedentes, Pinus taeda es una especie capaz de tolerar déficit hídrico moderado, con una importante variabilidad genotípica en las respuestas. Sin embargo, todos los estudios de comportamiento del crecimiento frente al déficit hídrico se han realizado en períodos acotados de tiempo durante la estación de crecimiento, sin analizar la influencia del momento de ocurrencia del estrés sobre la capacidad de respuesta de la planta, principalmente si se considera el estadio de plantín. Este tipo de información no sólo es escasa para $P$. taeda, sino para los estadios juveniles de otras especies arbóreas en general (Fernández et al. 2014). En contraste, numerosos son los estudios en árboles adultos que abordan esta temática (e.g. Schweingruber 1996; Suárez et al. 2004; Mundo et al. 2010), en muchos casos facilitado por las técnicas de la dendrocronología. Este conocimiento es importante para predecir las posibles respuestas de las especies leñosas en sus primeros años de 
vida ante la variabilidad predicha en el marco del cambio climático. En la región del Noreste de Argentina donde se cultiva P. taeda, los pronósticos indican que en líneas generales la precipitación anual se incrementará, pero además se tornará más variable, provocando estaciones secas más frecuentes (Hulme y Sheard 1999). Si bien es difícil conocer cuándo y cómo ocurrirán estos eventos, el predecir la respuesta potencial de las distintas especies vegetales a los mismos resulta más abordable a partir de ensayos controlados que modifican el momento de ocurrencia y/o la intensidad del evento de estrés. En la Figura 4.1 en el panel A se presentan los datos climáticos correspondientes a la región de estudio, donde se puede observar dos períodos de menor precipitación, correspondiéndose con el mes de marzo y de manera más pronunciada durante el período de junio a septiembre. Sin embargo, en la figura 4.1 panel B se presentan los datos meteorológicos registrados durante el período comprendido entre los años 2009 y 2012, período en el cual se desarrollaron los ensayos realizados para la obtención de resultados presentados en esta tesis. Durante este período se puede observar menores precipitaciones acumuladas anualmente $(1688 \mathrm{~mm})$ respecto a la media climática $(1981 \mathrm{~mm})$.

Las menores prcipitaciones de los últimos años registrados se dieron en los meses de mayor demanda atmosférica, como lo son de noviembre a febrero. Estos registros coinciden en parte con las predicciones anteriormente mencionadas, e intensificándose las menores precipitaciones en agosto respecto a la media histórica, siendo este mes clave dado que es el inicio de la temporada de crecimiento para la especie en estudio. 


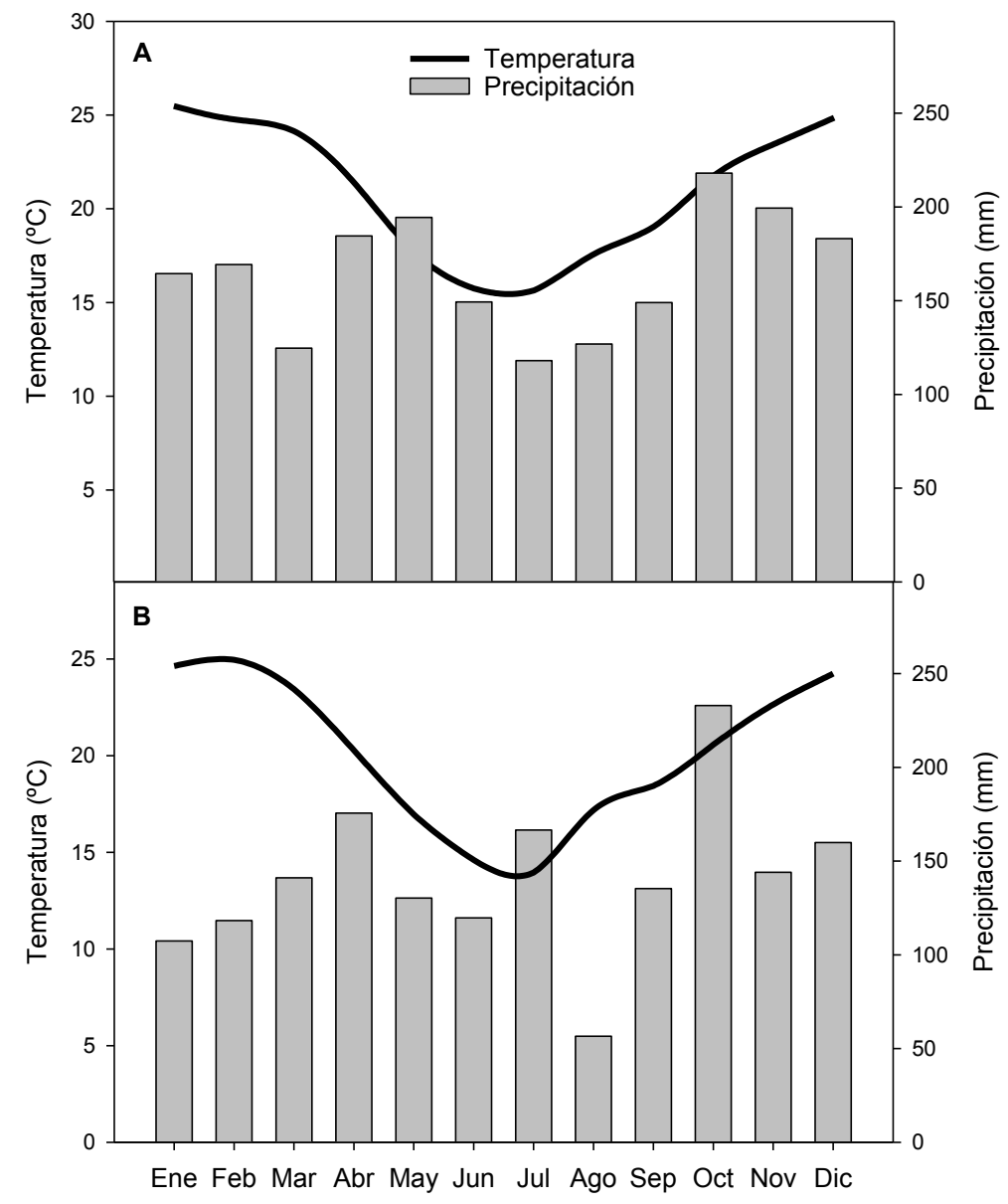

Figura 4.1 Información meteorológica de la región. A) Datos climáticos para la región durante el período comprendido entre los años 1963-2010 correspondientes a la Estación Meteorológica Iguazú (información provista por el Servicio Meteorológico Nacional de Argentina). B) Datos meteorológicos de la región para el período comprendido entre los años 2009-2012 correspondientes a la Estación Meteorológica del Campo Anexo Colonia Laharrague, Montecarlo. Promedio mensual de la temperatura del aire (으) y precipitación mensual acumulada $(\mathrm{mm})$.

Este estudio tuvo como objetivo evaluar el efecto del momento de ocurrencia del déficit hídrico sobre el crecimiento de plantines de Pinus taeda L. Al momento de llevar a cabo este ensayo, no existían antecedentes publicados sobre este tópico en estadios tempranos de especies coníferas, mientras que antecedentes en individuos adultos indicaban que un evento de sequía severa en primavera tiene mayor impacto sobre el intercambio gaseoso y/o el crecimiento anual de la planta, que si ocurre en otros momentos de la estación de crecimiento (Goldstein et al. 2000; Zhou et al. 2013). Un estudio realizado en paralelo al presente, pero en plantines de Pinus ponderosa en el N.O. de la Patagonia, también demostró que un evento de sequía en primavera provoca una disminución en el crecimiento que no se recupera aún cuando la planta 
recupera su estado hídrico y su capacidad de intercambio gaseoso durante la misma estación de crecimiento (Fernández et al. 2014). La hipótesis de trabajo planteada fue que la disminución del crecimiento acumulado al final de la estación de crecimiento es mayor cuando el déficit hídrico ocurre al inicio de la primavera en plantines de $P$. taeda, debido a que en este período se observan las tasas de crecimiento mayores. Aunque las condiciones sean favorables para el crecimiento de la planta posteriormente a un período de estrés, no alcanzarían a compensar la disminución del crecimiento provocada durante la etapa inicial del mismo.

\section{MATERIAL Y MÉTODOS}

\section{Área de estudio y diseño del ensayo}

Se instaló un ensayo con plantines de Pinus taeda en invernáculo durante la estación de crecimiento 2010-2011 en el Campo Anexo Laharrague del Instituto Nacional de Tecnología Agropecuaria (INTA EEA Montecarlo, Provincia de Misiones, 26 32'7" S; $54^{\circ} 38^{\prime \prime} 59^{\prime}$ O; 200 m.s.n.m.) (Figura 4.2). Las semillas para la producción de los plantines para el ensayo fueron provistas por el programa de mejoramiento genético del INTA, cuyos huertos semilleros están establecidos en el Campo Anexo Manuel

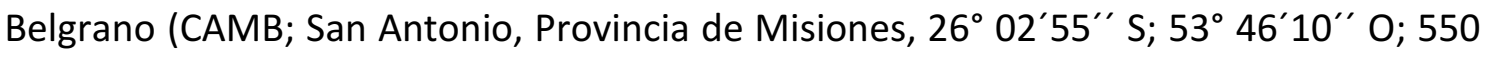
m.s.n.m.). Se trabajó con un pool de plantas de las familias AC1, AC2, BC1 y BC2 (Figura 4.2 panel A), familias estudiadas en otros ensayos donde se consideró la familia como factor (resultados presentados en el capítulo 2). De esta manera, en este ensayo se analizó la respuesta promedio de las cuatro familias selectas del programa de Mejoramiento Genético (PMG) de esta especie en Argentina. Cuarenta y ocho plantines de dos años de edad, en macetas de 20 litros fueron evaluados durante todo el período de estudio comprendido entre agosto de 2010 y febrero de 2011 (Figura 4.2 panel $B$ y C). Las macetas contenían como sustrato $1 / 3$ de suelo rojo (suelo donde se cultiva normalmente la especie en Misiones), 1/3 de corteza de pino y 1/3 de arena. Este sustrato resulta adecuado para el desarrollo de las plantas por su buen drenaje y fertilidad, facilitando además, por su textura, la recuperación de raíces. Si bien no fue un objetivo de este capítulo analizar este componente de la planta, se homogenizó el sustrato con el utilizado en otros ensayos paralelos que sí consideraban este órgano en 
el análisis. Se distribuyeron doce plantines en cada uno de cuatro bloques en el invernáculo, en los cuales se aplicaron cuatro tratamientos:

Control (C): plantines bajo condiciones hídricas óptimas en el suelo en toda la estación de crecimiento. En este grupo de plantas el riego se realizó con una frecuencia de dos veces por semana aplicando en cada riego agua hasta saturación, la cual fue de aproximadamente 2,5 litros por fecha de riego.

Déficit al inicio de la primavera (DIP): con restricción hídrica en el riego entre el 15 de agosto y el 15 de octubre de 2010. Durante este período se restringió el riego en este grupo de plantas, aplicándose en cada planta 1 litro de agua con una frecuencia de riego de dos veces por semana al igual que el control.

Déficit al final de primavera (DFP): con restricción hídrica en el riego entre el 15 de octubre y el 15 de diciembre de 2010. Durante este período se restringió el riego en este grupo de plantas, aplicándose en cada planta 1 litro de agua con una frecuencia de riego de dos veces por semana al igual que el control. El tratamiento de estrés anterior comenzó a ser nuevamente regado a igual nivel que el control cuando DFP comenzó a ser estresado.

Déficit en verano (DV): con restricción hídrica en el riego entre el 15 de diciembre de 2010 y el 2 de febrero de 2011. Durante este período se restringió el riego en este grupo de plantas, aplicándose en cada planta 1 litro de agua con una frecuencia de riego de dos veces por semana al igual que el control. El tratamiento de estrés anterior (DFP) comenzó a ser nuevamente regado a igual nivel que el control cuando DV comenzó a ser estresado, continuando con riego normal en DIP. 


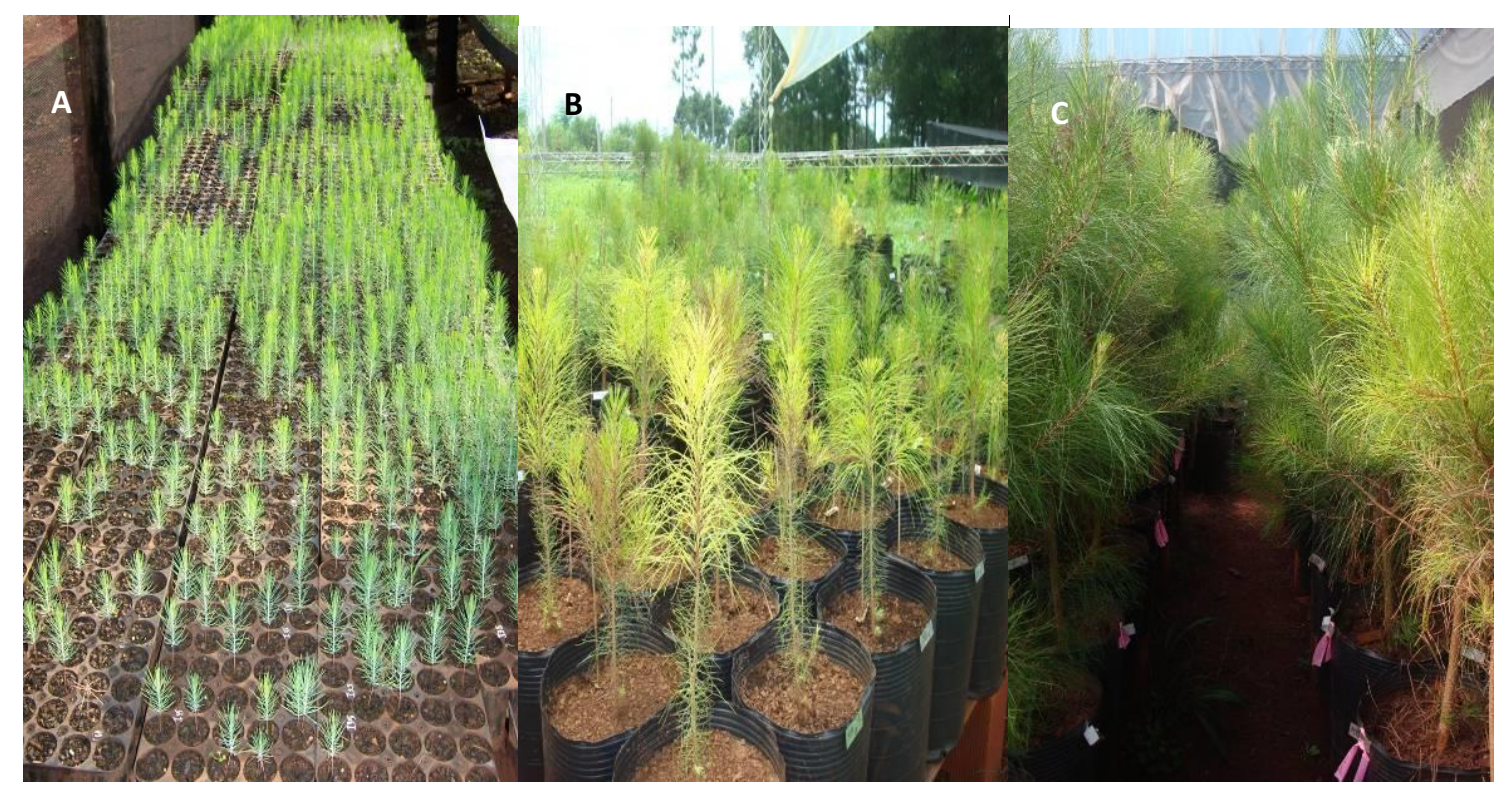

Figura 4.2 Ensayo en plantines de Pinus taeda L. A) Producción de plántulas en invernáculo de las diferentes familias estudiadas (pool de 4 familias). B) Vista general del ensayo previo a la aplicación de los tratamientos, foto tomada en Febrero de 2010. C) Vista general del ensayo durante la aplicación de los tratamientos, foto tomada en diciembre de 2010.

La cantidad de agua aplicada en los tratamientos de estrés se estimó en base a la determinación previa del consumo de agua promedio diario en plantines de Pinus taeda del tamaño de los estudiados y en las condiciones de invernáculo (Faustino L.; CONICET - UNLP - INTA EEA Delta, datos no publicados). El agua provista se encontraba por debajo del consumo potencial de agua de la especie, pero en niveles moderados, estimándose un consumo promedio de 3 litros por semana por planta. En este sentido, el agua provista en la condición control, y en los riegos post-estrés dentro de cada tratamiento, excedían los requerimientos promedios de la planta de manera de que no hubiera limitantes hídricas a nivel del suelo, principalmente en el control. Se registraron las variables temperatura del aire $(T, \underline{\circ})$ y humedad relativa $(H R, \%)$ en forma automática con un termohigrómetro Hobo (Pro v2 Onset) dentro del invernáculo. A partir de estas variables se estimó el déficit de presión de vapor de la atmósfera (DPV, kPa).

En la tabla Tabla 4.1 se pueden observar los valores promedios de los datos meteorológicos dentro del invernáculo para el período en el cual fue desarrollado el ensayo correspondiente para los resultados de este capítulo. 
Tabla 4.1 Datos meteorológico correspondientes al período comprendido entre Agosto de 2010 y Febrero de 2011 en el invernáculo donde se desarrollaró el ensayo en plantines de Pinus taeda L. para los resultados del presente capítulo.

\begin{tabular}{|c|c|c|c|c|}
\hline Mes & 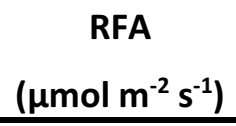 & $\begin{array}{c}\text { Temperatura } \\
\text { (ㅇ) }\end{array}$ & $\begin{array}{c}\text { Humedad } \\
\text { Relativa (\%) }\end{array}$ & DPV (kPa) \\
\hline Agosto & 246,3 & $16,9 \pm 7,6$ & $74,2 \pm 16,6$ & $0,7 \pm 0,7$ \\
\hline Septiembre & 235,9 & $16,9 \pm 5,8$ & $77,4 \pm 16,7$ & $0,7 \pm 0,7$ \\
\hline Octubre & 329,8 & $20,9 \pm 6,4$ & $75,3 \pm 18,6$ & $0,8 \pm 0,9$ \\
\hline Noviembre & 441,5 & $23,5 \pm 7,6$ & $71,1 \pm 20,5$ & $1,2 \pm 1,3$ \\
\hline Diciembre & 399,6 & $26,1 \pm 7,2$ & $78,1 \pm 17,7$ & $1,1 \pm 1,2$ \\
\hline Enero & 417,3 & $27,9 \pm 6,8$ & $75,8 \pm 16,7$ & $1,3 \pm 1,3$ \\
\hline Febrero & 187,7 & $26,8 \pm 5,2$ & $81,3 \pm 14,5$ & $0,9 \pm 1,0$ \\
\hline $\begin{array}{l}\text { Media } \\
\text { general }\end{array}$ & 343,9 & $23,9 \pm 4,6$ & $76,6 \pm 3,2$ & $0,9 \pm 0,2$ \\
\hline
\end{tabular}

\section{Crecimiento y biomasa aérea}

Para cuantificar el crecimiento en los distintos tratamientos se determinó el incremento en altura total $\left(h_{\mathrm{t}}\right)$ y el diámetro basal del tallo (dac) de todas las plantas de manera periódica. Durante toda la estación de crecimiento se realizaron mediciones de altura total con una cinta métrica $\left(h_{\mathrm{t}}, \mathrm{cm}\right)$ y del diámetro a la altura del cuello de la raíz con un calibre digital (dac, mm). Para la medición del dac se realizó una marca en el tallo a $10 \mathrm{~cm}$ de la base de la superficie del suelo, la cual fue tomada como referencia para todas las mediciones posteriores para de esta manera minimizar el error en las mediciones consecutivas. Las mediciones de $h_{\mathrm{t}} \mathrm{y}$ dac fueron realizadas cada 30 días aproximadamente, en todos los plantines de cada tratamiento. Con estas variables se estimó el crecimiento de las plantas a partir del incremento acumulado (absoluto y relativo) y la tasa de este proceso en los distintos períodos, en términos absolutos (IA) y relativos (IR), según las siguientes ecuaciones (Hunt 2003):

$$
\begin{array}{ll}
I A(\mathrm{~cm} ; \mathrm{mm})=y_{2}-y_{1} & \text { Ecuación (1) } \\
I R\left(\mathrm{~cm} ; m m \cdot \mathrm{di}^{-1}\right)=\frac{\left(y_{2}-y_{1}\right)}{y_{1}} & \text { Ecuación (2) }
\end{array}
$$

Donde: 
$\mathrm{y}_{1}=$ variable de tamaño (altura; dac) en $\mathrm{t}_{1}$

$\mathrm{y}_{2}=$ variable de tamaño (altura; dac) en $t_{2}$

La asignación de plantas a cada tratamiento fue un proceso totalmente aleatorio, sin embargo, la altura total promedio en las plantas control fue significativamente menor en comparación a la altura promedio de los grupos de plantas dentro de los tratamientos DIP y DFP al inicio del ensayo (previo a la aplicación de los tratamientos). Esto no ocurrió con el dac, que no presentó diferencias entre grupos al inicio de las mediciones. Estas diferencias en tamaño inicial (altura) de los grupos de plantas reforzaron la necesidad de evaluar tanto el crecimiento absoluto como el relativo (al tamaño inicial de cada planta) de manera de interpretar correctamente los patrones encontrados.

Al final de la estación de crecimiento se determinó la biomasa aérea y su distribución en los distintos compartimentos en 12 plantines del control y en ocho plantas en cada uno de los tratamientos con restricción hídrica (DIP, DFP y DV). Se calculó una aproximación a la relación de Hüber, como el cociente entre el área de xilema activo $\left(\mathrm{cm}^{2}\right)$ y la biomasa de hojas $(\mathrm{g})$.

La sobrevivencia de las plantas fue del $100 \%$ durante el período de estudio considerado.

\section{Mediciones anatómicas en hojas y leño}

Se estudió la anatomía foliar de un fascículo, compuesto de tres acículas, en cuatro plantas dentro de cada tratamiento, estas muestras fueron recolectadas por la tarde (aproximadamente 15 horas). Luego fueron llevadas a laboratorio y procesadas al día siguiente. En primer lugar se tomaron improntas sobre cada acícula del fascículo, para determinar la caracterización estomática de la misma. Para ello se aplicó laca transparente sobre cada acícula del fascículo, retirándola luego mediante una cinta adhesiva, la cual fue posteriormente adherida sobre un portaobjeto para la observación en microscopio (Figura 4.3 paneles A y B). Una vez obtenidas las muestras para la caracterización estomática, se realizaron cortes transversales de cada acícula que compone el fascículo, con un micrótomo manual con un espesor de corte de 25 a 
$40 \mu \mathrm{m}$ aproximadamente. Para los cortes histológicos del leño, las muestras fueron obtenidas del tallo principal, a $10 \mathrm{~cm}$ sobre la superficie de la maceta, en cinco plantas por tratamiento. De cada planta se tomó una porción de aproximadamente $3 \mathrm{~cm}$ de longitud, sobre la cual se realizaron los cortes histológicos del leño a mano alzada mediante bisturí. Todos los cortes, tanto de leño como de hojas, fueron deshidratados con distintas graduaciones alcohólicas para su posterior tinción con safranina al 1\%, y se montaron en Entellan ${ }^{\circledR}$ para la observación en microscopio óptico (D’Ambrogio de Argüeso 1986). Luego fueron fotografiados con una cámara digital Moticam 2000, montada sobre un microscopio trinocular Carl Zeiss (Axiolab, Alemania).
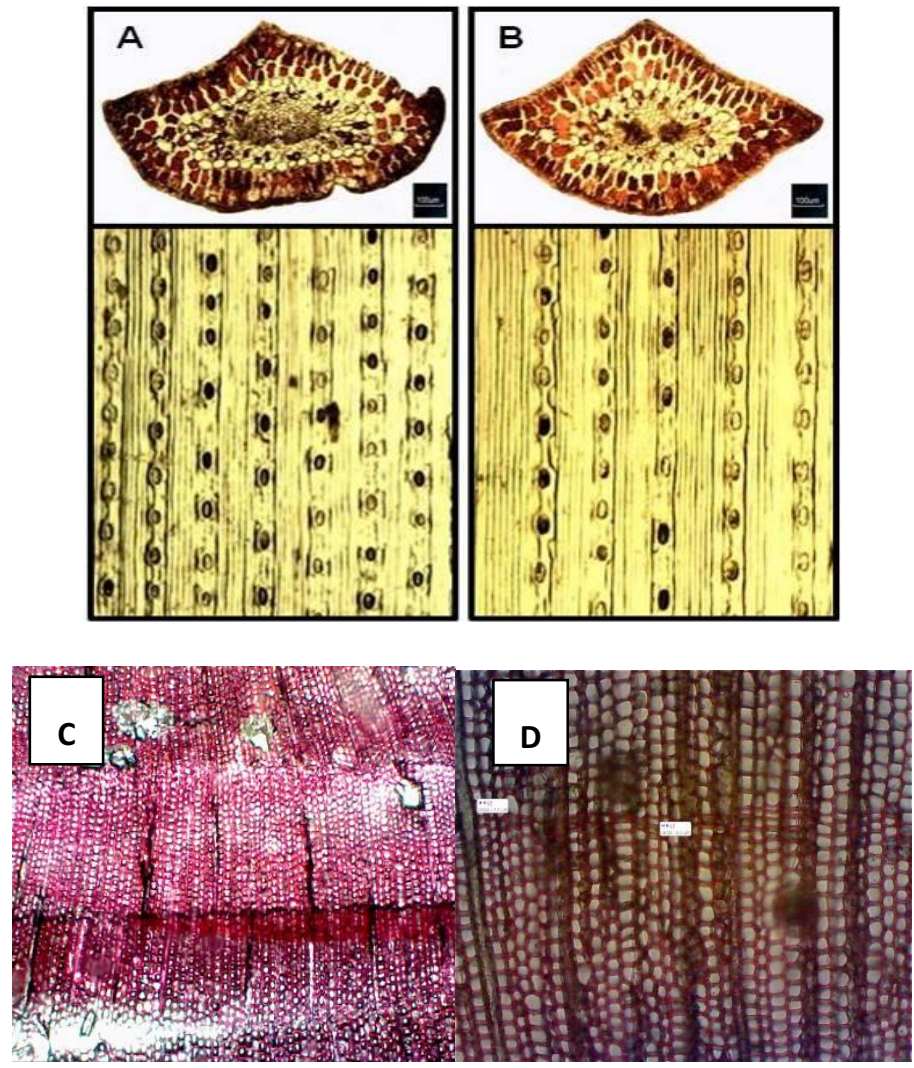

Figura 4.3 Anatomía en plantines de Pinus taeda L. A) Corte histológico e impronta de una acícula de una planta control. B) corte histológico e impronta de una acícula de una planta sometida a déficit hídrico al final de la primavera (DFP). C) Corte histológico del leño de una planta sometida al tratamiento DIP en 4X. D) Corte histológico del leño de una planta sometida al tratamiento DFP en $10 \mathrm{x}$.

Sobre las improntas de las hojas se midieron las variables diámetro de estomas ( $\varnothing_{\text {est, }}$ $\mu \mathrm{m})$ y densidad estomática $\left(D_{\text {est, }}\right.$ estomas $\mathrm{mm}^{-2}$ ), y sobre los cortes de hojas se 
midieron las variables espesor de la epidermis $\left(E_{\text {epidermis, }} \mu \mathrm{m}\right)$ y área del mesófilo $\left(A_{\text {mesófilo, }} \mathrm{mm}^{2}\right.$ ). Con las variables medidas, se estimaron el área promedio de cada estoma $\left(\mathrm{mm}^{2} \mathrm{~mm}^{-2}\right.$ ) y el índice de poro estomático (IPE, adimensional) el cual es un índice teórico de la máxima conductancia estomática (Sack et al. 2003) siguiendo la ecuación 3.

\section{$I P E=$ DensidadEstomática $\times$ LongitudEstoma ${ }^{2}$}

Ecuación (3)

En los cortes histológicos del leño se midieron las variables diámetro de lumen ( $D_{\text {lumen, }}$ $\mu \mathrm{m})$ y espesor de pared ( $\left.E_{\text {pared, }} \mu \mathrm{m}\right)$ dentro de cada tipo de leño (temprano y tardío). Se utilizó el mismo criterio que en el capítulo anterior (pág. 64 de esta tesis) para determinar los tipos de leño.

Todas las mediciones microscópicas fueron realizadas mediante el software Motic Images Plus 2.0 complementario a la cámara MOTICAM 2000.

\section{Variables fisiológicas}

Durante los primeros meses del experimento, se llevaron a cabo distintas determinaciones ecofisiológicas, de manera de explicar los patrones observados en crecimiento y producción de biomasa. Lamentablemente, estas mediciones no pudieron llevarse a cabo en el último período del ensayo (verano) por problemas técnicos, por lo que su utilidad se restringe a la contribución de explicar los efectos del déficit impuesto en primavera, período de crecimiento más activo. Las variables fisiológicas a nivel de hoja fueron realizadas siempre en el control y, en forma paralela, en el tratamiento de estrés que correspondiera de acuerdo al período en el cual se efectuaran las mediciones.

De manera periódica (cada 20 a 50 días) fue medido el potencial hídrico foliar $\left(\Psi_{\mathrm{f}}\right.$, $\mathrm{MPa}$ ) de un fascículo por planta en tres plantas por tratamiento en dos momentos del día, en pre-alba y al inicio de la tarde, aproximadamente a las 14 horas, momento de máxima radiación y temperatura ambiente. Para ello se utilizó una cámara de presión (Bio-control, Modelo 0-6 MPa, Argentina).

La conductancia estomática $\left(g_{\mathrm{s}}, \mathrm{mol} \mathrm{H} \mathrm{H} \mathrm{m}^{-2} \mathrm{~s}^{-1}\right)$ fue medida entre agosto y diciembre de 2010 en 12 plantas del control y de los tratamientos de estrés correspondientes en 
cada período de estudio (DIP o DFP). Estas determinaciones fueron realizadas en dos momentos del día, a media mañana (aproximadamente a las 9 horas), y al inicio de la tarde (aproximadamente a las 14 horas) utilizando un porómetro Decagon Devices, modelo SC-1. En todos los casos las mediciones fueron realizadas en tres fascículos por planta completamente expandidos de la parte media de la copa. Los fascículos fueron acomodados de manera cuidadosa a los fines de que el área de la cámara permaneciera completa al momento de cada medición.

Se midió la tasa de fotosíntesis neta a saturación lumínica $\left(A_{\text {sat }}\right)$ a inicios de primavera, entre agosto y setiembre con un analizador de gases infrarrojo PP Systems - modelo TPS-2. El nivel de radiación utilizado fue de $1200 \mu \mathrm{mol} \mathrm{m} \mathrm{m}^{-2} \mathrm{~s}^{-1}$. Cada medición fue realizada en tres fascículos completamente expandidos de la parte media de la copa, en 12 plantas dentro de cada tratamiento.

Se estimó la conductividad hidráulica específica $\left(k_{\mathrm{s}}, \mathrm{Kg} \mathrm{s}^{-1} \mathrm{~m}^{-1} \mathrm{MPa}^{-1}\right)$ en una rama por planta, de aproximadamente $10 \mathrm{~cm}$ de longitud la cual fue cortada al mediodía, variable determinada en cuatro plantas en el control y cuatro en el tratamiento DIP. Para la estimación de esta variable se utilizó un conductímetro multicanal construido en PVC, con ocho canales (e.g. Fernández et al. 2010). Se utilizó agua destilada para perfundir en cada rama, la cual fue colectada en un recipiente, siendo posteriormente pesado en una balanza digital con una precisión de 0,001 g. Se consideró a toda el área transversal de xilema, exceptuando la corteza, como área efectiva de conducción, sin descontar el porcentaje de médula. Si bien esto puede subestimar levemente el valor de $k_{\mathrm{s}}$, consideremos que, debido a que la porción de médula es muy poco significativa tratándose de plantas muy jóvenes, el error sería bajo y similar para ambos tratamientos.

A los efectos de determinar la existencia de procesos de ajuste osmótico y/o elástico de los tejidos foliares en respuesta al déficit hídrico, se determinaron los parámetros hídricos a través de las relaciones de presión-volumen $(P-V)$ en plantas del control y del tratamiento DIP ( $n=12$ ). Se extrajo un fascículo por planta, y se lo hidrató durante 24 horas en oscuridad hasta su saturación. Las curvas fueron creadas a partir del método de "transpiración libre" según lo descripto en Corcuera (2003). A partir de las curvas P$\checkmark$ se estimaron el potencial osmótico a saturación $\left(\Psi_{\Pi \text { sat, }} \mathrm{MPa}\right)$, el potencial hídrico en 
el punto de pérdida de turgencia ( $\left.\Psi_{\mathrm{TLP}}, \mathrm{MPa}\right)$, el contenido relativo de agua en el punto de pérdida de turgencia $\left(\mathrm{CRA}_{\mathrm{ppt}}, \%\right)$ y el contenido relativo de agua apoplástica (CRA ${ }_{\mathrm{apo}}$, \%). El cálculo de los ajustes se realizó de forma manual debido a que las curvas no ajustaron con el programa Pressure-Volume Curve Analysis Program (P-V Program).

\section{Análisis estadístico}

Los datos fueron analizados utilizando análisis de varianza (ANOVA, $\alpha=0,05$ ) para las variables crecimiento periódico y acumulado (dentro de cada fecha), biomasa total y en sus diferentes compartimentos, $k_{\mathrm{s}}$, potencial hídrico, $g_{\mathrm{s}}$ y las variables anatómicas de hojas y leño. Para la comparación de medias entre cada par de tratamientos, cuando el ANOVA indicó diferencias significativas, se utilizó el test de Tukey $(\alpha=0,05)$. Asimismo, se estimó el coeficiente de correlación de las variables potencial hídrico y $g_{\mathrm{s}}$ con el DPV. En todos los casos se utilizó un nivel de significancia de 0,05.

\section{RESULTADOS}

\section{Crecimiento en altura y diámetro basal}

Como ya se mencionó, si bien la asignación de plantas a cada tratamiento fue un proceso totalmente aleatorio, cuando se determinó el valor de altura total al inicio del ensayo, es decir, previamente a la aplicación de los tratamientos, las plantas del control fueron significativamente más pequeñas (en altura total) que las asignadas a los tratamientos de déficit hídrico DIP y DFP. Estas diferencias en tamaño inicial de plantas fueron consideradas en el análisis e interpretación posterior de los datos.

El incremento absoluto en altura y dac para todo el período de estudio (agosto de 2010-febrero de 2011) no presentó diferencias estadísticas entre los distintos tratamientos. Sin embargo, al tomar en cuenta el tamaño inicial de las plantas (incremento relativo en altura $\mathrm{y}$ dac) se observaron diferencias estadísticamente significativas entre algunos tratamientos para ambas variables. En altura se diferenciaron las plantas del DIP por su menor crecimiento con respecto a las de los tratamientos C y DV, así como las de la situación DFP por su menor crecimiento que las del C (Figura 4.4 panel A y B), mientras que en dac se diferenciaron solamente las 
plantas del DIP, por su menor crecimiento respecto a las plantas control, DFP y DV (Figura 4.4 paneles $C$ y D).

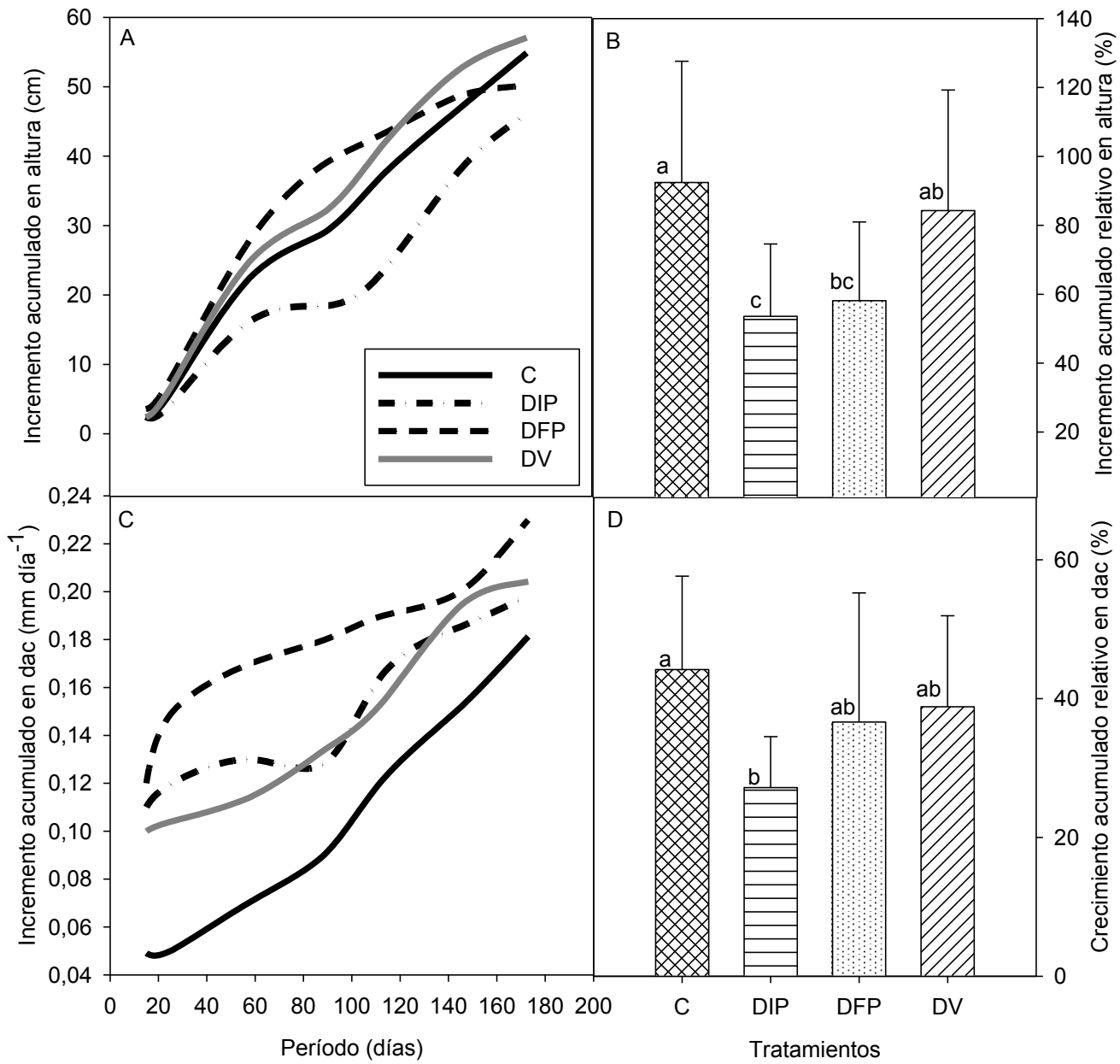

Figura 4.4 Incremento promedio en altura y dac para cada tratamiento en respuesta al déficit hídrico. A) Incremento absoluto en altura total (cm) acumulado a lo largo del período de ensayo (180 días). B) Incremento acumulado en altura relativo (\% con respecto al inicial) al final del período de estudio. C) Incremento absoluto en dac $(\mathrm{mm})$ a lo largo del período de ensayo (180 días). D) Incremento acumulado en dac relativo (\% con respecto al inicial) al final del período de estudio. Letras distintas indican diferencias estadísticas significativas, $\alpha=0,05$. C: control; DIP: déficit hídrico al inicio de la primavera; DFP: déficit hídrico al final de la primavera; DV: déficit hídrico en verano.

La tasa de crecimiento absoluto diaria promedio ( \pm desvío estándar) para todo el período fue de $0,32 \pm 0,09 ; 0,25 \pm 0,10 ; 0,27 \pm 0,08$ y 0,32 $\pm 0,08 \mathrm{~cm}^{\text {día }}{ }^{-1}$ para el control y los tratamientos DIP, DFP y DV, respectivamente, no habiendo diferencias estadísticas entre tratamientos de déficit. Sin embargo, en valores relativos las plantas 
del DIP presentaron incrementos promedios inferiores estadísticamente a los demás tratamientos.

Tanto el incremento diario en altura absoluto como el relativo tuvieron un patrón estacional, resultando muy variable durante el período de estudio, con dos picos, uno máximo en octubre y otro de menor magnitud en diciembre (Figura 4.5 paneles A y B).

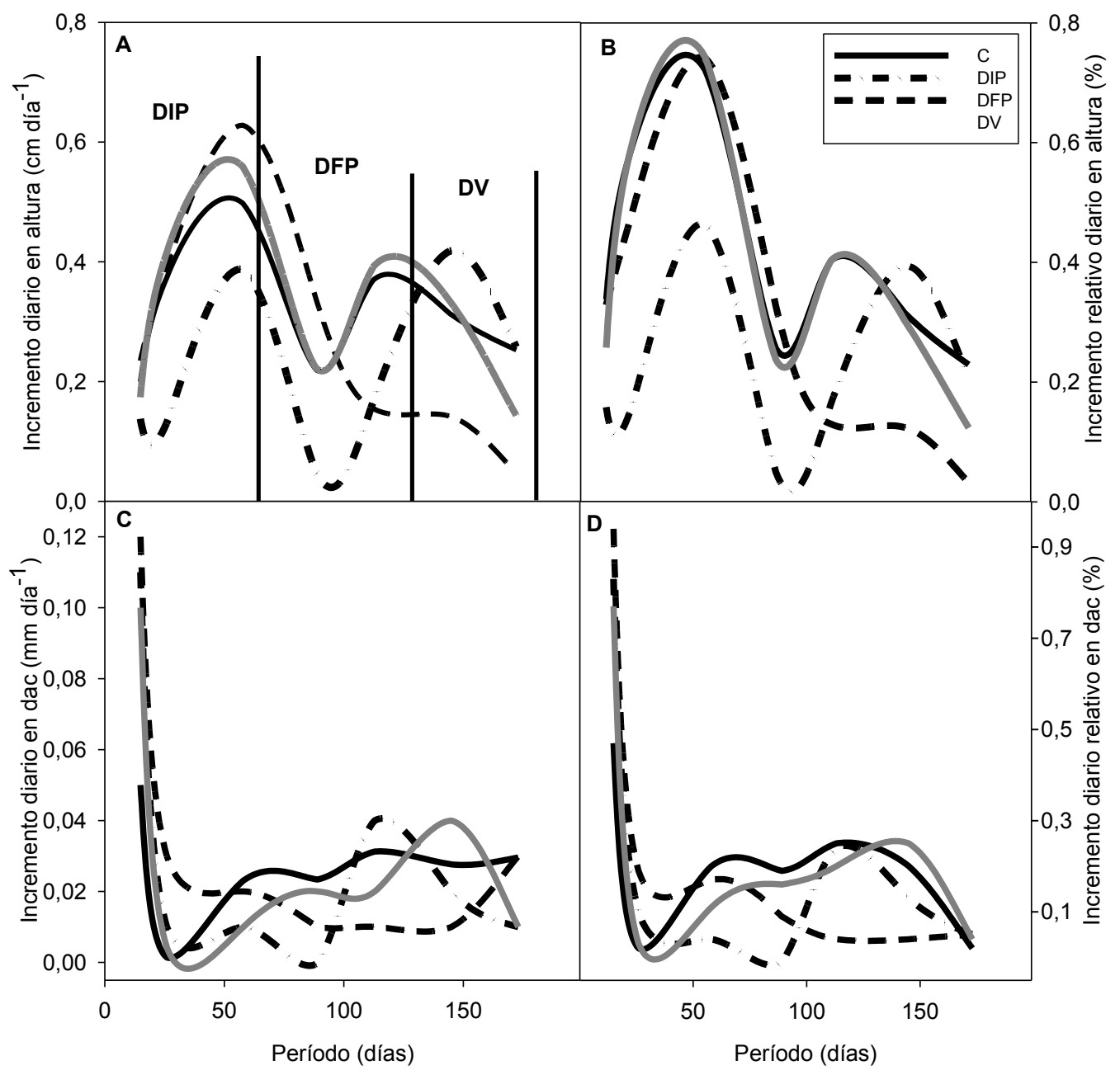

Figura 4.5 Tasa de incremento diario promedio en altura y dac para cada tratamiento en los diferentes momentos del período de crecimiento. A) Incremento absoluto en altura (cm día $\left.{ }^{-1}\right)$. B) Incremento relativo en altura (\% del valor inicial día $\left.{ }^{-1}\right)$. C) Incremento absoluto en dac ( $\left.\mathrm{mm} \mathrm{día}^{-1}\right)$. D) Incremento relativo en dac (\% del valor inicial día ${ }^{-1}$ ). C: control (sin restricciones de agua en el suelo), DIP: déficit hídrico (restricción de riego) al inicio de la primavera (hasta la primera línea vertical en la Figura 4.4 panel A); DFP: déficit hídrico al final de la primavera (período comprendido entre las dos primeras líneas verticales en Figura 4.4 panel A); DV: déficit hídrico en verano (período comprendido entre las dos últimas líneas verticales de la Figura 4.4 panel A). En el texto se indican las fechas en las que hubo diferencias significativas entre tratamientos. 
La tasa de incremento en altura total estimada en los diferentes períodos dentro de la estación de crecimiento, estuvo afectada por el déficit hídrico cuando éste se produjo en primavera (tratamientos DIP y DFP), no así cuando el déficit hídrico ocurrió en verano (Figura 4.5 paneles $A$ y B).

El déficit impuesto al inicio de la temporada de crecimiento (DIP) comenzó a tener un efecto significativo sobre el crecimiento diario, tanto absoluto como relativo, luego de 15 días de estar las plantas expuestas al déficit de agua en suelo (a partir de la segunda fecha de medición) en comparación con el crecimiento diario observado en el control. Estas diferencias significativas de crecimiento con respecto al control $(p<0,05)$ se mantuvieron posteriormente al cese del déficit hídrico en el DIP, notándose una recuperación en la tasa de crecimiento diario recién aproximadamente 60 días posteriores al cese del estrés (a los 120 días en el eje $x$ de la Figura 4.5 panel $A ; p>0,05$ al comparar el crecimiento entre C y DIP). Por otro lado, cuando el déficit fue aplicado al final de la primavera (DFP), se observó un efecto del tratamiento sobre el crecimiento diario recién a los 50 días posteriores al inicio del estrés en comparación al control $(p<0,05)$. En este punto (110 días en el eje $x$ de la Figura 4.5 panel A) los tratamientos DIP y DFP presentaron crecimientos diarios similares entre sí y menores al control, tanto en valor absoluto como relativo. Para el tratamiento DFP no se llegó a detectar una recuperación en su tasa de crecimiento incluso 50 días posteriores al cese del déficit hídrico (final del experimento) en este tratamiento. Para el tratamiento DV, no se observaron diferencias estadísticas significativas en las tasas de crecimiento diario en comparación con el control ( $p>0,05$ en todas las fechas de comparación), tanto en valores absolutos como relativos.

La tasa absoluta de incremento en dac ( \pm desvío estándar) para todo el período fue de $0,028 \pm 0,01 ; 0,020 \pm 0,003 ; 0,027 \pm 0,01$ y 0,026 $\pm 0,01 \mathrm{~mm}$ día $^{-1}$ para el control y los tratamientos DIP, DFP y DV respectivamente, sin diferencias estadísticas entre tratamientos (Figura 4.5 panel C). Sin embargo, en valores relativos los tratamientos DIP y DFP presentaron incrementos inferiores estadísticamente respecto al control y al DV (Figura 4.5 panel D).

El incremento absoluto en dac en los diferentes períodos presentó un patrón similar al descripto para la variable altura, destacándose las diferencias al inicio del ensayo en el 
incremento entre el control y los demás tratamientos (C y DV fueron estadísticamente diferentes de DIP y DFP). Estas diferencias al inicio imponen un retraso en la diferenciación estadística de los tratamientos respecto al control.

\section{Distribución de la biomasa aérea en los distintos compartimentos}

Todas las plantas tuvieron la misma biomasa aérea total al final del ensayo con un promedio para todos los tratamientos de $88,6 \pm 30,3 \mathrm{~g}$, sin diferencias estadísticas en su asignación a los distintos compartimentos que conforman la porción aérea de la planta $(p>0,05)$. En todos los tratamientos se observó una mayor asignación relativa al tallo, seguida por las hojas y por último, a las ramas (Tabla 4.2). Los valores promedio de biomasa en cada compartimento fueron de $49,5( \pm 4,7) ; 21,6( \pm 4,7)$ y $28,9( \pm 6,3) \mathrm{g}$ para el tallo, ramas y hojas respectivamente (promedio general para todos los tratamientos evaluados). En la Tabla 4.2 se describen los valores promedios de biomasa aérea y su distribución relativa dentro de cada compartimento para cada tratamiento.

Tabla 4.2 Distribución de la biomasa aérea en los distintos compartimentos al final del ensayo. Biomasa aérea total (g) y su distribución relativa en los distintos componentes aéreos (tallo, ramas y hojas) (\%). Promedio general y por tratamiento. C: Control; DIP: Déficit hídrico al inicio de la primavera; DFP: Déficit hídrico al final de la primavera y DV: Déficit hídrico en verano. En ninguna variable hubo diferencias significativas entre tratamientos $(\alpha=0,05)$.

\begin{tabular}{lcccc}
\hline Tratamientos & Aérea (g) & $\begin{array}{c}\text { Tallo } \\
\mathbf{( \% )}\end{array}$ & $\begin{array}{c}\text { Ramas } \\
\text { (\%) }\end{array}$ & $\begin{array}{c}\text { Hojas } \\
\text { (\%) }\end{array}$ \\
\hline C & $72,3 \pm 25,5$ & $47,9 \pm 4,7$ & $20,8 \pm 5,5$ & $31,3 \pm 7,4$ \\
DIP & $91,1 \pm 25,6$ & $50 \pm 5,7$ & $21,8 \pm 4,6$ & $28,2 \pm 3,1$ \\
DFP & $98,1 \pm 19,4$ & $51,4 \pm 3,3$ & $22,7 \pm 2,6$ & $25,8 \pm 3,4$ \\
DV & $104,1 \pm 44,3$ & $51,3 \pm 3,7$ & $22,4 \pm 4,4$ & $26,3 \pm 5,5$ \\
\hline General & $\mathbf{8 8 , 6 \pm 3 0 , 3}$ & $\mathbf{4 9 , 5 \pm 4 , 7}$ & $\mathbf{2 1 , 6 \pm 4 , 7}$ & $\mathbf{2 8 , 9 \pm 6 , 3}$ \\
\hline
\end{tabular}

La relación entre el área de xilema conductivo del tallo y la biomasa foliar de cada planta, que ha sido tomada como una aproximación a la relación de Hüber, tampoco mostró diferencias estadísticamente significativas entre tratamientos. El valor promedio general para esta variable fue de $9,5( \pm 2,7) \mathrm{cm}^{2} \mathrm{~g}^{-1}$, valor que incluye a todos los tratamientos. 


\section{Anatomía de hojas y leño}

Las plantas expuestas a déficit hídrico manifestaron algunas modificaciones en la anatomía foliar, especialmente a nivel estomático. El diámetro de los estomas aumentó, mientras que la densidad estomática disminuyó en los tratamientos con déficit hídrico (Tabla 4.3). Sin embargo, la magnitud de los cambios estuvo en función del momento de ocurrencia del estrés.

Tabla 4.3 Características morfológicas de las acículas de Pinus taeda en los distintos tratamientos. Diámetro de estoma $\left(\emptyset_{\text {est, }}(\mu \mathrm{m})\right.$; Densidad estomática $\left(D_{\text {est, }}\right.$ estomas $\left.\mathrm{mm}^{-2}\right)$; Espesor de epidermis $\left(E_{\text {epidermis, }}(\mu \mathrm{m})\right.$; Área del mesófilo $\left(A_{\text {mesófilo, }} \mathrm{mm} 2\right)$; Área del estoma $\left(A_{\text {est }}\left(\mathrm{mm}^{2} \mathrm{~mm}^{-2}\right)\right.$ : Índice de poro estomático (IPE). C: control (sin restricciones de agua en el suelo); DIP: déficit hídrico (restricción de riego) al inicio de la primavera; DFP: déficit hídrico al final de la primavera; DV: déficit hídrico en verano.

\begin{tabular}{lcccccc}
\hline Tratamiento & $\boldsymbol{\emptyset}_{\text {est }}(\boldsymbol{\mu m})$ & $\begin{array}{c}\boldsymbol{D}_{\text {est }} \\
\left(\mathbf{e s t} / \mathbf{m m}^{\mathbf{2}}\right)\end{array}$ & $\boldsymbol{E}_{\text {epidermis }}(\boldsymbol{\mu \mathrm { m } )}$ & $\begin{array}{c}\boldsymbol{A}_{\text {mesófilo }} \\
\left(\mathbf{m m}^{\mathbf{2}}\right)\end{array}$ & $\begin{array}{c}\boldsymbol{A}_{\text {est }}\left(\mathbf{m m}^{\mathbf{2}}\right. \\
\left.\mathbf{m m} \mathbf{~}^{\mathbf{2}}\right)\end{array}$ & IPE \\
\hline C & $14,6 \pm 2,5 \mathrm{~b}$ & $119,2 \pm 23,6 \mathrm{a}$ & $3,9 \pm 1,2$ & $0,9 \pm 0,5$ & $0,019 \pm 0,003$ & $0,025 \pm 0,004$ \\
DIP & $19,4 \pm 2,1 \mathrm{ab}$ & $76,8 \pm 29,6 \mathrm{ab}$ & $5,1 \pm 0,7$ & $0,8 \pm 0,4$ & $0,022 \pm 0,006$ & $0,027 \pm 0,008$ \\
DFP & $20,8 \pm 3,3 \mathrm{a}$ & $55,6 \pm 12,9 \mathrm{~b}$ & $5,8 \pm 0,6$ & $1,0 \pm 0,3$ & $0,020 \pm 0,009$ & $0,025 \pm 0,011$ \\
DV & $20,7 \pm 2,5 \mathrm{a}$ & $67,7 \pm 21,9 \mathrm{~b}$ & $5,3 \pm 0,5$ & $1,3 \pm 0,3$ & $0,023 \pm 0,009$ & $0,029 \pm 0,010$ \\
\hline
\end{tabular}

Letras distintas indican diferencias estadísticas, $\alpha=0,05$. No se indican letras en aquellas variables donde no hubo diferencias significativas entre ninguno de los tratamientos.

El diámetro de los estomas aumentó en mayor medida en los tratamientos DFP y DV, y con ello como es de esperarse, disminuyó en mayor grado la densidad estomática en ambos. Los cambios observados cuando el estrés ocurrió al principio de la primavera tuvieron las mismas tendencias pero no llegaron a ser estadísticamente diferentes a los valores observados en el control. En general, no se observaron diferencias significativas entre los tratamientos de déficit hídrico.

Por otro lado, haciendo referencia a la anatomía interna de la hoja, la epidermis mostró una tendencia a un aumento en su espesor en plantas expuestas a déficit hídrico respecto al control, sin diferencias significativas entre tratamientos. El área del mesófilo, el área de estomas y el índice de poro estomático no fueron afectados por los tratamientos (Tabla 4.3). 
A diferencia de las modificaciones anatómicas observadas a nivel foliar en respuesta al déficit hídrico, no se registraron modificaciones en la anatomía del leño en los tratamientos de déficit hídrico, en comparación con el control (Tabla 4.4).

Tabla 4.4 Características anatómicas del leño de Pinus taeda en los distintos tratamientos. Diámetro de lumen $\left(D_{\text {lumen, }} \mu \mathrm{m}\right)$ de las traqueidas; Espesor de pared $\left(E_{\text {pared }}, \mu \mathrm{m}\right)$ de las traqueidas. No hubo diferencias significativas entre tratamientos en ninguno de los parámetros analizados (tests aplicados a los datos cuyos promedio (DE) se presentan en las primeras dos columnas de la tabla). Promedios de los parámetros analizados en individuos de los tratamientos C, DIP y DV, donde se diferenció leño temprano y tardío (datos presentados en las últimas cuatro columnas de la tabla). DIP: déficit hídrico al inicio de la primavera; DFP: déficit hídrico al fin de la primavera; DV: déficit hídrico en verano.

Anillo completo Leño temprano Leño tardío

\begin{tabular}{llllccc} 
Tratamiento & \multicolumn{2}{c}{$(\mathbf{n = 5 )}$} & \multicolumn{2}{c}{$(\mathbf{n = 2} / \mathbf{3})$} & \multicolumn{2}{c}{$(\mathbf{n = 2 / 3 )}$} \\
\cline { 2 - 7 } & $\begin{array}{l}D_{\text {lumen }} \\
(\mu \mathrm{m})\end{array}$ & $\begin{array}{l}E_{\text {pared }} \\
(\mu \mathrm{m})\end{array}$ & $\begin{array}{c}D_{\text {lumen }} \\
(\mu \mathrm{m})\end{array}$ & $\begin{array}{c}E_{\text {pared }} \\
(\mu \mathrm{m})\end{array}$ & $\begin{array}{c}D_{\text {lumen }} \\
(\mu \mathrm{m})\end{array}$ & $\begin{array}{c}E_{\text {pared }} \\
(\boldsymbol{\mu m})\end{array}$ \\
\hline Control & $15,2 \pm 4,5$ & $2,4 \pm 0,8$ & 16,5 & 1,7 & 10,9 & 2,9 \\
DIP & $14,3 \pm 2,7$ & $2,8 \pm 1,0$ & 16,8 & 2,6 & 10,6 & 4,1 \\
DFP & $16,7 \pm 0,6$ & $2,3 \pm 0,6$ & ----- & ----- & ----- & ----- \\
DV & $15,7 \pm 3,6$ & $2,6 \pm 0,5$ & 19,5 & 2,5 & 10,6 & 3,3 \\
\hline
\end{tabular}

Dentro de cada tratamiento, hubo individuos en los que se pudo diferenciar el leño temprano y tardío, mientras que en otros, esta diferenciación entre tipos de leño no pudo realizarse. Por ello, las comparaciones entre tratamientos se realizaron en base al promedio de los caracteres (diámetro de lumen y espesor de pared) sin diferenciar tipos de leño (Tabla 4.4). De manera descriptiva, se presentan además los valores medios de la morfometría de traqueidas del leño temprano y tardío de aquellos individuos que presentaron una clara diferenciación en las dimensiones de sus traqueidas a lo largo del anillo de crecimiento (Tabla 4.4). No se realizó un test comparativo entre tratamientos debido al bajo $n$ que representaban.

\section{Relaciones hídricas y el intercambio gaseoso en las plantas}

El potencial hídrico, tanto en pre-alba como al mediodía, presentó valores menores, es decir más negativos, en las plantas con restricción hídrica respecto a las plantas control en cada período de estrés evaluado (Figura 4.6), siendo las diferencias estadísticamente significativas solamente durante la primavera tardía (mediciones entre octubre y diciembre). 


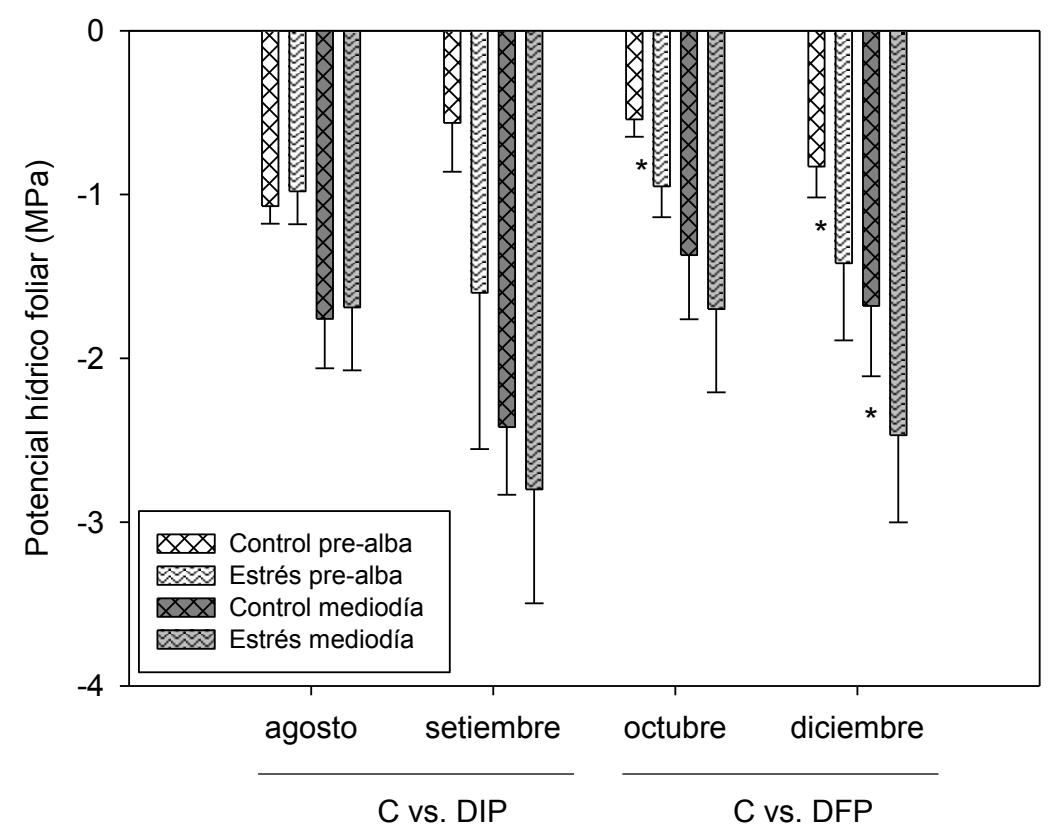

Figura 4.6 Potencial hídrico foliar $\left(\Psi_{\mathrm{f}}, \mathrm{MPa}\right)$ medido en plantas con y sin restricción hídrica en pre-alba y al mediodía en distintas fechas de la temporada de crecimiento. Los asteriscos indican diferencias significativas entre tratamientos en cada momento del día (pre-alba o mediodía) y fecha de medición con un nivel de significancia $\alpha=0,05$.

El máximo gradiente de potencial hídrico diario desarrollado en cada grupo de plantas (diferencia entre el potencial hídrico máximo obtenido en pre-alba y el mínimo a las 14 horas aproximadamente) en cada día fue similar entre tratamientos. Por otro lado, se observó que el potencial hídrico foliar estuvo inversamente relacionado con el DPV (Figura 4.7), descendiendo linealmente a medida que aumentó el DPV. Los coeficientes de correlación entre estas variables fueron de $-0,92(p=0,001)$ en el control y $-0,78(p=$ $0,02)$ para las plantas estresadas bajo los tratamientos DIP y DFP analizadas en este caso ambos tratamientos en conjunto. La comparación de las rectas de regresión ajustadas a estas variables mostró diferencias en ordenadas al origen $(p=0,043)$, no así entre las pendientes $(p=0,653)$ de las plantas control y las expuestas a déficit hídrico (Figura 4.7). Los parámetros de las rectas de regresión fueron los siguientes:

Control: $\Psi_{\mathrm{f}}(\mathrm{MPa})=-0,6632 \mathrm{DPV}(\mathrm{kPa})-0,6214\left(p=0,001 ; F=34,594 ; R^{2}=0,85\right)$

Plantas con déficit hídrico en suelo: $\Psi_{\mathrm{f}}(\mathrm{MPa})=-0,5647 \mathrm{DPV}(\mathrm{kPa})-1,1327(p=0,023 ; F=$ 9,$\left.231 ; R^{2}=0,62\right)$. 


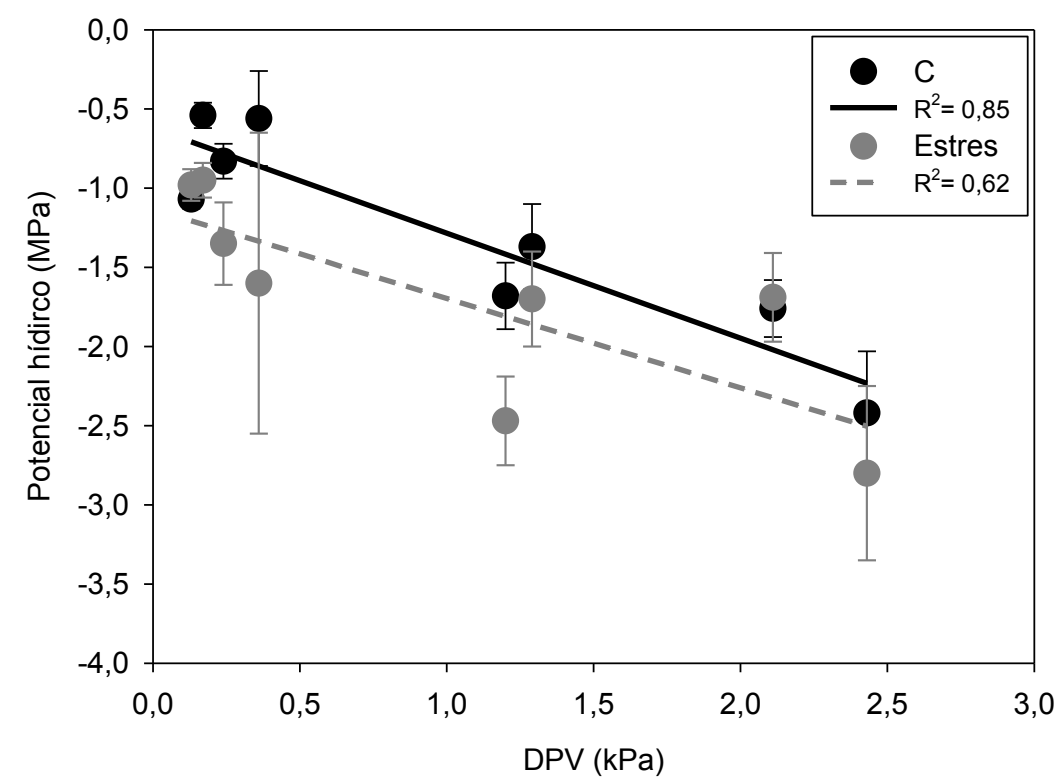

Figura 4.7 Relación entre el potencial hídrico foliar ( $\mathrm{MPa}$ ) y el déficit de presión de vapor de la atmósfera (DPV, kPa) al momento de la medición de esta variable fisiológica, en plantas con (DIP y DFP) y sin restricción hídrica (C). Cada punto representa el promedio de 12 plantas correspondientes a un tratamiento, fecha y momento de medición.

Se observó una disminución de la $g_{s}$ en los plantines bajo déficit hídrico (DIP y DFP) con respecto a la situación control, tanto a las 9 de la mañana, momento de máxima $g_{\mathrm{s}}$ esperada, como al momento de mínima $g_{\mathrm{s}}$ esperada (14 horas aproximadamente). Estas diferencias sucedieron a partir de septiembre $(p<0,05)$ (Figura 4.8). Las plantas en el tratamiento control mantuvieron altas $g_{\mathrm{s}}$ en ambos momentos de medición diaria, mientras que las estresadas presentaron una menor apertura estomática relativa al control, en ambos momentos del día. 


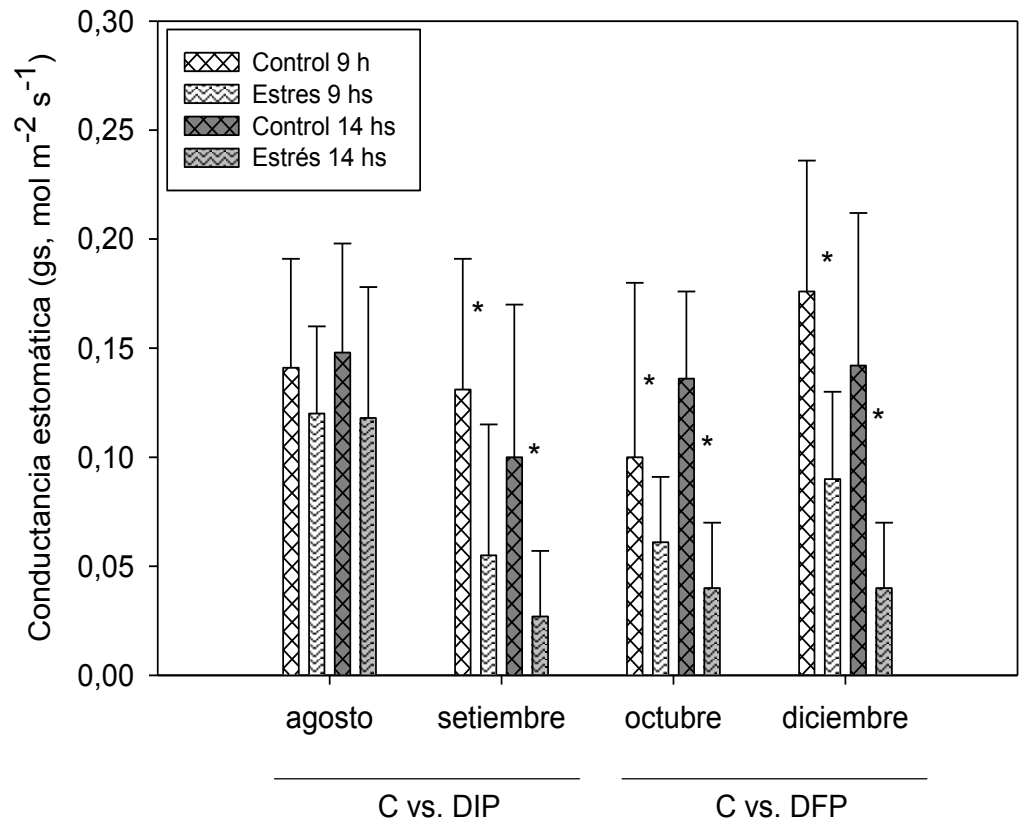

Figura 4.8 Conductancia estomática $\left(g_{\mathrm{s}}, \mathrm{mol} \mathrm{m}^{-2} \mathrm{~s}^{-1}\right)$ en plantas con y sin restricción hídrica, medida a las 9 y a las 14 hs. C: plantas control; Estrés: plantas con déficit hídrico al momento de la medición (plantas del tratamiento DIP en agosto y septiembre, y del tratamiento DFP en octubre y diciembre). Los asteriscos indican diferencias significativas entre $C$ y Estrés dentro de cada fecha y momento de medición con un nivel de significancia $p<0,05$. Cada columna representa el promedio y desvío estándar de 6 plantas.

Sin embargo, la conductancia estomática no presentó un patrón definido con respecto al DPV tanto en condiciones óptimas de agua en suelo como de deficiencia hídrica (coeficientes de correlación no significativos, $p>0,05$ ) (Figura 4.9), por lo que no se encontró el comportamiento esperado de acuerdo a una alta sensibilidad estomática, que predice una relación exponencial negativa entre la $g_{\mathrm{s}}$ y el DPV (o lineal negativa entre $g_{\mathrm{s}}$ y el InDPV). 


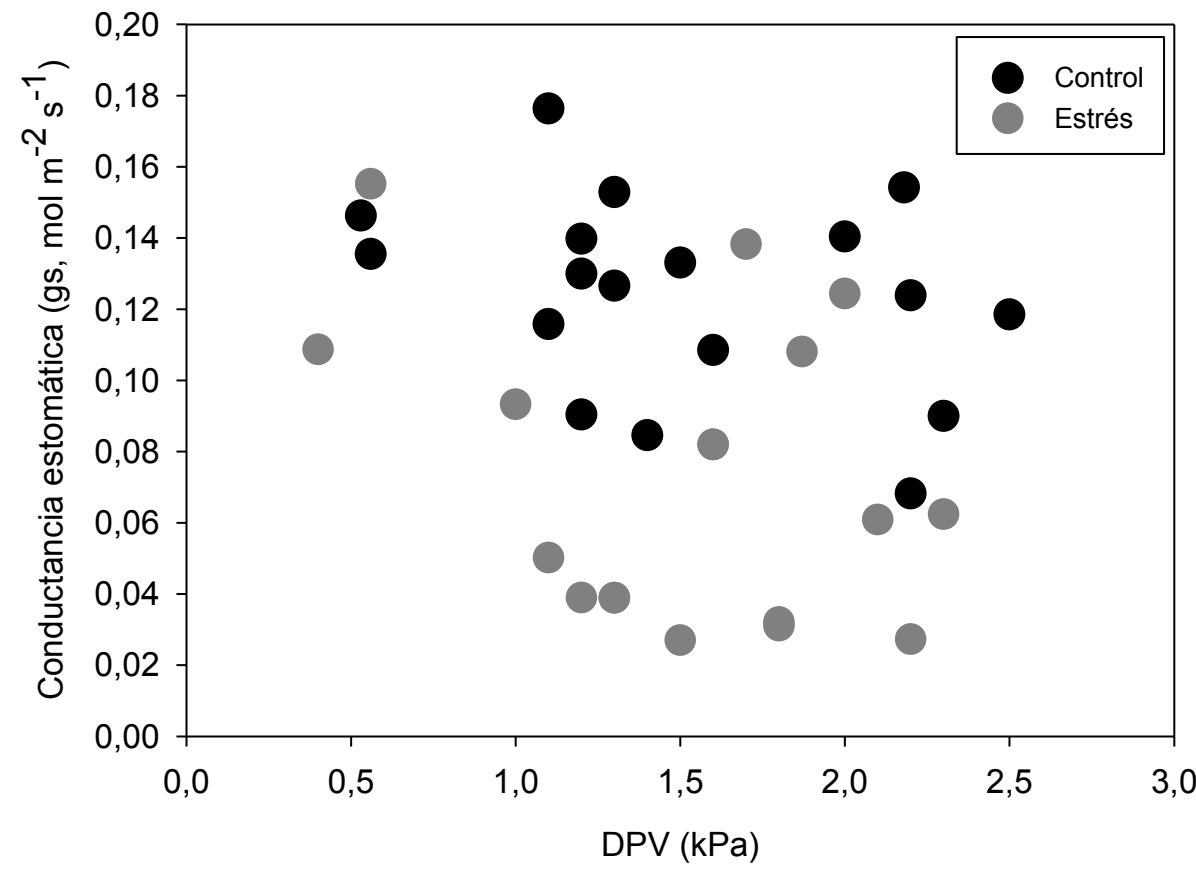

Figura 4.9 Conductancia estomática en función del déficit de presión de vapor de la atmósfera (DPV, $\mathrm{kPa}$ ) en plantines de Pinus taeda con y sin restricción hídrica en el suelo. Cada punto representa el promedio de 6 plantas del control y los tratamientos DIP y DFP.

La $A_{\text {sat }}$ promedio ( \pm desvío estándar) fue de $8,1 \pm 2,4 \mu \mathrm{mol} \mathrm{m}^{-2} \mathrm{~s}^{-1}$ en las plantas control y de $4,0 \pm 2,5 \mu \mathrm{mol} \mathrm{m}^{-2} \mathrm{~s}^{-1}$ en el tratamiento de estrés DIP, siendo las diferencias entre ambos estadísticamente significativas $(p<0,01)$.

Las curvas presión-volumen ajustadas al tejido foliar de plantas control y del tratamiento DIP indicaron que no hubo ajuste osmótico o elástico significativos en situaciones de déficit hídrico. Todos los parámetros analizados fueron similares entre $C$ y DIP. El $\Psi_{\text {Пsat }}$ promedio ( \pm desvío estándar) de ambos tratamientos fue de $-1,9( \pm 0,5)$ MPa; el $\Psi_{\text {TLP }}$ fue $-2,5( \pm 0,9) \mathrm{MPa}$, y la fracción apoplástica fue de $65( \pm 9) \%$. El módulo de elasticidad presentó gran variabilidad entre individuos de un mismo tratamiento, con un valor medio ( \pm desvío estándar) de $20( \pm 21,6) \mathrm{MPa}$.

La conductividad hidráulica específica $\left(k_{s}\right)$ de las ramas tampoco mostró diferencias entre el control y el tratamiento DIP, con valores promedios ( \pm desvío estándar) de $1,07( \pm 0,21)$ y $0,91( \pm 0,19) \mathrm{Kg} \mathrm{s}^{-1} \mathrm{~m}^{-1} \mathrm{MPa}^{-1}$ respectivamente. 


\section{DISCUSIÓN}

\section{Crecimiento en altura y diámetro basal}

Las plantas bajo déficit hídrico tuvieron un patrón general de crecimiento en altura y dac similar al de las plantas control, presentando sus valores máximos y mínimos en los mismos momentos. Este tipo de patrón coincide con el encontrado por Gelid de Rubial et al. (1997), quienes determinaron para esta especie e igual región en la que se realizó este estudio, Noreste de Argentina, que la altura total presenta un aumento del incremento mensual entre los meses de julio a octubre, momento éste a partir del cual el incremento comienza a declinar para esta especie.

El déficit hídrico impuesto en verano no afectó el crecimiento en altura y dac de los árboles, mientras que el déficit impuesto en la primavera, ya sea al inicio o al final de la misma, sí tuvo un efecto significativo sobre la tasa de crecimiento en altura y dac. Las plantas expuestas a déficit de agua en el suelo al inicio del período de crecimiento, lograron recuperar las tasas de crecimiento a los 30 días posteriores al cese del déficit hídrico. Este grupo de plantas pertenecientes a DIP, alcanzaron un segundo pulso máximo de tasa de crecimiento de magnitud similar al primero para el caso de la altura, tasa que había sido menor al de las plantas control debido a que coincidió temporalmente con la imposición del déficit hídrico. En contraste, las plantas expuestas a estrés más avanzada la primavera, no recuperaron su crecimiento en altura aún a los 50 días posteriores de cese del déficit hídrico (fecha en que culminó el experimento). Sin embargo el dac manifestó una leve recuperación en el crecimiento a los 20 días aproximadamente luego del cese del déficit hídrico. Posiblemente, la falta de recuperación del crecimiento en altura se debió a que el momento de imposición del estrés coincidió con el momento en el que se observa una disminución en la tasa de crecimiento diaria, siendo esto normal dentro del período de crecimiento, ya que fue observado también dentro del control sin estrés, y con ello limitando su capacidad de recuperación posterior. Estos resultados ponen de manifiesto la importancia de considerar el momento de ocurrencia de la restricción de agua en el suelo, para poder predecir las respuestas en crecimiento inmediatas y posteriores al mismo. 
Por otro lado, si bien se observó una recuperación del crecimiento en el tratamiento DIP, el crecimiento relativo acumulado fue inferior al control, tanto en altura como en diámetro del tallo. Esto se debió a que la mayor proporción del crecimiento acumulado ocurre al inicio del período de crecimiento, básicamente entre agosto y septiembre, momento en el que se impuso el déficit de agua en el tratamiento DIP, y que condujo a una significativa disminución de la tasa de crecimiento, afectando así el crecimiento acumulado. Por el contrario, el déficit hídrico impuesto en verano (DV) no afectó el crecimiento relativo acumulado en ninguna de las dos variables consideradas.

\section{Distribución de la biomasa aérea en los diferentes compartimentos}

Si bien se observaron efectos significativos del déficit hídrico en primavera sobre el crecimiento en altura total y dac, no se observaron cambios en la partición de la biomasa dentro de la fracción aérea de la planta, así como tampoco sobre la función del leño $\left(k_{s}\right)$ de los plantines. Respecto a la biomasa, no se cuenta con información de esta variable al inicio del ensayo, por lo cual no es posible afirmar con seguridad que las plantas del control hayan tenido menor biomasa al inicio. Sin embargo, su menor altura total y dac registrados al inicio del ensayo sugieren que este grupo de plantas dentro del control presentó una biomasa también menor en ese momento. En este sentido, se observó que la biomasa final estuvo estrechamente relacionada con el incremento en dac y en volumen de los plantines $\left(R^{2}\right.$ promedio para las regresiones de los cuatro tratamientos $=0,71$, datos no mostrados), sugiriendo que las plantas que más incrementaron su volumen de tallo fueron las que presentaron la mayor producción de biomasa al final del ensayo. Por lo tanto, es plausible deducir que la misma biomasa al final del ensayo en todos los tratamientos nos reflejaría una mayor producción aérea relativa de biomasa en el control respecto de los tratamientos donde se impuso el déficit hídrico, siendo esto un resultado esperado de acuerdo a los patrones de crecimiento en la altura total y dac, $g_{\mathrm{s}}$ y $A_{\text {sat }}$ registrados en el período. $\mathrm{Si}$ bien las plantas en este estudio no mostraron diferencias en la asignación de biomasa entre los distintos compartimentos, en líneas generales la asignación diferencial entre compartimentos es un fenómeno que suele ser observado (King et al. 1999). También es común, ante déficit hídrico, detectar modificaciones en la partición entre los 
compartimentos aéreos y subterráneos, sin embargo este último no fue considerado en este ensayo, por lo cual no se pueden hacer inferencias al respecto.

\section{Anatomía foliar y de leño}

De manera menos contundente, nuestros resultados muestran que las plantas manifestaron algunas respuestas morfológicas a nivel foliar ante el déficit hídrico, como ser una tendencia a un mayor espesor de epidermis, y un aumento en el tamaño de los estomas acompañado de una reducción en la densidad estomática. Desde el punto de vista de la regulación del estado hídrico de las plantas, los estomas son estructuras importantes tanto para hacer frente a cambios ambientales diarios (corto plazo) como estacionales. En este último caso, la regulación estomática a más largo plazo puede desarrollarse a través de una aclimatación ambiental mediada por una modificación de los estomas, alterando su morfología y frecuencia (Casson y Gray 2008; England y Attiwill 2011), fenómeno que sí se observó en este sistema de estudio. Sin embargo, los cambios observados a nivel estomático (mayor tamaño individual de estoma y menor densidad) resultan en un mantenimiento del área de poros, lo que resulta difícil de explicar como una respuesta con carácter adaptativo. En este sentido, al igual que lo determinado en este capítulo, antecedentes en otras especies reportan una disminución de la frecuencia de estomas en respuesta al déficit hídrico (e.g. Xu y Zhou 2008), asociándose la característica de menor densidad estomática a una mayor tolerancia a este tipo de estrés (Yu et al. 2008; Liu et al. 2012) y una mayor eficiencia en el uso del agua (Monclus et al. 2006). Sin embargo, y contrariamente a lo observado aquí para Pinus taeda, el tamaño de los estomas generalmente disminuye frente al déficit hídrico (Nautiyal et al. 1994; Xu y Zhou 2008; Bosabalidis y Kofidis 2002), pero existen algunos estudios que muestran un aumento del tamaño de los estomas frente a este factor de estrés (e.g. Rodiyati et al. 2005).

\section{Relaciones hídricas e intercambio gaseoso}

Si bien la regulación estomática puede manifestarse en el corto plazo mediante una alta sensibilidad estomática al DPV (Buckley 2005, Casson y Gray 2008), ésta no fue encontrada en estos resultados. Esta baja sensibilidad estomática al DPV también ha 
sido descripta para Pinus taeda por Aspinwall et al. (2011a) y Tang et al. (2003), y ha resultado en el presente estudio en un comportamiento anisohídrico, pero isohidrodinámico (Franks et al. 2007), de los plantines evaluados, en los que las plantas cuyos potenciales hídricos en pre-alba fueron menores, como en los tratamientos de déficit, alcanzaron potenciales hídricos foliares al mediodía también menores respecto al control, manteniéndose gradientes de potenciales hídricos foliares similares entre tratamientos. Este mantenimiento del gradiente de potencial entre el suelo (estimado por el potencial hídrico de las hojas en pre-alba y considerando equilibrio termodinámico nocturno entre el suelo y el tejido foliar) y las hojas contribuiría a mantener el movimiento de agua en fase líquida en magnitud similar entre tratamientos.

Por otro lado, y más allá de la anatomía de los estomas y de su densidad discutidos en el apartado anterior, la conductancia estomática sí reflejó los efectos del déficit hídrico en el suelo, observándose el cierre estomático parcial en los tratamientos de déficit en algunas fechas, lo que disminuyó la capacidad de fijación de $C$ por unidad de área foliar (menor $A_{\text {sat }}$ ). Estos resultados coinciden con lo determinado por Faustino et al. (2013) para la misma especie y zona de estudio, quienes encontraron que las tasas de crecimiento menores observadas en algunas familias estaban relacionados a $g_{\mathrm{s}}$ también menores.

Si bien el comportamiento estomático mostró una respuesta a la deficiencia de agua en el suelo, ésta no se vio sinergizada por una sensibilidad alta al DPV, resultando en una ausencia de cierre estomático completo en todo el período de estudio. Esto permitiría a los genotipos estudiados de Pinus taeda continuar fijando carbono y consecuentemente, alcanzar crecimientos diarios significativos aún bajo deficiencia hídrica moderada. En este sentido, Zweifel et al. (2009) determinaron que P. sylvestris puede abrir sus estomas en condiciones moderadas de sequía y soportar por cortos períodos de tiempo un déficit más severo; sin embargo requiere de precipitaciones a intervalos regulares para permanecer con sus estomas abiertos y seguir siendo productiva.

Por otro lado, si bien el ajuste osmótico es una respuesta al déficit hídrico ampliamente observada en muchas especies (e.g. Parker et al. 1982; Meier et al. 1992; 
Nguyen-Queyrens y Bouchet-Lannat 2003; Villar-Salvador et al. 2004), para Pinus taeda no fueron observados ajustes osmóticos ni elásticos. Este resultado es similar a los encontrados por Fernández et al. (2014) en P. ponderosa y por Villar-Salvador et al. (1999) en P. halepensis; sin embargo están en contraposición a los encontrados por Meier et al. (1992) en dos familias de $P$. taeda con valores promedios para $\Psi_{\Pi \text { sat }}$ y $\Psi_{\text {TLP }}$ de -1,3 MPa y -1,9 MPa, respectivamente, para plantas no estresadas, y de -1,5 MPa y2,13 MPa respectivamente, en plantas bajo condiciones de déficit hídrico. Estos valores y aquellos encontrados por Schulte y Henry (1992) son superiores a los determinados aquí lo cual sugiere que, a pesar de no presentar ajuste osmótico, estos orígenes de $P$. taeda poseen parámetros hídricos consistentes con una relativamente alta capacidad de mantenimiento de la turgencia celular, carácter que constituye una ventaja frente a condiciones de déficit hídrico.

Como se mencionó anteriormente, la $k_{\mathrm{s}}$ no difirió entre los tratamientos. Esta variable fue determinada al mediodía donde la tensión en el xilema es alta y podría provocar la cavitación de los conductos xilemáticos. Sin embargo, la similitud en la capacidad de transporte de agua en todas las plantas sugiere que los potenciales hídricos foliares menores experimentados por las plantas bajo déficit hídrico no afectaron la $k_{\mathrm{s}}$, a menos que la $k_{\mathrm{s}}$ máxima, la cual no fue determinada en este estudio, difiera entre los tratamientos.

\section{CONCLUSIONES}

Los resultados de este capítulo constituyen una primera aproximación a las relaciones entre crecimiento y fisiología foliar en respuesta a la variación temporal en la disponibilidad de agua en el suelo para algunos orígenes genéticos selectos de Pinus taeda. El déficit de agua en el suelo durante la primavera tuvo un marcado efecto negativo sobre el crecimiento en altura total y dac, con distinta capacidad de recuperación (al menos en el mediano plazo) en función del momento de ocurrencia del estrés. Por el contrario, el déficit de agua en el suelo en momentos de menor crecimiento dentro de la temporada (verano) no impactó de manera significativa sobre la tasa diaria ni el crecimiento acumulado, en comparación con las plantas creciendo sin restricciones hídricas en el suelo. Posiblemente las altas temperaturas que 
conducen a DPV elevados en este momento del año impliquen una limitación a la fijación de carbono, independientemente de la disponibilidad de agua a nivel de las raíces, homogenizando las respuestas en crecimiento.

Estos resultados ponen de manifiesto la importancia de considerar el momento de ocurrencia del déficit hídrico sobre el crecimiento de plantines de Pinus taeda, lo que puede contribuir a la predicción del comportamiento de la especie frente a cambios en el clima ya sean debidos a la variabilidad climática en un sitio dado, o bien por modificaciones en las áreas de implantación de la especie. En este sentido, haciendo referencia a la menor precipitación acumulada en agosto que ha sido detectada en los últimos años respecto a la histórica en la Pcia. de Misiones, ésta resulta ser de suma importancia dado que este mes coincide con el inicio del período de crecimiento para la especie en esta región. Por otro lado, también se observaron menores precipitaciones en los últimos años durante los meses de mayor demanda atmosférica, lo cual influye en la disminución del crecimiento durante el verano, aunque no de manera significativa. Sin embargo, en términos económicos esta disminución puede resultar de interés para los productores. Se requieren investigaciones futuras que evalúen la capacidad de recuperación del crecimiento (resiliencia) a mayores plazos que los analizados en el presente capítulo, así como la posible respuesta diferencial entre genotipos (variabilidad genética intraespecífica). Asimismo, se requiere estudiar aún el posible impacto diferencial sobre otros destinos del carbono como las reservas de carbohidratos o el desarrollo radical de las plantas, los que pueden afectar la tolerancia al estrés y el crecimiento en eventos posteriores de sequía. 
CAPÍTULO 5

\section{PROCESOS ECO-FISIOLÓGICOS QUE} EXPLICAN EL CRECIMIENTO DIFERENCIAL DE FAMILIAS DE Pinus taeda L. EN CONDICIONES DE CAMPO 


\section{PROCESOS ECO-FISIOLÓGICOS QUE EXPLICAN EL CRECIMIENTO DIFERENCIAL DE FAMILIAS DE Pinus taeda L. EN CONDICIONES DE CAMPO}

\section{RESUMEN}

Este capítulo pretende evaluar variables morfo-fisiológicas responsables del crecimiento diferencial de plantines de Pinus taeda bajo condiciones ambientales naturales en la Provincia de Misiones, Argentina. Los plantines manifiestan en general una mayor susceptibilidad al estrés biótico y abiótico que los árboles adultos, por lo que el crecimiento y supervivencia al inicio es crucial para la instalación de las plantaciones y con ello, la sustentabilidad de la actividad forestal. Los individuos evaluados constituyen dos grupos de medios-hermanos (de polinización abierta) provenientes de dos madres, una de alto crecimiento $(A C)$ y una de bajo crecimiento (BC). Se evaluó el incremento en altura y diámetro a la altura del cuello (dac), la conductancia estomática $\left(g_{\mathrm{s}}\right)$, el potencial hídrico foliar $\left(\Psi_{\mathrm{f}}\right)$ al mediodía y en pre-alba, la fotosíntesis a saturación de luz $\left(A_{\mathrm{sat}}\right)$, la conductancia hidráulica $\left(K_{\mathrm{h}}\right)$ y conductividad hidráulica específica $\left(k_{s}\right)$ y foliar específica $\left(k_{l}\right)$ de ramas, y la asignación de biomasa aérea. La familia AC presentó mayor incremento absoluto en altura y dac durante el período evaluado, y mayor producción de biomasa aérea que la familia BC. Los patrones diarios de $g_{\mathrm{s}}$ y $\Psi_{\mathrm{f}}$, y la $A_{\text {sat }}$ fueron similares entre ambas familias dentro de cada fecha de evaluación. La familia AC presentó mayor $k_{l}$ y su $k_{\mathrm{s}}$ fue más afectada bajo condiciones de déficit hídrico que la BC. Las diferencias observadas en la asignación de la biomasa entre órganos aéreos de la planta, que resultan en cambios en la arquitectura hidráulica de la misma, serían responsables -al menos en parte- de las tasas diferenciales de crecimiento. Sin embargo, algunos parámetros, como las mayores caídas en $k_{\mathrm{s}}$ y $g_{\mathrm{s}}$ en un período seco y la tendencia a menores potenciales hídricos mínimos, sugieren que los genotipos $A C$ podrían ser más susceptibles al déficit hídrico, requiriéndose más estudios para poner a prueba esta hipótesis. 
Los resultados de este capítulo se encuentran en revisión en la Revista Bosque con la siguiente denominación de manuscrito: Bulfe N, Faustino L, Pinazo M, Graciano C y Fernández ME. Bases fisiológicas del crecimiento diferencial en la fase inicial del desarrollo de dos progenies de Pinus taeda bajo condiciones de campo, en Misiones Argentina. 


\section{INTRODUCCIÓN}

Pinus taeda L. fue introducida en zonas subtropicales de Sudamérica, tanto en Brasil como en Argentina. En ambos países se han logrado, mediante programas de mejoramiento genético, diferentes grados de éxito en lo que se refiere a productividad de la especie. Es así que se verifican mayores productividades a las de su lugar de origen, alcanzando incrementos promedios anuales de entre $30-35 \mathrm{~m}^{3} \mathrm{ha}^{-1}$ año-1 (Cubbage et al. 2007). Esta alta productividad es altamente dependiente de las condiciones edáficas del sitio (Fernández et al. 2012), así como también de su genética. Los programas de mejoramiento genético se vienen desarrollando en la región desde la década del '70 del siglo pasado, intensificándose a fines de los '90 (Rodríguez y Gauchat 2005).

Además del factor genético, el crecimiento es altamente dependiente de factores ambientales como el suelo y el clima. Según los Informes del IPCC (2007), que proyectan cambios en la temperatura y las precipitaciones para la región noreste de Argentina, previéndose eventos climáticos adversos de mayor magnitud e intensidad, la productividad de las forestaciones y en algunos casos, su sobrevivencia, estarían en situación de riesgo. De esta manera, los procesos fisiológicos que determinan el crecimiento y las estrategias de sobrevivencia de las especies en general y de Pinus taeda en particular, resultan de importancia. Dentro de éstas, las fases iniciales del desarrollo resultan particularmente de interés para la instalación de plantaciones comerciales. En este sentido, son numerosos los estudios (revisados y citados en Niinemets 2010) que indican que la resistencia general a la sequía, estrés por ozono y por factores bióticos es mayor en árboles grandes no senescentes que en plantines y juveniles. La utilización de un enfoque ecofisiológico para describir y predecir la productividad se encuentra ampliamente desarrollada para $P$. taeda en su lugar de origen (e.g. Teskey et al. 1987; Barnes 2002; Tang et al. 2003; Rahman et al. 2003; Aspinwall et al. 2011ab, 2013), en el que las condiciones ambientales son diferentes a la región subtropical donde ha sido introducida. En contraste, muy pocos son los estudios ecofisiológicos de los materiales genéticos introducidos en Argentina. Una excepción son los estudios de Faustino et al. (2012, 2013), quienes aplicaron un 
enfoque ecofisiológico a la evaluación de orígenes genéticos cultivados en este país, con énfasis en respuestas a la fertilización.

A pesar de que el conocimiento de Pinus taeda en su lugar de origen es muy vasto, tal como ocurre con otras especies, el enfoque ecofisiológico ha sido históricamente más aplicado al manejo silvícola y al desarrollo de modelos de producción basados en procesos que en los programas de mejoramiento genético tradicionales (Martin et al. 2005). Sin embargo, las ventajas de la aplicación de criterios ecofisiológicos en la selección de individuos más productivos, pero también más eficientes en el uso de los recursos del ambiente y más resistentes a estrés abiótico son evidentes, particularmente a la luz de los desafíos que impone el cambio climático global. En este contexto, es relevante el conocimiento del conjunto de los caracteres y procesos que determinan el crecimiento, el uso de los recursos y la resistencia al estrés en cada una de las especies de interés, de manera de contribuir al desarrollo de criterios de selección adecuados para cada caso.

Entre los principales factores que afectan la fijación de carbono en Pinus taeda se destaca la limitación estomática (Teskey et al. 1986; Grissom y McKeand 2001), dada la estrecha relación entre la conductancia estomática $\left(g_{s}\right)$ y la fotosíntesis (Teskey et al. 1987). En algunos trabajos se ha reportado un comportamiento estacional de la $g_{\mathrm{s}}$ (Tang et al. 2003; Aspinwall et al. 2011b), que puede ser el resultado de la influencia de la temperatura ambiental (Teskey y Will 1999), la disponibilidad hídrica, la humedad del aire, o la intensidad e interceptación lumínica (Teskey et al. 1986; Tang et al. 2003). La $g_{\mathrm{s}}$ y la sensibilidad estomática, es decir, la respuesta a corto plazo de esta variable a condiciones del ambiente como el déficit de presión de vapor de la atmósfera (DPV), tienen además una relación estrecha con la funcionalidad del sistema conductivo (Oren et al. 1999). En el caso de P. taeda, se han observado comportamientos diferenciales en la sensibilidad estomática al DPV entre genotipos (Aspinwall et al. 2011ab). Esto y/o una diferente vulnerabilidad a la cavitación del xilema podrían explicar el decrecimiento diferencial de la conductividad hidráulica específica $\left(k_{\mathrm{s}}\right)$ de tallos con la disminución del agua en el suelo observado en distintos genotipos (ANoborio et al. 1999). Si bien la regulación estomática del intercambio gaseoso sí tendría influencia en el crecimiento diferencial entre genotipos ante distintas 
condiciones ambientales, la capacidad fotosintética $\left(A_{\text {sat }}\right)$ en sí no sería responsable del crecimiento diferencial entre progenies (Martin et al. 2005).

La mayoría de los trabajos que abordan la influencia de las condiciones ambientales en la fisiología y crecimiento de Pinus taeda se han desarrollado bajo condiciones controladas. Sin embargo, es de suma importancia sumar a este tipo de estudios conocimientos sobre el comportamiento de la especie bajo las múltiples y/o sucesivas condiciones de estrés que se pueden dar en situaciones de campo (Niinemets 2010). Si bien en este caso no es posible modificar dichas condiciones ni aislar factores que permitan describir relaciones causales, este tipo de estudio tiene la ventaja de someter a las plantas a una situación realista de disponibilidad de agua en el suelo, contrario a los ensayos en macetas, especialmente en especies de rápido crecimiento caracterizadas por altas tasas transpiratorias. Este estudio tiene como objetivo identificar bajo condiciones ambientales naturales, las variables morfo-fisiológicas responsables del crecimiento diferencial en altura total y diámetro basal en plantines de $P$. taeda descendientes de dos genotipos seleccionados por sus tasas de crecimiento contrastantes. Como hipótesis de trabajo se planteó que las diferencias en crecimiento (altura total y dac) entre las familias están relacionadas con diferencias en comportamiento estomático, conductividad hidráulica específica del xilema y asignación de biomasa entre compartimentos aéreos (hojas vs. tejido leñoso) que favorecen el aumento de la conductividad hidráulica por unidad de área foliar. En este sentido, se hipotetiza que las familias de rápido crecimiento presentan una menor sensibilidad estomática que las de bajo crecimiento, cerrando más tardíamente o en menor magnitud los estomas ante condiciones de déficit hídrico en el suelo o la atmósfera, lo que podría redundar en una mayor capacidad de fijación de carbono. Asimismo, se postula que las familias de alto crecimiento presentan una mayor $k_{\mathrm{s}}$ de ramas o menor asignación de biomasa a hojas y una mayor biomasa a fuste que las de bajo crecimiento, permitiéndoles una alta capacidad de provisión de agua por unidad de área foliar (alta conductividad hidráulica foliar específica). 


\section{MATERIAL Y MÉTODOS}

\section{Área de estudio y material utilizado}

El ensayo fue instalado en el Campo Anexo Laharrague del Instituto Nacional de Tecnología Agropecuaria (INTA) de Argentina, ubicado en el departamento de Montecarlo, Provincia de Misiones (26 30’ S, 54 40’ O). El clima de la región es subtropical sin estación seca marcada, con precipitación media acumulada de 2000 $\mathrm{mm}$ anuales y temperatura media anual de 20 ㅇ (Ligier 2000).

Las variables ambientales fueron registradas a través de una estación meteorológica (Davis GroWeather) situada a $100 \mathrm{~m}$ aproximadamente del ensayo. Debido a problemas de funcionamiento del sensor de humedad relativa que arrojó valores dudosos, el promedio de DPV presentado en la Figura 5.1 corresponde al calculado en base a las temperaturas registradas en el sitio y período de estudio, y la humedad relativa promedio de cada mes (período 1991-2010) correspondiente a la Estación Meteorológica Iguazú (información provista por el Servicio Meteorológico Nacional de Argentina). Dicha estación está situada a $120 \mathrm{Km}$ de distancia del área de estudio. Dentro del período de estudio (septiembre 2009-noviembre 2010) ocurrieron períodos contrastantes en cuanto a las condiciones climáticas, especialmente en la cantidad de agua, donde puede observarse que la primavera de 2010 presentó menor precipitación acumulada respecto a la primavera de 2009. En este sentido, se pueden destacar dos períodos contrastantes respecto a la cantidad de agua en el suelo, ambos con valores de DPV similares: marzo, con abundantes precipitaciones, y agosto como un mes de mayor estrés ambiental (menor precipitación acumulada) (Figura 5.1). 

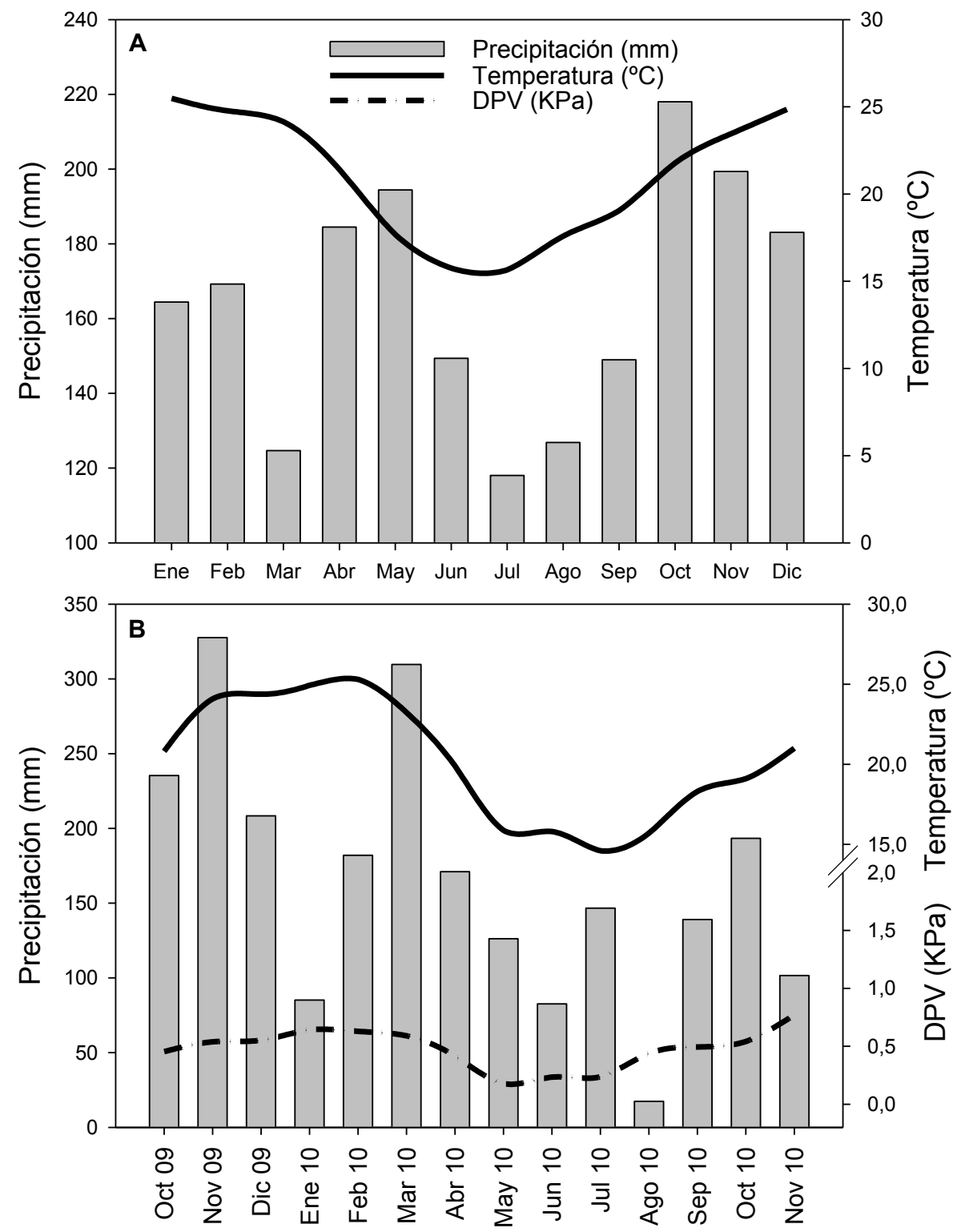

Figura 5.1 Información meteorológica del área de estudio. A) Datos climáticos para el área de estudio, para el período comprendido entre 1963-2010. B) Datos meteorológicos en el período primavera 2009-primavera 2010 registrados en el Campo Anexo Colonia Laharrague, Misiones, Argentina. Promedio mensual en el caso de temperatura del aire y déficit de presión de vapor, y valor acumulado mensual en el caso de las precipitaciones.

En septiembre de 2009 , plantines de tres meses de edad producidos de semilla proveniente de la polinización abierta (medios-hermanos) de dos familias de Pinus taeda clasificadas por el Programa de Mejoramiento Genético (PMG) como familias con diferentes tasas de crecimiento, fueron llevados al campo, luego de ser producidos en un invernáculo en condiciones de producción estándar en la región de estudio. Los genotipos utilizados en el ensayo forman parte PMG de esta especie llevado a cabo por 
el INTA (Instituto Nacional de Tecnología Agropecuaria) de Argentina. Los genotipos analizados en este capítulo, al igual que en los otros, fueron seleccionados por provenir de madres con diferentes tasas de crecimiento en volumen y rectitud de fuste, dentro de un ranking realizado al quinto año de edad (etapa juvenil). Este se elaboró mediante la combinación de ambas variables, representando cada una de ellas un $70 \%$ y $30 \%$, respectivamente. Se evaluó así la descendencia (medio-hermanos) de una familia catalogada como de alto crecimiento $(\mathrm{AC} / \mathrm{I35})$ y una de bajo crecimiento (BC/T10).

\section{Diseño del experimento a campo}

Para la realización de la plantación se consideró una distancia de plantación de 0,8 $\mathrm{x}$ 0,8 m entre filas y líneas. Este espaciamiento reducido entre las plantas pretendía minimizar la heterogeneidad espacial de las condiciones topográficas, edáficas y lumínicas dentro de la misma. Dada la corta duración del ensayo, este espaciamiento fue adecuado para el tamaño que alcanzaron las plantas dentro del mismo (Figura 5.2).

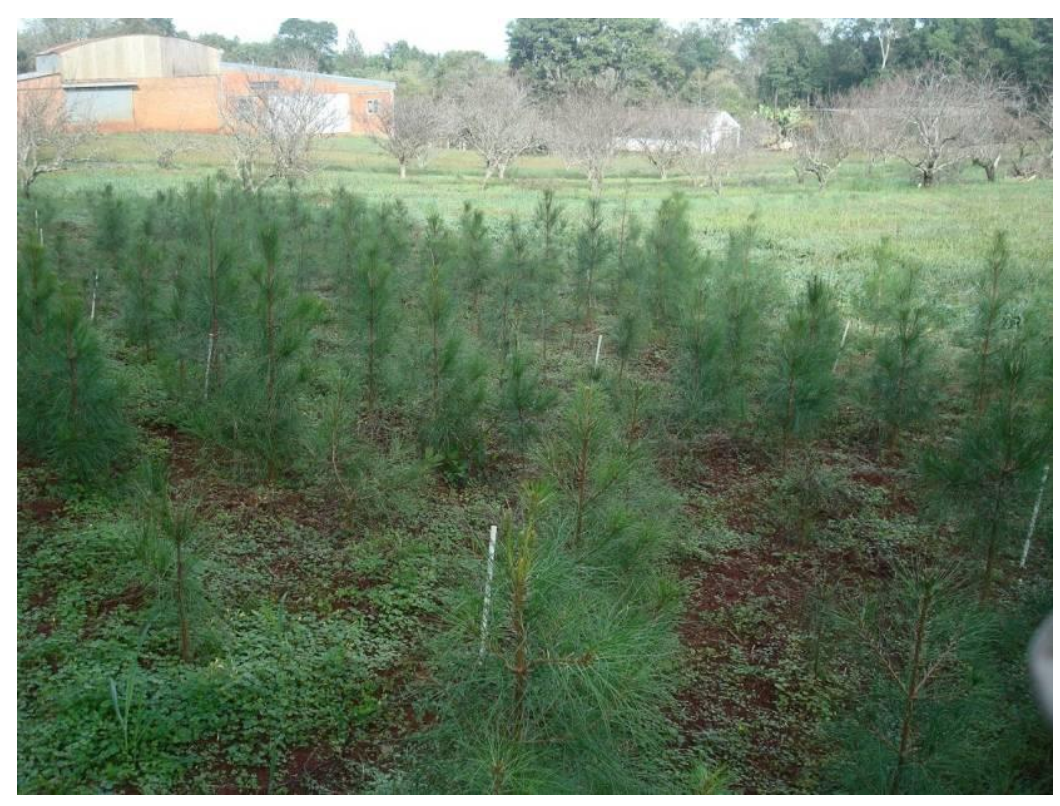

Figura 5.2 Vista general del ensayo a campo a los 10 meses de realizada la plantación (foto tomada en junio de 2010). 
Se instalaron tres parcelas conteniendo la progenie de ambas familias ( $A C$ y $B C$ ) dentro de cada una. Cuatro individuos de cada una de ellas fueron distribuidos en una línea de plantación, siendo esta línea de plantación considerada una sub-parcela. De esta manera se obtuvo un total de 12 individuos por madre en todo el ensayo.

\section{Variables medidas}

Los registros de las diferentes variables consideradas en el ensayo comenzaron en marzo del año 2010 (seis meses posteriores a la plantación), y se extendieron hasta noviembre del mismo año. Se registraron las variables altura total de cada planta $\left(h_{t}\right)$ (precisión: 0,01 m) con una cinta métrica y el diámetro a la altura del cuello (dac) (precisión: 0,01 $\mathrm{mm}$ ) de las plantas con un calibre digital. Con estas variables se estimaron el incremento absoluto (IA) y el incremento relativo (IR) de ambas variables correspondiente al período de estudio según las siguientes ecuaciones:

Donde:

$$
\begin{array}{ll}
I A(m ; m m)=T_{\text {final }}-T_{\text {inicial }} & \text { Ecuación (1) } \\
I R(\%)=\frac{T_{\text {final }}-T_{\text {inicial }}}{T_{\text {inicial }}} \cdot 100 & \text { Ecuación (2) }
\end{array}
$$

Donde:

$\mathrm{T}_{\text {final }}=$ variable de tamaño (Altura; dac) al inicio del ensayo

$\mathrm{T}_{\text {inicial }}=$ variable de tamaño (Altura; dac) al final del ensayo

De manera periódica se registraron las siguientes variables fisiológicas:

○ Conductancia estomática $\left(g_{\mathrm{s}}, \mathrm{mol} \mathrm{m}^{-2} \mathrm{~s}^{-1}\right)$ : se midió cada 2 horas $(10,12$ y 14 hs) con un porómetro Decagon Devices modelo SC-1 en dos individuos por familia de cada parcela (6 individuos por familia). Para cada medición se consideró tres fascículos completamente expandidos de la porción media de la copa, ocupando el área completa de la cámara. Las mediciones se realizaron en tres fechas durante el período de estudio, puntualmente en marzo, junio y agosto de 2010 . 
- Potencial hídrico foliar $\left(\Psi_{\mathrm{f}}, \mathrm{MPa}\right)$ : esta variable fue registrada en pre-alba y al mediodía en un individuo por familia de cada parcela $(n=3)$, utilizando para ello una cámara de presión tipo Scholander (Bio-control, Argentina). Estas determinaciones se realizaron en un fascículo completamente expandido de la parte media de la copa de la planta en marzo y agosto de 2010.

○ Fotosíntesis a saturación lumínica $\left(A_{\text {sat }}, \mu \mathrm{mol} \mathrm{m} \mathrm{m}^{-2} \mathrm{~s}^{-1}\right)$ : esta variable se midió en marzo, bajo una condición lumínica de saturación de $1200 \mu \mathrm{mol} \mathrm{m} \mathrm{m}^{-2} \mathrm{~s}^{-1}$. La misma fue realizada en la porción media de la copa en tres fascículos completamente expandidos en una planta por familia de cada parcela $(n=3)$ con un analizador de gases infrarrojo PPSystems Ciras-2 (concentración de $\mathrm{CO}_{2}: 400$ ppm; temperatura media del aire durante la medición: 25 ㄷ) $)$.

- Conductividad hidráulica $\left(k_{\mathrm{h}}, \mathrm{kg} \mathrm{m} \mathrm{s}^{-1} \mathrm{MPa}^{-1}\right)$ de ramas, conductividad hidráulica específica $\left(k_{\mathrm{s}}, \mathrm{kg} \mathrm{s}^{-1} \mathrm{~m}^{-1} \mathrm{MPa}^{-1}\right)$ y conductividad hidráulica foliar específica $\left(k_{\mathrm{l}}, \mathrm{m}\right.$ $\left.\mathrm{s}^{-1} \mathrm{MPa}^{-1}\right)$ : estas variables se midieron en ramas extraídas de la parte media de la planta de tres individuos por familia de cada parcela ( 9 individuos por familia en total). Las mediciones fueron realizadas en marzo, cuando las condiciones de crecimiento fueron óptimas de acuerdo a las condiciones climáticas, utilizándose el método del conductímetro multicanal (Fernández et al. 2010). La $k_{\text {। }}$ fue estimada como el cociente entre la $k_{\mathrm{h}}$ y la biomasa foliar alimentada por la rama. Al final del ensayo, en noviembre de 2010, cuando las condiciones ambientales fueron de mayor estrés relativo, se estimó en dos individuos por familia y parcela $(n=6)$ la conductancia hidráulica $\left(K_{\mathrm{h}}, \mathrm{kg} \mathrm{s}^{-1} \mathrm{MPa}^{-1}\right)$ en ramas con hojas. Para ello se utilizó el método de flujo estable de baja presión (SSFM, steady-state flow meter). Este método utiliza la caída de presión a través de una resistencia conocida, junto con la presión en la conexión del tallo (Zwieniecki et al. 2000), para medir el flujo en el tallo con acículas. Las muestras fueron tomadas entre las 7 y 8 horas de la mañana, colocadas en bolsas plásticas y luego llevadas al laboratorio, todas con diámetros y longitudes similares. Una vez obtenida la conductancia hidráulica de la rama con hojas, se procedió a cortar la porción con hojas de cada rama para la estimación de la $k_{\mathrm{h}}$ y la $k_{\mathrm{s}}$, estimándose luego la $k_{\downarrow}$ a partir de la $k_{\mathrm{h}}$ y la biomasa foliar de la rama. 
Al finalizar el ensayo, en noviembre de 2010, se determinó la asignación de biomasa en los distintos compartimentos aéreos (tallo, ramas y hojas) en tres plantas por familia y parcela ( 9 individuos por familia). Se pesó el total del material en fresco de cada compartimento, se extrajo una sub-muestra de cada compartimento, la cual fue pesada y luego llevada a estufa a $65 \pm 5 \stackrel{\circ}{ } \mathrm{C}$ hasta peso constante. A partir de la relación peso fresco:peso seco de las sub-muestras, se estimó el peso seco de cada compartimiento de la planta. Las muestras fueron pesadas con una precisión de 0,01 g. La selección de las plantas para el registro de las diferentes variables fue realizada completamente al azar.

\section{Análisis estadísitico}

Los datos de incremento en altura total y dac en función del tiempo fueron analizados mediante el ajuste de un modelo exponencial, realizado con el software Table Curve 2D (Jandel Scientific, AISN Software). Los modelos fueron comparados entre familias mediante el test $F$ (Zar 1999). Para el análisis de los datos de las restantes variables, se utilizó ANOVA de una vía cuyo factor de análisis fue la familia $(p<0,05)$, aplicándose un análisis por fecha de medición cuando la variable se midió en más de una fecha. Se utilizó el diseño de parcelas divididas con un $n=3$. En el caso de la $g_{\mathrm{s}}$ y la $k_{\mathrm{s}}$, además se compararon los valores dentro de cada familia entre fechas de medición con una prueba de $t$ de Student apareado $(\alpha=0,05)$.

\section{RESULTADOS}

\section{Crecimiento en altura total y dac}

El tamaño de las plantas al inicio y al final del período de medición dependió significativamente de la familia para la variable altura total, mientras que el dac no tuvo efecto de la familia al inicio del período $(p>0,05)$. El incremento absoluto en altura de cada familia entre marzo y noviembre de 2010 fue de 1,09 $\pm 0,17$ y 0,58 \pm $0,08 \mathrm{~m}$ para las familias $A C$ y $B C$, respectivamente, siendo las diferencias significativas entre ellas (Figura 5.3 panel A). El mismo tipo de diferenciación se observó en el incremento en dac para el mismo período, siendo los valores promedios de $28,2 \pm 6,4$ y 
$15,5 \pm 2,3 \mathrm{~mm}$ para las familias $A C$ y $B C$, respectivamente. Sin embargo, a diferencia de la altura total que difirió entre familias desde la primera fecha de medición, el dac se diferenció entre las mismas a partir de la medición registrada en junio de 2010 (Figura 5.3 panel B). Los modelos exponenciales ajustados a ambos parámetros en función del tiempo difirieron significativamente entre familias.

Los modelos exponenciales ajustados para la familia AC fueron:

Para la altura total $h_{\mathrm{t}}=0,166 \mathrm{e}^{(0,004 \mathrm{x})}$ con un $\mathrm{R}^{2}$ ajustado de 0,70 y para el diámetro a la base del cuello dac $=1,890 \mathrm{e}^{(0,006 \mathrm{x})}$ con un $\mathrm{R}^{2}$ ajustado de 0,75 .

Para la progenie BC los modelos ajustados fueron:

Para la altura total $h_{\mathrm{t}}=0,114 \mathrm{e}^{(0,004 \mathrm{x})}$ cuyo $\mathrm{R}^{2}$ ajustado fue de 0,75 y para el diámetro a la base del cuello dac $=2,089 \mathrm{e}^{(0,0045 x)}$ con un $\mathrm{R}^{2}$ ajustado de 0,65 .

En todos los casos, la variable independiente fue el tiempo, expresado en "cantidad de días desde la germinación" (Figura 5.3). 


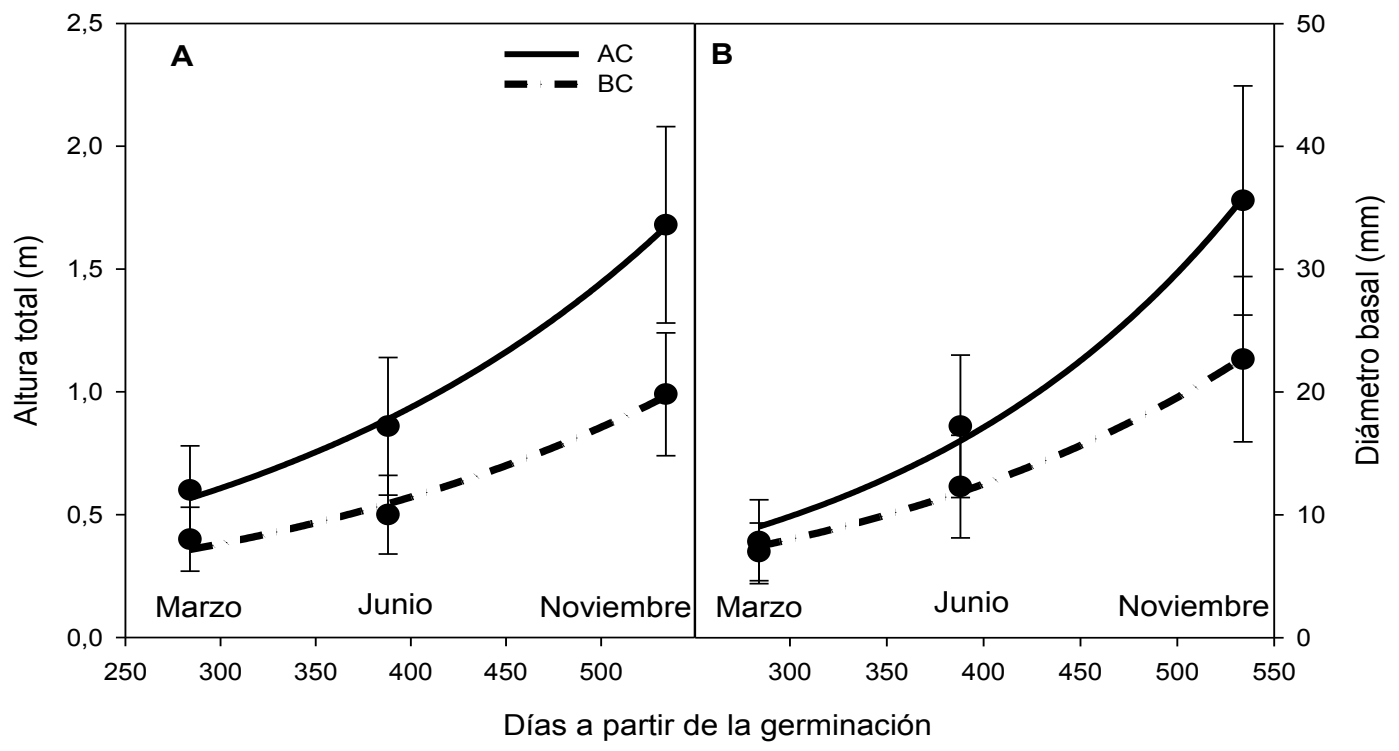

Figura 5.3 Evolución de la altura total de la planta y el diámetro basal del tallo registrada durante el período de medición marzo-noviembre de 2010 en plantines de Pinus taeda de dos familias del Programa de Mejoramiento Genético (PMG) del INTA, Argentina. A) Altura total $\left(h_{t}, m\right)$, B) Diámetro al cuello de la raíz (dac, $\mathrm{mm}$ ). AC: familia catalogada de alto crecimiento, BC: familia catalogada de bajo crecimiento. Las líneas corresponden a los modelos exponenciales ajustados al conjunto de los datos de cada familia (ver parámetros y ajustes en el texto), los que fueron distintos entre ellas (test de $F, p<0,05$ ) tanto para la variable altura como para el diámetro basal.

Contrario al incremento absoluto, el incremento relativo al tamaño inicial registrado durante el período de estudio no manifestó diferencias significativas entre progenies tanto para la variable altura total como para el incremento relativo del dac (Figura 5.4). 


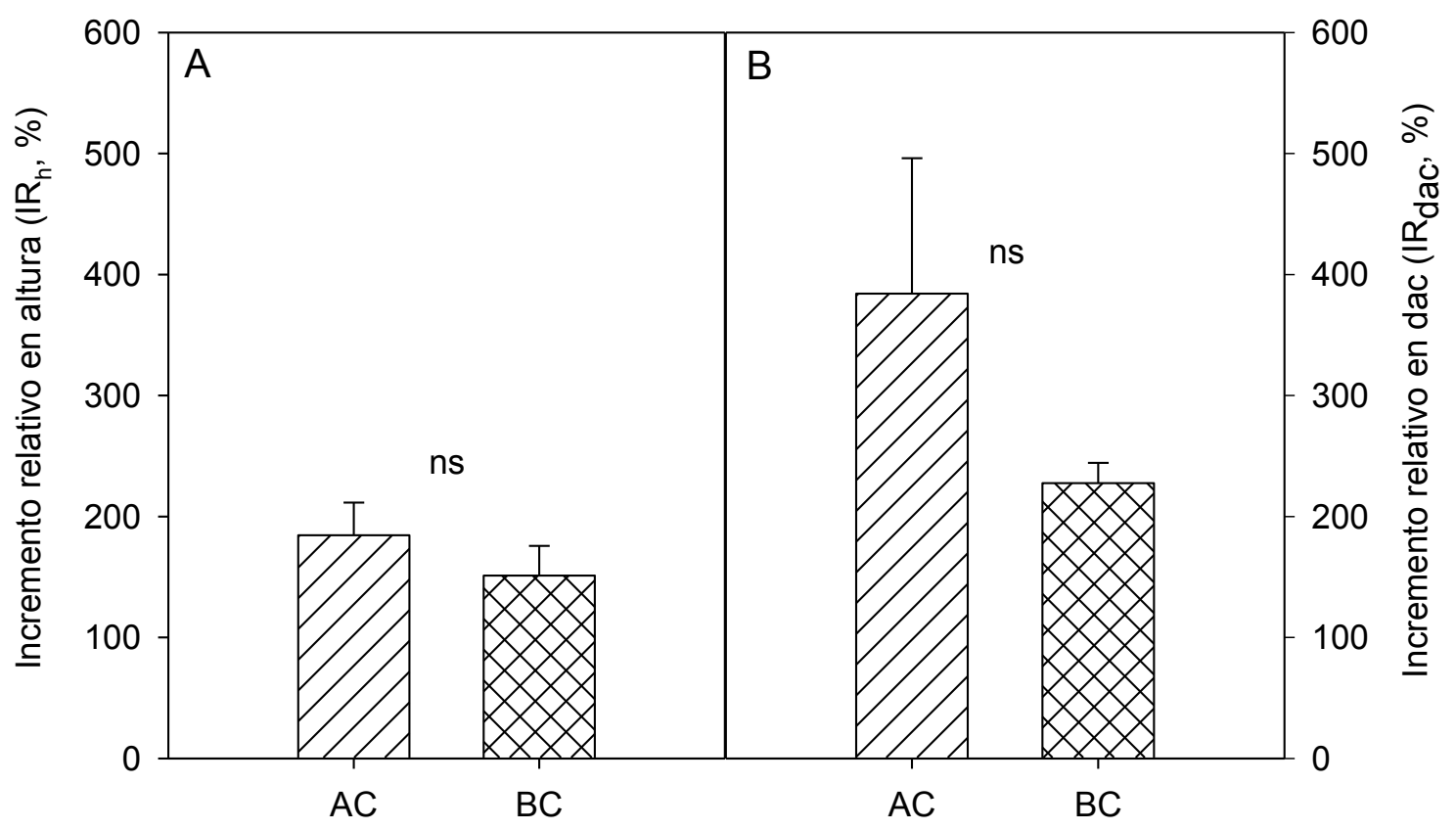

Figura 5.4 Incremento relativo de la altura total (\%, panel A) y del diámetro al cuello de la raíz (\%, panel B) entre marzo y noviembre de 2010, registrada en plantines de Pinus taeda de dos familias del Programa de Mejoramiento Genético (PMG) del INTA, Argentina ( $n=12$ ). AC: familia catalogada de alto crecimiento. BC: familia catalogada de bajo crecimiento. ns: no significativo.

\section{Producción y distribución de la biomasa aérea}

Siguiendo la tendencia del incremento en altura total y diámetro basal, la biomasa aérea absoluta al final del ensayo fue significativamente mayor en la familia AC respecto a la familia BC (Figura 5.5 panel A). Dentro de cada familia se observó una gran variabilidad en la biomasa aérea entre individuos, mostrando así un comportamiento individual a nivel de planta. La distribución relativa en los diferentes compartimentos aéreos también fue diferente en cada familia (Figura 5.5 panel B); en este sentido, la familia BC presentó una mayor proporción de biomasa foliar respecto a la familia AC. Esta combinación de distribución de materia seca en los diferentes compartimentos aéreos entre las familias resultó en distintas relaciones alométricas entre ellas. La familia BC presentó 4,1 \pm 1,3 g de materia seca de hojas por $\mathrm{g}$ de materia seca de rama, siendo este cociente estadísticamente superior al de la familia $\mathrm{AC}\left(2,4 \pm 0,8 \mathrm{~g} \mathrm{~g}^{-1}\right)$. 


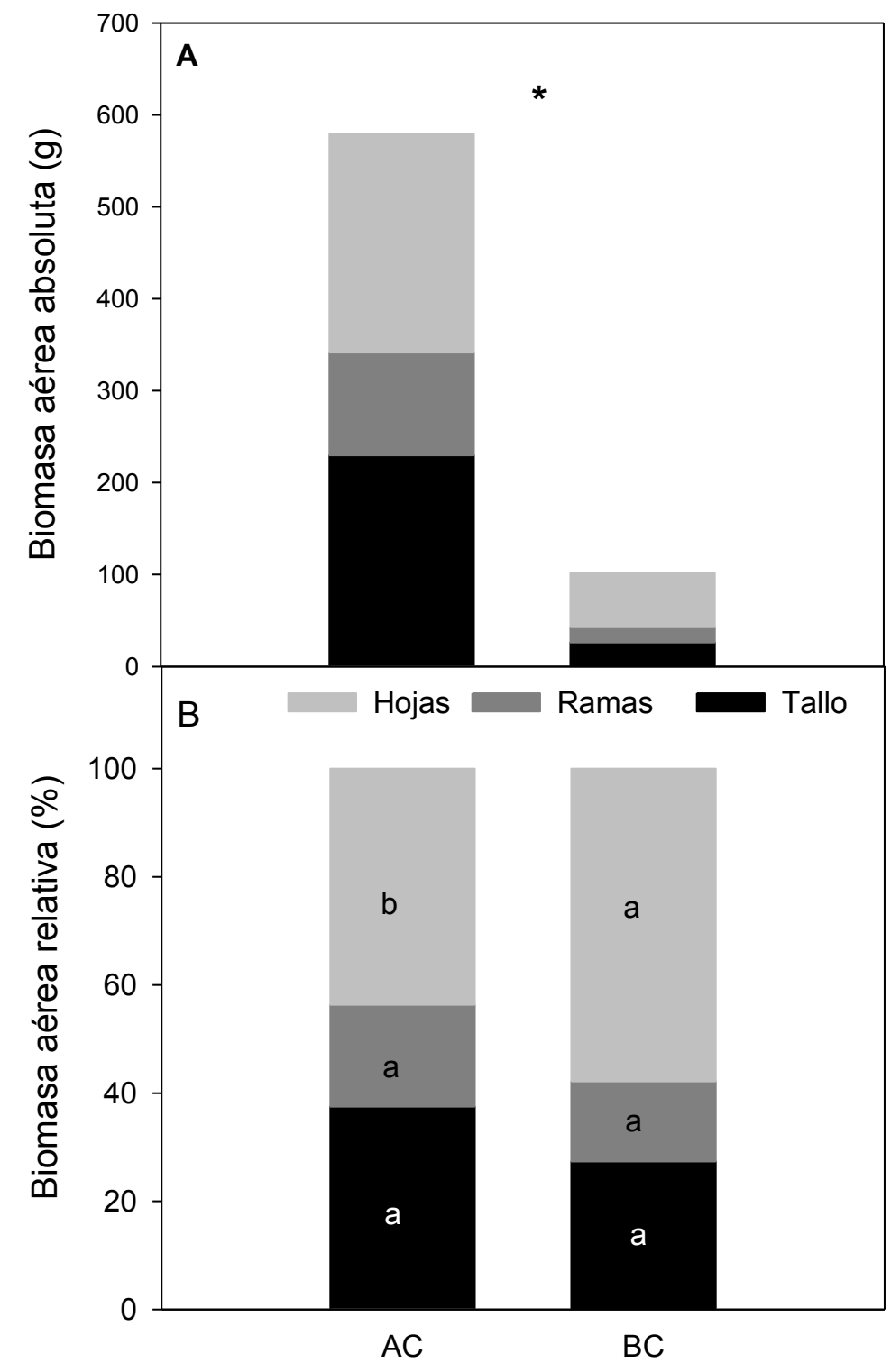

Figura 5.5 Biomasa aérea al final del ensayo de individuos de dos familias de Pinus taeda. A) Biomasa aérea total (g) discriminada por compartimentos. B) Proporción de biomasa aérea en los compartimentos tallo, ramas y hojas (\%). AC: familia catalogada de alto crecimiento. BC: familia catalogada de bajo crecimiento. *: $p<0,05$ para la biomasa aérea absoluta total. Letras diferentes indican diferencias estadísticas significativas entre familias para cada compartimento (Tukey $\alpha=0,05$; $n=9)$.

Como tendencia se observó que la familia AC presentó mayor asignación a los compartimentos tallo y ramas respecto a la familia BC. Si bien estas diferencias no fueron significativas, resultan de interés dado que en los resultados presentados anteriormente (capítulo 2), esta misma familia presentó un comportamiento similar, 
aún cuando creció en condiciones ambientales distintas a las del presente capítulo (invernáculo en maceta vs campo).

\section{Conductancia estomática, potencial hídrico y fotosíntesis neta a saturación lumínica}

Ambas familias presentaron, dentro de cada fecha, patrones diarios similares de conductancia estomática (Figura 5.6), caracterizados por valores relativamente constantes durante todo el período evaluado (10 a 14 horas), sin cierre estomático en el horario de mayor demanda evaporativa (14 horas aproximadamente). Si bien los valores promedios de $g_{\mathrm{s}}$ registrados en los diferentes momentos del período de estudio no fueron diferentes entre familias (ANOVA, $p>0,05$ ), sí se observó que esta variable tuvo una fuerte disminución cuando las condiciones ambientales fueron de mayor estrés (Figura 5.6).

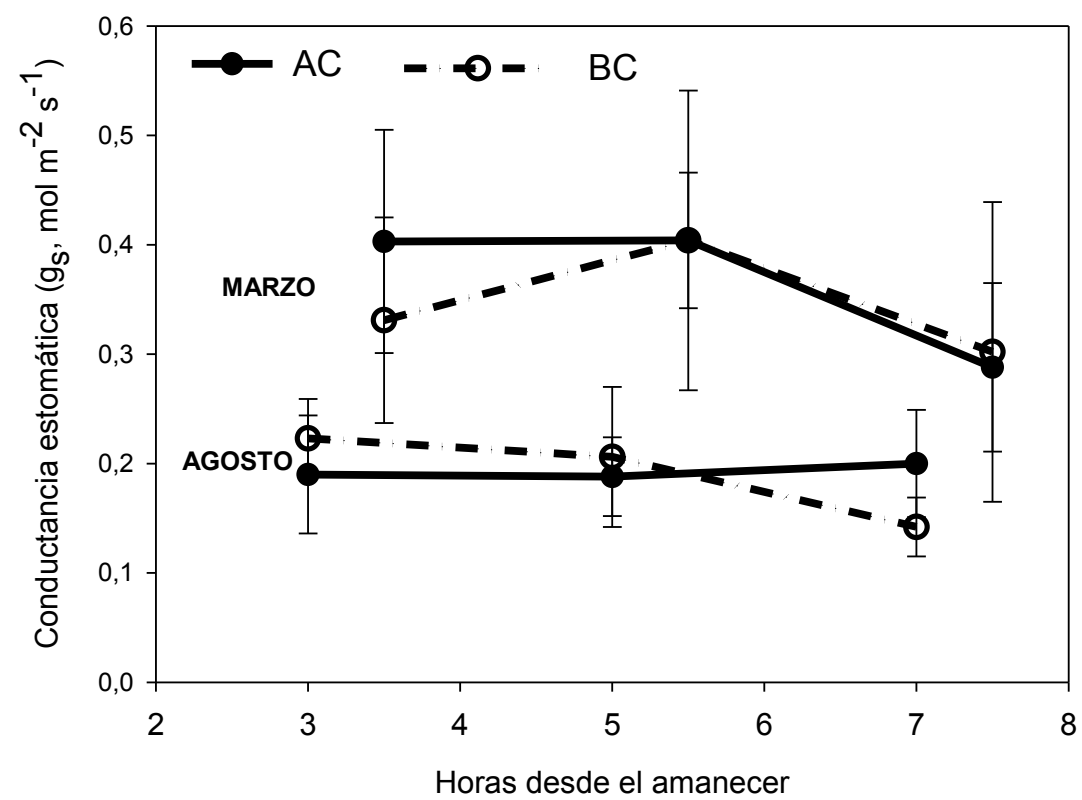

Figura 5.6 Evolución diurna de la conductancia estomática $\left(g_{\mathrm{s}}, \mathrm{mol} \mathrm{m} \mathrm{m}^{-2} \mathrm{~s}^{-1}\right)$ promedio registrada en hojas $(n=6)$ de dos familias de Pinus taeda en marzo y agosto de 2010. AC: familia de alto crecimiento (círculos cerrados y líneas completas); BC: familia de bajo crecimiento (círculos abiertos y líneas punteadas). En ninguna fecha hubo diferencias significativas entre familias.

La mayor $g_{\mathrm{s}}$ se observó en marzo, y la menor fue registrada en agosto, siendo este último mes en el que se registraron las menores precipitaciones del período evaluado. 
Sin embargo, dentro de cada familia, las diferencias en la $g_{\mathrm{s}}$ entre fechas de medición fueron significativas sólo en el caso de la familia AC (prueba $t$ apareada, $p<0,05$ ). Los valores promedios diarios de $g_{\mathrm{s}}$ para todo el período fueron de $0,269 \pm 0,098$ y $0,260 \pm$ $0,090 \mathrm{~mol} \mathrm{~m}^{-2} \mathrm{~s}^{-1}$ para las familias $A C$ y $B C$, respectivamente.

Dentro de cada fecha de medición, ambas familias presentaron similares valores de potencial hídrico foliar registrados en pre-alba y al mediodía. El potencial hídrico foliar en pre-alba descendió en agosto, denotando las menores precipitaciones en este mes que seguramente redundaron en un menor contenido de agua en el suelo (Figura 5.7). En contraste, los menores valores de potencial al mediodía se registraron en marzo, alcanzándose valores por debajo de $-4 \mathrm{MPa}$. Si bien se observó que la familia AC alcanzó potenciales hídricos más negativos al mediodía en ambas fechas de medición, las diferencias no llegaron a ser estadísticamente significativas entre progenies dentro de cada fecha de medición. Los potenciales hídricos en pre-alba y mediodía manifestaron un comportamiento estacional marcado (Figura 5.7).

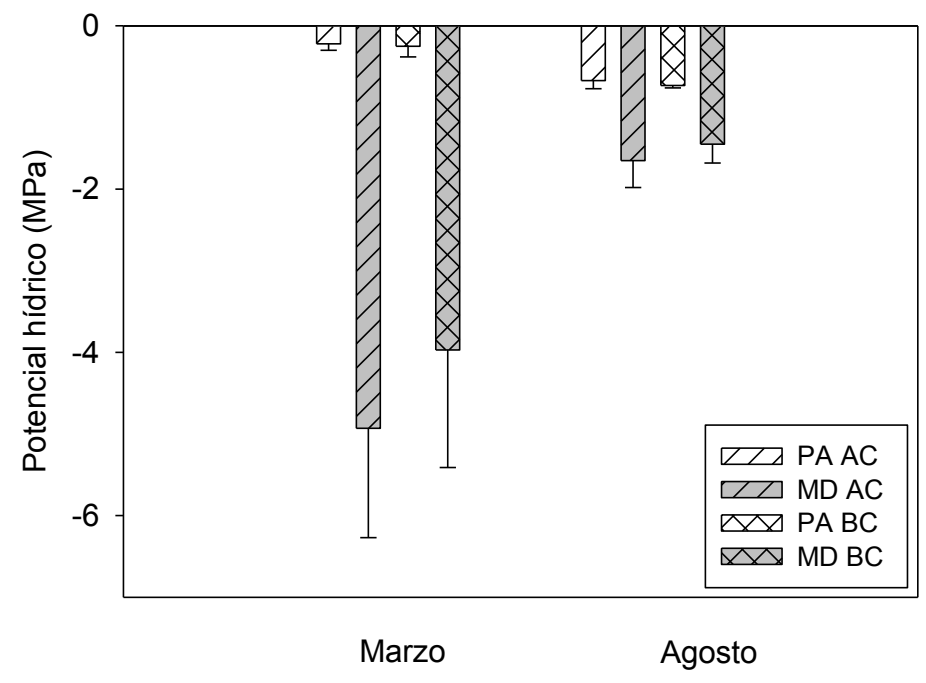

Figura 5.7 Estado hídrico (promedio \pm desvío estándar) en dos progenies de Pinus taeda en condiciones de campo registrado en marzo y agosto de 2010. Potencial hídrico en pre-alba (PA) y mediodía (MD), en MPa. AC: genotipo de alto crecimiento; BC: genotipo de bajo crecimiento.

La diferencia de potencial entre pre-alba y mediodía, el cual refleja el gradiente máximo de potencial hídrico para el movimiento de agua dentro de la planta, fue máxima en marzo con una tendencia a la diferenciación entre las familias AC y BC. Este 
gradiente de potencial fue mayor para la familia AC, siendo más marcada esta diferencia en marzo, cuando las condiciones ambientales estuvieron en un rango más óptimo para la especie.

Respecto a la capacidad fotosintética a saturación lumínica, ésta fue similar entre familias. Los valores promedios generales $( \pm D E$ ) fueron de $18,7 \pm 2,0$ y $17,4 \pm 1,2 \mu \mathrm{mol}$ $\mathrm{m}^{-2} \mathrm{~s}^{-1}$ para las familias $\mathrm{AC}$ y $\mathrm{BC}$, respectivamente.

\section{Parámetros hidráulicos}

No se observaron diferencias significativas entre familias de crecimiento contrastante en la conductancia hidráulica de las ramas con hojas $\left(K_{\mathrm{h}}\right)$, cuyo promedio ( \pm desvío estándar) para ambas familias fue de 5,7 x 10-7 $\pm 7,1 \times 10^{-7} \mathrm{Kg} \mathrm{s}^{-1} \mathrm{MPa}^{-1}$ en noviembre de 2010. Tampoco se observaron diferencias en la conductividad hidráulica $\left(k_{\mathrm{h}}\right)$ e hidráulica específica $\left(k_{s}\right)$ de la madera entre familias, dentro de cada fecha de medición (Tabla 5.1).

Tabla 5.1 Parámetros hidráulicos (media \pm DE) medidos en plantines de Pinus taeda de dos familias de crecimiento contrastante. Conductividad hidráulica $\left(k_{h}, \mathrm{~kg} \mathrm{~m} \mathrm{~s}^{-1} \mathrm{MPa}^{-1}\right)$, conductividad hidráulica foliar específica $\left(k_{1}, \mathrm{~m} \mathrm{~s}^{-1} \mathrm{MPa}^{-1}\right)$ y conductividad hidráulica específica $\left(k_{\mathrm{s}}, \mathrm{kg} \mathrm{m}^{-1} \mathrm{~s}^{-1} \mathrm{MPa}^{-1}\right)$ de ramas medidas en marzo y noviembre de 2010 en una familia de alto crecimiento (AC) y en una de bajo crecimiento (BC). $*: \alpha=0,05$.

\begin{tabular}{lcccccc}
\hline \multirow{2}{*}{ Familia } & \multicolumn{3}{c}{ Marzo } & \multicolumn{3}{c}{ Noviembre } \\
\cline { 2 - 7 } & $\mathbf{k}_{\mathbf{h}}$ & $\mathbf{k}_{\mathbf{l}}$ & $\mathbf{k}_{\mathbf{s}}$ & $\mathbf{k}_{\mathbf{h}}$ & $\mathbf{k}_{\mathbf{1}} *$ & $\mathbf{k}_{\mathbf{s}}$ \\
\hline AC & $3,710^{-5} \pm 1,710^{-5}$ & $0,02 \pm 0,013$ & $0,62 \pm 0,24$ & $5,610^{-6} \pm 4,910^{-6}$ & $3,710^{-4} \pm 3,110^{-4}$ & $0,20 \pm 0,16$ \\
BC & $2,710^{-5} \pm 1,710^{-5}$ & $0,017 \pm 0,009$ & $0,52 \pm 0,29$ & $9,610^{-6} \pm 1,110^{-5}$ & $1,410^{-3} \pm 1,910^{-3}$ & $0,75 \pm 0,93$ \\
\hline
\end{tabular}

Los promedios para ambas familias juntas para las variables $k_{\mathrm{h}}$ y $k_{\mathrm{s}}$ medidas en marzo fueron de $3,2 \times 10^{-5} \pm 1,7 \times 10^{-5} \mathrm{~kg} \mathrm{~m} \mathrm{~s}^{-1} \mathrm{MPa}^{-1}$ y $0,57 \pm 0,26 \mathrm{~kg} \mathrm{~m}^{-1} \mathrm{~s}^{-1} \mathrm{MPa}^{-1}$, respectivamente. En noviembre, los promedios para las mismas variables (conjunto de ambas familias) fueron de 7,6 $\times 10^{-6} \pm 7,9 \times 10^{-6} \mathrm{~kg} \mathrm{~m} \mathrm{~s}^{-1} \mathrm{MPa}^{-1}$ y $0,47 \pm 0,67 \mathrm{~kg} \mathrm{~m}^{-1} \mathrm{~s}^{-1}$ $\mathrm{MPa}^{-1}$.

En el mes de marzo, la $k_{\downarrow}$ fue similar entre progenies, aunque con una tendencia a ser mayor en $A C$ que en $B C$ (Tabla 5.1). Sin embargo, en el mes de noviembre la $k$ f fue significativamente inferior $(p<0,05)$ en la familia AC (Tabla 5.1). 


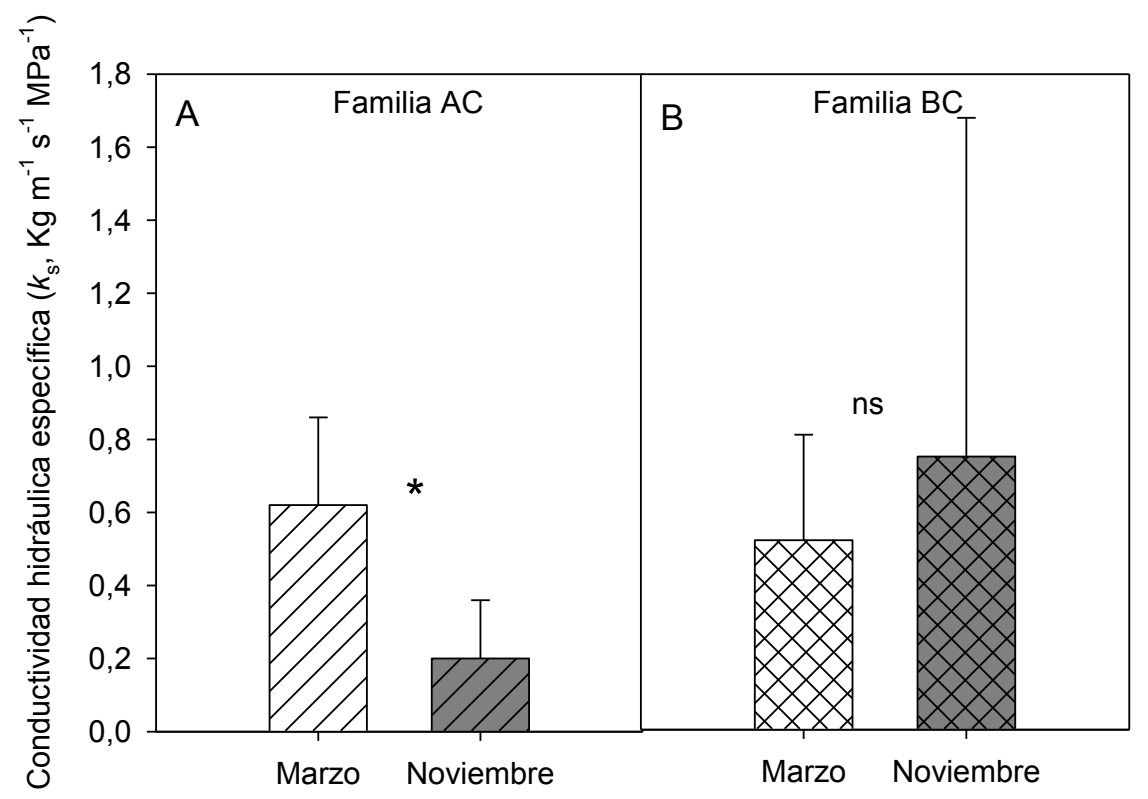

Figura 5.8 Conductividad hidráulica específica $\left(k_{s}, \mathrm{Kg} \mathrm{m}^{-1} \mathrm{~s}^{-1} \mathrm{MPa}^{-1}\right)$ de ramas, medida en marzo y noviembre de 2010 en plantines de una familia de alto crecimiento (AC) y en una familia de bajo crecimiento (BC). *: $\alpha=0,05$. ns: no significativo.

Por otro lado, al comparar los valores de $k_{\mathrm{s}}$ en los diferentes momentos de medición, se observó una disminución significativa de esta variable en la familia $A C$ en noviembre, donde el estrés ambiental fue mayor, mientras que la familia BC presentó valores similares para este parámetro en ambas fechas de determinación (Tabla 5.1, Figura 5.8).

\section{DISCUSIÓN}

\section{Crecimiento en altura total y dac y producción de biomasa}

Tal como se esperaba en función de la clasificación de sus madres, entre las dos progenies evaluadas se encontraron diferencias estadísticas en incrementos absolutos de altura total y diámetro a la base del cuello, en la fase inicial de desarrollo de las plantas, presentando la progenie de la familia AC mayores incrementos que la progenie de la familia BC. Estos resultados coinciden con los determinados por Faustino et al. (2012) y Faustino (2013) en la misma región de estudio y especie, donde se han analizando otras cuatro familias con crecimientos diferenciales entre ellas, 
también en la fase inicial de desarrollo de los individuos. Sin embargo, el incremento relativo en altura no manifestó diferencias significativas entre ambas familias estudiadas, así como tampoco para la variable dac.

Las tasas diferenciales de incremento absoluto en altura total y dac observadas entre las familias también se manifestaron en una diferenciación en la biomasa aérea entre ellas al final del ensayo, con una mayor biomasa en la familia $A C$ respecto a la BC. Barnes (2002) encontró diferencias en la biomasa total en plantines de Pinus taeda de diferentes procedencias con y sin restricción hídrica, sin embargo, los valores de biomasa determinados en el presente estudio son muy superiores (valores entre $100 \mathrm{y}$ $600 \mathrm{~g}$ respectivamente para biomasa aérea solamente) respecto a los encontrados por el citado trabajo (Barnes 2002, valores entre 30 y 100 g para biomasa total con y sin restricción hídrica, respectivamente) en plantas de igual edad, evidenciando esto los crecimientos superiores alcanzados fuera de la región originaria de la especie, así como también el mayor potencial de crecimiento alcanzado cuando las plantas no presentan restricción hídrica alguna. Los incrementos diferenciales encontrados en las familias implicarían en el largo plazo un tamaño de individuo también diferencial, el cual se magnificaría durante el ciclo de la plantación, dadas las diferencias en cuanto a capacidades de captación de recursos entre ellos. Sin embargo, si bien los individuos de mayor tamaño podrían captar más recursos cuando éstos están disponibles, esta familia podría ser más sensible ante condiciones ambientales de mayor estrés, por ejemplo a causa de su mayor biomasa foliar absoluta (mayor superficie transpiratoria) (e.g. McDowell et al. 2006; Niinemets 2010). Si esta mayor demanda transpiratoria no tiene un correlato en un ajustado control estomático, el xilema de estas plantas podría a su vez estar más expuesto a cavitar por las mayores tensiones, dadas las condiciones ambientales de la región, donde se manifiestan mediante altos valores de DPV. De acuerdo con esta hipótesis de mayor sensibilidad al estrés en la familia AC, en el presente estudio se verificó una mayor caída en la $k_{\mathrm{s}}$ de ramas en la misma al comparar fechas, lo que sugiere una mayor vulnerabilidad a la cavitación y/o un menor control estomático del potencial hídrico. En este sentido, si bien las diferencias no fueron estadísticamente significativas, las plantas AC tendieron a alcanzar valores de potencial hídrico foliar más bajos que las plantas de la familia BC. Asimismo, estudios 
complementarios al presente capítulo, presentados en los capítulos precedentes, han confirmado que las dos familias del grupo BC (entre las que se encuentra la utilizada en este capítulo, BC2) presentan una menor vulnerabilidad a la cavitación que ambas familias del grupo AC (capítulo 3).

\section{Distribución de la biomasa y su relación con el crecimiento}

La distribución de la biomasa en la planta es una característica importante desde el punto de vista funcional, y contribuye a determinar la arquitectura hidráulica de la misma. Se predice que una planta asignará más carbono a los órganos que le permitan maximizar la captura de los recursos más limitantes para su desarrollo (Bloom et al. 1985; Barnes 2002), a la vez que los cambios en la partición a órganos que proveen agua vs. los que transpiran, determinan en parte la eficiencia hidráulica del sistema en su conjunto. La partición de la biomasa en los distintos compartimentos podría ser considerada entonces una variable de interés como criterio de selección temprana de genotipos en programas de mejoramiento genético. La variación intraespecífica en la partición de la biomasa en Pinus taeda ha sido reportada tanto en condiciones de campo (Aspinwall et al. 2013) como bajo invernáculo, donde fueron más marcadas las diferencias ante condiciones de déficit hídrico (Barnes 2002). En árboles de mayor edad de P. taeda (15 años de edad) que los estudiados aquí, Blazier et al. (2004) observaron que distintos genotipos presentaron diferentes asignaciones a hojas $y$ ramas, e iguales proporciones de biomasa de tallo entre ellos, coincidiendo en parte con los resultados del presente capítulo. Sin embargo, Aspinwall et al. (2013) mencionan que, si bien la partición de la biomasa es una característica que presenta importantes implicancias para la captura y fijación del carbono en los diferentes genotipos, las diferencias intraespecíficas en la productividad de $P$. taeda no pueden ser explicadas solamente por los patrones diferenciales en esta variable. En el caso del presente trabajo, se encontró una diferente asignación entre órganos aéreos en las dos familias analizadas, con mayor proporción de biomasa foliar, en relación a la de ramas, en la familia $\mathrm{BC}$. Ante similares valores de $k_{s}$, esto puede redundar en una menor eficiencia de conducción por unidad de área foliar en estos genotipos, contribuyendo a explicar posiblemente la baja tasa de crecimiento de esta familia. 
Cabe destacarse que la familia AC analizada en este ensayo a campo es la misma que la denotada como AC1 en el ensayo presentado en el capítulo 2. Esta familia se caracterizó en el ensayo presentado en dicho capítulo por una mayor asignación a órganos leñosos aéreos (tallo, ramas) en comparación con el resto de las familias, coincidiendo en parte con los resultados observados a campo. La otra familia AC analizada en el ensayo en macetas (AC2) presentó una mayor asignación a hojas que el resto de las familias. Por lo tanto, las conclusiones derivadas del presente ensayo a campo no pueden extrapolarse a familias $A C$ en general, siendo que evidentemente existe variación en la asignación de biomasa dentro de las familias de rápido crecimiento, fenómeno ya discutido en el capítulo 2.

En líneas generales, y tomando como base los resultados presentados en este capítulo, se puede inferir que ambas familias tienen diferentes capacidades de crecimiento (absoluto) en altura total desde muy tempranamente en su desarrollo, lo que se evidenció ya en el tamaño inicial de las plantas, y se mantuvo en los meses posteriores de evaluación del ensayo. En contraste, la diferenciación en dac ocurre unos meses más tarde, partiendo las plantas con similares dac y manteniendo durante todo el período evaluado un similar crecimiento relativo. Sin embargo, lentamente comienza a producirse también una diferenciación en esta dimensión del tallo, y hacia el final del ensayo, las diferencias fueron estadísticamente significativas entre las familias. Asimismo, la familia AC acumuló una mayor biomasa aérea a las edades tempranas evaluadas, que coinciden con la fase de establecimiento de una plantación comercial. Intentando explicar estas diferencias tempranas encontradas, los antecedentes en la literatura sugieren distintas causas. Una de ellas es la diferencia en el tamaño/peso inicial de la semilla, que se refleja en un vigor diferencial entre individuos, tanto en especies herbáceas como leñosas (Black 1958; Premoli 1991; Aráos et al. 2004; JuárezAgis et al. 2006; Kitajima 2007). Por otro lado, las diferencias de tamaño manifestadas a temprana edad podrían deberse a una susceptibilidad diferencial al estrés durante la fase de establecimiento de la plantación y/o a una distinta asignación inicial de biomasa entre órganos aéreos y subterráneos. En el caso de este estudio, se encontraron diferencias en el tamaño de semillas entre familias (datos no mostrados), pero en el sentido contrario al esperado. En este sentido, las familias del grupo BC 
presentaron mayor tamaño de semilla que las familias del grupo AC, por lo que no podría atribuirse a esta causa un mayor tamaño inicial en las plantas AC que en las BC. Con respecto al patrón inicial de partición de la biomasa, se ha propuesto (Barnes 2002) que en la fase de establecimiento (primera etapa) ocurre un rápido crecimiento de la raíz a expensas de la biomasa de hojas, seguido por una etapa de desarrollo foliar a expensas de las raíces (fase de crecimiento en altura, posterior al establecimiento). Asimismo, en el experimento expuesto en el capítulo 2 se observó que las familias BC asignan más biomasa a raíces que las $A C$, sugiriendo que esta asignación diferencial entre órganos aéreos y subterráneos podría ser clave para explicar las diferencias iniciales en el desarrollo entre progenies. Asimismo, un mayor desarrollo relativo de la raíz en la familia $B C$ sería consistente con una mayor conductancia hidráulica total resultante en la tendencia (no estadísticamente significativa) observada a desarrollar potenciales hídricos más altos, a iguales $g_{\mathrm{s}}$ y demanda evaporativa, en esta familia en comparación con la AC a pesar de su mayor superficie transpiratoria (en relación a la biomasa de ramas) y menor $k$ । de ramas (ver más abajo).

\section{Conductancia estomática, fotosíntesis y potencial hídrico}

En contraste con la asignación de biomasa aérea, en general no se encontraron diferencias significativas en la fisiología foliar entre familias durante el período de estudio. Al igual que lo expuesto en el presente capítulo, Blazier et al. (2004) reportaron la falta de diferencias significativas entre progenies de Pinus taeda para las variables $g_{\mathrm{s}}, A_{\text {sat }} \mathrm{Y}$ potencial hídrico foliar durante la estación de crecimiento, a pesar de que las mismas difirieron en función de las condiciones climáticas en las cuales fueron medidas, disminuyendo los valores promedios bajo condiciones ambientales más adversas. Este comportamiento estacional para las variables fisiológicas ha sido reportado para la especie por varios autores (Lewis et al. 1996; Tang et al. 2003; Blazier et al. 2004; Aspinwall et al. 2011b), coincidentemente con los resultados del presente capítulo, en el que las variables fueron afectadas por las condiciones ambientales de mayor estrés, dadas por las menores precipitaciones con iguales demandas atmosféricas, afectando a ambas familias analizadas de igual manera. Sin embargo, cabe destacarse que la caída relativa en $g_{\mathrm{s}}$ fue significativamente mayor en 
la familia $A C$ que en la $B C$ al comparar fechas de medición (si bien dentro de cada fecha, no hubo diferencias significativas entre familias), lo que sugiere que la familia AC tendría mayores limitaciones hídricas en condiciones adversas, posiblemente dadas por un mayor tamaño promedio de planta. Por otro lado, dentro de cada fecha, y al analizar el comportamiento estomático y los valores de potencial hídrico foliar mínimo alcanzados, se observó en ambas familias un bajo control estomático del potencial hídrico. En este sentido, se encontró evidencia preliminar a favor de la hipótesis planteada de que esta familia AC tendría una menor sensibilidad estomática, alcanzando en general potenciales hídricos menores (aunque las diferencias entre familias no fueron estadísticamente significativas).

\section{Parámetros hidráulicos}

En general la conductividad hidráulica específica $\left(k_{s}\right)$ de distintos órganos, como las ramas, está relacionada en forma directa con el crecimiento de los individuos. Esto ha sido reportado en distintas especies de latifoliadas (e.g. Brodribb et al. 2005; Kondoh et al. 2006; Hajek et al. 2014) y coníferas (e.g. Domec y Gartner 2003; Wang et al. 2003; Gonzalez-Benecke y Martin 2010). Contrariamente a estos antecedentes, la $k_{\mathrm{s}}$ medida en ramas en las familias $A C$ y $B C$ de Pinus taeda no presentó diferencias entre familias bajo condiciones ambientales favorables. Si bien la falta de diferencias en $k_{\mathrm{s}}-$ parámetro de alta variabilidad observada entre individuos- pudo deberse al relativamente bajo $n$ utilizado en este estudio $(n=9)$, limitando la capacidad de ser conclusivo en torno a esta variable, resultados presentados en otros capítulos (Capítulos 2, 3 y 4) son igualmente conducentes a afirmar que esta variable no tiene una alta correlación con el crecimiento de los individuos, no pudiendo explicar de esta manera el diferencial de crecimiento entre las familias. Por otro lado, coincidentemente con los resultados de este capítulo, Wang et al. (2003) determinaron diferencias en $k_{\downarrow}$ entre progenies de $P$. contorta, variable que también presentó una relación directa con la tasa de crecimiento de dicha especie. En el presente estudio, la $k$ fue superior en la familia AC, como producto de la menor proporción de biomasa foliar alimentada por cada rama en esta familia específicamente. De acuerdo con la hipótesis inicialmente planteada, esto permitiría 
una mayor eficiencia de conducción de agua por unidad de área foliar en esta familia AC, permitiéndole un incremento relativo similar (o absoluto mayor) a pesar de una menor inversión en su superficie de captación de radiación y fijación de carbono, respecto a la familia $\mathrm{BC}$.

\section{CONCLUSIONES}

Las familias de Pinus taeda estudiadas presentaron distintas tasas de incremento absoluto en el período de estudio, sin diferencias en el incremento relativo. Coincidiendo con los criterios de selección genética, la descendencia de la familia clasificada como de alto crecimiento presentó incrementos en altura total y dac superiores, así como una mayor producción de biomasa aérea al final del período de ensayo. Asimismo, esta familia se diferenció de la de bajo crecimiento (BC) por una menor asignación de biomasa a hojas y una mayor asignación relativa a ramas, redundando en una mayor $k_{l}$ de ramas. La familia AC presentó a su vez, una mayor pérdida relativa de $k_{\mathrm{s}}$ ante condiciones de estrés (durante el período de bajas precipitaciones) que la familia $\mathrm{BC}$, así como una mayor caída relativa en $g_{\mathrm{s}}$. Sin embargo, no se llegaron a detectar diferentas estadísticas entre familias en variables funcionales como el potencial hídrico en pre-alba y mediodía, $g_{\mathrm{s}}$ y $A_{\text {sat }}$ dentro de las fechas en las que se midieron, lo que sugiere la necesidad de aumentar el $n$ muestral y las fechas de medición a fin de confirmar la ausencia de diferencias en estas variables, o bien confirmar algunas tendencias observadas, como el menor potencial hídrico mínimo en la familia AC. Los resultados de este capítulo, en conjunto con los de capítulos precedentes, sugieren que las diferencias en asignación de biomasa aérea vs. subterránea entre las familias en la etapa inicial del establecimiento, resultan en diferencias de tamaño a los nueve meses de edad (inicio de las mediciones), que se amplían en el tiempo. Sin embargo, los cambios observados en la asignación del carbono dentro de la parte aérea de la planta, acompañados con ajustes de todo el sistema hidráulico, serían también responsables de las tasas diferenciales de crecimiento entre las familias de $P$. taeda estudiadas. Asimismo, la familia AC estudiada en este capítulo posiblemente sería más eficiente en el uso de los recursos del ambiente, por poseer menor (en términos relativos a su biomasa) superficie 
transpiratoria. Se requieren estudios de patrones de enraizamiento diferencial entre familias en condiciones de campo, así como de uso de los recursos (agua, nitrógeno, radiación) y productividad para poner a prueba estas hipótesis. Cabe destacarse, que, dado que los patrones morfo-fisiológicos presentan patrones diferentes en la ontogenia de un individuo, estos resultados son exclusivos para la fase inicial de establecimiento de la plantación.

Los resultados presentados en este capítulo ponen de manifiesto la variabilidad genética intraespecífica observada en caracteres fenotípicos relacionados con el crecimiento. Se requieren más estudios que permitan avanzar sobre las implicancias de las tasas diferenciales de crecimiento $-\mathrm{y}$ los procesos fisiológicos que las determinan- sobre la sensibilidad y resiliencia de las distintas familias ante condiciones de estrés ambiental. 
CAPÍTULO 6

REGULACIÓN ESTOMÁTICA DEL POTENCIAL HÍDRICO EN Pinus taeda L. BAJO DIFERENTES CONDICIONES AMBIENTALES 


\section{REGULACIÓN ESTOMÁTICA DEL POTENCIAL HÍDRICO EN Pinus taeda L. BAJO DIFERENTES CONDICIONES AMBIENTALES.}

\section{RESUMEN}

El tipo de control estomático del potencial hídrico -isohidrismo, anisohidrismo, isohidrodinamismo- resulta de distintas estrategias ecofisiológicas de respuesta al déficit hídrico, que condicionan la capacidad de crecer en mayor o en menor medida ante distintas disponibilidades de agua en el suelo y en la atmósfera. Los antecedentes en este sentido para Pinus taeda son contrastantes dependiendo del estudio, lo que podría resultar del hecho de que existe variabilidad intraespecífica en la sensibilidad estomática a las variables ambientales, fenómeno que ha sido sugerido en los distintos experimentos llevados a cabo en el marco de esta tesis. Es por ello, que en este capítulo se analiza en forma conjunta la información generada de respuesta estomática bajo diferentes niveles de demanda evaporativa del aire y de disponibilidad del agua en suelo, tanto en plantas en macetas bajo invernáculo como creciendo a campo. Se han encontrado resultados contrastantes en diferentes situaciones, presentando un comportamiento isohídrico o anisohídrico dependiendo de las condiciones ambientales. Así, cuando las condiciones hídricas son óptimas y los valores de DPV son relativamente bajos (menores a $3 \mathrm{kPa}$ ), P. taeda puede manifestarse como una especie del tipo anisohídrica, condición en la que la planta no cierra sus estomas y alcanza potenciales hídricos muy bajos. Por otro lado, cuando esta misma especie es sometida a una restricción hídrica en el suelo, ésta pasa a tener una regulación estomática más estricta, manifestando así un comportamiento de carácter más isohídrico incluso a bajos valores de DPV. Frente a estas situaciones de estrés, dadas por un déficit hídrico en el suelo y/o por altas demandas evaporativas del aire ( $>3$ $\mathrm{kPa})$, esta especie presenta además un comportamiento del tipo isohidrodinámico, dado por el mantenimiento de su gradiente de potencial hídrico en valores constantes entre 1 y $1,25 \mathrm{MPa}$. 


\section{INTRODUCCIÓN}

En las relaciones hídricas de la planta, los estomas actúan como un regulador, limitando la variación en el potencial hídrico de la planta y evitando caídas abruptas en el mismo que puedan resultar perjudiciales para su sistema hidráulico (Sperry et al. 2002). Esta regulación del potencial hídrico a través de los estomas redunda en cambios en la conductancia hidráulica en el continuo suelo-hoja, así como también en la conductancia estomática y la traspiración.

En líneas generales, el potencial hídrico foliar en plantas bajo condiciones hídricas óptimas presenta una fluctuación diaria en función de la demanda evaporativa y la apertura estomática con la luz. El máximo valor observado al amanecer resulta del equilibrio existente entre el potencial hídrico del suelo y la planta en ausencia de flujo de agua, lo que puede deducirse de la ecuación 1 , en la que a baja demanda evaporativa del aire y conductancia estomática cero, el potencial hídrico foliar $\left(\Psi_{\mathrm{f}}\right)$ depende solamente del contenido de agua en el suelo $\left(\Psi_{s}\right)$. Cuando la planta transpira, el potencial hídrico foliar decrece en función de la conductancia estomática $\left(g_{\mathrm{s}}\right)$, de la demanda atmosférica del aire (DPV) y de la resistencia al flujo de agua a través del continuo suelo-planta $\left(R_{\mathrm{s}}-R_{\mathrm{p}}\right)$. De este modo, ante la ausencia de regulación estomática, el potencial hídrico foliar alcanzaría valores cada vez más bajos.

$$
\Psi_{f}(M P a)=\Psi_{s}-\left(R_{s}+R_{p}\right) \cdot\left(\frac{g_{a} \cdot g_{s}}{g_{a}+g_{s}}\right) \cdot \frac{M_{w}}{R \cdot T_{a}} \cdot D P V
$$

donde $\Psi_{\mathrm{f}}$ y $\Psi_{\mathrm{s}}$ son el potencial hídrico foliar y del suelo, respectivamente, $g_{a}$ es la conductancia de la capa límite, $g_{\mathrm{s}}$ es la conductancia estomática, $R_{\mathrm{s}}$ y $R_{\mathrm{p}}$ son las resistencias al flujo de agua del suelo y de la planta, $M_{\mathrm{w}}$ es el peso molar del agua, DPV es el déficit de presión de vapor de la atmósfera, $R$ es la constante universal de los gases y $T_{a}$ es la temperatura del agua (e.g. Tardieu y Simonneau 1998).

La regulación estomática del potencial hídrico foliar está estrechamente relacionada con la evitación de pérdidas de conductividad hidráulica $\left(k_{\mathrm{h}}\right)$ a niveles irreversibles (Sperry e Ikeda 1997). Si bien hoy se discute si existen especies que pierden importantes niveles de $k_{\mathrm{h}}$ y luego, reparan sus embolismos en ciclos diarios, o si los 
reportes de grandes pérdidas diarias de $k_{\mathrm{h}}$ son sólo un artificio metodológico (Wheeler et al. 2013; aunque por ej. ver: Trifiló et al. 2014), en términos generales se acepta que las plantas tienden a evitar el fenómeno de cavitación (Cochard y Delzon 2013). Sin embargo, el hecho de que existan distintos valores y combinaciones de $k_{\mathrm{h}}$ del xilema, de capacitancia, de vulnerabilidad a la cavitación y de reparación de embolismos, todos ellos dados por distintas anatomías de la madera, es esperable que algunas plantas puedan intrínsecamente desarrollar valores de potencial hídrico más o menos negativos que otras, sin poner en riesgo su supervivencia. Consecuentemente, el comportamiento del potencial hídrico foliar difiere entre especies, y el mismo está relacionado con el "tipo" de control o regulación estomática que presente. Esta regulación no necesariamente es perfecta, sin embargo, existe una nomenclatura clásica utilizada para dividir un continuo en dos categorías amplias basadas en cómo la hidratación de los tejidos es mantenida bajo condiciones ambientales fluctuantes. En un extremo, desde el punto de vista conceptual, se ubican las plantas con un comportamiento isohídrico, que son aquellas con un fuerte control estomático de la tasa de transpiración, alcanzando similares potenciales hídricos a mediodía en plantas con y sin déficit hídrico. Estas plantas suelen ser relativamente vulnerables a la cavitación, y basan su supervivencia en un estricto control del potencial hídrico que les permita evitar este fenómeno. Asimismo, suelen ser plantas con altas conductancias hidráulicas, lo que disminuye las tensiones internas del xilema y colabora en su comportamiento evitador de la sequía. Otro grupo es el constituido por las plantas con comportamiento anisohídrico, las cuales exhiben en general una menor sensibilidad estomática a la demanda evaporativa del aire y a la humedad del suelo, permitiendo de esta manera mayores fluctuaciones en el potencial hídrico foliar (Tardieu y Simonneau 1998). Estas plantas suelen ser más resistentes a la cavitación que las anteriores, lo que les permite tolerar bajos potenciales hídricos sin sufrir pérdidas importantes de $k_{\mathrm{h}}$. Por otro lado Franks et al. (2007) mencionan un tercer grupo de plantas, el cual presenta un comportamiento isohidrodinámico. Este grupo se caracteriza por presentar un fuerte control estomático, el cual le permite, en vez del mantenimiento de un potencial hídrico mínimo, el mantenimiento de un gradiente de potencial hídrico relativamente constante, presentando al mismo tiempo una gran 
fluctuación estacional en el potencial hídrico foliar de manera sincronizada con el potencial hídrico del suelo (Figura 6.1). Si bien este comportamiento ha sido estudiado por Franks et al. (2007) en Eucalyptus gomphocephala, Gonzalez-Benecke y Martin (2010) han reportado para individuos de 11 años de edad de Pinus taeda L. también un comportamiento isohidrodinámico. En dicho estudio, las plantas incrementaron la tasa de transpiración y la $g_{\mathrm{s}}$ cuando el agua no fue limitante, sin embargo, ante limitaciones hídricas, la $g_{\mathrm{s}}$ se vio afectada. Estos autores observaron un mantenimiento constante del gradiente de potencial hídrico en un valor promedio de 0,75 $\mathrm{MPa}$, a un costo de pérdidas de conductividad hidráulica bajo condiciones hídricas limitantes. Sin embargo, Hacke et al. (2000) y Ewers et al. (2000) determinaron un comportamiento isohídrico para $P$. taeda, con una regulación del potencial hídrico foliar mínimo en función del tipo de suelo, en torno a -2,3 y -1,6 MPa, para suelos arcilloso y arenoso, respectivamente.

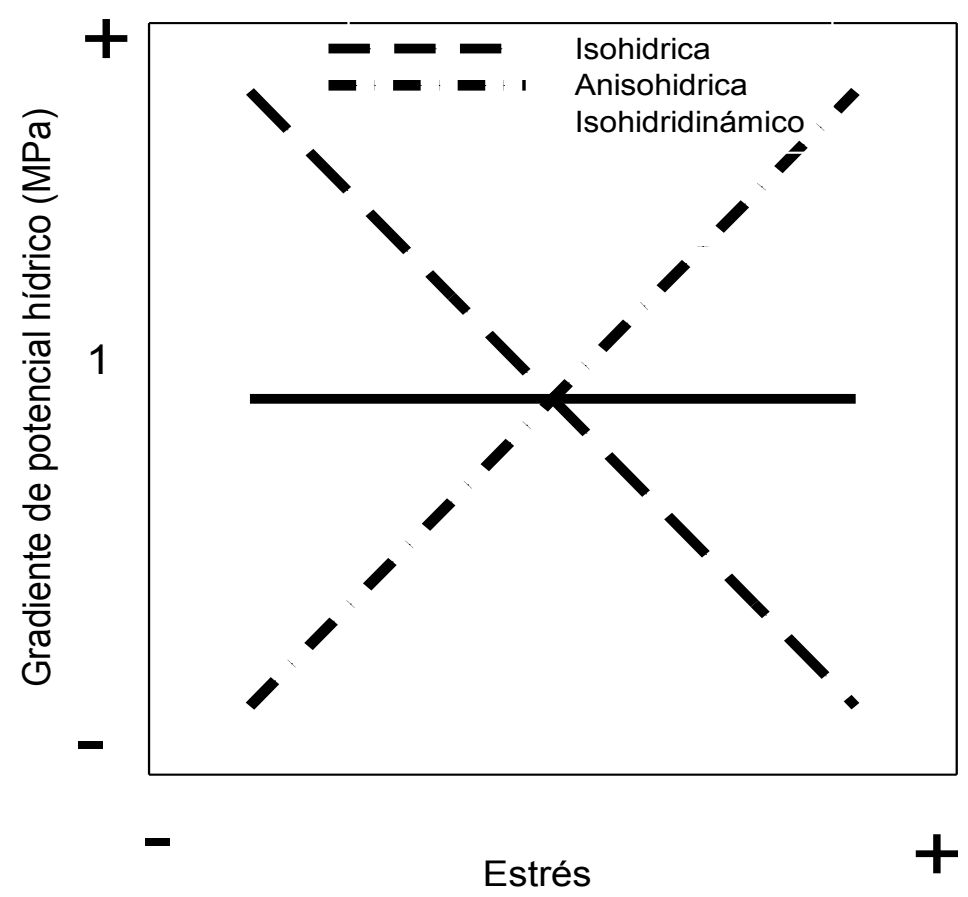

Figura 6.1 Modelo de regulación del gradiente de potencial hídrico de la planta (i.e. diferencia de potencial entre el suelo y las hojas) adaptado de Franks et al. (2007). Estrés definido por una combinación hipotética de disponibilidad de agua en suelo y Déficit de Presión de Vapor de la atmósfera (DPV). 
A medida que se avanzó en el análisis de los ensayos expuestos en los capítulos precedentes, se vislumbró que existía cierta variación en el comportamiento estomático de los plantines entre los diferentes ensayos, y con respecto a los antecedentes de la especie. Es por ello que el objetivo de este capítulo fue integrar la información de los tres ensayos desarrollados (dos en macetas bajo condiciones semicontroladas y uno a campo), a la luz del análisis de la regulación estomática del potencial hídrico en plantines de Pinus taeda, intentando encontrar un patrón que explique los resultados obtenidos bajo diferentes situaciones ambientales. En este sentido, se cuenta con resultados correspondientes a distintos niveles de demanda evaporativa del aire y de disponibilidad del agua en suelo, tanto en plantas en macetas bajo invernáculo como creciendo a campo, bajo condiciones ambientales naturales.

\section{MATERIAL Y MÉTODOS}

\section{Área de estudio y material utilizado}

Los diferentes ensayos utilizados para la obtención de datos del presente capítulo fueron desarrollados en la estación experimental Campo Anexo Laharrague,

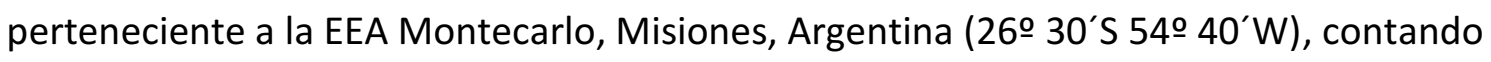
con uno a campo bajo condiciones ambientales naturales y dos en invernáculo bajo condiciones semi-controladas.

El clima de la región es subtropical sin estación seca marcada, con una precipitación media anual de $2000 \mathrm{~mm}$ y temperatura media anual de 20 ㄷ (Ligier 2000).

Las plantas utilizadas fueron obtenidas a partir de semillas del Programa de Mejoramiento Genético (PMG) del INTA, cuyos huertos semilleros están establecidos en el Campo Anexo Manuel Belgrano (CAMB; San Antonio, Provincia de Misiones, $26^{\circ}$ $02^{\prime} 55^{\prime \prime} \mathrm{S} ; 53^{\circ} 46^{\prime} 10^{\prime \prime} \mathrm{O} ; 550$ m.s.n.m.). El material genético que se utilizó fueron familias de origen Marion, con diferentes procedencias del norte de la provincia de Misiones (Montecarlo, Iguazú y Eldorado). Para el desarrollo de este capítulo se analizaron las respuestas promedio en plantines de las cuatro familias de Pinus taeda L. de diferentes ensayos los cuales son descriptos brevemente en la siguiente sección. 


\section{Descripción de los ensayos}

Las plantas evaluadas pertenecen a tres ensayos realizados en diferentes períodos de crecimiento. Las mismas fueron producidas en diferentes períodos, por lo cual al momento de evaluación de cada ensayo las plantas presentaron edades y tamaños similares entre los diferentes ensayos considerados para el desarrollo del presente capítulo. Los ensayos son descriptos en mayor detalle a continuación:

Ensayos en macetas (EnM): Estos fueron realizados en macetas de 20 litros, analizando los plantines hasta aproximadamente los dos años de edad bajo invernáculo. Las macetas contenían como sustrato $1 / 3$ de suelo rojo (suelo donde se cultiva normalmente la especie en Misiones), $1 / 3$ de corteza de pino y $1 / 3$ de arena. Este sustrato resulta adecuado para el desarrollo de las plantas por su buen drenaje y fertilidad. Las variables temperatura del aire $(T, \stackrel{\circ}{ })$ y humedad relativa $(H R, \%)$ fueron registradas en forma automática con un termohigrómetro Hobo (Pro v2 Onset) dentro del invernáculo. A partir de estas variables se estimó el déficit de presión de vapor de la atmósfera (DPV, kPa). Bajo estas condiciones se realizaron dos ensayos en diferentes períodos:

- EnM1: este ensayo fue evaluado durante la estación de crecimiento comprendida entre agosto de 2010 a febrero de 2011. Se distribuyeron doce plantines en cuatro bloques, entre los cuales se estableció un Control (C: plantines bajo condiciones hídricas óptimas en el suelo en toda la estación de crecimiento) y un déficit hídrico en distintos momentos de la estación de crecimiento (E: plantines con restricción hídrica en el riego). El riego se realizó dos veces por semana aplicando agua hasta saturación (aproximadamente 2,5 litros por riego) en las macetas del control y 1 litro en cada maceta del grupo de plantas estresadas. Mayores detalles de este ensayo fueron presentados en el capítulo 4.

O EnM2: este ensayo fue evaluado durante la estación de crecimiento comprendido entre septiembre de 2011 y febrero de 2012. Se distribuyeron 12 plantines entre los cuatro bloques, estableciéndose un Control (C: plantines bajo condiciones hídricas óptimas en el suelo en toda la estación de 
crecimiento) y dos intensidades de déficit hídrico (DM: plantines con Déficit hídrico moderado, con dos riegos semanales de $500 \mathrm{~cm}^{3} /$ planta y DS: plantines con déficit hídrico severo, con un solo riego semanal de $500 \mathrm{~cm}^{3} /$ planta). Mayores detalles de este ensayo fueron presentados anteriormente en el capítulo 2.

Ensayo a campo (EnC): este ensayo fue evaluado durante el período de crecimiento comprendido entre septiembre de 2009 a noviembre de 2010 (14 meses). Durante este período ocurrieron condiciones climáticas contrastantes, especialmente en cuanto a la disponibilidad de agua en suelo, dado que la primavera de 2010 presentó menor precipitación acumulada respecto a la primavera de 2009 (Figura 6.2), siendo además inferiores a los valores climáticos históricos (1963-2010) (Figura 5.1 panel A).

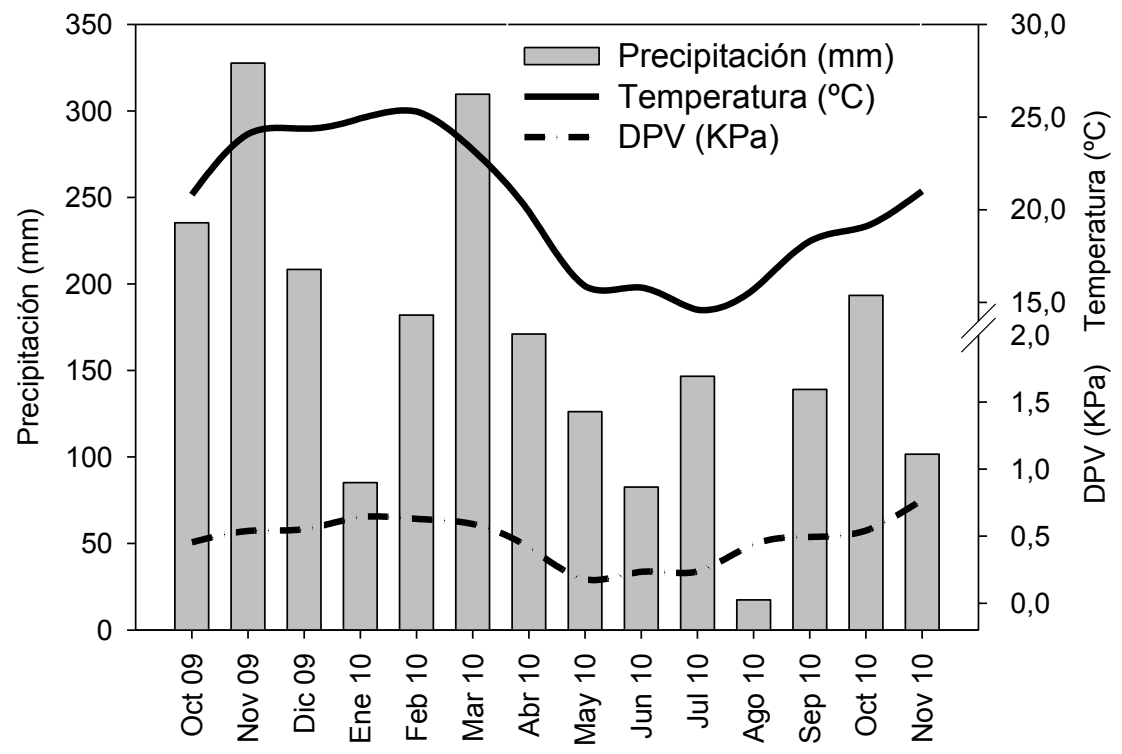

Figura 6.2 Datos meteorológicos en el período primavera de 2009 - primavera de 2010 registrados en el Campo Anexo Colonia Laharrague, Misiones, Argentina. Déficit de presión de vapor (DPV, kPa) y precipitación acumulada mensual $(\mathrm{mm})$.

En este sentido, se pueden destacar dos períodos contrastantes: marzo, con abundantes precipitaciones, y agosto como un mes de mayor estrés ambiental (menor precipitación acumulada), en ambos casos con DPV similares. Las variables ambientales fueron registradas a través de una estación meteorológica (Davis 
GroWeather) situada a $100 \mathrm{~m}$ aproximadamente del ensayo. Mayores detalles de este ensayo fueron presentados en el capítulo 5.

\section{Variables medidas}

En todos los ensayos se registraron las siguientes variables fisiológicas:

- Conductancia estomática $\left(g_{\mathrm{s}}, \mathrm{mol} \mathrm{m}^{-2} \mathrm{~s}^{-1}\right)$ : se midió en dos momentos del día (9 y 14 horas) con un porómetro Decagon Devices modelo SC-1 en 6 individuos por tratamiento, en distintos momentos del año en función de los objetivos de cada ensayo en particular.

- Potencial hídrico foliar ( $\left.\Psi_{\mathrm{f}}, \mathrm{MPa}\right)$ en pre-alba y al mediodía: se midieron ambos en el mismo día con una cámara de presión (Bio-control, Argentina) en 6 individuos por tratamiento, en distintas fechas en función de los objetivos de cada ensayo en particular. Este parámetro fue registrado el mismo día en que se midió el comportamiento estomático.

A partir de los parámetros arriba descriptos se estimó la conductancia hidráulica $\left(K_{\mathrm{h}}\right.$, mol m $\mathrm{m}^{2} \mathrm{sPa}^{-1}$ ) de las plantas para cada ensayo en particular, según la ecuación 2

$$
K_{h}\left(m o l \cdot m^{-2} \cdot s^{-1} \cdot M P a^{-1}\right)=\frac{g_{s} \cdot D P V}{\Delta \Psi}
$$

Donde $g_{\mathrm{s}}$ es la conductancia estomática medida a las 14 horas, DPV es el déficit de presión de vapor del aire $(\mathrm{kPa})$ (dividido por la presión atmosférica promedio de la zona, $991 \mathrm{kPa}), \Delta \Psi(\mathrm{MPa})$ es la diferencia de potencial hídrico entre pre-alba y mediodía.

\section{Análisis estadístico}

Se utilizó análisis de la varianza (ANOVA) para examinar el efecto de los tratamientos sobre el potencial hídrico mínimo y máximo, $g_{\mathrm{s}}$ y $K_{\mathrm{h}}$ dentro de cada fecha de medición. 


\section{RESULTADOS}

\section{Ensayo en Macetas 1 (EnM1)}

En este ensayo en macetas se observó un comportamiento caracterizado por una tendencia al anisohidrismo en todo el rango de potenciales de pre-alba (Figura 6.3 panel A). Este comportamiento fue particularmente evidente en las plantas del tratamiento control, que alcanzaron valores mínimos de potencial hídrico de hasta -5 $\mathrm{MPa}$, mientras que las sometidas a restricciones de agua en suelo tuvieron un mayor control estomático del potencial hídrico (Figura 6.3 panel A). Estas plantas en general no superaron los $-3 \mathrm{MPa}$, semejando los patrones y umbrales mínimos observados en el ensayo EnM2 (resultados presentados en el apartado siguiente).

El gradiente de potencial hídrico dependió del período y de la disponibilidad de agua en suelo. En las fechas en las que las plantas control manifestaron los menores valores de potencial hídrico (anisohidrismo marcado), el gradiente alcanzó valores de aproximadamente $2 \mathrm{MPa}$, mientras que se mantuvo en valores de alrededor de $1 \mathrm{MPa}$ en las otras situaciones, especialmente en el tratamiento de restricción hídrica en el suelo (Figura 6.3 panel B).

En este experimento fue evidente la baja sensibilidad estomática de los plantines al DPV (Figura 6.3 panel C y Figura 6.4), aunque cabe remarcar que en este ensayo nunca se registraron valores de DPV tan altos como en el ensayo del apartado siguiente. 


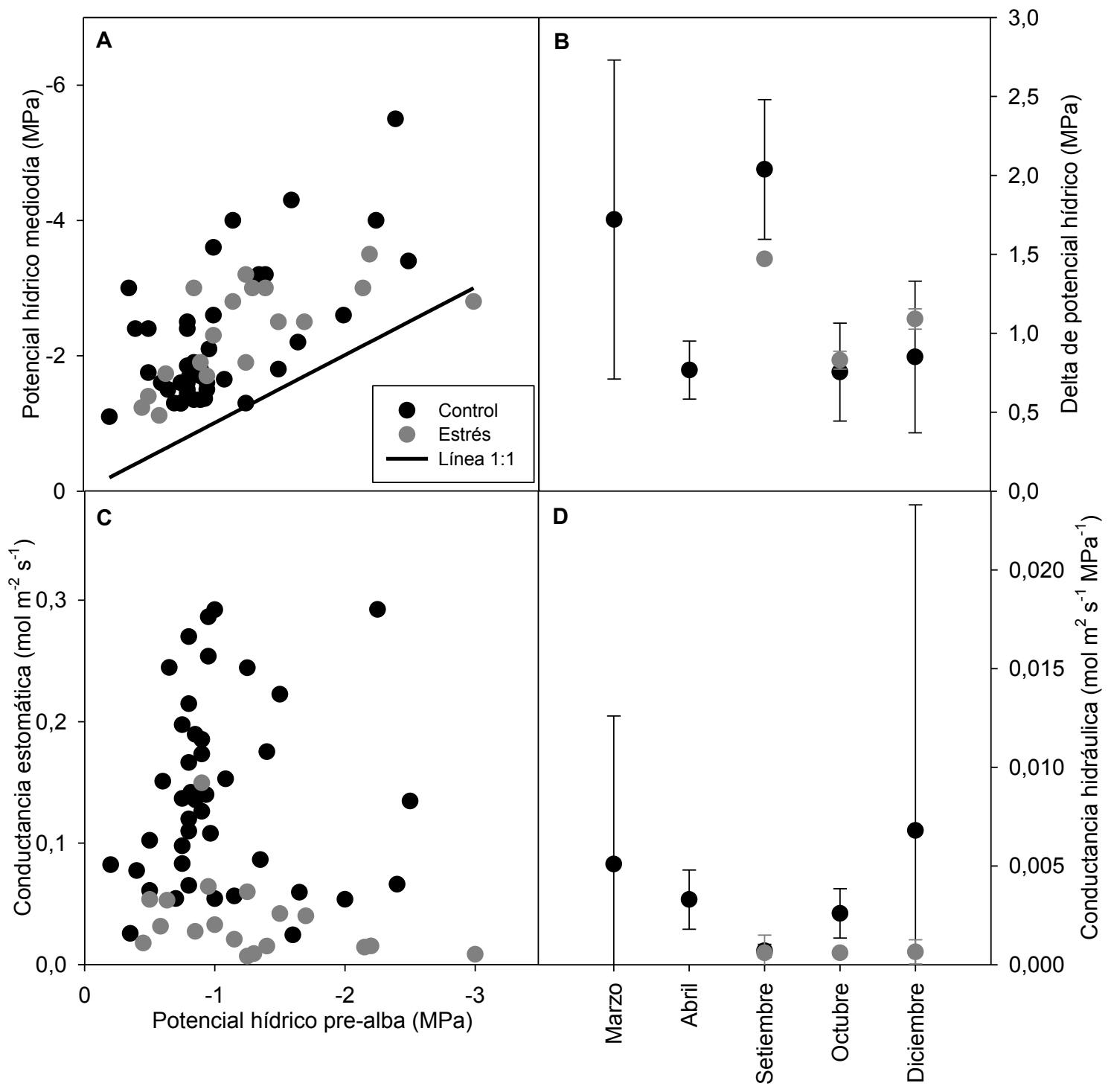

Figura 6.3 Regulación del potencial hídrico y comportamiento estomático en plantas de Pinus taeda $\mathrm{L}$. en dos condiciones hídricas contrastantes bajo invernáculo. A) Relación entre potencial hídrico en prealba y potencial hídrico al mediodía (MPa). B) Delta de potencial hídrico (diferencia entre máximo en pre-alba y mínimo al mediodía) ( $\mathrm{MPa}$ ) en distintas fechas. C) Conductancia estomática $\left(\mathrm{mol} \mathrm{m}^{-2} \mathrm{~s}^{-1}\right.$ ) en función del estado hídrico de las plantas (potencial en pre-alba). D) Conductancia hidráulica promedio $\left(\mathrm{mol} \mathrm{m}^{2} \mathrm{~s}^{-1} \mathrm{Mpa}^{-1}\right)$ de plantas enteras durante el período del ensayo. 


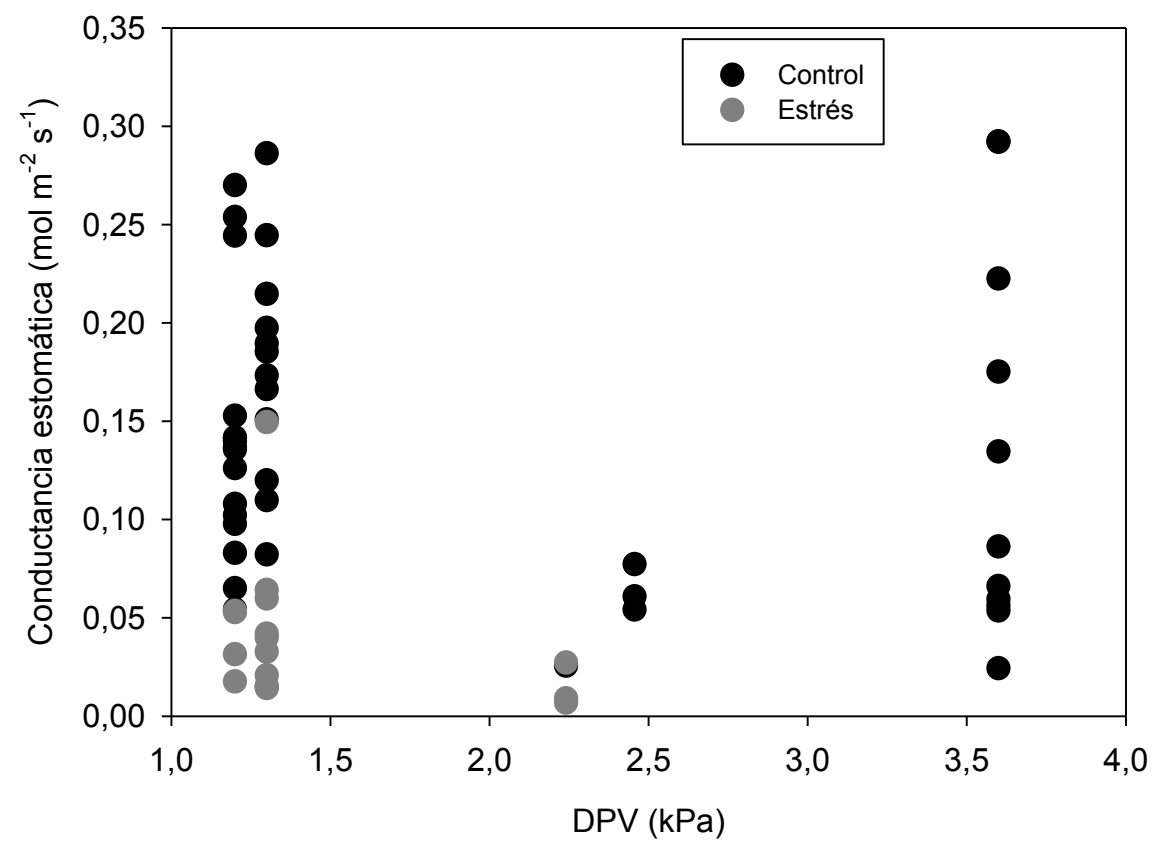

Figura 6.4 Conductancia estomática $\left(\mathrm{mol} \mathrm{m}^{-2} \mathrm{~s}^{-1}\right.$ ) en función de la demanda atmosférica (DPV, $\left.\mathrm{kPa}\right)$ en situaciones hídricas contrastantes en plantas de Pinus taeda L. bajo invernáculo.

A pesar de la baja sensibilidad estomática al DPV (Figura 6.4), la variación promedio en la $K_{\mathrm{h}}$ no fue tan marcada en el tiempo como se hubiese esperado en función de los bajos potenciales hídricos alcanzados por las plantas control en algunas fechas (Figura 6.3 panel D). Cabe destacarse que en la situación control se observaron fechas con individuos que presentaron altas pérdidas de $K_{\mathrm{h}}$ (manifiesto en la alta variabilidad de los datos, ver desvíos en Figura 6.3 panel D), y otras posteriores con una recuperación de la misma, sugiriendo que estas pérdidas son fenómenos reversibles o compensables en el tiempo con la formación de nuevos tejidos.

\section{Ensayo en Macetas 2 (EnM2)}

En este segundo ensayo en macetas, las plantas bajo invernáculo mostraron un comportamiento que podría considerarse "isohídrico" en términos generales, manteniendo relativamente constantes los valores mínimos diarios de potencial en aproximadamente -3 MPa (Figura 6.5 panel A). Sin embargo, cuando la disponibilidad de agua en el suelo fue alta (considerando como un valor umbral valores de potencial de pre-alba mayores a -0,9 MPa) y el DPV fue bajo, las plantas no llegaron a ese nivel mínimo de potencial, manifestando un comportamiento más anisohídrico, lo cual se 
observa en la primera porción de la relación potencial al mediodía-potencial en prealba (Figura 6.5 panel A).

Por otro lado, considerando el gradiente de potencial desarrollado (diferencia entre potencial mínimo y máximo diario), se observó una tendencia isohidrodinámica en la mayor parte del período evaluado, en el que el gradiente de potencial diario se mantuvo en torno a 1,25 MPa independientemente del DPV (Figura 6.5 panel B). Sin embargo, en situaciones de gran déficit hídrico en el suelo (como en el caso del déficit severo) y alta demanda evaporativa, combinación que se da comúnmente en diciembre y es característico en la región de estudio (Provincia de Misiones), el potencial en pre-alba resultó ser similar al umbral mínimo diario y las plantas prácticamente no abrieron los estomas en todo el día, resultando en un gradiente de potencial promedio igual a cero (Figura 6.5 panel B, ver valor de diciembre). En los otros casos, es decir para potenciales de pre-alba de entre $-0,25$ y $-2,5 \mathrm{MPa}$, correspondientes al déficit moderado y al control, las plantas presentaron control estomático frente al aumento del DPV, pero éste nunca fue total, especialmente en el tratamiento control en el que las plantas cerraron los estomas, aunque nunca por completo, a valores de DPV tan altos como $6 \mathrm{kPa}$ (Figura 6.5 panel C y Figura 6.6).

Esta relativamente baja sensibilidad estomática podría ser la causa de las pérdidas de $K_{\mathrm{h}}$ en fechas con alta demanda atmosférica (Figura 6.5 panel D), inclusive en la situación control donde la disponibilidad de agua en suelo fue alta. 


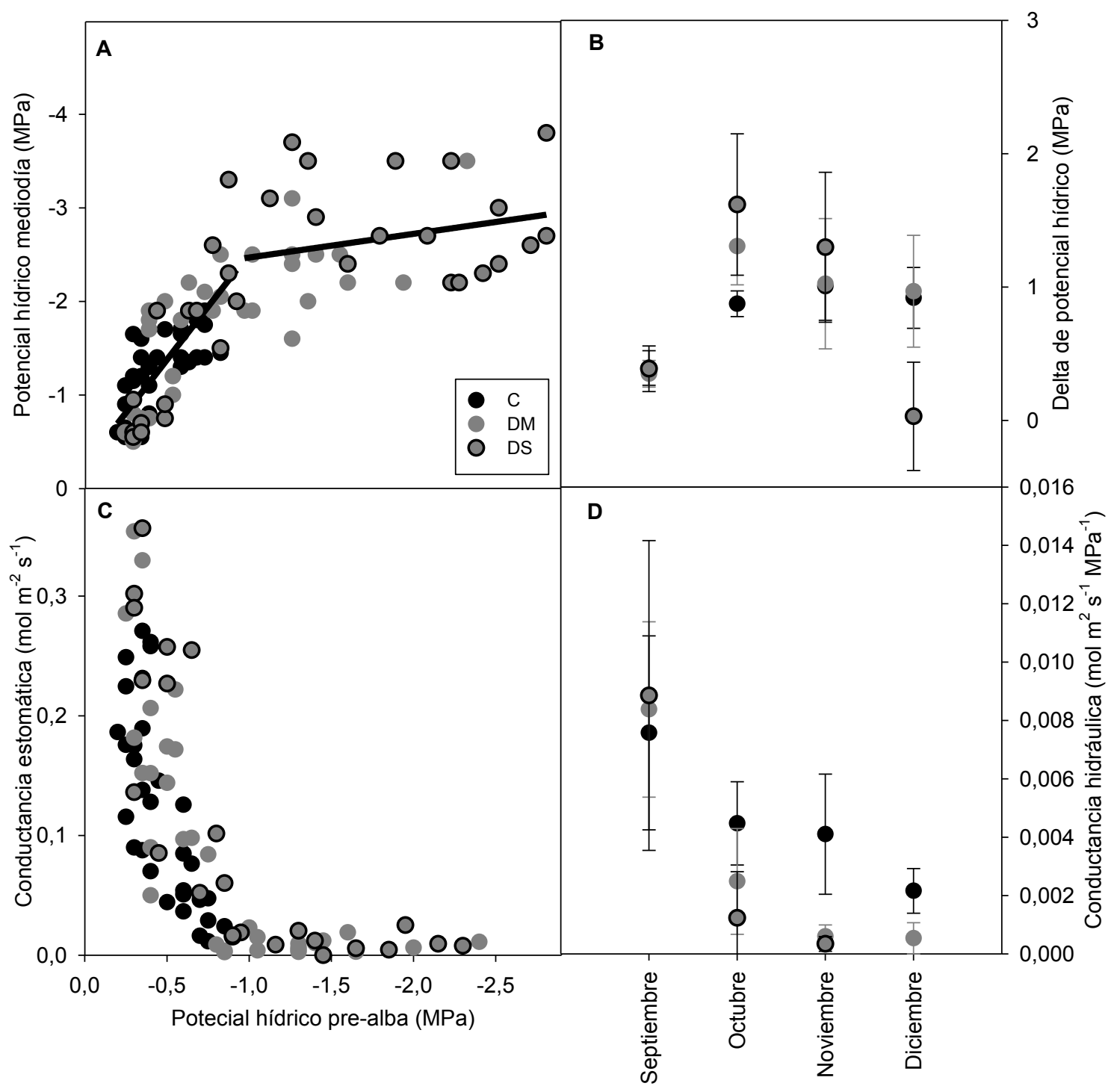

Figura 6.5 Regulación del potencial hídrico y comportamiento estomático en plantas de Pinus taeda L. bajo diferentes condiciones hídricas bajo invernáculo. A) Relación entre potencial hídrico en pre-alba y potencial hídrico al mediodía (MPa). B) Gradiente de potencial hídrico (diferencia entre máximo en pre-alba y mínimo al mediodía) (MPa) en distintas fechas. C) Conductancia estomática (mol m $\mathrm{m}^{-2} \mathrm{~s}^{-1}$ ) medida a las $14 \mathrm{hs}$ en función del estado hídrico de las plantas (potencial hídrico en pre-alba). D) Conductancia hidráulica promedio $\left(\mathrm{mol} \mathrm{m}^{2} \mathrm{~s}^{-1} \mathrm{Mpa}^{-1}\right)$ de plantas enteras durante el período del ensayo. 


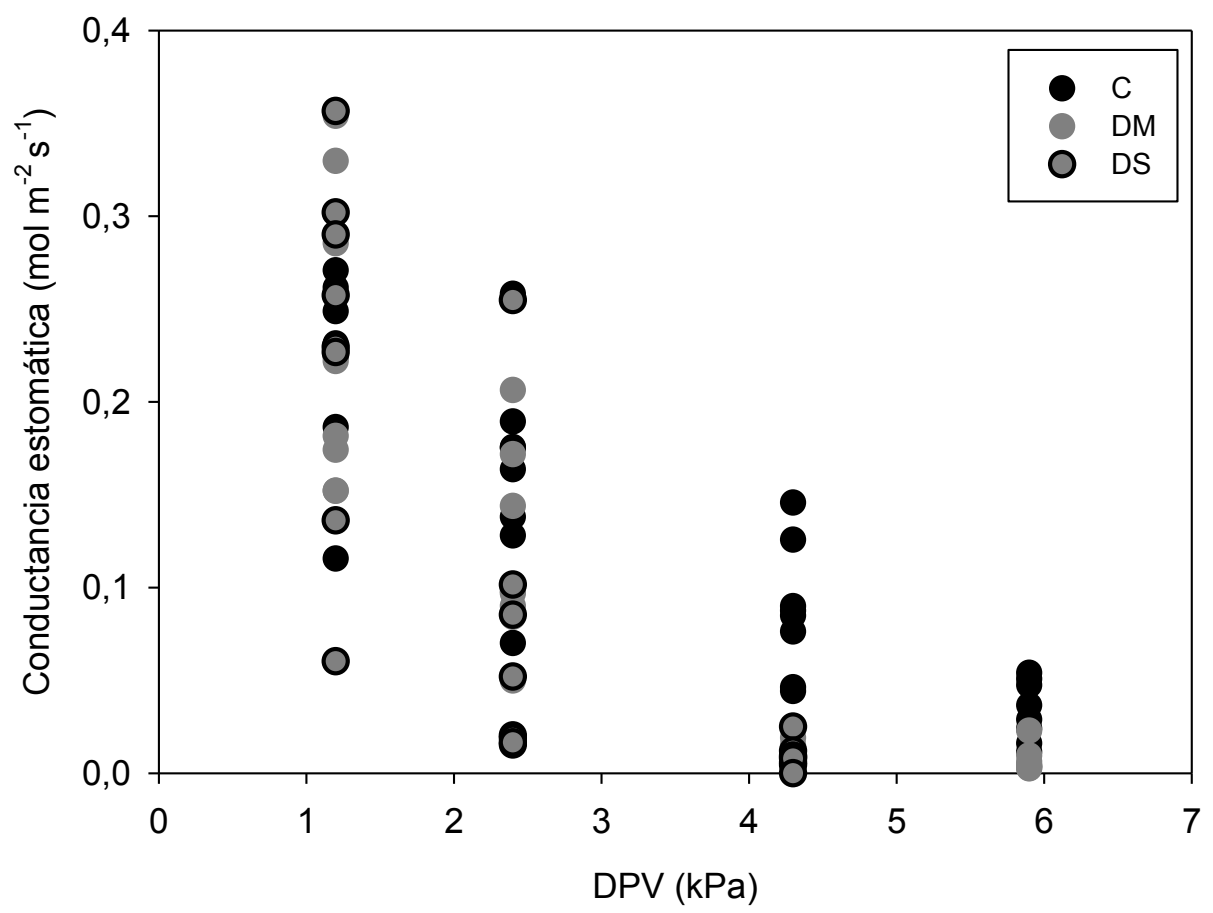

Figura 6.6 Conductancia estomática $\left(\mathrm{mol} \mathrm{m}^{-2} \mathrm{~s}^{-1}\right)$ en función de la demanda atmosférica (DPV, $\mathrm{kPa}$ ) en los diferentes tratamientos en plantas de Pinus taeda L. bajo invernáculo. C: control (sin déficit de agua en el suelo); DM: déficit moderado; DS: déficit severo.

En los tratamientos con déficit de agua en el suelo, las pérdidas de $K_{\mathrm{h}}$ fueron aún mayores y ocurrieron antes en el tiempo respecto al control, manifestándose estas diferencias entre tratamientos a partir de octubre. La menor $K_{\mathrm{h}}$, que es una medida de la capacidad de conducción de agua en fase líquida de la planta completa, no permite discernir en qué lugar se producen estas pérdidas de conductividad hidráulica, si en el mesófilo, los pecíolos, las ramas, el tallo o las raíces. Sin embargo, las curvas de vulnerabilidad a la cavitación de ramas de las mismas familias (resultados presentados en el capítulo 3 de esta tesis) sugieren que los valores de $-3 \mathrm{MPa}$, alcanzados a nivel foliar en la mayor parte de las fechas de medición, son consistentes con pérdidas de $k_{\mathrm{h}}$ en las ramas del orden de $70 \%$ si asumimos que la diferencia de potencial entre la rama y las hojas es mínima.

\section{Ensayo a Campo (EnC)}

Bajo condiciones ambientales naturales como las del ensayo desarrollado a campo, las plantas nunca alcanzaron potenciales de pre-alba demasiado bajos, aun luego de períodos de déficit de precipitaciones según los registros climáticos (Figura 6.2). 
Seguramente una mayor exploración del sistema radical les permitió el abastecimiento de agua (Hacke et al. 2000), por lo cual alcanzaron un valor mínimo promedio en prealba de - 0,75 MPa durante todo el período del ensayo (Figura 6.7 panel A). EI DPV en las fechas evaluadas tampoco no alcanzó valores muy altos (máximo absoluto de DPV de 2,5 kPa) (Figura 6.8), lo que en conjunto con la disponibilidad de agua en suelo se tradujo en un bajo control estomático del potencial hídrico (Figura 6.7 panel C). En marzo, momento de mayor disponibilidad de agua en suelo (potencial hídrico pre-alba promedio: -0,23 $\mathrm{MPa}$ ) se alcanzaron valores mínimos diarios de potencial hídrico de hasta -6 MPa (promedio para marzo: -4,5 MPa) debido a la ausencia de cierre estomático. En este sentido, el gradiente de potencial hídrico en esta fecha fue muy diferente al de los meses posteriores, los que presentaron mayor restricción hídrica dadas las menores precipitaciones acumuladas (Figura 6.7 panel B). Los meses donde la disponibilidad de agua en el suelo fue menor (junio y agosto), el gradiente de potencial hídrico descendió a valores cercanos a $1 \mathrm{MPa}$, presentando las plantas un comportamiento similar al de los experimentos analizados anteriormente (EnM1 y EnM2) (Figura 6.7 panel B).

Las condiciones dadas en marzo (alta disponibilidad de agua en suelo y baja regulación estomática) redundaron en pérdidas de $K_{\mathrm{h}}$ en comparación con junio y agosto, fechas en las cuales los potenciales hídricos mínimos fueron mayores (en torno a -2 MPa) (Figura 6.7 paneles $A$ y D). Estos resultados sugieren que cuando las plantas no tienen restricciones hídricas en el suelo pueden manifestar una altísima capacidad de intercambio gaseoso, aun a expensas de pérdidas de su integridad hidráulica (Figura 6.8). Este comportamiento puede ser parte de la explicación de las altas tasas de crecimiento verificadas en las plantas a campo (ver capítulo 5). 


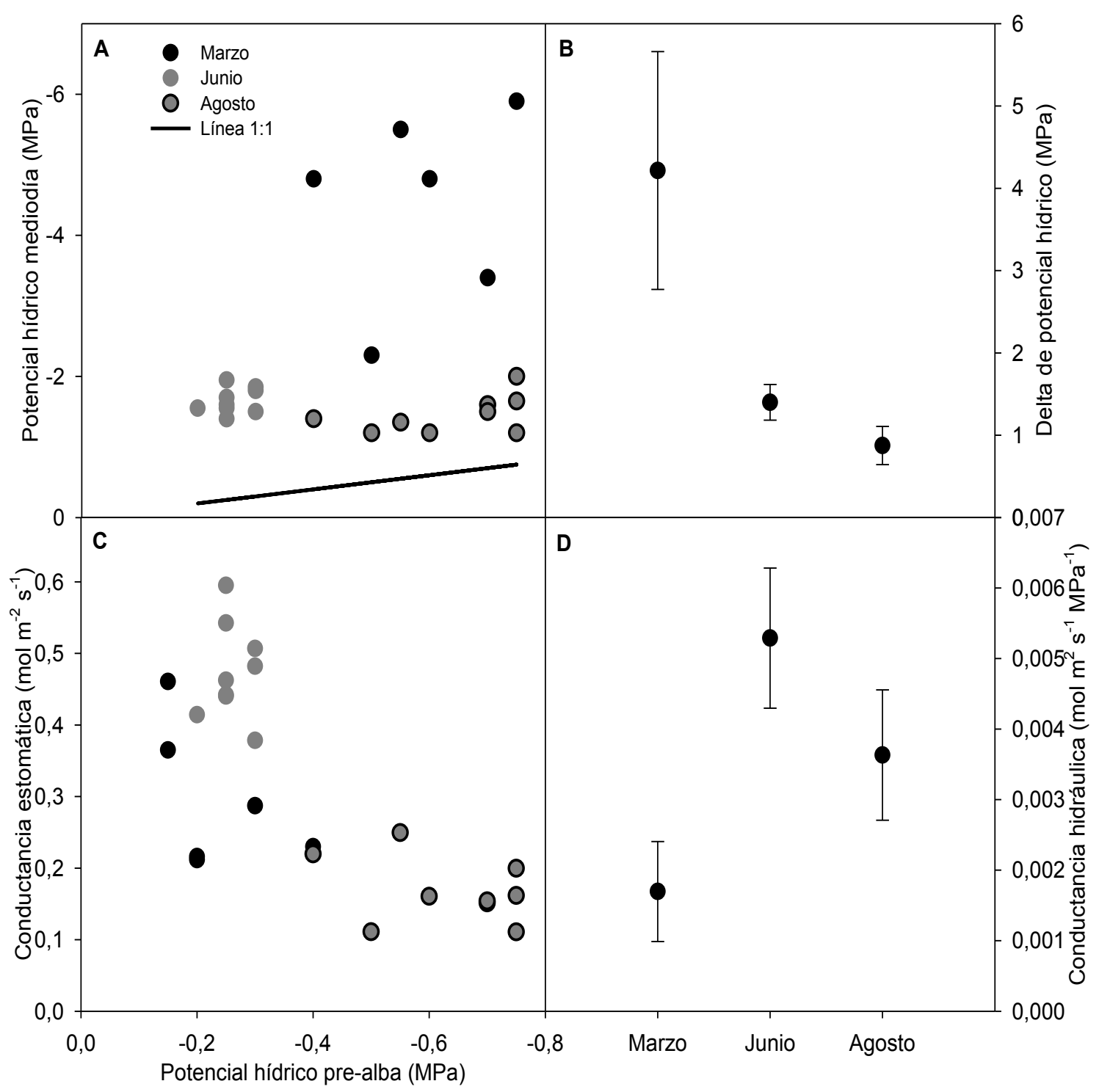

Figura 6.7 Regulación del potencial hídrico y comportamiento estomático en plantas de Pinus taeda $\mathrm{L}$. bajo condiciones de campo. A) Relación entre potencial hídrico en pre-alba y potencial hídrico al mediodía (MPa). B) Gradiente de potencial hídrico (diferencia entre mínimo en pre-alba y máximo al mediodía) (MPa) en distintas fechas. C) Conductancia estomática $\left(\mathrm{mol} \mathrm{m}^{-2} \mathrm{~s}^{-1}\right)$ en función del estado hídrico de las plantas. D) Conductancia hidráulica promedio $\left(\mathrm{mol} \mathrm{m}^{2} \mathrm{~s}^{-1} \mathrm{Mpa}^{-1}\right)$ de plantas enteras durante el período del ensayo. 


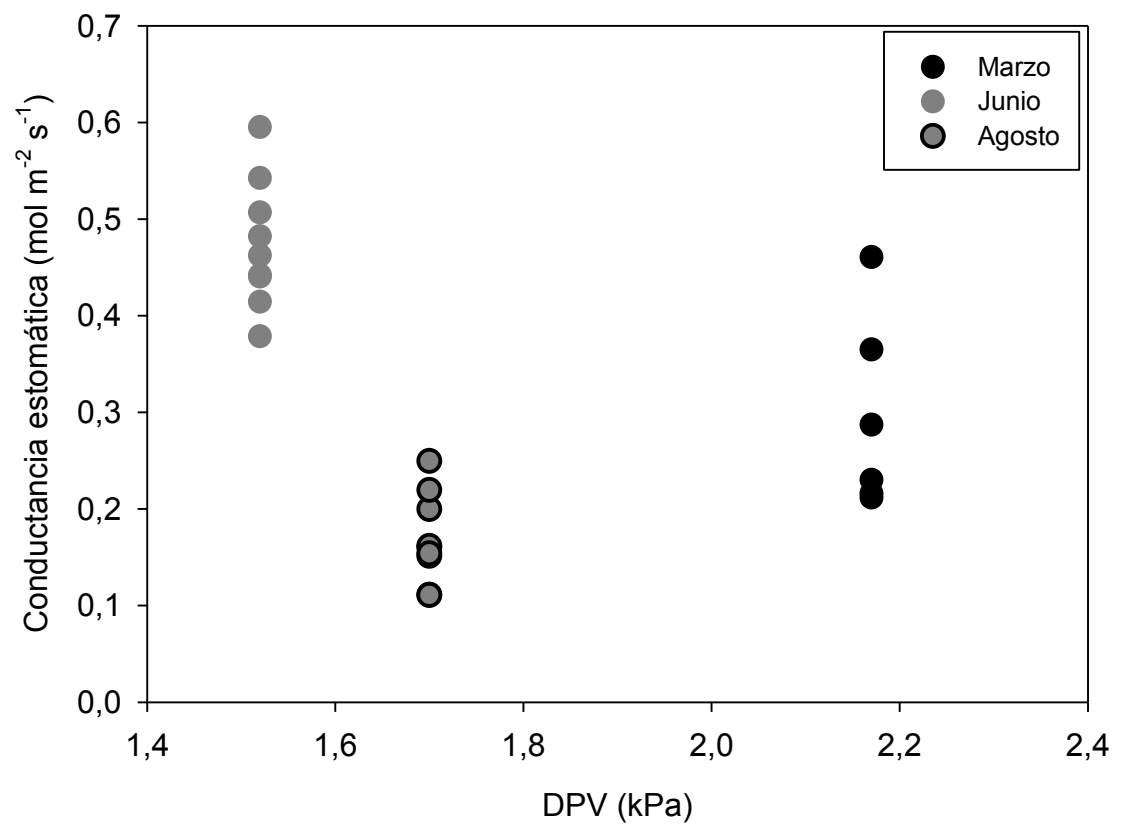

Figura 6.8 Conductancia estomática $\left(\mathrm{mol} \mathrm{m}^{-2} \mathrm{~s}^{-1}\right.$ ) en función de la demanda atmosférica (DPV, $\mathrm{kPa}$ ) en plantas de Pinus taeda L. creciendo en condiciones de campo.

Cabe mencionar que los valores de DPV registrados en este período de desarrollo del ensayo no fueron tan altos como los observados en el ensayo presentado con anterioridad (EnM2). Por otro lado, las restricciones hídricas son muy distintas en macetas que en el suelo a campo, donde las plantas cuentan con menos restricciones de exploración a nivel radical.

\section{DISCUSIÓN}

Se han presentado resultados de dos ensayos en macetas y uno a campo, en los que a primera vista, los patrones son algo contrastantes entre el EnM2 en maceta y los otros dos (EnM1 y EnC). En el primer caso, EnM2, se verificó un comportamiento muy similar al observado por Gándara et al. (2014) en plantas de 5 años de edad para igual especie, donde han determinado un comportamiento tendiente al isohidrismo en términos generales, con valores umbrales mínimos de $-3 \mathrm{MPa}$. Es así que hemos observado, sólo en fechas en las que la disponibilidad de agua en el suelo fue alta (potencial de pre-alba alto) y al mismo tiempo el DPV fue relativamente bajo, una variación en el potencial hídrico del mediodía, con valores por encima de -3 MPa (primera recta en la Figura 6.3 panel A). En este caso, la baja demanda evaporativa 
seguramente impidió que las plantas pudieran alcanzar gradientes de potencial importantes. Sin embargo, en EnM1, también en macetas, y en el ensayo a campo, la tendencia predominante fue el anisohidrismo, especialmente evidente en las plantas sin restricciones de agua en el suelo. La principal diferencia ambiental entre el ensayo EnM2 y los otros dos (EnM1 y EnC) es que en estos dos últimos nunca se alcanzaron déficits de presión de vapor de la atmósfera muy altos. En el ensayo EnM2, hubo fechas en las que el DPV fue de $6 \mathrm{kPa}$, mientras que en los otros nunca se alcanzaron los 3,5 kPa. Esto sugiere que, ante alta disponibilidad de agua en el suelo y si el DPV no es demasiado alto (menor a $3 \mathrm{kPa}$ aproximadamente), los plantines de Pinus taeda no "sensan" condiciones de déficit hídrico en el ambiente y por lo tanto, no cierran sus estomas. Esto los lleva a alcanzar potenciales hídricos muy bajos, de hasta menos de -5 MPa. Recién se produce un cierre estomático parcial en condiciones de alta disponibilidad de agua en suelo cuando el DPV es alto, de más de $3 \mathrm{kPa}$, conduciendo a un control más fino del potencial hídrico mínimo. En contraste, cuando hay restricciones de agua en el suelo, la sensibilidad estomática al DPV aumenta produciéndose cierre estomático parcial a bajos valores de DPV. Esto resulta en una regulación más estricta del potencial hídrico, que no supera el umbral de $-3 \mathrm{MPa}$. El comportamiento isohídrico en P.taeda (en nuestro caso sólo verificado en el experimento EnM2) ha sido reportado por Hacke et al. (2000), Ewers et al. (2000) y Gándara et al. (2014). En estos estudios, el mantenimiento del potencial al mediodía se produjo en torno a $-2 \mathrm{MPa}$, o inferior inclusive, lo que sugiere que los genotipos estudiados en estos últimos trabajos citados serían más vulnerables a la cavitación, teniendo que cerrar sus estomas antes, que las familias aquí estudiadas, y/o que la distinta regulación estomática está dada por diferencias en la hidráulica del suelo entre los diferentes estudios. En este sentido, y como se mencionó en la Introducción, Ewers et al. (2000) encontraron que en suelos arcillosos las plantas de P. taeda alcanzan potenciales hídricos más negativos comparados con aquellas establecidas en suelos arenosos.

En contraste con estos antecedentes, no se han encontrado reportes de marcado anisohidrismo en Pinus taeda, como el que se verificó en dos de los tres experimentos de esta tesis. 
Por otro lado, el tipo de regulación estomática verificada en las distintas condiciones ambientales, dio lugar a dos situaciones en torno al gradiente de potencial hídrico que desarrollan las plantas. En un primer caso, cuando existen déficits hídricos, ya sea en el suelo y/o por una demanda evaporativa relativamente alta (> 3,5 $\mathrm{kPa}$ aproximadamente), la especie tiende a desarrollar un comportamiento del tipo isohidrodinámico, manteniendo el gradiente de potencial hídrico constante alrededor de 1-1,25 MPa, lo cual coincide en parte con lo determinado por Samuelson y Stokes (2006) y Gonzalez-Benecke y Martin (2010) quienes han reportado un gradiente de potencial hídrico de 0,86 y 0,75 MPa respectivamente para esta especie en su región de origen. Gándara et al. (2014) reportan gradientes máximos de 1 MPa en individuos de Pinus taeda en Uruguay, aunque en la mayoría de las fechas evaluadas, el gradiente fue aún menor a este valor. Asimismo, Faustino (2013) determinó un comportamiento isohidrodinámico en plantines de esta especie de 2 años de edad bajo invernáculo. En ese ensayo, se determinó que el potencial hídrico foliar disminuyó en función de la disponibilidad de agua en el suelo, tanto en su valor máximo como mínimo, pero la tasa de disminución entre ambas mediciones fue similar independientemente de la disponibilidad hídrica. En el presente estudio, el comportamiento cuasiisohidrodinámico se corresponde con las condiciones ambientales en las que existe regulación estomática del potencial hídrico, y que redundan en isohidrismo. El gradiente de aproximadamente $1 \mathrm{MPa}$ que se observa en condiciones de déficit hídrico moderado no se puede mantener, sin embargo, cuando el suelo presenta muy bajo contenido de agua y el DPV es muy alto, momento en el que el gradiente tiende a cero por el cierre estomático casi completo y por la pérdida de $K_{\mathrm{h}}$ (Figura 6.3, Figura 6.5 y Figura 6.7 paneles $C$ y $D$ en cada una de ellas).

Por otro lado, y contrario a la situación anterior, cuando el contenido de agua en el suelo es muy alto y el DPV es moderado, el gradiente de potencial hídrico tiende a aumentar hasta más de $4 \mathrm{MPa}$ debido a valores de potencial hídrico mínimos diarios sumamente negativos. Bajo estas condiciones, ocurre una fase anisohídrica producto de una escasa o nula sensibilidad estomática al DPV y ausencia de cierre estomático. Esto es contrario a lo postulado por Franks et al. (2007) como mecanismo anisohídrico clásico (Figura 6.1), que se observa en arbustos o herbáceas. Estos autores mencionan 
que el aumento del gradiente de potencial hídrico se produce en momentos de alto nivel de estrés debido a que la baja regulación estomática de las especies anisohídricas hace que el potencial hídrico baje mucho en momentos en que el agua en el suelo es escasa. En condiciones de campo estas condiciones además coinciden con los mayores valores de DPV, haciendo al estrés aún mayor.

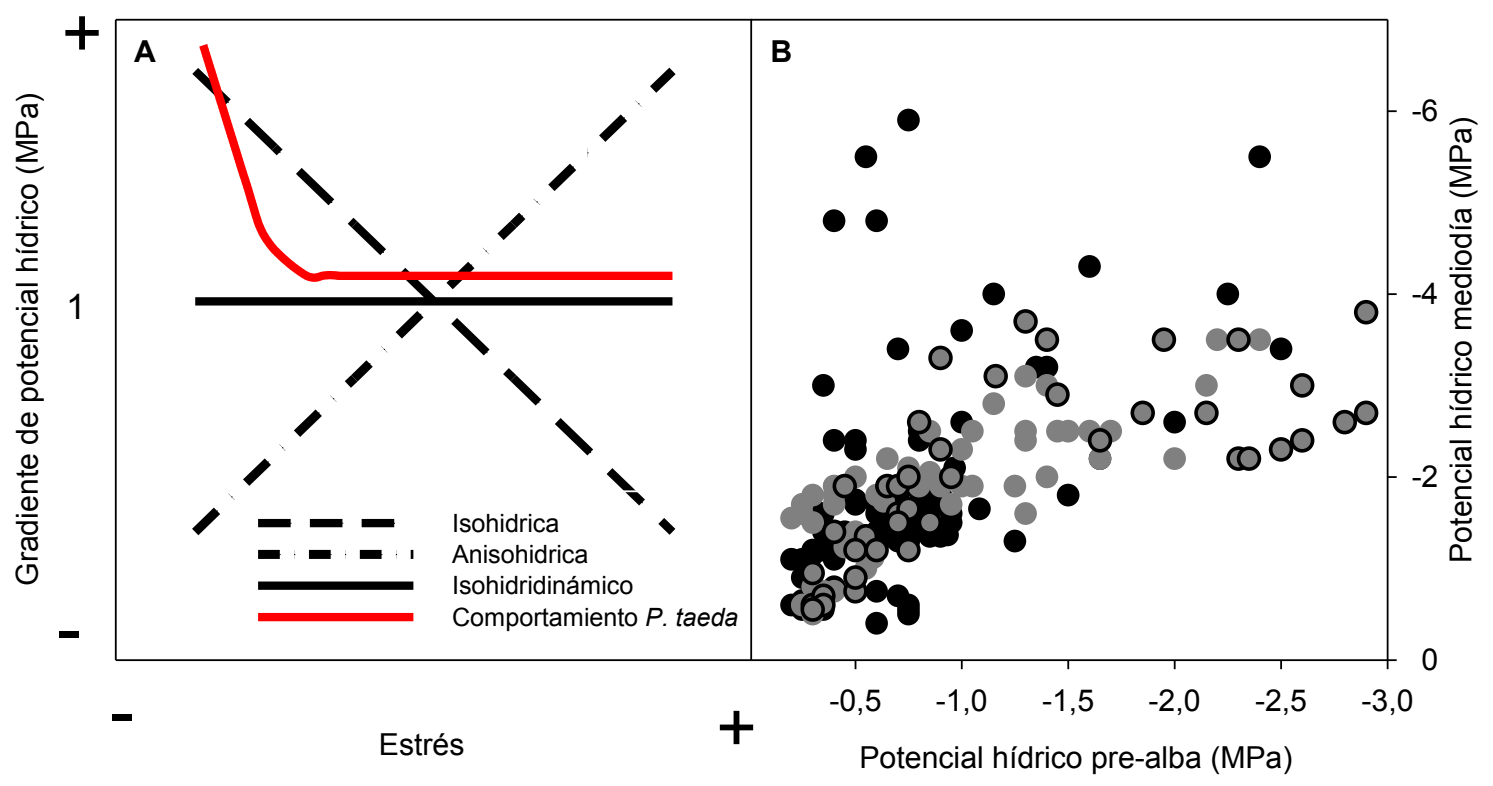

Figura 6.9 Modelo de regulación estomática del potencial hídrico para Pinus taeda. A) Líneas negras: modelos de regulación estomática adaptados de modelos clásicos resumidos en Franks et al. (2007) (Ver Figura 6.1). La línea roja es el nuevo modelo propuesto para plantines de esta especie, caracterizado por una fase anisohídrica cuando no hay restricciones hídricas en el suelo y la demanda evaporativa es moderada (DPV < $3 \mathrm{MPa}$ ), y una fase isohídrica (en torno a -3 MPa) e isohidrodinámica (en torno a $1 \mathrm{MPa}$ ) cuando existen restricciones hídricas en el suelo y/o en la atmósfera (DPV > 3 $\mathrm{MPa}$ ). En el eje de abscisas el nivel de estrés resulta de una combinación hipotética de disponibilidad de agua en suelo y de la demanda evaporativa ambiental. B) Relación entre potencial hídrico en prealba y potencial hídrico al mediodía ( $\mathrm{MPa}$ ) para el pool de plantas de los diferentes ensayos. Círculos negros: plantas bajo condiciones óptimas de agua en suelo y moderados DPV; círculos grises: plantas con disponibilidad de agua en suelo menor a la condición anterior y similar DPV; círculos grises con contornos negros: plantas con muy baja disponibilidad de agua en suelo y altos DPV.

Por lo expuesto, en la Figura 6.9 se propone un modelo de regulación estomática del potencial hídrico para Pinus taeda diferente a cualquiera de las opciones presentadas anteriormente (Figura 6.1 y Figura 6.9). Así, bajo condiciones óptimas de crecimiento, caracterizadas por un potencial hídrico en pre-alba de alrededor de -0,25 MPa y DPV < a $3 \mathrm{kPa}$, se observa un pobre control estomático del potencial hídrico alcanzándose 
valores mínimos muy bajos y gradientes de potencial muy altos. Esto redunda en anisohidrismo. Sin embargo, el comportamiento más frecuente, debido posiblemente a la presencia común de restricciones hídricas ya sea en el suelo y/o en la atmósfera, es aquel en el que la especie presenta un comportamiento tendiente al isohidrismo, en torno a -3 MPa, e isohidrodinamismo, dado por el mantenimiento del gradiente de potencial hídrico en torno a $1 \mathrm{MPa}$. En todos los casos, se observa una relativamente baja sensibilidad estomática al DPV, aunque ésta aumenta a medida que aumenta el déficit hídrico, lo cual se traduce en pérdidas de $K_{\mathrm{h}}$ aun en condiciones de alta disponibilidad de agua en el suelo.

\section{CONCLUSIONES}

Si bien se ha observado en capítulos anteriores que el déficit hídrico es uno de los principales factores que afectan el crecimiento en plantines de Pinus taeda, la regulación estomática del potencial hídrico es uno de los componentes que más influye en esta respuesta. Las plantas aquí estudiadas han manifestado diferentes patrones en su regulación estomática del potencial hídrico, resultado novedoso de este estudio. El comportamiento estomático se vio estrechamente ligado a las condiciones ambientales prevalecientes en cada sistema analizado. En este sentido se pueden describir dos tipos de comportamientos:

Cuando las condiciones hídricas son óptimas y los valores de DPV son relativamente bajos (menor a $3 \mathrm{kPa}$ ), Pinus taeda puede manifestarse como una especie del "tipo" anisohídrica, condición en la que la planta no cierra sus estomas y alcanza potenciales hídricos muy bajos (más negativos).

Por otro lado, cuando esta misma especie es sometida a una restricción hídrica en el suelo, ésta pasa a tener una regulación estomática más estricta, manifestando así un comportamiento de carácter más isohídrico incluso a bajos valores de DPV. Frente a estas situaciones de estrés, dadas por un déficit hídrico en el suelo y/o por altas demandas evaporativas del ambiente $(>3,5 \mathrm{kPa})$, esta especie presenta además un comportamiento del tipo isohidrodinámico, dado por el mantenimiento de su gradiente de potencial hídrico en valores constantes entre 1 y 1,25 MPa. 
Entender la regulación estomática del potencial hídrico de la especie nos aporta conocimiento acerca del comportamiento de la misma frente a diferentes situaciones ambientales. Resulta interesante avanzar en la variación intraespecífica en estas respuestas, lo que podría ser clave para determinar la resistencia al déficit hídrico de distintos genotipos, en combinación con estudios de asignación de biomasa a distintos compartimentos de la planta. 
CAPÍTULO 7

CONTRASTE DE HIPÓTESIS,

CONCLUSIONES GENERALES Y LÍNEAS DE INVESTIGACIÓN FUTURAS 


\section{CONTRASTE DE HIPÓTESIS, CONCLUISONES GENERALES Y LÍNEAS DE INVESTIGACIÓN FUTURAS}

Debido a que en los capítulos anteriores se discutió cada uno de los resultados obtenidos y se plantearon las conclusiones para cada uno de los objetivos particulares planteados en esta tesis, en el presente capítulo solo se retomarán las hipótesis inicialmente planteadas y serán contrastadas con el conjunto de evidencias hasta aquí expuestas. Asimismo, se indicarán las principales conclusiones del mismo y las líneas de investigación futuras que podrían seguirse para complementar el presente estudio.

\section{CONTRASTE DE HIPÓTESIS}

La principal hipótesis de esta tesis es que existe un compromiso entre crecimiento y resistencia al déficit hídrico en Pinus taeda debido a que las estructuras de la planta que permiten un mayor crecimiento (ej. mayor desarrollo de área foliar y mayor $k_{\mathrm{s}}$ ) son penalizantes frente a condiciones de déficit hídrico (por una mayor superficie transpiratoria y mayor vulnerabilidad a la cavitación, respectivamente). Como hipótesis alternativa se propuso que es posible encontrar combinaciones de atributos en algunos genotipos de esta especie que permiten la selección conjunta de alta productividad y alta resistencia al déficit hídrico. En el presente estudio no se encontró un compromiso claro entre crecimiento y resistencia al estrés en las progenies analizadas, que fueron elegidas para ser estudiadas por poseer distintas combinaciones de tasa de crecimiento potencial y densidad de madera. Las diferencias en crecimiento entre progenies se verificaron sólo ante condiciones óptimas de crecimiento (alta disponibilidad de agua en suelo) en las que las progenies de las familias de alto crecimiento produjeron más biomasa que las de bajo crecimiento. Sin embargo, en términos de crecimiento relativo estas familias crecieron igual (a campo) o menos (en invernáculo) que las de bajo crecimiento absoluto. Este primer resultado pone de manifiesto la dificultad de clasificar a las plantas en este tipo de categorías. El mayor crecimiento absoluto observado en las progenies de algunas familias se debió a que las mismas poseían al inicio del período evaluado un mayor tamaño y por lo tanto, 
mayor superficie de intercambio gaseoso. Este mayor tamaño inicial, en plantas sembradas en iguales fechas, sí está reflejando una mayor capacidad de crecimiento en términos absolutos y relativos en las etapas iniciales del desarrollo. Sin embargo, los resultados indican que al menos a los nueve meses de edad (inicio de las mediciones en la mayoría de los experimentos) las diferencias en crecimiento relativo entre familias desaparecen o inclusive se invierten. Aun así, hasta el segundo año de vida las progenies de mayor crecimiento inicial muestran ventajas con respecto a las otras a pesar de que su crecimiento relativo sea menor o igual. Las progenies que más crecieron en términos absolutos cuando las condiciones ambientales fueron favorables, crecieron en igual magnitud que las otras en condiciones de déficit de agua en el suelo. Las progenies AC no presentaron una mayor capacidad fotosintética por unidad de área foliar o una mayor capacidad de conducción de agua por unidad de superficie de xilema. En este sentido, contrariamente a lo hipotetizado, las familias AC no presentaron mayor $k_{\mathrm{s}}$, aunque una de ellas sí presentó una mayor $k_{\mathrm{l}}\left(k_{\mathrm{h}}\right.$ ponderada por la biomasa de hojas que alimenta la rama) debido a una menor asignación relativa a hojas y una mayor a fuste. Este cambio en la arquitectura hidráulica de una de las familias AC (AC1) podría ser consistente con parte de la hipótesis, aunque no es una estrategia única que explica las altas tasas de crecimiento en la especie desde el momento que se verificó la estrategia contraria (mayor asignación a hojas en detrimento del fuste) en la otra familia AC (AC2). Por otro lado, no se verificó una relación negativa entre $k_{\mathrm{s}}$ y vulnerabilidad a la cavitación, aunque sí hubo variación en esta última variable no asociada con la eficiencia de conducción de agua.

Las progenies de las familias $\mathrm{BC}$ de bajo crecimiento absoluto aéreo (pero alto crecimiento relativo) se caracterizaron por tener mayor asignación a raíces, mayor $g_{\mathrm{s}}$ máxima, menor sensibilidad estomática al DPV (al relacionarla con la $g_{\mathrm{s}}$ máxima), mayor capacidad fotosintética, y una levemente mayor resistencia a la cavitación que las progenies de las familias AC. Algunas de estas estrategias (mayor asignación a raíces, menor vulnerabilidad a la cavitación) las posicionan como familias con mayor resistencia potencial al déficit hídrico, aunque en las condiciones ensayadas en esta tesis esta ventaja no fue evidente, tal vez por su menor sensibilidad estomática al DPV. En este sentido, se puede concluir que dentro del rango de condiciones ambientales 
ensayadas, las familias AC poseen una ventaja en crecimiento, posiblemente ligada a una menor asignación a raíces y una mayor sensibilidad estomática al DPV.

Por otro lado, si se analiza la caída relativa en el crecimiento, es decir la diferencia de crecimiento absoluto en condiciones óptimas vs. condiciones de déficit hídrico, se observa que las familias de alto crecimiento absoluto son más sensibles a la falta de agua que las de bajo crecimiento, lo que podría sugerir cierto compromiso entre crecimiento potencial y resistencia al estrés. Nuevamente surge el dilema de considerar crecimientos absolutos o caídas relativas de crecimiento a la hora de categorizar a las distintas familias.

Por otro lado, las otras hipótesis planteadas en esta tesis se refieren a aspectos más particulares dentro del tópico de resistencia al déficit hídrico y crecimiento en Pinus taeda, y por lo tanto han sido discutidas en los capítulos correspondientes. En relación a ellas y a modo de síntesis podemos concluir que:

- Tal como se había predicho, la disminución del crecimiento acumulado al final de la estación de crecimiento fue mayor cuando el déficit hídrico ocurrió al inicio de la primavera, debido a que en este período se observaron mayores tasas de crecimiento. La tasa de crecimiento posterior, aun cuando las condiciones fueron favorables para el crecimiento de la planta, no alcanzaron a compensar la disminución durante la etapa inicial del período (capítulo 4). Este resultado es coincidente con lo encontrado por Fernández et al. (2014) en plantines de P. ponderosa creciendo en el N.O. de la Patagonia Argentina. Sería interesante ampliar estos estudios realizados en condiciones controladas a situaciones de campo así como analizar este aspecto en otras especies de coníferas a fin de determinar si éste es un fenómeno generalizable o bien particular de estas especies de Pinus.

- Se hipotetizó que en condiciones de campo las familias con tasas de crecimiento diferentes presentarían un comportamiento estomático y una asignación de biomasa entre compartimentos aéreos (hojas vs. tejido leñoso) diferencial. Se esperó una mayor sensibilidad estomática (cierre estomático más marcado ante condiciones de déficit hídrico en el suelo y/o la atmósfera) 
en la familia de bajo crecimiento, que le permitiera una menor caída relativa de su conductividad hidráulica (comportamiento más evitador), que redunda en una menor fijación de $C$. Asimismo, además de una menor sensibilidad estomática que le permita tener los estomas abiertos por más tiempo, se esperó una menor asignación de biomasa a hojas y una mayor asignación a fuste en la familia de alto crecimiento, resultante en una alta capacidad de provisión de agua por unidad de área foliar (alta conductividad hidráulica foliar específica). Contrariamente a lo esperado, si bien hubo diferencias en crecimiento absoluto, a favor de la familia de alto crecimiento ( $A C$ ), los crecimientos relativos fueron similares entre familias, indicando que las diferencias en biomasa establecidas en los primeros estadíos del desarrollo son esenciales para explicar las diferencias en tamaño absoluto, que se amplían en el tiempo, entre genotipos. Si bien hubo un comportamiento estomático que siguió la tendencia hipotetizada (mayor sensibilidad estomática en la familia $\mathrm{BC})$, las diferencias no llegaron a ser estadísticamente significativas. Se requiere realizar un estudio más exhaustivo en este sentido, aumentando el número muestral y las fechas de análisis. A favor de la hipótesis, se observaron diferencias en la asignación de carbono a hojas vs. leño entre familias. En este ensayo no se midió asignación a raíces, factor que podría ser importante para explicar el mayor tamaño de las plantas de la familia AC al inicio del ensayo. Esta variable sí fue analizada en uno de los ensayos de condiciones semicontroladas, donde efectivamente se observó que ambas familias BC poseen mayor asignación de biomasa a raíces en comparación a las familias AC.

- Respecto a la regulación estomática del potencial hídrico en Pinus taeda, algunos antecedentes describían a esta especie como isohídrica mientras que otros la clasificaron como anisohídrica-isohidrodinámica. Asimismo existen reportes de una regulación estomática diferencial entre progenies que sugieren que puede haber distintos patrones de acuerdo al material genético analizado. Los tres ensayos llevados a cabo en esta tesis permiten señalar un comportamiento similar entre progenies (en términos generales), que se diferencia de las clásicas definiciones de iso y anisohidrismo, que plantean una 
disminución y un aumento del gradiente de potencial hídrico a medida que progresa el estrés, respectivamente. En condiciones de disponibilidad hídrica no limitante (sólo verificadas en condiciones de campo y en un período muy acotado de tiempo) la especie sería anisohídrica disminuyendo su potencial hídrico hasta valores sumamente negativos, aumentando así el gradiente de potencial hídrico entre el suelo y las hojas. En períodos de cierto déficit de agua en el suelo o en la atmósfera (condiciones normales de crecimiento en la zona de estudio) la especie tendería a un comportamiento isohídrico y cuasiisohidrodinámico. Es decir tendería a mantener un mismo potencial hídrico mínimo en el tiempo, pero con cambios en la conductancia hidráulica total tales que permiten mantener a la vez un gradiente de potencial entre el suelo y las hojas de aproximadamente $1 \mathrm{MPa}$. Este comportamiento diferencial está explicado por un muy bajo control estomático del potencial hídrico en condiciones altamente favorables, y una relativamente baja sensibilidad estomática cuando las condiciones ambientales son más desfavorables. Consecuentemente, en todos los casos ocurren pérdidas de conductancia hidráulica aunque de distinta magnitud dependiendo del nivel de déficit hídrico. Esta baja sensibilidad estomática al DPV podría explicar en parte las altas tasas de crecimiento de la especie pero seguramente suponen un cuello de botella que debería ser considerado frente a condiciones de mayor déficit hídrico.

Una mención especial merece el análisis de la densidad de madera como variable relacionada con la resistencia al estrés y el crecimiento. En este estudio se seleccionaron 4 familias que reunían distintas combinaciones de tasa de crecimiento y densidad de madera, medidos en árboles madres y en juveniles-adultos de la progenie, en un planteo experimental similar al trabajo de Wang et al. (2003), que analizó los compromisos entre crecimiento y resistencia a estrés hídrico en Pinus contorta, en familias con alta y baja densidad de madera. Sin embargo, si bien se encontraron las mismas tendencias en crecimiento entre los plantines medidos y los antecedentes reportados para cada progenie ( $A C$ vs. $B C$ ), esto no ocurrió a nivel de densidad de madera, que resultó una variable que no se correlacionó con los valores de las madres. 
La densidad básica no dio diferencias entre familias, y la densidad localizada, estimada a partir de las dimensiones de las traqueidas del leño temprano y tardío, fue mayor en ambas familias AC que en las BC. La densidad de la madera es una variable con alto grado de heredabilidad en general, por lo que podemos suponer que las tendencias en densidad se establecen a edades posteriores a los dos años en Pinus taeda. Por otro lado, la bibliografía reporta que cuando existe relación entre vulnerabilidad a la cavitación y densidad de madera, ésta es del tipo: mayor densidad, menor vulnerabilidad. En este estudio, las diferencias en VC no fueron muy marcadas entre procedencias, pero cuando existieron fueron en el sentido contrario al esperado. Las familias BC tendieron a ser más resistentes a la cavitación, pero presentaron menor densidad localizada. Por lo expuesto, si bien se requieren estudios específicos que relacionen la VC y la densidad de la madera en $P$. taeda, estos primeros resultados sugieren que, al menos en los dos primeros años del desarrollo, las relaciones entre ambas variables no serían como las hipotetizadas, y que no existen compromisos entre crecimiento y densidad de madera.

\section{CONCLUSIONES GENERALES}

Las familias de bajo crecimiento absoluto en las condiciones evaluadas manifestaron una alta potencialidad de fijación de carbono por unidad de área foliar, lo que sugiere que podrían crecer más que lo observado ante otro tipo de condiciones ambientales. Estas familias se caracterizaron por una menor sensibilidad estomática al DPV que las de alto crecimiento, en relación a sus máximas conductancias estomáticas, lo que seguramente es una desventaja en condiciones de alta demanda evaporativa como las de la región de estudio ya que conduciría a importantes pérdidas de conductancia hidráulica en las plantas. Es por ello que este trabajo sugiere que las altas tasas de crecimiento observadas en algunas familias están intrínsecamente ligadas a estrategias relacionadas a la resistencia al déficit hídrico, como un buen control estomático del potencial hídrico. Esto refuerza la conclusión de que no existe un compromiso entre crecimiento y resistencia al estrés en Pinus taeda, aunque esta aseveración es válida para condiciones climáticas particulares donde prevalezca una alta demanda evaporativa en la mayor parte del período de crecimiento. 
Resulta interesante mencionar que las dos familias clasificadas como de alto crecimiento $(A C)$, así como las dos de bajo crecimiento $(B C)$, tuvieron comportamientos similares entre sí dentro de cada grupo de familias. Sin embargo, al analizar los patrones de partición de biomasa que podrían explicar dichos comportamientos, se encontró una respuesta muy homogénea dentro del grupo de las familias de bajo crecimiento (familias BC1 y BC2 (T17 y T10 respectivamente dentro del PMG)), pero disímil entre las familias de alto crecimiento (AC1 y AC2 (I35 y M11 respectivamente dentor del PMG)). Para el caso de estas dos útimas, por un lado hubo una alta partición a tallo en detrimento del tejido foliar (familia AC1), mientras que en el otro, se priorizó el área foliar (familia AC2). En ambos casos, se llegó a un crecimiento en fuste similar entre ambas familias, por lo que no se puede decir que un determinado tipo de asignación de biomasa sea en forma particular el responsable de las altas tasas de crecimiento de estas familias.

Desde el punto de vista de los caracteres a seleccionar en un programa de mejoramiento genético, buscando genotipos que optimicen el crecimiento y la resistencia al déficit hídrico, este estudio sugiere que deben tenerse en cuenta los patrones de crecimiento iniciales a nivel de plántula (no estudiados en esta tesis, pero que explicarían los tamaños iniciales distintos entre familias, y que se mantuvieron en el tiempo), una alta sensibilidad estomática al DPV y una baja vulnerabilidad a la cavitación del leño. Asimismo una alta asignación de biomasa al leño en forma relativa al área foliar puede ser un carácter deseable optimizando la producción de madera y la eficiencia en el uso de los recursos del ambiente. Esta combinación de caracteres es posible de ser identificada en progenies de Pinus taeda.

Respecto a la anatomía de la madera no se han observado respuestas, a nivel de célula, entre las familias analizadas tanto en condiciones hídricas óptimas como bajo situación de estrés, exceptuando por el tamaño del torus de las puntuaciones. Sin embargo, se manifestaron diferencias significativas entre las familias en cuanto a la proporción de leño temprano y tardío, lo cual ha sido detectado no sólo bajo condiciones de déficit hídrico sino además cuando las condiciones de disponibilidad hídrica fueron óptimas, lo cual refuerza las diferencias entre las familias respecto a la producción de los diferentes tipos de leño. En este mismo contexto las familias BC 
fueron las que presentaron una mayor proporción de leño temprano respecto al grupo de las familias AC, característica que se tradujo en una tendencia (no estadísticamente significativa) a una mayor $k_{\mathrm{s}}$ máxima. A su vez, el grupo de familias de bajas tasas de crecimiento fueron las que se manifestaron como de mayor resistencia a la cavitación, lo que podría estar asociado al tamaño diferencial de torus que presentan con respecto a las familias $A C$. Estos resultados se contraponen al compromiso entre eficiencia de conducción y vulnerabilidad a la cavitación propuestos para otras especies.

\section{LÍNEAS DE INVESTIGACIÓN FUTURAS}

A partir de los resultados obtenidos en esta tesis, surgen nuevos interrogantes que podrían conducir a investigaciones futuras. Algunos de ellos podrían ser:

- Dilucidar mediante simulaciones el efecto de distintos escenarios de cambio climático de la Mesopotamia Argentina sobre el crecimiento y sobrevivencia de familias de Pinus taeda que difieran en la combinación de caracteres morfofisiológicos.

- Evaluar si el peor desempeño de crecimiento de las familias de bajas tasas de crecimiento $(\mathrm{BC})$ en condiciones de alta demanda evaporativa de Misiones se revierte en otra condición ambiental de menor déficit hídrico en la atmósfera como es sugerido por sus altas capacidades de intercambio gaseoso potencial.

- Determinar los patrones de asignación de biomasa en condiciones de campo/invernáculo en las distintas progenies desde el estadio de plántula, con especial énfasis en el sistema radical.

- Determinar la capacidad de recuperación (resiliencia) post-estrés hídrico de distinta magnitud en las diferentes progenies.

- Analizar la plasticidad fenotípica en la vulnerabilidad a la cavitación frente a condiciones de déficit hídrico en distintas progenies, y su relación con los cambios a nivel hidráulico de la planta entera. 


\section{BIBLIOGRAFÍA}

Abe H y Nakai T. 1999. Effect of the water status within a tree on tracheid morphogenesis in Cryptomeria japonica D. Don. Trees, 14: 124-129

A-Noborio IW, Heilman JL, Newton RJ y Messina MG. 1999. Diurnal changes in water conduction in loblolly pine (Pinus taeda) and Virginia pine ( $P$. virginiana) during soil dehydration. Tree Physiology, 19: 575-581

Antonova GF y Stasova VV. 1997. Effects of environmental factors on wood formation in larch (Larix sibirica Ldb.) stems. Trees, 11: 462-468

Aráos S, Del Longo 0 y Karlin O. 2004. Germinación de semillas de Zizyphus mistol Grisebach III. Correlaciones paramétricas del tamaño y peso de drupas, endocarpos y semillas con la germinación y el vigor. Multquina, 13: 51-56

Aspinwall MJ, King JS, Domec JC y McKeand SE. 2011a. Genetic effects on transpiration, canopy conductance, stomatal sensitivity to vapour pressure deficit, and cavitation resistance in loblolly pine. Ecohydrology, 4: 168-182

Aspinwall MJ, King JS, McKeand SE y Domec JC. 2011b. Leaf-level gas exchange uniformity and photosynthetic capacity among loblolly pine (Pinus taeda L.) genotypes of constrasting inherent genetic variation. Tree Physiology, 31: 78-91

Aspinwall J, King JS y McKeand SE. 2013. Productivity differences among loblolly pine genotypes are independent of individual-tree biomass partitioning and growth efficiency. Trees, 27: 533-545

Baker JB y Langdon OG. Pinus taeda L. Reporte USFS (en línea). Disponible en http://www.na.fs.fed.us/pubs/silvics_manual/Volume_1/pinus/taeda.htm. Ultimo acceso: Octubre de 2012

Barnes AD. 2002. Effects of phenology, water availability and seed source on loblolly pine biomass partitioning and transpiration. Tree Physiology, 22: 733-740 
Birk EM y Vitousek PM. 1986. Nitrogen availability and nitrogen use efficiency in loblolly pine stands. Ecology, 67: 69-79

Black JN. 1958. Competition between plants of different initial seed sizes in swards of Subterranean Clover (Trifolium subterraneum L.) with particular reference to leaf area and light microclimate. Australian Journal of Agricultural Research, 9: 299-318

Blazier MA, Hennessey TC, Lynch TB, Wittwer RF y Payton ME. 2004. Productivity, crown architecture, and gas exchange of North Carolina and Oklahoma/Arkansas loblolly pine families growing on a droughty site in southeastern Oklahoma. Forest Ecology and Management, 194: 83-94

Bloom AJ, Chapin FS y Mooney HA. 1985. Resource limitation in plants-an economic analogy. Annual Review of Ecology, Evolution, and Systematics, 16: 363-392

Bongarten BC y Teskey RO. 1986. Water relation of loblolly pine seedling from diverse geographic origins. Tree Physiology, 1: 265-276

Bongarten BC y Teskey RO. 1987. Dry weight partitioning and its relationship to productivity in loblolly pine seedlings from seven sources. Forest Science, 33: 255-267

Bond BJ y Kavanagh KL. 1999. Stomatal behavior of four woody species in relation to leaf-specific hydraulic conductance and threshold water potential. Tree Physiology, 19: 503-510

Bosabalidis AM y Kofidis G. 2002. Comparative effects of drought stress on leaf anatomy of two olive cultivars. Plant Science, 163: 375-379

Bouche PS, Larter M, Domec JC, Burlett R, Grasson P, Jansen S y Delzon S. 2014. A broad survey of hydraulic and mechanical safety in the xylem of conifers. Journal of Experimental Botany, 65: 4419-4431

Bouffier LA, Gartner BL y Domec JC. 2003. Wood density and hydraulic properties of Ponderosa pine from the Willamette Valley Vs. the Cascade Mountains. Wood and Fiber Science, 35: 217-233 
Bouffier L, Raffin A, Rozenberg P, Meredieu C y Kremer A. 2009. What are the consequences of growth selection on wood density in the French maritime pine breeding programe? Tree Genetics - Genomes, 5: 11-25

Brodribb TJ, Holdbrook NM y Hill RS. 2005. Seedling growth in conifers and angiosperms: impacts of constrasting xylem structure. Australian Journals of Botany, 53: $749-755$

Bucci SJ, Goldstein G, Meinzer FC, Scholz FG, Franco AC y Bustamente M. 2004. Functional convergence in hydraulic architecture and water relations of tropical savanna trees: from leaf to whole plant. Tree Physiology, 24: 891-899

Buckley TN. 2005. The control of stomata by water balance. New Phytologist, 168: $275-292$

Burgess SS, Pittermann OJ y Dawson TE. 2006. Hydraulic efficiency and safety of branch xylem increases with height in Sequoia sempervirens (D. Don) crowns. Plant, Cell and Environment, 29: 229-239

Campelo F, Nabais C, Freitas H y Gutierrez E. 2006. Climatic significance of tree-ring width and intra-annual density fluctuations in Pinus pinea from a dry Mediterranean area in Portugal. Annals of Forest Science, 64: 229-238

Carrasco LO, Bucci S, Di Francescantonio D, Lezcano OA, Campanello PI, Scholz FG, Rodriguez S, Madanes N, Cristiano PM, You Hao G, Holbrook NM y Goldstein G. 2015. Water storage dynamics in the main stem of subtropical tree species differing in wood density, growth rate and life history traits. Tree Physiology, 35: 354-365

Casson S y Gray JE. 2008. Influence of environmental factors on stomatal development. New Phytologist, 178: 9-23

Choat B, Jansen S, Brodribb TJ, Cochard H, Delzon S, Bhaskar R, Bucci S, Field TS, Gleason SM, Hacke UG, Jacobsen AL, Lens F, Mahelari H, Martínes-Vilalta J, Mayr S, Mencuccini M, Mitchell PJ, Nardini A, Pittermann J, Pratt RB, Sperry JS, Westoby 
M, Wright IJ y Zanne AE. 2012. Global convergence in the vulnerability of forests to drought. Nature, 491: 752-756

Cochard H y Delzon S. 2013. Hydraulic failure and repair are not routine in trees. Annals of Forest Science, 70: 659-661

Cochard H, Badel E, Herbette S, Delzon S, Choat B y Jansen S. 2013. Methods for measuring plant vulnerability to cavitation: a critical review. Journal of Experimental of Botany, 64: 4779-4791

Corcuera L. 2003. Comparación de dos métodos para generar curvas presiónvolumen en especies del género Quercus. Investigación Agraria: Sistemas y Recursos Forestales, 12: 111-121

Cregg BM, Dougherty PM y Hennessey TC. 1988. Growth and good quality of young loblolly pine trees in relation to stand density and climatic factors. Canadian Journal of Forest Research, 18: 851-858

Cubbage F, Mac Donagh P, Sawinski J, Rubilar R, Donoso P, Ferreira A, Hoeflich V, Morales Olmos V, Ferreira G, Balmelli G, Siry J, Báez MN y Alvarez J. 2007. Timber investment returns for selected plantations and native forests in South America and the Southern United States. New Forests, 33: 237-255

Dalla-Salda G, Fernández ME, Sergent AS, Rozenberg P, Badel E y Meier AM 2014. Dynamics of cavitation in douglas-fir tree-ring: transition-wood, the lord of the ring? Journal of Plant Hydraulics, 1: e-0005

D'Ambrogio de Argüeso A. 1986. Manual de técnicas de histología vegetal. Hemisferio Sur. 83p

Denne MP. 1988. Definition of latewood according to Mork (1928). IAWA Bulletin, 10: 59-62

Domec JC y Gartner BL. 2002. How do water transport and water storage differ in coniferous earlywood and latewood? Journal of experimental botany, 53: 2369-2379 
Domec JC y Gartner BL. 2003. Relationship between growth rates and xylem hydraulic characteristics in young, mature and old-growth ponderosa pine trees. Plant, Cell and Environment, 26: 471-483

Domec JC, Lachenbruch B y Meizner FC. 2006. Bordered pit structure and function determine spatial Patterns of air-seeding thresholds in xylem of Douglas-fir (Pseudotsuga menziesii; Pinaceae) trees. American Journal of Botany, 93: 1588-1600

Dutilleu P, Herman M y Avella-Shaw T. 1998. Growth rate effects on correlations among ring width, wood density, and mean tracheid length in Norway spruce (Picea abies). Canadian Journal of Forest Research, 28: 56-68

eFloras. 2014. Missouri Botanical Garden, St. Louis, MO \& Harvard University Herbaria. http://www.efloras.org

England JR y Attiwill PM. 2011. Change in stomatal frequency, stomatal conductance and cuticle thickness during leaf expansion in the broad-leaved evergreen species, Eucalyptus regnans. Trees, 25: 987-966

Ewers BE, Oren R y Sperry JS. 2000. Influence of nutrient versus water supply on hydraulic architecture and water balance in Pinus taeda. Plant, Cell and Environment, 23: 1055-1066

Faustino L. 2013. Cambios en la arquitectura y fisiología de Pinus taeda en respuesta a la fertilización y al estrés por sequía. Tesis doctoral. Facultad de Ciencias Agrarias, Universidad Nacional de La Plata, Buenos Aires, Argentina. 227 pp

Faustino LI, Bulfe NML, Pinazo MA y Graciano C. 2012. Crecimiento de cuatro familias de Pinus taeda en respuesta a la fertilización con nitrógeno y fósforo en el establecimiento de la plantación. Revista de la Facultad de Agronomía, 111: 54-63

Faustino LI, Bulfe NML, Pinazo MA, Monteoliva SE y Graciano C. 2013. Dry partitioning and hydraulic traits in Young Pinus taeda trees fertilized with noitrogen and phosphorus in a subtropical area. Tree Physiology, 33: 241-251 
Fernández ME, Gyenge J, Graciano C, Varela S y Dalla Salda G. 2010. Conductancia y conductividad hidráulica. En: Técnicas de medición en Ecofisiología vegetal. Concepto y procedimientos. M.E. Fernández y J. Gyenge. Ed. INTA. Argentina pp: 53-68

Fernández ME, Gyenge JE, Varela S y de Urquiza M. 2014. Effects of the time of drought occurrence within the growing season on growth and survival of Pinus ponderosa seedlings. Trees, 28: 745-756

Fernández RA, Lupi AM, Pezutti R, Martiarena R, Pahr N y Von Wallis A. 2012. Respuesta del crecimiento de Pinus taeda y Pinus elliotti a los 10 años de edad a técnicas de establecimiento en suelos hidromórficos del noreste de Argentina. $15^{\text {as }}$ Jornadas Técnicas Forestales y Ambientales. Facultad de Ciencias Forestales, UNaM EEA Montecarlo, INTA. Del 7 al 9 de Junio de 2012. Misiones, Argentina

Fonti $\mathbf{P}$ y Jansen S. 2012. Xylem plasticity in response to climate. New Phytologist, 195: 734-736

Franks PJ, Drake PL y Froend RH. 2007. Anisohydric but isohydrodynamic: seasonally constant plant water potential gradient explained by a stomatal control mechanism incorporating variable plant hydraulic conductance. Plant, Cell and Environment, 30: 19-30

Gándara J, Viega L, Ross S, Munka C y Bentancourt O. 2014. Variación estacional del estado hídrico y crecimeinto de Pinus taeda L. bajo diferente manejo silvícola en el noreste de Uruguay. Agrociencia Uruguay, 18: 1-11

García Esteban L, Guindeo Casasús A, Peraza Oramas C y de Palacios P. 2003. Estructura microscópica de la madera de coníferas. En: La madera y su anatomía. Mundi-Prensa. Madrid, España. 49-69 pp

Gauchat ME y Rodríguez GH. 2005. Producción de semillas de alta calidad. IDIA XXI Forestales, 5: 164-167 
Gebremedhin MT. 2003. Variation in growth, water relation, gas exchange, and stable carbon isotope composition among clones of lobollly pine (Pinus taeda L.) under water stress. Tesis de maestría. Universidad de Florida, Gainesville, FL. 83pp

\section{Gelid de Rubial M, Fassola HE, Wabo E, Velázquez JD, Alegranza DA y Lupi} AM. 1997. Ciclo de crecimiento en diámetro y altura en árboles jóvenes de Pinus taeda L. en la provincia de Misiones. Informe técnico № 17. INTA, EEA Montecarlo 11 pp

Goldstein AH, Hultman NE, Fracheboud JM, Bauer MR, Panek JA, Xu M, Qi Y, Guenther AB y Baugh W. 2000. Effects of climate variability on the carbon dioxide, water, and sensible heat fluxes above a ponderosa pine plantation in the Sierra Nevada (CA). Agricultural and Forest Meteorology, 101: 113-129

Gonzalez-Benecke CA y Martin TA. 2010. Water availability and genetic effects on water relations of loblolly pine (Pinus taeda) stands. Tree Physiology, 30: 376-392

Green TH, Mitchell RJ y Gjerstad DH. 1994. Effect of the nitrogen on the response of loblolly pine to drought. New Phytologist, 128: 145-152

Grissom JE y McKeand SE. 2001. Comparative physiology of contrasting genotypes of loblolly pine under dry field conditions. Proceedings, $26^{\text {th }}$ Biennal SFTIC, Athens, GA: $122-124$

Gyenge JE, Fernández ME y Schlichter TM. 2009. Effect of pruning on branch production and water relations in widely spaced ponderosa pine. Agroforestry Systems, 77: 223-235

Gyenge J y Dalla Salda G. 2010. Curvas de vulnerabilidad a la cavitación. En: Técnicas de medición en Ecofisiología vegetal: Conceptos y procedimientos. Ed.: Fernández, ME; Gyenge, J. Pp. 70-83

Gyenge J y Fernández ME. 2014. Patterns of resource use efficiency in relation to intra-specific competition, size of the trees and resource availability in ponderosa pine. Forest Ecology and Management, 312: 231-238 
Hacke UG y Jansen S. 2009. Embolism resistance of three boreal conifer species varies with pit structure. New Phytologist, 182: 675-686

Hacke UG y Sperry JS. 2001. Functional and ecological xylem anatomy. Perspectives in Plant Ecology, Evolution and Systematic, 4: 97-115

Hacke UG, Sperry JS, Ewers BE, Ellsworth DS, Schäfer KVR y Oren R. 2000. Influence of soil porosity on water use in Pinus taeda. Oecologia, 124: 495-505

Hacke UG, Sperry JS y Pittermann J. 2004. Analysis of circular bordered pit function. II. Gymnosperm tracheids with torus-margo pit membranes. American journal of Botany, 91: 386-400

Hacke UG, Sperry JS, Pockman WT, Davis SD y McCulloh KA. 2001. Trends in Wood density and structure are linked to prevention of xylem implosion by negative pressure. Oecologia, 126: 457-461

Hajek P, Leuschner C, Hertel D, Delzon S y Schuldt B. 2014. Trade-offs between xylem hydraulic properties, wood anatomy and yield in Populus. Tree physiology, 34: 744-756

Herralde Traveria F. 2000. Estudio integral de las respuestas ecofisiológicas al estrés hídrico: caracterización de variedades de almendro. Tesis doctoral. Facultad de Biología, Universidad de Barcelona, Barcelona, España. 140 pp

Hoefs J y Schidlowski M. 1967. Carbon isotope composition of carbonaceous matter from the Precambrian of the Wirwatersrand system. Science, 155: 1096-1098

Hubbard RM, Ryan MG, Stiller V y Sperry JS. 2001. Stomatal conductance and photosynthesis vary linearly with plant hydraulic conductance in ponderosa pine. Plant, Cell and Environment, 24: 113-121

Hulme M y Sheard N. 1999. Escenarios de Cambio Climático para Argentina, Unidad de Investigación Climática. Disponible en http://www.cru.uea.ac.uk/ mikeh/research/argentina.pdf. Ultimo acceso: Marzo de 2009 
Hunt R. 2003. Growth analysis, individual plants. In: Thomas, B., D.J. Murphy \& D. Murray Eds. Encyclopedia of applied plant science. Academic Press. London. Pp: 588-596

Inskeep WP y Bloom PR. 1985. Extinction Coefficients of Chlorophyll $a$ and b in N,N-Dimethylformamide and 80\% Acetone. Plant Physiology, 77: 483-485

IPCC (Intergovernmental Panel on Climate Change). 2007. Cambio climático 2007: Informe de síntesis. Cuarto Informe de evaluación del Grupo Intergubernamental de Expertos sobre el Cambio Climático. Ginebra, Suiza. 104 p

Juárez-Agis A, López-Upton J, Vargas-Hernández JJ y Sáenz-Romero C. 2006. Variación geográfica en la germinación y crecimiento inicial de plántulas de Pseudotsuga menziesii de México. Agrociencia, 40: 783-792

King JS, Albaugh TJ, Allen HL y Kress LW. 1999. Stand-level allometry in Pinus taeda as affected by irrigation and fertilization. Tree Physiology, 19: 769-778

Kitajima K. 2007. Seed and seedling ecology. In: Functional plant ecology. Ed. Pugnire F.I y Valladares F. Second edition. CRC Press. Pp: 549-579

Kondoh S, Yahata H, Nakashizuka T y Kondoh M. 2006. Interspecific variation in vessel size, growth and drought tolerance of broad-leaved trees in semi-arid regions of Kenya. Tree Physiology, 26: 899-904

Kramer PJ y Boyer JS. 1995. Water relation of plants and soils. Academic Press, New York. $495 p$

Lambers H, Chapin FS y Pons TL. 1998. Plant physiological ecology. Springer, New York. $540 p$

Lewis JD, Tissue DT y Strain BR. 1996. Seasonal response of photosynthesis to elevated $\mathrm{CO}_{2}$ in loblolly pine (Pinus taeda L.) over two growing seasons. Global Change Biology, 2: 103-114 
Ligier H. 2000. Caracterización geomorfológica y edáfica de la provincia de Misiones. EEA INTA Corrientes. Tomo II. Pp. 111-152

Liu J, Zhang F, Zhou J, Chen F, Wang B y Xie X. 2012. Phytochrome B control of total leaf area and stomatal density affects drought tolerance in rice. Plant Molecular Biology, 78: 289-300

Livingston AK, Cameron AD, Petty JA y Lee SL. 2004. Effect of growth rate on wood properties of genetically improved Sitka spruce. Forestry, 77: 325-334

López JA. 2005. Mejoramiento genetic de la calidad de la madera. I Jornada sobre potencialidad Foresto-Industrial del Eucalipto en Santiago del Estero, 16 y 17 de junio de 2005

López JA y Genes PY. 2009. Análisis genético de la densidad de la madera de 3 Huertos Semilleros Clonales de Pinus taeda en el Nordeste de Argentina. XIII Congreso Forestal Mundial. 18 al 23 de octubre. Buenos Aires, Argentina

López JA y Staffieri GM. 2003. Interacción genotipo-ambiente y heredabilidad de la densidad de la madera de Pinus elliottii var. elliottii en el Nordeste de Argentina. XVIII Jornadas Forestales de Entre Ríos. 23 y 24 de octubre. Concordia, Entre Ríos. Actas en $C D$

MAGyP. 2013. Argentina: Plantaciones forestales y gestión sostenible. 15 p

Martín TA, Dougherty PM, Topa MA y McKeand SE. 2005. Stratedies and case studies for incorporating ecophysiology into southern pine tree improvement programs. Southern Journal of Applied Forestry, 29:70-79

McDowell NG, Adams HD, Bailey JD, Hess M y Kolb TE. 2006. Homeostatic maintenance of ponderosa pine gas exchange in response to stand density changes. Ecological Applicatins, 16: 1164-1182

Meier CE, Newton RJ, Puryear JD y Sen S. 1992. Physiological Responses of Loblolly Pine (Pinus taeda L.) Seedlings to Drought Stress: Osmotic Adjustment and Tissue Elasticity. J. Plant Physiology, 140: 754-760 
Meinzer FC, Campanello PI, Domec JC, Gatti MG, Goldstein G, Villalobos-Vega R y Woodroff DR. 2008. Constraints on physiological function associated with branch architecture and wood density in tropical forest trees. Tree Physiology, 28: 1609-1617

Meinzer FC, Jhonson DM, Lachenbruch B, McCulloh KA y Woodruff DR. 2009. Xylem hydraulic safety margins in woody plants: coordination of stomatal control of xylem tension with hydraulic capacitance. Functional Ecology, 23: 922-930

Meinzer FC y McCulloh KA. 2013. Xylem recovery from drought-induced embolism: where is the hydraulic point of no return? Tree Physiology, 33: 331-334

Monclus R, Dreyer E, Villar M, Delmotte FM, Delay D, Petit JM, Barbaroux C, Thiec DL, Bréchet C y Brignolas F. 2006. Impact of drought on productivity and water use efficiency in 29 genotypes of Populus deltoids x Populus nigra. New Phytologist, 169: 765-777

Mundo IA, EI Mujtar VA, Perdomo MH, Gallo LA, Villalba R y Barrera MD. 2010. Austrocedrus chilensis growth decline in relation to drought events in northern Patagonia, Argentina. Trees, 24: 561-570

Nautiyal S, Badola HK, Pal M y Negi DS. 1994. Plant responses to water stress: changes in growth, dry matter production, stomatal frequency and leaf anatomy. Biologia Plantarum, 36: 91-97

Nguyen-Queyrens A y Bouchet-Lannat F. 2003. Osmotic adjustment in threeyear-old seedlings of five provenances of maritime pine (Pinus pinaster) in response to drought. Tree Physiology, 23: 397-404

Niinemets U. 2010. Responses of forest trees to single and multiple environmental stresses from seedlings to mature plants: past stress history, stress interactions, tolerance and acclimation. Forest Ecology anda Management, 260: 16231639 
Oren R, Sperry JS, Katul GG, Pataki DE, Ewers BE, Phillips N y Schäfer KVR. 1999. Survey and synthesis of intra and interspecific variation in stomatal sensitivity to vapour pressure deficit. Plant Cell and Environment, 22: 1515-1526

Pammenter NW y Vander Willigen C. 1998. A mathematical and statistical analysis of the curves illustrating vulnerability of xylem to cavitation. Tree Physiology, 18: $589-593$

Panarello HO. 1987. Relaciones entre isótopos de elementos livianos para estudiar procesos ambientales y paleotemperaturas. Tesis doctoral. Universidad de Buenos Aires, FCEN. Buenos Aires, Argentina. $105 \mathrm{p}$

Parker WC, Pallardy SG, Hinckley TM y Teskey RO. 1982. Seasonal changes in tissue water relations of three woody species of the Quercus-carya forest type. Ecology, 63: 1259-1267

Pita P, Cañas I, Soria F, Ruiz F y Toval G. 2005. Use of physiological traits in tree breeding for improved yield in drought-prone environments. The case of Eucalyptus globulus. Investigación Agraria: Sistema y Recursos Forestales, 14: 383-393

Pittermann J, Sperry JS, Hacke UG, Wheeler JK y Sikkema EH. 2006a. Intertracheid pitting and the hydraulic efficiency of conifer wood: the role of tracheid allometry and cavitation protection. American journal of Botany, 93: 1265-1273

Pittermann J, Sperry JS, Wheeler JK, Hacke UG y Sikkema EH. 2006b. Mechanical reinforcement of tracheids compromises the hydraulic efficiency of conifer xylem. Plant, cell and Environment, 29: 1618-1628

Premoli A. 1991. Morfología y capacidad germinativa en poblaciones de Nothofagus antartica (Forster) Oerst. Del noroeste andino patagónico. Bosque, 12: 5359

Rahman MS, Messina MG y Newton RJ. 2003. Performance of loblolly pine (Pinus taeda L.) seedlings and micropropagated plantlets on an east Texas site I. Above-and belowground growth. Forest Ecology and Management, 178: 245-255 
Rice KJ, Matzner SL, Byer W y Brown JR. 2004. Patterns of tree dieback in Queensland, Australia: the importance of drought stress and the role of resistance to cavitation. Oecologia, 139: 190-198

Rodiyati A, Arisoesilaningsih E, Isagi Y y Nakagoshi N. 2005. Responses of Cyperus brevifolius (Rottb.) Hassk. and Cyperus kyllingia Endl. to varying soil water availability. Environmental and Experimental Botany, 53: 259-269

Rodríguez GH. 2003. Avances en el mejoramiento de Pinus elliottii, Pinus taeda y Araucaria angustifolia. Estrategias para el abastecimiento de semillas de calidad. Décimas Jornadas Técnicas Forestales y ambientales. Eldorado, Misiones. CD

Rodríguez G y Gauchat ME. 2005. Subprogramas de producción de material de propagación mejorado. Mejora genética. En: Mejores árboles para mas forestadores: el programa de producción de material de propagación mejorado y el mejoramiento genético en el Proyecto Forestal de Desarrollo. Fernández R. Ed. Secretaría de Agricultura, Ganadería, Pesca y Alimentos. Buenos Aires, Argentina. Pp: 23-41

Sack L, Cowan PD, Jaikumar N y Holbrook NM. 2003. The 'hydrology' of leaves: co-ordination of structure and function in temperate woody species. Plant, Cell and Environment, 26: 1343-1356

\section{Santiago LS, Goldstein G, Meinzer FC, Fisher JB, Machado K, Woodruff D y} Jones T. 2004. Leaf photosynthetic traits scale with hydraulic conductivity and wood density in Panamanian forest canopy trees. Oecologia, 140: 543-550

Samuelson LJ y Stokes TA. 2006. Transpiration and canopy stomatal conductance of 5-years-old loblolly pine in response to intensive management. Forest Science, 52: 313-323

Scholz F, Bucci SJ, Goldstein G, Meinzer FC, Franco A y Miralles-Wilhelm F. 2007. Biophysical properties and functional significance of stem water storage tissues in Neotropical savanna tres. Plant Cell Environment, 30: 236-248 
Schulte PJ y Henry LT. 1992. Pressure-volume analysis of tissue water relations parameters for individual fascicles of loblolly pine (Pinus taeda L.). Tree Physiology, 10: 381-389

Schweingruber FH. 1996. Tree rings and environment: dendroecology. Swiss Federal Institute for Forest, Snow and Landscape Research. $609 \mathrm{p}$

SIFIP. 2010. Inventario forestal provincial 2009 - 2010. Sistema de Información Foresto-Industrial Provincial, Ministerio del Agro y la Producción - Gobierno de la $\begin{array}{llll}\text { Provincia de } & \text { Misiones. }\end{array}$ http://extension.facfor.unam.edu.ar/sifip/inventario.htm. Ultimo acceso: Octubre 2013

Sperry JS y Pockman WT. 1993. Limitation of transpiration by hydraulic conductance and xylem cavitation in Betula occidentalis. Plant, Cell and Environment, 16: $279-287$

Sperry JS e Ikeda T. 1997. Xylem cavitation in roots and stems of Douglas-fir and white fir. Tree Physiology, 17: 275-280

Sperry JS, Hacke UG, Oren R y Comstock JP. 2002. Water deficits and hydraulic limits to leaf water supply. Plant, Cell and Environment, 25: 251-263

Sperry JS, Hacke UG y Pittermann J. 2006. Size and function in conifer tracheids and angiosperm vessels. American Journal of Botany, 93: 1490-1500

Sperry JS, Meinzer FC y McCulloh KA. 2008. Safety and efficiency conflicts in hydraulic architecture: scaling from tissues to trees. Plant, Cell and Environment, 31: 632-645

Sperry JS y Tyree MT. 1990. Water-stress-induced xylem ambolism in three species of conifers. Plant, Cell and Environment, 13: 427-436

Suárez ML, Ghermandi L y Kitzberger T. 2004. Factors predisposing episodic drought-induced tree mortality in Nothofagus- site, climatic sensitivity and growth trends. Journal of Ecology, 92: 954-966 
Tang Z, Chambers JL, Sword MA y Barnett JP. 2003. Seasonal photosynthesis and water relations of juvenile loblolly pine relative to stand density and canopy position. Trees, 17: 424-430

Tardieu F y Simonneau T. 1998. Variability among species of stomatal control under fluctuating soil water status and evaporative demand: modelling isohydric and anisohydric behaviours. Journal of Experimental Botany, 49: 419-432

Teskey RO, Bongarten BC, Cregg BM, Dougherty PM y Hennessey TC. 1987. Physiology and genetics of tree growth response to moisture and temperature stress: an examination of the characteristics of loblolly pine (Pinus taeda L.) Tree Physiology, 3: $41-61$

Teskey R0, Fites JA, Samuelson LJ y Bongarten BC. 1986. Stomatal and nonstomatal limitations to net photosynthesis in Pinus taeda L. under different environmental conditions. Tree Physiology, 2: 131-142

Teskey RO y Will RE. 1999. Acclimation of loblolly pine (Pinus taeda) seedlings to high temperatures. Tree physiology, 19: 519-525

Trifiló P, Barbera P, Raimondo F, Nardini A y Lo Gullo MA. 2014. Coping with drought-induced xylem cavitation: coordination of embolism repair and ionic effects in three Mediterranean evergreens. Tree Physiology, 34: 109-122

Tyree M y Ewers F. 1991. The hydraulic architecture of tres and other woody plants. New Phytology, 119: 345-360

Tyree MT. 1999. Water relations and hydraulic architecture. En: Hand book of functional plant ecology. Pugnire, F.I.; F. Valladares. Ed. Marcel Dekker, New York. Pp. 221-268

Tyree MT. 2003. Hydraulic limits on tree performance: transpiration, carbon gain and growth of trees. Trees, 17: 95-100 
Valladares F, Vilagrosa A, Peñuelas J, Ogaya R, Camarero JJ, Corcuera L, Sisó S y Gil-Pelegrín E. 2004. Estrés hídrico: ecofisiología y escalas de sequía. En: Valladares, F. Ecología del bosque mediterráneo en un mundo cambiante. Pp. 163-190

Van den Driessche R. 1992. Absolute and relative growth of Douglas-fir seedling of different sizes. Tree Physiology, 10: 141-152

Vergeynst LL, Dierick M, Bogaerts JAN, Cnudd V y Steppe K. 2014. Cavitation: a blessing in disguise? New mwthod to establish vulnerability curves and assess hydraulic capacitance of wood tissue. Tree Physiology, 35: 400-409

Villar-Salvador P, Ocaña L, Peñuelas J y Carrasco I. 1999. Effect of water stress conditioning on the water relations, root growth capacity, and the nitrogen and nonstructural carbohydrate concentration of Pinus halepensis Mill. (Aleppo pine) seedlings. Annals of Forest Science, 56: 459-465

Villar-Salvador P, Planelles R, Oliet J, Peñuelas-Rubira JL, Jacobs DF y González M. 2004. Drought tolerance and transplanting performance of holm oak (Quercus ilex) seedlings after drought hardening in the nursery. Tree Physiology, 24: 1147-1155

Wakamiya-Noborio I, Heilman JL, Newton RL y Messina MG. 1999. Diurnal changes in water conduction in loblolly pine (Pinus taeda) and Virginia pine ( $P$. virginiana) during soil dehydration. Tree physiology, 19: 575-581

Wang T, Aitken SN y Kavanagh KL. 2003. Selection for improved growth and wood quality in loblolly pine: effects on phenology, hydraulic architecture and growth of seedlings. Trees, 17: 269-277

Wheeler JK, Huggett BA, Tofte AN, Rockwell FE y Holbrook NM. 2013. Cutting xylem under tension or supersaturated with gas can generate PLC and the appearance of rapid recovery from embolism. Plant, Cell and Environment, 36: 1938-1949

Winck RA, Fassola HE y Área MC. 2015. Efecto del raleo sobre las propiedades anatómicas de la madera de Pinus taeda. Maderas. Ciencia y Tecnología, 17: 391-406 
Xu Z y Zhou G. 2008. Responses of leaf stomatal density to water status and its relationship with photosynthesis in a grass. Journal of Experimental Botany, 59: 33173325

Yu H, Hong YY, Wang Y, Xu P, Ke SD, Liu HY, Zhu JK, Oliver DJ y Xiang CB. 2008. Activated expression of an Arabidopsis HD-RTART protein confers drought tolerance with improved root system and reduced stomatal density. The Plant Cell, 20: 11341151

Zar JH. 1999. Biostadistical Analysis. Prentice Hall press, New Jersey. Fourth edition. $663 p$

Zhang JW, Feng Z, Cregg BM y Schumann CM. 1997. Carbon isotopic composition, gas exchange, and growth of three populations of ponderosa pine differing in drought tolerance. Tree Physiology, 17: 461-466

Zhou J, Zhang Z, Sun G, Fang X, Zha T, McNulty S, Chen J, Jin Y y Noormets A. 2013. Response of ecosystem carbon fluxes to drought events in a poplar plantation in Northern China. Forest Ecology and Management, 300: 33-42

Zhu JY, Wahey DW y Scott CT. 2008. Some observations of wood density and anatomical properties in a Douglas-fir sample with suppressed growth. Wood and Fiber Science, 40: 225-232

Zimmermann MH. 1983. Xylem structure and the ascent of sap. SpringerVerlag, Berlin. $141 \mathrm{p}$

Zweifel R, Rigling A y Dobbertin M. 2009. Species-specific stomatal response of trees to drought - a link to vegetation dynamics? Journal of Vegetation Science, 20: $442-454$

Zwieniecki MA, Hutyra L, Thompson MV y Holbrook NM. 2000. Dynamic changes in petiole specific conductivity in red maple (Acer rubrum L.), tulip tree (Liriodendron tulipifera L.) and northern fox grape (Vitis labrusca L.). Plant, Cell and Environment, 23: 407-414 